ORNL-6963

\title{
Projecting Fatalities in Crashes Involving Older Drivers, 2000-2025
}

\author{
Patricia S. $\mathrm{Hu}^{*}$ \\ Donald W. Jones* \\ Timothy Reuscher** \\ Richard S. Schmoyer, Jr.* \\ Lorena F. Truett* \\ *Oak Ridge National Laboratory \\ Oak Ridge, Tennessee \\ **Oak Ridge Institute for Science and Education \\ Oak Ridge, Tennessee
}

October 2000

This research was funded by

GM pursuant to an agreement between

GM and the U.S. Department of Transportation

under CRADA No. ORNL98-0500

Prepared by the

OAK RIDGE NATIONAL LABORATORY

Oak Ridge, Tennessee 37831

managed by

UT-BATTELLE, LLC

for the

U. S. DEPARTMENT OF ENERGY

under contract DE-AC05-00OR22725 



\section{TABLE OF CONTENTS}

LIST OF FIGURES $\ldots \ldots \ldots \ldots \ldots \ldots \ldots \ldots \ldots \ldots \ldots \ldots$ vii

LIST OF TABLES $\ldots \ldots \ldots \ldots \ldots \ldots \ldots \ldots \ldots \ldots \ldots \ldots \ldots \ldots \ldots \ldots$ viii

ACRONYMS LIST $\ldots \ldots \ldots \ldots \ldots \ldots \ldots \ldots \ldots \ldots \ldots \ldots \ldots \ldots \ldots$

EXECUTIVE SUMMARY $\ldots \ldots \ldots \ldots \ldots \ldots \ldots \ldots \ldots \ldots \ldots \ldots \ldots \ldots \ldots \ldots$

1. INTRODUCTION $\ldots \ldots \ldots \ldots \ldots \ldots \ldots \ldots \ldots \ldots \ldots \ldots \ldots \ldots \ldots \ldots$

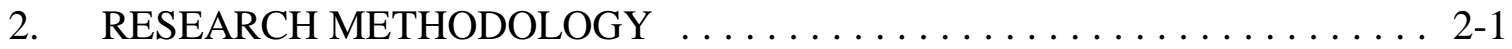

3. OVERVIEW OF THE LITERATURE . . . . . . . . . . . . . . 3-1

3.1 THE ELDERLY POPULATION IN THE UNITED STATES . . . . . . . . 3-1

3.1.1 By Age Groups and Cohorts . . . . . . . . . . . . . . 3-2

3.1 .2 By Gender . . . . . . . . . . . . . . . . . . . 3-3

3.1 .3 By Economic Status . . . . . . . . . . . . . . 3-4

3.1.4 By Race, Ethnicity, and Social Characteristics . . . . . . . . . . 3-6

3.1.5 By Geographic Distribution . . . . . . . . . . . . . . 3-7

3.2 HEALTH ISSUES . . . . . . . . . . . . . . . . . . . . . 3-10

3.2.1 Impacts of Failing Health on Driving Abilities . . . . . . . . . . 3-11

3.2.2 Impacts of Increasing Frailty on Casualty Rates . . . . . . . . . . 3-14

3.2.3 Health and Education Levels ... . . . . . . . . . . . . . . . . . . . . . 3-14

3.2.4 Assessment Tools and Retraining . . . . . . . . . . . . 3-15

3.2.5 Better Health, Extended Life Spans, Later Retirement, and

Greater Mobility . . . . . . . . . . . . . . . . . . . . . 3-16

3.3 TRANSPORTATION AND MOBILITY . . . . . . . . . . . . 3-17

3.3.1 Numbers of Drivers . . . . . . . . . . . . . . . . . 3-17

3.3.2 Changes in Driving Habits . . . . . . . . . . . . . . . . . . 3-20

3.3.3 Driving Distances . . . . . . . . . . . . . . . . . 3-21

3.3.4 Alternative Transportation Modes . . . . . . . . . . . . . . . 3-22

3.3.5 "Intelligent" Technologies and Other Adaptive Equipment . . . . . 3-23

3.4 CRASH LITERATURE . . . . . . . . . . . . . . . . . 3-26

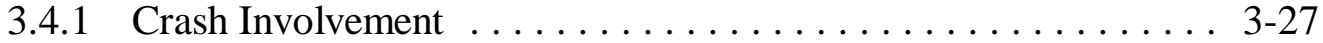

3.4.2 Other GM Project Results (Projects G.1 and G.8) . . . . . . . . 3-28

3.4 .3 Gender Effects . . . . . . . . . . . . . . . . . 3-30

3.4.4 Crashes Involving Elderly Drivers . . . . . . . . . . . . . 3-32

3.4.5 Projections of Crashes and Casualties . . . . . . . . . . . 3-34 


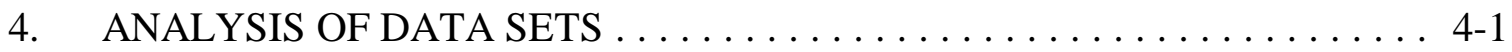

4.1 INTRODUCTION $\ldots \ldots \ldots \ldots \ldots \ldots \ldots \ldots \ldots \ldots \ldots \ldots \ldots, 4-1$

4.2 ASSESSMENT OF DATA SOURCES $\ldots \ldots \ldots \ldots \ldots \ldots \ldots \ldots 4-2$

4.2.1 Population Data and Projections .................. 4-2

4.2.2 Income Data ....................... 4-2

4.2.3 Drivers and Driving Distance Information . . . . . . . . . . 4-4

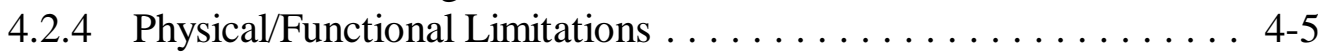

4.2.5 Crashes, Casualties, and Fatalities . . . . . . . . . . . . 4-7

4.2.6 Other Data Categories Considered $\ldots \ldots \ldots \ldots \ldots \ldots \ldots$. 4 .9 . . . .

4.3 CONCLUSIONS $\ldots \ldots \ldots \ldots \ldots \ldots \ldots \ldots \ldots \ldots \ldots \ldots . \ldots \ldots$

5. OVERVIEW OF THE MODELING SYSTEM $\ldots \ldots \ldots \ldots \ldots \ldots \ldots \ldots$ 5-1

5.1 INTRODUCTION TO MODELING $\ldots \ldots \ldots \ldots \ldots \ldots \ldots \ldots \ldots 5-1$

5.2 BRIEF EXPLANATION OF DEMAND THEORY $\ldots \ldots \ldots \ldots \ldots \ldots 5-2$

5.3 POPULATION PROJECTIONS $\ldots \ldots \ldots \ldots \ldots \ldots \ldots \ldots \ldots \ldots$

5.4 HEALTH STATUS DATA $\ldots \ldots \ldots \ldots \ldots \ldots \ldots \ldots \ldots \ldots \ldots \ldots \ldots$

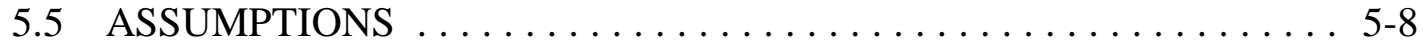

6. THE PROPORTION OF THE ELDERLY POPULATION THAT DRIVES .. 6-1

6.1 HISTORICAL TRENDS IN ELDERLY DRIVING $\ldots \ldots \ldots \ldots \ldots \ldots 6-1$

6.2 MODELING THE DECISION TO DRIVE .............. 6-2

6.3 PROJECTING THE PROPORTION OF OLDER POPULATIONS

THAT WILL DRIVE $\ldots \ldots \ldots \ldots \ldots \ldots \ldots \ldots \ldots \ldots \ldots .6,6$

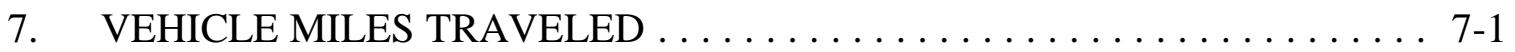

7.1 HISTORICAL TRENDS IN ELDERLY DRIVING $\ldots \ldots \ldots \ldots \ldots \ldots 7-1$

7.2 EMPIRICAL MODELING OF VMT $\ldots \ldots \ldots \ldots \ldots \ldots \ldots \ldots \ldots .7,3$

7.3 PROJECTING VMT $\ldots \ldots \ldots \ldots \ldots \ldots \ldots \ldots \ldots \ldots \ldots \ldots$

8. FATAL CRASH RATES $\ldots \ldots \ldots \ldots \ldots \ldots \ldots \ldots \ldots \ldots \ldots . \ldots \ldots$. 1

8.1 MODELING FATALITY RATES FOR OLDER DRIVERS . . . . . . 8 8-1

8.2 FATAL CRASH RATE PROJECTIONS $\ldots \ldots \ldots \ldots \ldots \ldots \ldots \ldots .8-10$

8.3 DRIVER FATALITY PROJECTIONS $\ldots \ldots \ldots \ldots \ldots \ldots \ldots . . \ldots$

9. ANALYSIS OF THE FATALITY PROJECTIONS $\ldots \ldots \ldots \ldots \ldots . . . .9-1$

9.1 CONTRIBUTIONS OF INDIVIDUAL COMPONENTS TO DRIVER

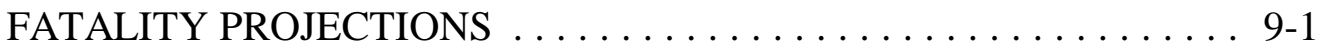

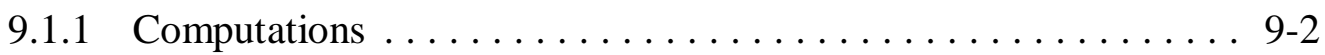

9.1.2 Contributions to Driver Fatalities $\ldots \ldots \ldots \ldots \ldots \ldots \ldots$. $9-3$

9.2 SENSITIVITY ANALYSIS . . . . . . . . . . . . . . . . 9-4

9.2.1 Total Impacts on Older Driver Fatalities . . . . . . . . . . . 9-7

9.2.2 Sensitivity of the Projection Components to Individual Variables . 9-9 
9.3 A LOWER BOUND FOR DRIVER FATALITIES AND VMT . . . . . . 9-9

9.3.1 The Effect of Time on VMT Projections ............... . 9-14

9.3.2 Driver Fatalities with Lower Bounded VMT . . . . . . . . . . . . . 9-16

9.4 USER INTERFACE FOR “WHAT-IF” ANALYSIS . . . . . . . . . 9 9-18

9.4.1 Customized Projections Wizard $\ldots \ldots \ldots \ldots \ldots \ldots \ldots . . .69$

10. SUMMARY, CONCLUSIONS, AND RECOMMENDATIONS $\ldots \ldots \ldots$ 10-1

10.1 SUMMARY OF FINDINGS $\ldots \ldots \ldots \ldots \ldots \ldots \ldots \ldots \ldots \ldots \ldots \ldots \ldots$

10.1.1 Aggregate Fatality Projections $\ldots \ldots \ldots \ldots \ldots \ldots \ldots$ 10-1

10.1.2 Comparison of ORNL Aggregate Fatality Projections to Other

Studies ........................... 10-2

10.1.3 Disaggregated Projection Results $\ldots \ldots \ldots \ldots \ldots \ldots \ldots$ 10-8

10.2 CONCLUSIONS . . . . . . . . . . .

10.3 DIRECTIONS FOR FUTURE RESEARCH $\ldots \ldots \ldots \ldots \ldots \ldots \ldots$ 10-12

10.3.1 The Role of Infrastructure and Equipment $\ldots \ldots \ldots \ldots \ldots$. 10-12

10.3.2 Asymptotic Projection of VMT . . . . . . . . . . . . . 10 10 12

10.3.3 Additional and Improved Measures of Health Status . . . . . . . . 10-13

10.3.4 Comparison of Younger and Older Drivers' Behavior . . . . . . . 10-14

10.3.5 Alternate Transportation Options for the Elderly ......... 10-14

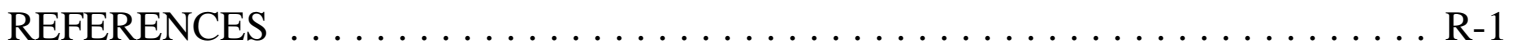

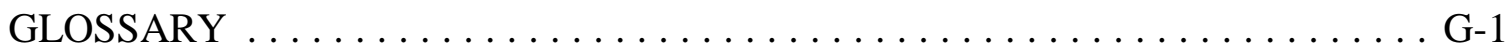

APPENDIX A. Endogenous Variable Projections $\ldots \ldots \ldots \ldots \ldots \ldots \ldots \ldots$ A -1

APPENDIX B. Exogenous Variable Projections .................... B-1

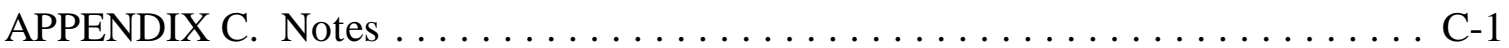




\section{LIST OF FIGURES}

Figure ES-1 Projected Active Drivers as a Percentage of the Population . . . . . ES-4

Figure ES-2 Projected Vehicle Miles of Travel per Person . . . . . . . . . . . . . ES-4

Figure ES-3 Driver Risk (deaths per 100 million miles) . . . . . . . . . . . ES-5

Figure $1.1 \quad$ U.S. Elderly Population Estimates, by Age and Year . . . . . . . . . 1-1

Figure 1.2 United States Projected Population Increase, 1995 to 2020 . . . . . . . 1-4

Figure 3.1 Distribution of the Elderly Population in the Northeast Region by

Gender and Age Group between 1995 and 2020 . . . . . . . . . . 3-8

Figure 3.2 Distribution of the Elderly Population in the Midwest Region by Gender and Age Group between 1995 and 2020 . . . . . . . . . . . 3-8

Figure 3.3 Distribution of the Elderly Population in the South Region by

Gender and Age Group between 1995 and 2020 . . . . . . . . . . . 3-9

Figure 3.4 Distribution of the Elderly Population in the West Region by Gender and Age Group between 1995 and 2020 . . . . . . . . . . . . 3-9

Figure 3.5 Licensed Drivers by Gender and Age Group, 1963-1995 . . . . . . . . 3-18

Figure 3.6 Fatalities of Drivers Age 65 or Over from 1980-1997 . . . . . . . . 3-33

Figure 3.7 Comparison of Selected Causes of Death, by Age Group, 1996 Data . 3-36

Figure 5.1 Projected National Non-Institutionalized Population . . . . . . . . . 5-4

Figure 6.1 Active Drivers as a Percentage of the Population, 1977-1995 . . . . . . 6-1

Figure 6.2 Projected Active Drivers as a Percentage of the Population . . . . . . 6-10

Figure 7.1 Annual Vehicle Miles of Travel per Driver, 1977-1995 . . . . . . . . . . 7-2

Figure 7.2 Average Person Trips per Person by Mode of Transportation and Trip

Purpose, for Individuals under 65 and Individuals 65 and Over . . . . . 7-2

Figure 7.3 Annual Projected Vehicle Miles of Travel per Driver . . . . . . . . 7-14

Figure 8.1 Historical Elderly Driver Fatality Rate by Age . . . . . . . . . . . . 8 8-2

Figure 8.2 Historical Elderly Driver Fatality Rate by Region . . . . . . . . . . . . 8-2

Figure 8.3 Projected Driver Risk By Age . . . . . . . . . . . . . . . 8-13

Figure $8.4 \quad$ Projected Driver Fatalities By Age . . . . . . . . . . . . . . 8 8-15

Figure 9.1 Component Contributions to 2025 Driver Fatality Projections, Men ... 9-5

Figure 9.2 Component Contributions to 2025 Driver Fatality Projections, Women 9-5

Figure 9.3 Projected VMT, Men . . . . . . . . . . . . . . . . . . . 15

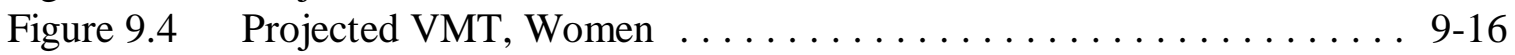

Figure 9.5 Component Contributions to Driver Fatality Projections Using Lower-

Bounded VMT, Men . . . . . . . . . . . . . . . . . 9-17

Figure 9.6 Component Contributions to Driver Fatality Projections Using Lower-

Bounded VMT, Women . . . . . . . . . . . . . . . . . 9-18 


\section{LIST OF TABLES}

Table ES-1 Elderly Driver Fatality Projections, Male and Female . . . . . . . . . ES-6

Table ES-2 Total Fatality Projections, Male and Female . . . . . . . . . . . . E ES-6

Table ES-3 Elder Driver Fatality Projections for 2025 (as Percentages of 1995 Driver

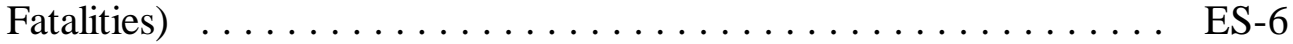

Table 1.1 Older Driver Research Projects Sponsored by General Motors

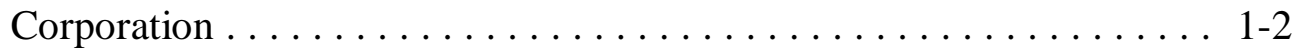

Table 3.1 Population Projections for the Total United States, by Age Group, for the Years 2000-2025, with Comparison to the 1995 Population . . . 3-3

Table 3.2 Projected Ratios of Men to Women, Total United States, Compared with the 1995 Ratios . . . . . . . . . . . . . . . . . . . . 3-4

Table 3.3 Median Household Income by Type of Household for Selected Years . . 3-5

Table 3.4 Mean Income for the Elderly, by Gender . . . . . . . . . . . . . . 3-5

Table 3.5 Comparison of Changes in Percentages of the Elderly in the General Population and in a Count of Total Traffic Fatalities, 1986-1996 . . . . 3-35

Table $4.1 \quad$ Data Sources Examined . . . . . . . . . . . . . . . . . . . . . . 4-10

Table 5.1 NHIS Activity Limitation Status Regression Coefficients and T-Values . . . . . . . . . . . . . . . . . . . . . . . . . . . . 5-7

Table 6.1 Regression Results for the Probability of Continuing to Drive . . . . . 6-4

Table 6.2 Determinants of Projected National Driver Growth . . . . . . . . . . 6-12

Table 6.3 Determinants of Projected Regional Driver Growth . . . . . . . . . . . 6-12

Table $7.1 \quad$ VMT Regressions Results . . . . . . . . . . . . . . . . . 7-7

Table 7.2 Determinants of Projected National VMT Growth, 1995-2025 . . . . 7-15

Table 7.3 Determinants of Projected Regional VMT Growth . . . . . . . . . 7-16

Table $8.1 \quad$ Driver Crash Rate Regression . . . . . . . . . . . . . . . . . . . 8 8-7

Table 8.2 Total Risk Crash Rate Regression . . . . . . . . . . . . . . . . . . 8-9

Table 8.3 The Determinants of Projected Changes in Driver Risk,

National Level . . . . . . . . . . . . . . . . . . . . . . . . . . . . . . . 8-14

Table 8.4 The Determinants of Projected Changes in Driver Risk,

Regional Level . . . . . . . . . . . . . . . . . . . . . . 8-16

Table 9.1 Sensitivity of Total Driver Fatalities to Perturbations in Independent Variables: Elasticities of Projected Driver Fatalities in 2025 . . . . . . . 9-6

Table 9.2 Sensitivity of 2025 Projections to Perturbations in Income Growth . . 9-10

Table 9.3 Sensitivity of 2025 Projections to Perturbations in Projected

Employment Status . . . . . . . . . . . . . . . . . . 9 9-10

Table 9.4 Sensitivity of 2025 Projections to Perturbations in Projected Percentage of Elderly Households with Other Drivers . . . . . . . . . . . 9 9-11

Table 9.5 Sensitivity of 2025 Projections to Perturbations in Projected Trend in Health Status . . . . . . . . . . . . . . . . . . 9-11

Table 9.6 Sensitivity of 2025 Projections to Perturbations in Projected

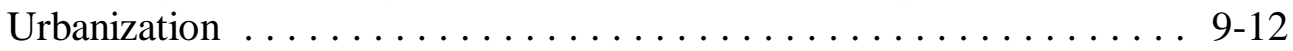


Table 9.7 Sensitivity of 2025 Projections to Perturbations in Projected Seat Belt Use . . . . . . . . . . . . . . . . . . . . . . 9-12

Table 9.8 VMT Projections for 2025 with and Without Pure Time Effects and with Improving Health Status, National Level . . . . . . . . . . 9 9-15

Table 9.9 Comparison of 2025 National Driver Fatality Projections, with Upper-bounded and Lower-bounded VMT Projections . . . . . . . . . 9-17

Table 10.1 Older Driver Fatality Projections by Age Group, Male and Female . . . 10-2

Table 10.2 Total Fatality Projections by Age Group, Male and Female . . . . . . . 10 10-2

Table 10.3 Burkhardt et al. and ORNL Projections of Elderly Driver Fatalities as a Percent of 1995 Traffic Fatalities . . . . . . . . . . . . . . . . . . . 10-4

Table 10.4 Wiggers' and ORNL's Projections of Elderly Traffic Fatalities as a Percent of Historical Fatalities . . . . . . . . . . . . . . . . . 10-6

Table 10.5 Elder Driver Fatality Projections for $2025 \ldots \ldots \ldots \ldots$. . . . . . . . 10-9

Table A.1.1 Projections of Vehicle Miles of Travel, Males, in Miles Driven . . . . . A-1

Table A.1.2 Projections of Vehicle Miles of Travel, Males, as Percents of 1995

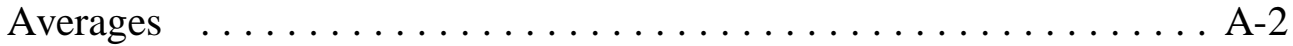

Table A.1.3 Projections of Vehicle Miles of Travel, Females, in Miles Driven . . . . A-3

Table A.1.4 Projections of Vehicle Miles of Travel, Females, as Percents of 1995

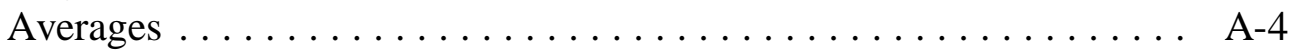

Table A.2.1 Projections of Drivers in Age Groups, Males, Percentages . . . . . . . . A-5

Table A.2.2 Projections of Drivers in Age Groups, Males, as Percentages of 1995 Percentages ..................... A-6

Table A.2.3 Projections of Drivers in Age Groups, Females, Percentages . . . . . . A A-7

Table A.2.4 Projections of Drivers in Age Groups, Females, as Percentages of 1995 Percentages . . . . . . . . . . . . . . . . .

Table A.3.1 Elder Driver Fatality Rate Projections, Males, Deaths per 100 Million Miles Driven . . . . . . . . . . . . . . . . . . . . A-9

Table A.3.2 Elder Driver Fatality Rate Projections, Males, Deaths per 100 Million Miles Driven, as Percentage of 1995 Rates . . . . . . . . . . . . A-10

Table A.3.3 Elder Driver Fatality Rate Projections, Females, Deaths per 100 Million Miles Driven . . . . . . . . . . . . . . . . . . A-11

Table A.3.4 Elder Driver Fatality Rate Projections, Females, Deaths per 100 Million Miles Driven, as Percentage of 1995 Rates . . . . . . . . . . . . A A-12

Table A.4.1 Projected Elderly Driver Fatalities, Males, Total Number of Fatalities A-13

Table A.4.2 Projected Elderly Driver Fatalities, Males, Total Number of Fatalities as Percent of 1995 Fatalities . . . . . . . . . . . . . . . . A A-14

Table A.4.3 Projected Elderly Driver Fatalities, Females, Total Number of Fatalities ........................ A-15

Table A.4.4 Projected Elderly Driver Fatalities, Females, Total Number of Fatalities as Percent of 1995 Fatalities . . . . . . . . . . . . . . . . . A-16

Table A.5.1 Projected Total Fatality Rate Attributed to Male Drivers, Deaths per 100 Million Miles . . . . . . . . . . . . . . . . A 17

Table A.5.2 Projected Total Fatality Rate Attributed to Male Drivers, Deaths per 100 Million Miles, as Percentage of 1995 Rates . . . . . . . . . . . . A-18 
Table A.5.3 Projected Total Fatality Rates Attributed to Female Drivers,

Deaths per 100 Million Miles ..................... A-19

Table A.5.4 Projected Total Fatality Rates Attributed to Female Drivers, Deaths per 100 Million Miles, as Percent of 1995 Rates ........ . A-20

Table A.6.1 Projected Total Fatalities Attributed to Male Drivers, Number of Fatalities .......................... A-21

Table A.6.2 Projected Total Fatalities Attributed to Male Drivers, as Percentage of 1995 Fatalities . . . . . . . . . . . . . . . . . . . A A-22

Table A.6.3 Projected Total Fatalities Attributed to Female Drivers, Number of

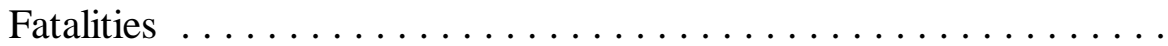

Table A.6.4 Projected Total Fatalities Attributed to Female Drivers, as Percentage of 1995 Fatalities . . . . . . . . . . . . . . . . . . . A

Table B.1 Projections of Non-Institutionalized Population, Males ........ B-2

Table B.2 Projections of Non-Institutionalized Population, Males, as Percent

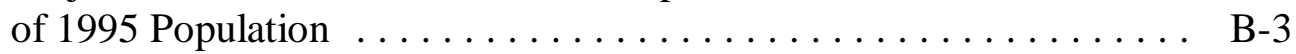

Table B.3 Projections of Non-Institutionalized Population, Females ......... . B-4

Table B.4 Projections of Non-Institutionalized Population, Females, as Percent of 1995 Population . . . . . . . . . . . . . . . . . . . . B-5

Table B.5 Male DRI Income Projections $\ldots \ldots \ldots \ldots \ldots \ldots \ldots \ldots \ldots \ldots$ B-8

Table B.6 Female DRI Income Projections $\ldots \ldots \ldots \ldots \ldots \ldots \ldots \ldots$ B-9

Table B.7 Ratio of Average 1995 NPTS Income to 1995 DRI Estimates, by

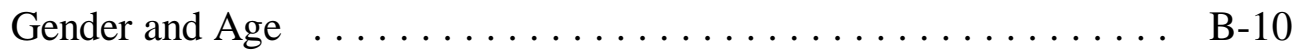

Table B.8 Employment Status Projections as a Percent of Population . . . . . . B-11

Table B.9 Other Driver Projections as a Percent of Population ........... B-11

Table B.10 National Seat Belt Use Projections . . . . . . . . . . . . . . B-12

Table B.11 Percent of Population in Urban Areas, 1990 Census . . . . . . . . . B-12

Table C.1 Average VMT per Person of Southern Men, 1995 NPTS and Adjusted Numbers . . . . . . . . . . . . . . . . . . . C-1

Table C.2 Year Coefficients (Adjusted and Non-Adjusted, and 1977-90/1977-95 Coefficient Ratios) . . . . . . . . . . . . . . . . . . . . . . . C-4 


\section{ACRONYMS LIST}

AAA American Automobile Association

AARP American Association of Retired Persons

AD Alzheimer Disease

ADA Americans with Disabilities Act

ADL Activities of Daily Living

AFDC Aid to Families with Dependent Children

AHEAD Asset and Health Dynamics Among the Oldest Old

AISG American Insurance Services Group

ALS Activity Limitation Status

AMA American Medical Association

AoA Administration on Aging

BEA Bureau of Economic Analysis

BLS Bureau of Labor Statistics

CODES Crash Outcome Data Evaluation System

DHHS Department of Health and Human Services

DOE Department of Energy

DOT Department of Transportation

EIA Energy Information Administration

EPESE Established Populations for Epidemiologic Studies of the Elderly

FARS Fatality Analysis Reporting System

FHWA Federal Highway Administration

GES General Estimates System

GM General Motors

HRS Health and Retirement Survey

HUD Head Up Display

IADL Instrumental Activities of Daily Living

ITN Independent Transportation Network

ITS Intelligent Transportation System

LFP Labor Force Participation 
NASS National Automotive Sampling System

NCSA National Center for Statistics and Analysis

NHIS National Health Interview Survey

NHTSA National Highway Traffic Safety Administration

NIA National Institute on Aging (DHHS)

NLTCS National Long Term Care Surveys

NPTS Nationwide Personal Transportation Survey

NSC National Safety Council

OAA Older Americans Act

ORNL Oak Ridge National Laboratory

PAR Police Accident Report

PILR Property Insurance Loss Register

POV Privately Owned Vehicle

SIPP Survey of Income and Program Participation (Bureau of Census)

SSA Social Security Administration

UFOV Useful Field of View

VMT Vehicle Miles Traveled 


\section{EXECUTIVE SUMMARY}

At the turn of the century - the $20^{\mathrm{h}}$ century that is - the median age in the United States was under 30 years; America was $60 \%$ rural in nature; and there were only 36 highway fatalities all year. As we leave the $20^{\text {th }}$ century behind, the route into the $2 \mathrm{P}^{\text {st }}$ century is very different. "Intelligent" cars speed down multi-lane "smart" highways in a nation that is $75 \%$ urban. According to the Federal Highway Administration's Highway Statistics, there are 28,000 times more vehicles on theroad in 2000 than there were in 1900, and these vehicles travel about 2.6 trillion miles each year. Annual fatalities resulting from highway crashes have also increased - by over $1100 \%$.

We see other changes as well. The face of America is changing. It is growing older. In 2025, persons 65 and over will make up $18.5 \%$ of the total population. The number of persons aged 85 and over is increasing more rapidly than any other age group. More importantly, the elderly are taking more trips, driving further, and continuing to drive much later in life. These conditions lead to concerns about traffic safety.

Although the elderly are healthier and drive safer cars than they did just two decades ago, their frailty makes them more susceptible to injury than younger persons involved in traffic crashes of the same severity. In addition, visual, physical, and cognitive skills, all of which contribute to driving abilities, decrease with advancing age. The familiar "U"-shaped curve depicting the rate of fatalities per vehicle miles traveled, shows that the elderly experience a higher highway fatality rate than any other age group except teenagers. While the overall number of highway fatalities has decreased regularly since 1972, the number of fatalities of elderly travelers has continued to increase steadily. This increase is cause for concern for both the elderly driver and for other persons on the roads who mighbe placed in danger through crashes involving elderly drivers. 
Over the past century, the numbers of highways, vehicles, and drivers have increased dramatically. It is easy to allow the imagination to run rampant concerning the upcoming quarter century, to visualize super highways and technology-enhanced vehicles and a multitude of elderly, perhaps unsafe, drivers. Because of these concerns, Oak Ridge National Laboratory (ORNL) was tasked with developing a projection system to determine the impact of the elderly driver in the future.

ORNL's system of projection models provides national estimates and estimates for each of the four Census regions, in five-year increments between the year 2000 and the year 2025, for:

- The number of older drivers in the future who willstill be driving, by age group and gender,

- The average number of miles to be driven annually by an elderly driver, by age group and gender,

- The total number of elderly driver fatalities resulting from crashes in which older drivers are involved, and

- The total number of all occupant and non-occupant fatalities (all ages) resulting from crashes in which older drivers are involved.

Our approach to developing a logical, transparent, and defensible model was as follows:

- Review the literature to ascertain the current state of the research and to identify issues.

- Examine data sources to determine compatibility between modeling issues and data.

- Build a mathematical link between two national surveys so that information on health status could be included in the model.

- Develop three empirical models (percentage of drivers, miles driven, and crash rate) based on historical data.

- Formulate assumptions on the projections of independent variables in the empirical models for the years 2000-2025. 
- Adjust some empirically estimated parameter values in the models, primarily time trends.

- For the years 2000-2025, project the number of older drivers, the average vehicle miles traveled (VMT) per older driver, and crash rates, in order to generate projections of highway traffic fatalities by age group, gender, and Census region.

- Analyze the projections in terms of the extent to which various factors contribute to the increased fatalities.

Thus, our approach to projecting the number of fatalities involving older drivers uses four distinct components: (1) projection of the non-institutionalized population, (2) projection of the percentage of that population that drives, (3) projection of the average miles driven per driver, and (4) projection of the fatal crash risk associated with each mile driven. Our methodology, which has its motivation in behavioral theory, separates exposure to crashes from crash risk per se. It further divides exposure into two components, VMT and the likelihood of being a driver. This component structure permits conceptually different determinants of traffic fatalities to be projected separately. It also permits finer targeting of particular aspects of projections that need improvement and closer linking of projections to possible policy instruments for influencing them.

The first component of our model, population projections provided by the U.S. Census Bureau, indicates that nearly all subgroups of the elderly population will increase from 50 to 150 percent by the year 2025 . This enormous increase will have a substantial effect on the projection of the absolute number of casualties, even when crash risk per mile driven decreases or remains constant.

The second component of our projection system involves estimation of the historical determinants of people's decisions to drive. Figure ES-1 shows the projected levels of drivers between 1995 and 2025 for males and females. 


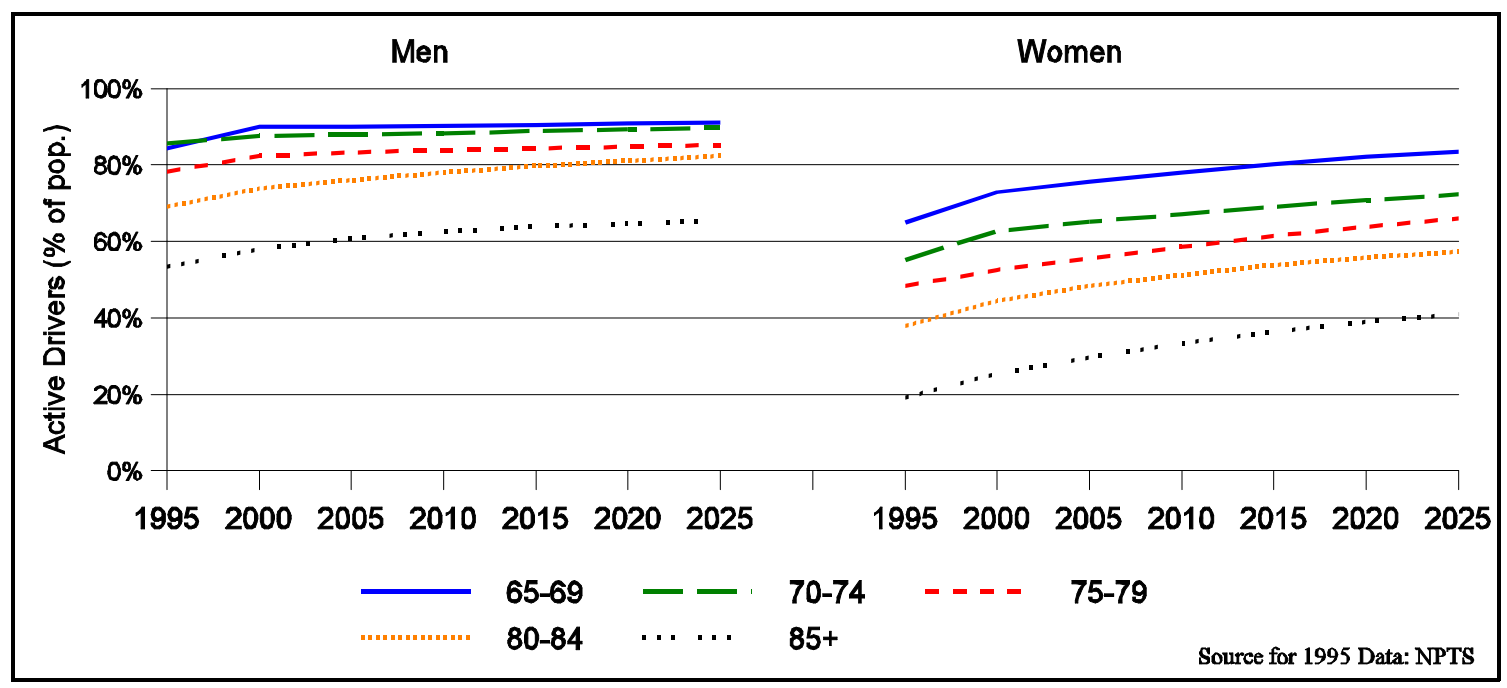

Figure ES-1. Projected Active Drivers as a Percentage of the Population

The third component of our projection system estimates the average miles driven for each age-gender-region group. The VMT projectionon a national basis is shown in Figure ES-2, which illustrates the rapid growth in VMT for all elderly age groups, but especially for elderly women.

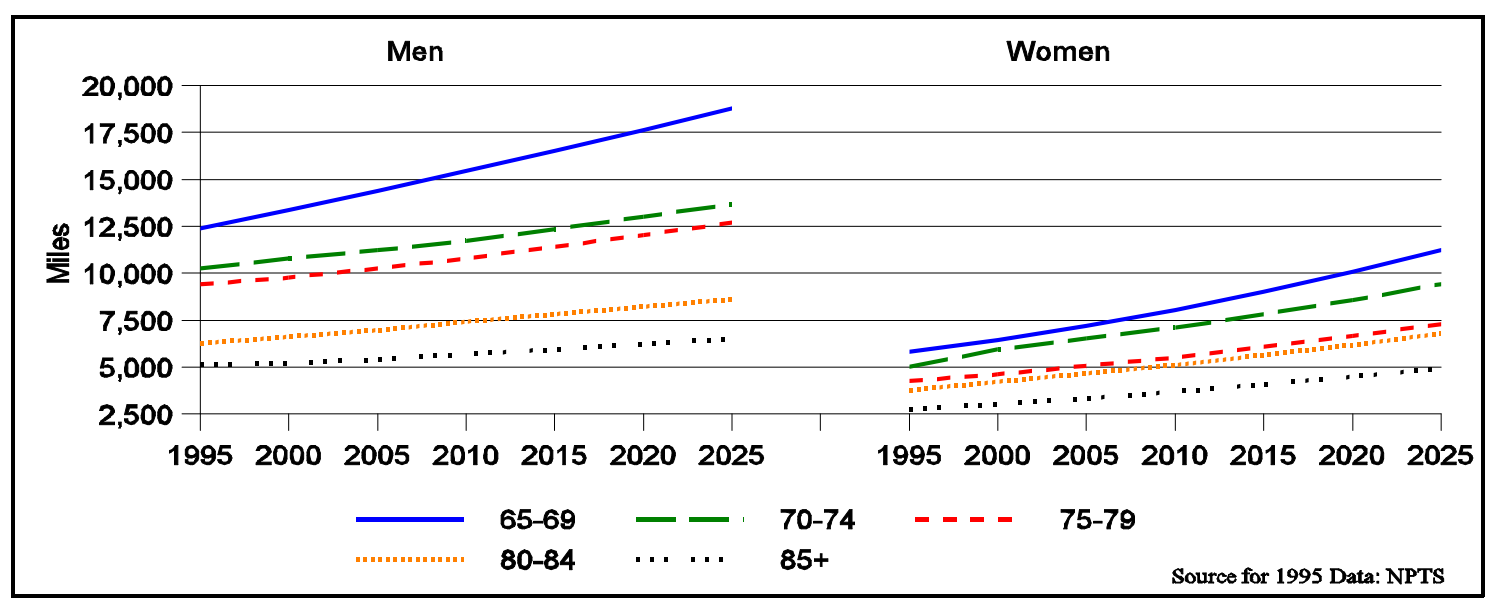

Figure ES-2. Projected Vehicle Miles of Travel per Person 
The final component of the modeling system is the crash risk. Two crash risks were modeled, that of the elderly driver and that of the total number of fatalities associated with a crash in which an older driver is involved. The projected driver risk is shown in Figure ES-3. While the number of elderly drivers and the VMT of elderly drivers are projected to dramatically increase between 2000 and 2025, the crash risk is projected to decrease.

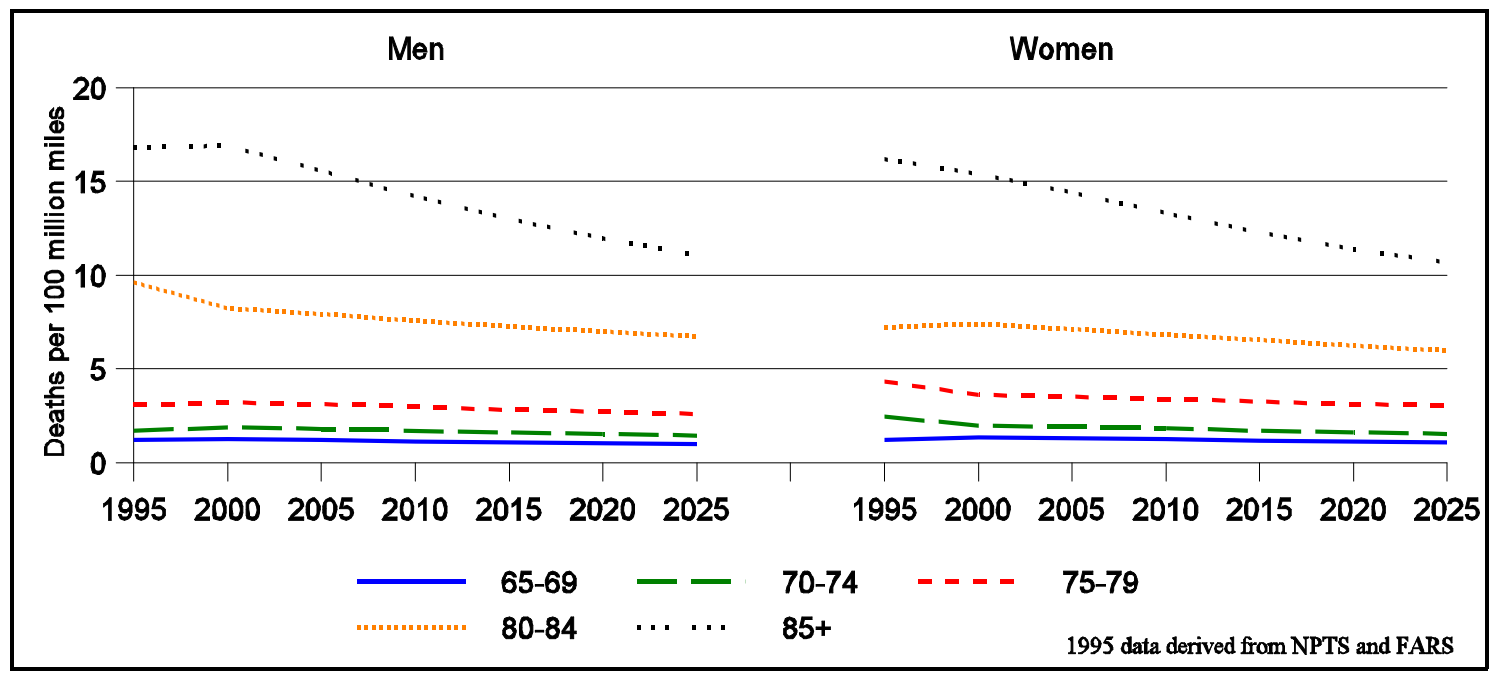

Figure ES-3. Driver Risk (deaths per 100 million miles)

Tables ES-1 and ES-2 summarize ORNL's projections of the two fatality measures used in this study, fatalities of elderly drivers and pro-rated total fatalities. It is important to note that our measurement of "total fatalities," which extends to passengers in a fatally injured elder driver's vehicle and to drivers and passengers of other vehicles in such a crash, divides the total number of fatalities among the number of vehicles involved in the crash. The concept was adopted as a concession to the absence of information on which driver in a crash was at fault. 
Table ES-1. Elderly Driver Fatality Projections, Male and Female

\begin{tabular}{|lrrrrrrr|}
\hline Age Group & 1995 & 2000 & 2005 & 2010 & 2015 & 2020 & 2025 \\
\hline $65-69$ & 881 & 983 & 1115 & 1425 & 1911 & 2287 & 2688 \\
$70-74$ & 956 & 1045 & 1040 & 1158 & 1447 & 1888 & 2216 \\
$75-79$ & 876 & 1136 & 1212 & 1235 & 1398 & 1793 & 2419 \\
$80-84$ & 704 & 1064 & 1325 & 1448 & 1511 & 1770 & 2329 \\
$85+$ & 474 & 670 & 838 & 1039 & 1202 & 1294 & 1489 \\
Total & $\mathbf{3 8 9 1}$ & $\mathbf{4 8 9 8}$ & $\mathbf{5 5 3 0}$ & $\mathbf{6 3 0 4}$ & $\mathbf{7 4 6 9}$ & $\mathbf{9 0 3 2}$ & $\mathbf{1 1 1 4 0}$ \\
\hline
\end{tabular}

Table ES-2. Total Fatality Projections, Male and Female

\begin{tabular}{|lrrrrrrr|}
\hline & 1995 & 2000 & 2005 & 2010 & 2015 & 2020 & 2025 \\
\hline $65-69$ & 1120.505 & 1267 & 1464 & 1917 & 2628 & 3221 & 3871 \\
$70-74$ & 1094.46 & 1221 & 1219 & 1369 & 1744 & 2333 & 2802 \\
$75-79$ & 935.457 & 1240 & 1342 & 1400 & 1627 & 2139 & 2953 \\
$80-84$ & 665.039 & 1022 & 1282 & 1429 & 1518 & 1803 & 2410 \\
$85+$ & 376.745 & 530 & 666 & 840 & 990 & 1082 & 1265 \\
Total & $\mathbf{4 1 9 2 . 2 0 6}$ & $\mathbf{5 2 7 9}$ & $\mathbf{5 9 7 3}$ & $\mathbf{6 9 5 5}$ & $\mathbf{8 5 0 8}$ & $\mathbf{1 0 5 7 9}$ & $\mathbf{1 3 3 0 1}$ \\
\hline
\end{tabular}

Men and women have widely different fatality projections. Male driver fatalities continue to be greater than females in overall numbers; however, the percent of growth is projected to be less than that of female fatalities for most age groups, as shown in Table ES-3 for the year 2025 .

Table ES-3. Elder Driver Fatality Projections for 2025

(as Percentages of 1995 Driver Fatalities)

\begin{tabular}{|ccc|}
\hline Age Group & Male & Female \\
\hline $65-69$ & $301.3 \%$ & $457.8 \%$ \\
$70-74$ & $236.7 \%$ & $295.0 \%$ \\
$75-79$ & $325.5 \%$ & $297.0 \%$ \\
$80-84$ & $329.3 \%$ & $441.5 \%$ \\
$85+$ & $261.1 \%$ & $526.1 \%$ \\
Total & $290.8 \%$ & $375.9 \%$ \\
\hline
\end{tabular}


The full report contains projections by age-gender-region in five-year intervals for the number of drivers, VMT/driver, and crash risks, as well as projected fatalities. In addition to the projections provided in this report, a spreadsheet-based tool was developed thatlows a user of the model to modify the assumptions we used in projecting highway fatalities. These assumptions include projections of household income, health and employment status, and other determinants of driving and crash involvement. This feature provides a mechanism to consider alternative scenarios about the future.

ORNL's methodology for deriving the fatality projections is based on a logical, wellgrounded component approach. Because of data limitations, however, several assumptions were required. It is not generally possible to form direct links between data sets. Therefore, when possible, we either constructed a surrogate for a critical missing link, as in our development of the projected health status index, or simply excluded a particular projection from our model. In situations where the magnitude of historical trends, when continued indefinitely into the future yield absurd results, we logically modified coefficients of variables to provide more reasonable estimates of our modeling system components.

Additional research is recommended. Especially important research areas include the role of infrastructure and equipment, the asymptotic projection of VMT, additional and improved measures of health status, and further comparisons of younger and older drivers' behavior. 


\section{INTRODUCTION}

America is graying. The proportion of the population that is 65 years of age or older is increasing each year, and the group of older persons who are age 85 or over is the fastest growing segment of the population (Figure 1.1). These increases in the elderly population raise many issues, among which transportation safety is a major concern. Physical and cognitive limitations are known to affect the driving performance of the elderly, and their relative frailty further exacerbates the effects of a crash that younger people would more readily survive. As the over-65 population grows, American society is also changing, with more elderly - especially women - driving more miles and more frequently, with people working later in life, and with vast changes in health management and in physical and functional abilities. These and other factors are likely to contribute to changes in the number of fatal traffic crashes involving the elderly. The purpose of this research is to develop projections from 2000 through 2025 of highway traffic fatalities that involve older drivers.

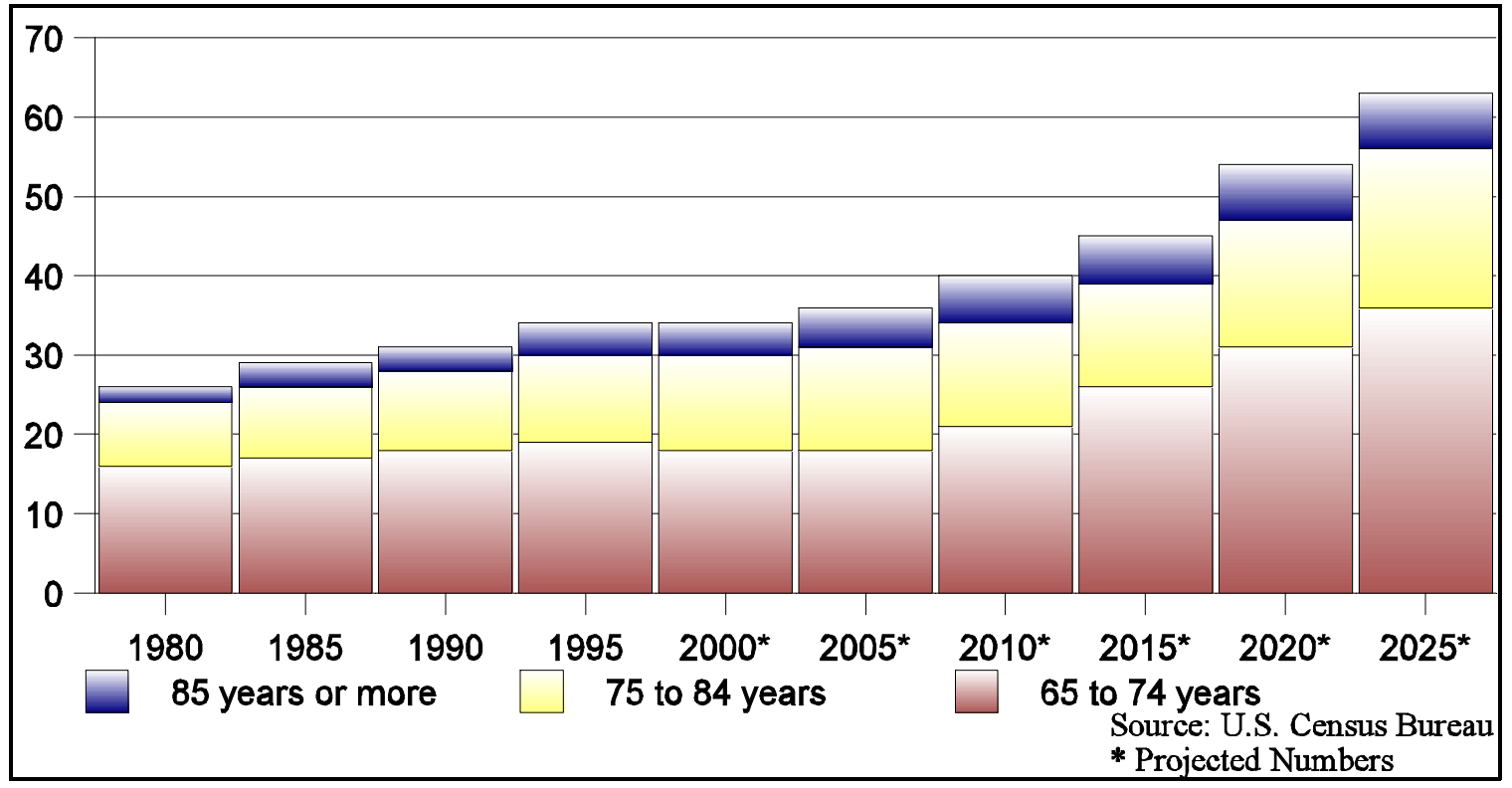

Figure 1.1. U.S. Elderly Population Estimates, by Age and Year (in millions) 
This research was funded by General Motors (GM) pursuant to an agreement between GM and the U.S. Department of Transportation (DOT). Under Section I.G of the agreement, GM agreed to conduct or fund research in the area of driver impairment, including the effects of aging. The other older driver research projects agreed upon by both GM and the National Highway Traffic Safety Administration (NHTSA) are listed in Table 1.1.

Table 1.1. Older Driver Research Projects Sponsored by General Motors Corporation

Project ID

G.1 Changes in Crash-Involvement Rates as Drivers Age

G.2 Self-Regulation as a Mechanism for Improving the Safety of Older Drivers

G.3 Understanding the Influence of Older Driver Disability on Mobility and Quality of Life

G.4 Improvement of Senior-Driver Safety Through SelfEvaluation

G.5 Reduction or Cessation of Driving Among Older Drivers

G.6 Projections of Crashes and Casualties Caused by Older Drivers

G.7 Factors Contributing to Premature Reduction or Cessation of Driving by Older Men and Women

G.8 Investigations of Crashes and Casualties Associated with Older Drivers

G.9 Remediation Through Adaptive Equipment and Training

Oak Ridge National Laboratory (ORNL) was tasked (GM Project G.6) to conduct research and develop a model to project the numbers of fatalities in highway crashes involving older drivers. Tasks included a brief review/overview of the literature on older drivers in the United States, a study of travel behavior and patterns of the elderly, an investigation of the influence of various factors on older drivers' crash involvement, and an extensive examination 
of existing data bases, including historical crash records. These tasks led to the development of a model to predict the involvement of older drivers in fatal vehicle crashes in the future.

This project provides national estimates and estimates for each of the four Census regions, in five-year increments between the year 2000 and the year 2025, for:

- The number of older drivers in the future who will still be driving, by age group and gender,

- The average number of miles to be driven annually by an elderly driver, by age group and gender,

- The total number of elderly driver fatalities resulting from crashes in which older drivers are involved, and

- The total number of all occupant and non-occupant fatalities (all ages) resulting from crashes in which older drivers are involved.

Estimates are generated for each Census region of the country: Midwest, Northeast, South and West, anticipating that the elderly population will continue the migration trends to the southern and western regions. According to population projections estimated by the U.S. Census Bureau, the elderly population in the western region will more than double by the year 2020 (Figure 1.2).

The relationships in our model are based on statistical examination of travel behavior and crash involvement over the previous quarter century. Among the influences on travel behavior and crashes are health status, household income, employment status, the presence of another driver in the household, the availability of public transit, and seat belt use and usage of other in-vehicle devices. The model relies on the evolution of these determinants of driving behavior and crash involvement to project future fatalcrashes among the American elderly population, by gender and five-year age groups. 


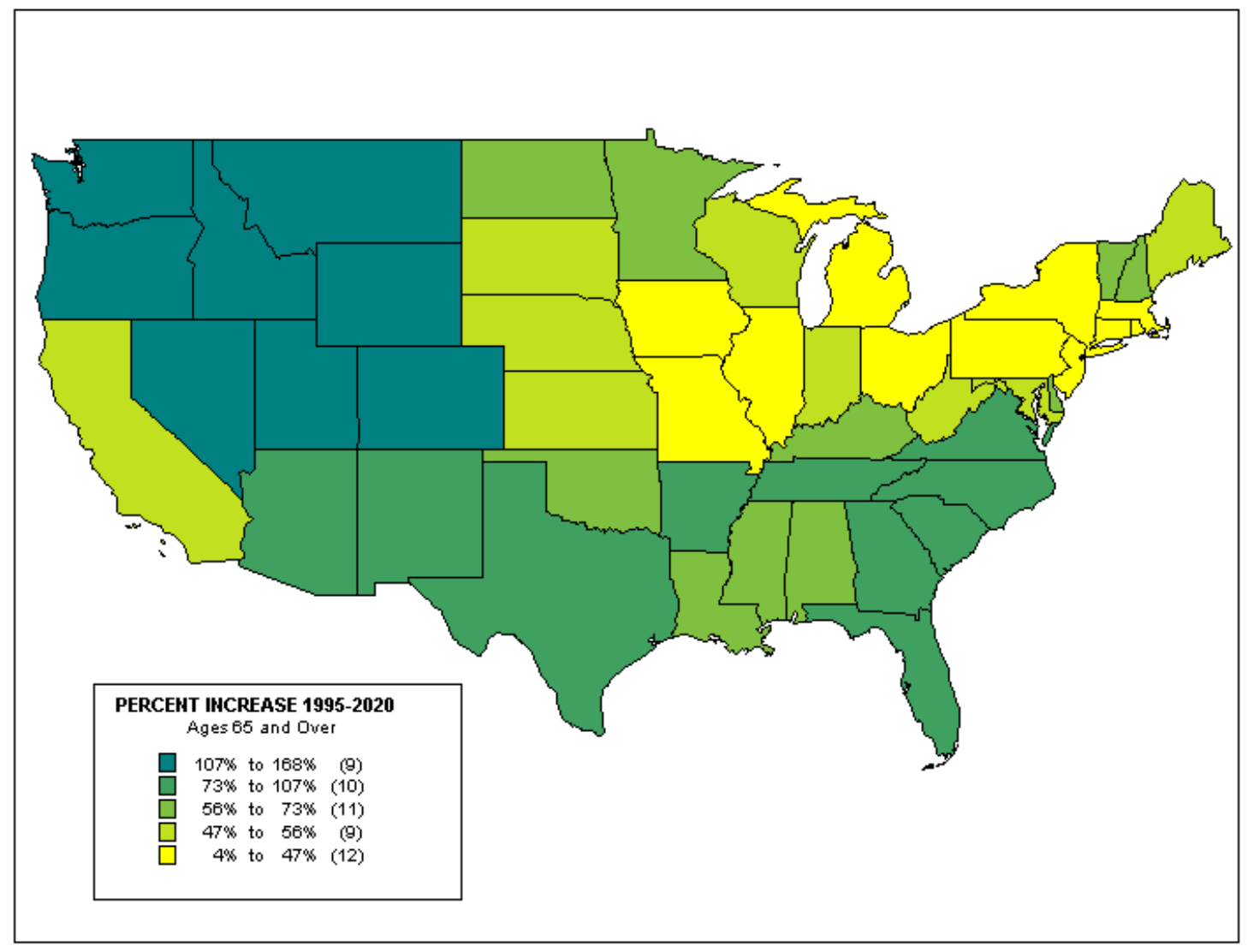

Figure 1.2. United States Projected Population Increase, 1995 to 2020

A spreadsheet-based tool was developed that allows a user of the model to modify the assumptions used in projecting highway fatalities. These assumptions include projections of household income, health and employment status, and other determinants of driving and crash involvement. This feature provides a mechanism to consider alternative scenarios about the future.

This report documents the research that was conducted, describes the model, and provides output from the model. Specifically, Chapter 2 describes the research method we applied to derive the fatality projections. An overview of the literature that focuses on driving behavior and crash involvement of older drivers is reported in Chapter 3. Chapter 4 discusses 
various data sources and their ability to meet our modeling needs. A series of models that led to the final fatality projections are detailed in Chapters 5 through 8 . Chapter 9 presents an analysis of different components that contribute to the change in total projected fatalities. Chapter 10 concludes this report by summarizing major findings, and recommending future research and data needs. 


\section{RESEARCH METHODOLOGY}

This chapter describes the research method we adopted to project highway crash fatalities involving older drivers. First, we surveyed the literature pertaining to elderly driving and crashes to identify issues and relationships that influence crashes involving the elderly. The U.S. Census Bureau has projected the number of elderly persons in the future. These estimates comprise elderly population that are potentially at risk to traffic fatalities. Much has been written about the population over 65 years of age - for example, health, social characteristics, and the impact of physical and cognitive impairments on driving behavior. Changing income levels brought on by changes in retirement ages and by the economy have also been studied. Travel habits and trip patterns of the elderly have been documented in national transportation surveys. Existing longitudinal studies have examined health issues. In addition, the U.S. DOT has collected a significant body of data on crashes and casualties. Currently, safety on the highway is being improved partially with increased seat belt use and usage of other in-vehicle devices. Furthermore, it is anticipated that deployments of Intelligent Transportation System (ITS) technologies, both within the vehicle and on the highway, will further improve highway safety. Our literature review (Chapter 3) concentrated on the U.S. population over 65 years of age and specifically on the driving behavior of this population.

After a review of the existing literature, we examined various data sources for potential use in the model. A number of criteria were used to determine the feasibility of these data sources. First, because the projections would be for years 2000 through 2025 , it was desirable to have as much historical data as possible. Second, it was desirable to have a single data source that contains all necessary information on individual older drivers that is pertinent to crash involvement such as household characteristics, demographics, health status with respect to physical and functional limitations, chronic conditions (e.g. Parkinson's disease, glaucoma, etc.), driving patterns, and medication use. 
Finally, data sets should contain, at a minimum, information categorized by age, gender, and regional designations.

Unfortunately, no single data source contained all necessary information. Some data sets were compiled for only a few years, and the data sets were not totally compatible. Sufficient data were available that allow us to estimate the probability of an older driver's decision to drive and the average number of miles driven per year. However, that was not the case for estimating crash risk. Data were inadequate to estimate crash risk on an individual driver basis. Consequently, the crash risk model had to be based on the typical characteristics of subgroups of older drivers specified by age, gender and Census region combination. Chapter 4 discusses the data sources that were examined and the rationale for selecting and using a specific data source.

To project the future, one needs first to acquire a comprehensive understanding of what conditions have influenced current and past trends. In the example of older drivers' decisions to drive, we rely on historical data to identify what influences an older driver's decision to drive. The next challenge is to identify the future directions that are likely to "alter" historical trends. Again, in the example of older drivers' decisions to drive, we speculate that the future older population will be healthier, more financially secure, more accustomed to driving, and enjoy longer life expectancy than their counterparts today. All of these trends suggest that the future older population is likely to continue to drive well into their advanced years and will drive more miles and more frequently than the older population today.

To project the future based on the past, we were constrained to predictors (e.g., driving determinants) for which reliable projections are possible. This constraint is consequential in that the explanatory power of our empirical models is less than desirable because only selected explanatory variables, for which reliable projections are possible, are included in the model. Consequently, the predictive power of our crash model is seriously reduced. For example, vision impairment from cataracts or glaucoma has been suggested 
in the literature to be a significant crash risk factor. However, without reliable projections on the percentage of older drivers who will suffer from vision impairment, we had to omit that factor in our empirical models.

Using historical data, we developed a series of empirical models: (1) a model to estimate the probability of an older driver's decision to drive; (2) a model to estimate the average number of miles driven in a year by an older driver; and (3) a model to estimate the crash risk of a group of older drivers categorized by age, gender and Census region. The crash risk is defined in two ways: as the total number of driver fatalities from crashes involving older drivers per one million miles driven, and as the total number of fatalities, regardless of age, associated with a crash in which an older driver is involved. The rationale for developing this series of models is that:

- Given the projections of future older population, we can estimate the number of older drivers in the future by multiplying population projections and the estimated probability of an older driver's decision to drive,

- Applying the estimated number of older drivers in the future (from the previous step) to the average number of miles driven annually by an older driver, we can estimate the total annual vehicle miles of travel (VMT) by each age group of older drivers,

- Multiplying the crash risk (fatalities per one million VMT) and the total annual VMT by older drivers, we can estimate the two measures of fatalities involving older drivers.

These models are described in greater detail in Chapters 5 through 9.

In summary, ORNL's approach to developing a logical, transparent, and defensible model was as follows:

- Review the literature to ascertain the current state of the research and to identify issues. 
- Examine data sources to determine compatibility between modeling issues and data.

- Build a mathematical link between two national surveys so that the minimal information on health status could be included in the model.

- Develop three empirical models based on historical data.

- Formulate assumptions on the projections of independent variables in the empirical models for the years 2000-2025.

- Adjust some empirically estimated parameter values in the models, primarily time trends, to ensure logical projections (e.g. percentages of the population that drives between 0 and 1)

- For the years 2000-2025, project (1) the number of older drivers, (2) the average VMT per older driver, and (3) crash rates and highway traffic fatalities. Projections are generated by age group, gender, and Census region.

- Analyze the projections in terms of the extent to which various factors contribute to the increased fatalities. This type of analysis is crucial for policy makers to help them identify and prioritize areas where actions can be taken to improve older driver safety. 


\section{OVERVIEW OF THE LITERATURE}

The population of the United States is growing, and the number of elderly persons (aged 65+) is growing more rapidly than any other age group. In this chapter, we briefly review the current literature on the aging population, elderly drivers, and driving. With an emphasis on the elderly, we will identify trends in population growth, review some of the studies addressing driving and health issues of the elderly, review impacts related to transportation and mobility, examine crash literature, and look at other factors that could affect projections of the number of crashes involving the elderly driver.

\subsection{THE ELDERLY POPULATION IN THE UNITED STATES}

According to the U.S. Census Bureau, half the population of the United States in 1860 was under age 20; ninety years later, the median age had increased to 30 . The Census projects that, in 2035, the median age will reach its peak at 38.7 years. (Day, 1996, p. 7)

In the 20th century, our nation's population tripled, but the number of elderly (i.e., persons 65 and over) increased by a factor of eleven (Hobbs and Damon, 1996, p. 2-2). The number of elderly U.S. residents went from 3.08 million (4.1\% of the total U.S. population) in 1900 to 12.3 million $(8.1 \%)$ in 1950 to 31.08 million $(12.5 \%)$ in 1990 . The number of elderly persons is predicted to reach 53.35 million (16.4\%) by 2020. Only ten years later, the percentage of the U.S. population that is over 65 years of age is predicted to be over $20 \%$, and this percentage is not expected to decrease before mid-century (Hobbs and Damon, 1996, p. 2-3).

Several explanations for this aging of the population exist. Two of the more obvious reasons are the maturing of the "baby boom" generation and improvements in 
health care, resulting in longer life expectancies. Between 1946 and 1964, 75 million babies were born in the United States. In 2010, the first of these individuals will be nearing retirement. In the year 2020, the baby boom generation will be between the ages of 56 and 74 (Day, 1996, pp. 7-9). By 2030, all "boomers" will be over 65 years of age.

Improvements in health care have resulted in an increase in life expectancy. In the late 1700s, life expectancy at birth was only about 35 years! A hundred years later, it was approximately 47 years for whites, although it was much lower for non-whites. For baby boomers, average life expectancy is around 68 years (Hobbs and Damon, 1996, p. 3-1).

\subsubsection{By Age Groups and Cohorts}

"The older population itself is getting older" (Administration on Aging 1999). Of the three age groups $(65-74,75-84$, and $85+)$ considered in this study, the $85+$ group is growing the fastest. In 1998, the 65-74 age group was eight times larger than the same age group in 1900; the 75-84 age group was 16 times larger; and the 85 and over age group was 33 times larger! (Administration on Aging, 1999).

The growth trend of this oldest-old group is projected to continue. Between 1995 and 2025, this age group is expected to almost double (Table 3.1).

It should be noted that the percent ofthe young-old population (i.e., age group 6574) as a part of the entire U.S. population will actually decrease slightly around the years 2000-2005. This decrease is due to a decrease in the birth rate during the Depression years. Following 2010, however, the population of all elderly age groups will increase sharply. 
Table 3.1. Population Projections for the Total United States, by Age Group, for the Years 2000-2025, with Comparison to the 1995 Population

\begin{tabular}{|c|c|c|c|c|c|c|c|}
\hline$\overline{\text { Age g }}$ & $\begin{array}{c}\text { Number in } \\
1995\end{array}$ & $\begin{array}{c}\text { Number in } \\
2000\end{array}$ & $\begin{array}{c}\text { Number in } \\
2005\end{array}$ & $\begin{array}{c}\text { Number in } \\
2010\end{array}$ & $\begin{array}{c}\text { Number in } \\
2015\end{array}$ & $\begin{array}{c}\text { Number in } \\
2020\end{array}$ & $\begin{array}{c}\text { Number in } \\
2025\end{array}$ \\
\hline $1 \operatorname{ages}^{a}$ & $262,820,000$ & $74,634,000$ & $85,981,000$ & $297,716,000$ & 4,000 & $322,742,000$ & 50,000 \\
\hline$\%$ increase & & $4 \%$ & $4 \%$ & $4 \%$ & $4 \%$ & $4 \%$ & $4 \%$ \\
\hline All elderly (ages & $33,532,395$ & $34,709,734$ & $36,166,552$ & $39,408,398$ & $45,566,613$ & $53,219,272$ & $61,951,824$ \\
\hline \multicolumn{8}{|l|}{$65+)$} \\
\hline$\%$ of al & $13 \%$ & $13 \%$ & $13 \%$ & $13 \%$ & $15 \%$ & $16 \%$ & $18 \%$ \\
\hline$\%$ increase & & $4 \%$ & $4 \%$ & $9 \%$ & $16 \%$ & $17 \%$ & $16 \%$ \\
\hline Ages & $18,759,220$ & $18,135,538$ & $18,368,960$ & $21,057,448$ & $26,243,458$ & $31,384,875$ & $35,424,538$ \\
\hline$\%$ of all ages & $7 \%$ & $7 \%$ & $6 \%$ & $7 \%$ & $8 \%$ & $10 \%$ & $11 \%$ \\
\hline$\%$ in & & $-3 \%$ & $1 \%$ & $15 \%$ & $25 \%$ & $20 \%$ & $13 \%$ \\
\hline Ages 75-84 & $11,145,006$ & $12,314,793$ & $12,898,112$ & $12,680,364$ & $13,129,891$ & $15,374,496$ & $19,481,045$ \\
\hline$\%$ of all ages & $4 \%$ & $4 \%$ & $5 \%$ & $4 \%$ & $4 \%$ & $5 \%$ & $6 \%$ \\
\hline$\%$ ir & & $10 \%$ & $5 \%$ & $-2 \%$ & $4 \%$ & $17 \%$ & $27 \%$ \\
\hline Ages 8 & $3,628,169$ & $4,259,403$ & $4,899,480$ & $5,670,586$ & $6,193,264$ & $6,459,901$ & $7,046,241$ \\
\hline$\%$ of all ages & $1 \%$ & $2 \%$ & $2 \%$ & $2 \%$ & $2 \%$ & $2 \%$ & $2 \%$ \\
\hline$\%$ increase & & $17 \%$ & $15 \%$ & $16 \%$ & $9 \%$ & $4 \%$ & $9 \%$ \\
\hline
\end{tabular}

Sources: total population counts through 2025 from U.S. Census Bureau publication P25-1130,

Table F, p. 9, middle series ( http://www.census.gov/prod/1/pop/p25-1130/); elderly population counts through 2025 derived fromhttp://www.census.gov/population/www/projections/stproj.htm/(Series A).

${ }^{a}$ Note that these numbers represent total (institutionalized and non-institutionalized) elderly population projections. The projections provided in Chapter 5 are for non-institutionalized populations.

\subsubsection{By Gender}

Mortality rates for men exceed those for women. For the older age groups, the gender imbalance is even greater. The male to female ratio is growing closer, however. In 1995, there were only 69 men for every 100 women for persons 65 years or older. In 2025 , the ratio is expected to be closer to 83 men for every 100 women. Table 3.2 shows the projected ratios of men to women in different age groups.

Projecting population totals by gender is important because of historical driving trends. For example, in 1965, only about $28 \%$ of all drivers' licenses for ages 65 and over were issued to women. In 1995, however, over $50 \%$ of all drivers' licenses for ages $65+$ were issued to women. 
Table 3.2. Projected Ratios of Men to Women, Total United States, Compared with the 1995 Ratios

\begin{tabular}{|lccccccc|}
\hline \multicolumn{1}{|c}{$\begin{array}{c}\text { Age } \\
\text { group }\end{array}$} & $\begin{array}{c}\text { Gender } \\
\text { ratio }{ }^{a} \\
1995\end{array}$ & $\begin{array}{c}\text { Gender } \\
\text { ratio, } \\
2000\end{array}$ & $\begin{array}{c}\text { Gender } \\
\text { ratio, } \\
2005\end{array}$ & $\begin{array}{c}\text { Gender } \\
\text { ratio, } \\
2010\end{array}$ & $\begin{array}{c}\text { Gender } \\
\text { ratio, } \\
2015\end{array}$ & $\begin{array}{c}\text { Gender } \\
\text { ratio, } \\
2020\end{array}$ & $\begin{array}{c}\text { Gender } \\
\text { ratio, } \\
2025\end{array}$ \\
\hline All ages & 95.4 & 95.5 & 95.6 & 95.7 & 95.8 & 95.9 & 96 \\
All elderly & 69.0 & 70.4 & 72.4 & 75.0 & 78.1 & 80.8 & 82.9 \\
Ages 65-74 & 80.1 & 82.2 & 84.4 & 86.3 & 87.8 & 89.1 & 90.5 \\
Ages 75-84 & 63.5 & 66.9 & 69.9 & 73.3 & 77.0 & 80.2 & 83.0 \\
Ages 85+ & 38.9 & 40.5 & 43.0 & 45.4 & 47.5 & 49.6 & 52.4 \\
\hline
\end{tabular}

Source: U.S. Census Bureau, www.census.gov/population/www/projections/stproj.htmland www.census.gov/population/www/projections/natproj.html.

${ }^{a}$ Gender ratio is defined as the number of males per 100 females.

\subsubsection{By Economic Status}

Personal income/economic status is an extremely important factor for the elderly. For example, medical expenses are generally greater for the elderly than they are for the average person under age 65. In addition, a fixed income may not keep up with the general rate of inflation. A major source of income for the elderly is Social Security, as reported by $91 \%$ of older persons (Administration on Aging, 1999). Many older persons continue employment, about half of which is part-time work. In the transportation equation, elderly persons find that the costs of owning an automobile may be too high or that they must limit the number of trips they take to save on the costs of transportation.

The U.S. Census Bureau provides historical data on average annual incomes, for different age groups. The median income for all households in the United States in 1995, for all ages, was $\$ 34,076$, and for the same time period, the median income for the elderly (i.e., 65 and over) was $\$ 19,096$. Table 3.3 presents historical data on income levels of the elderly in comparison with the income level of "all households." 
Table 3.3. Median Household Income by Type of Household for Selected Years (1996 Dollars)

\begin{tabular}{|c|c|c|c|c|c|c|}
\hline & 1969 & 1979 & 1983 & 1989 & 1993 & 1996 \\
\hline All households & $\$ 33,072$ & $\$ 34,666$ & $\$ 32,941$ & $\$ 36,598$ & $\$ 33,660$ & $\$ 35,172$ \\
\hline \multicolumn{7}{|c|}{ Married-couple, no children, householder $65+$} \\
\hline Including wife's income & $\$ 18,553$ & $\$ 23,724$ & $\$ 27,642$ & $\$ 29,230$ & $\$ 28,263$ & $\$ 29,210$ \\
\hline Excluding wife's income & $\$ 14,340$ & $\$ 15,675$ & $\$ 18,116$ & $\$ 18,982$ & $\$ 18,710$ & $\$ 19,174$ \\
\hline One-person household, male $65+$ & $\$ 8,936$ & $\$ 11,227$ & $\$ 13,615$ & $\$ 14,288$ & $\$ 14,821$ & $\$ 14,586$ \\
\hline One-person household, female $65+$ & $\$ 7,025$ & $\$ 9,382$ & $\$ 10,926$ & $\$ 11,388$ & $\$ 10,823$ & $\$ 11,454$ \\
\hline
\end{tabular}

Source: U.S. Census Bureau, "Changes in Median Household Income," from Table 4, at http://www.census.gov/hhes/income/mednhhld/t4.html.

The U.S. Census Bureau also provides historical mean incomes by age-gender groupings. Table 3.4 shows mean income for individuals in two elderly age categories for selected years.

Table 3.4. Mean Income for the Elderly, by Gender (1998 Dollars) ${ }^{2}$

\begin{tabular}{|lccccccc|}
\hline Year & $\begin{array}{c}\text { Mean } \\
\text { income in } \\
1969\end{array}$ & $\begin{array}{c}\text { Mean } \\
\text { income in } \\
1979\end{array}$ & $\begin{array}{c}\text { Mean } \\
\text { income in }\end{array}$ & $\begin{array}{c}\text { Mean } \\
\text { income in }\end{array}$ & $\begin{array}{c}\text { Mean } \\
\text { income in } \\
1983\end{array}$ & $\begin{array}{c}\text { Mean } \\
\text { income in } \\
1989\end{array}$ & $\begin{array}{c}\text { Mean } \\
\text { income } \\
\text { in } 1998\end{array}$ \\
\hline All Males, 65+ & $\$ 17,814$ & $\$ 19,719$ & NA & $\$ 24,779$ & $\$ 24,138$ & $\$ 25,247$ & $\$ 27,997$ \\
All Females, 65+ & $\$ 8,977$ & $\$ 11,331$ & $\$ 13,012$ & $\$ 14,515$ & $\$ 13,413$ & $\$ 14,480$ & $\$ 15,419$ \\
Males, 65-74 & NA & NA & NA & $\$ 27,305$ & $\$ 25,870$ & $\$ 27,891$ & $\$ 30,441$ \\
Females, 65-74 & NA & NA & NA & $\$ 15,045$ & $\$ 14,090$ & $\$ 15,236$ & $\$ 16,043$ \\
Males, 75+ & NA & NA & NA & $\$ 20,091$ & $\$ 21,262$ & $\$ 21,226$ & $\$ 24,547$ \\
Females, $75+$ & NA & NA & NA & $\$ 13,791$ & $\$ 12,545$ & $\$ 13,608$ & $\$ 14,729$ \\
\hline
\end{tabular}

Source: U.S. Census Bureau, Historical Income Tables, from Table P-9, at http://www.census.gov/hhes/income/histinc/p09.html.

${ }^{a} \mathrm{NA}=$ not available.

The Bureau of Economic Analysis provides data on total personal income, by state, for all ages and makes projections for future income. However, these projections are for total personal income and are not provided by age-gender categories. The U.S. Census Bureau does not make income projections.

Full retirement age in the year 2000 is 65; however, beginning in 2003, full retirement age gradually increases to age 67 for those born in 1960 or later. It is possible 
that individuals will not retire at their full retirement age. For example, persons born in 1943 (or later) who work beyond their normal retirement age will receive an $8 \%$ benefit for each year that they delay their retirement (http://www.ssa.gov/pubs/10035.html).

\subsubsection{By Race, Ethnicity, and Social Characteristics}

The size of non-white racial/ethnic groups is projected to increase dramatically after the year 2010. This increase is due to higher fertility rates (especially among Hispanics and Blacks) as well as immigration and lower mortality rates (among Asian and Pacific Islanders and Hispanics). Although the racial and ethnic components of the elderly population will change, how this change will affect transportation and mobility among the elderly cannot be quantified at this time. Therefore, this factor will not be considered further in this study.

Social characteristics, including marital status, living/housing arrangements, and education, of the elderly population may be important characteristics to consider when describing transportation usage. Historically, older men are more likely to be married than

older women; women are more likely to be widowed than men. In 1997, the numbers of single (never married) and divorced elderly were approximately equal for men and women.

In 1995, most elderly men (73\%) lived with a spouse while only $41 \%$ of elderly women lived with a spouse. More elderly women (42\%) lived alone or with non-relatives. About $7 \%$ of elderly men and $17 \%$ of elderly women lived with other relatives. In 1996, the percentage of elderly persons living in nursing homes increased dramatically with higher age groups, ranging from about $1 \%$ in the $65-74$ age group to almost $20 \%$ in the $85+$ age group. In 1997, most (79\%) households headed by older persons owned their own homes; only $21 \%$ were renters (Administration on Aging, 1999). In addition, there is a trend for households comprised of older persons to move to rural or suburban communities. In these locations, transportation needs are greater than in urban settings where mass transportation is available (National Association of Development Organizations Research Foundation, 1999, p. 3).

\begin{tabular}{lll}
\hline GM Project G.6 & $3-6$ & October 2000
\end{tabular}


The highest educational level achieved by the elderly is increasing. In 1970, only $28 \%$ of the elderly had completed high school; in 1998, 67\% had high school degrees. Education level varies by race and ethnicity, with Blacks and Hispanics having lower educational levels than Whites. As the racial composition of the elderly changes, it is highly likely that the educational levels will also change. The relation of education level to health has been studied and is discussed more fully in Section 3.2.3.

In summary, race, ethnicity, and social characteristics are important factors to understanding the makeup of the elderly population and their transportation needs. It is difficult, however, to quantify the impact of these factors on transportation use by the elderly. Therefore, race, ethnicity, and the social characteristic of marital status will not be considered further in this analysis. Educational levels and health are very closely related and will be considered together in a later section. In addition, living/housing arrangements have an impact on the decision to drive. That is, in households in which there is another driver, the elderly, especially elderly women, do not drive as much. This fact has been incorporated within our projection model and is explained more fully in Chapter 5.

\subsubsection{By Geographic Distribution}

According to Census estimates, about half of the elderly population in the United States currently lives in nine states - California, Florida, New York, Texas, Pennsylvania, Ohio, Illinois, Michigan, and New Jersey. The states with the highest per capita elderly population are Florida, Pennsylvania, Rhode Island, West Virginia, and Iowa, all of which have an elderly population which is at least $15 \%$ of their total population (Administration on Aging, 1999). Although some elderly persons maintain homes in different areas of the country and alternate their residence location based on personal reasons (e.g., changes in the weather), this migration pattern is difficult to quantify and will not be considered in this analysis. Immigration has changed the racial profiles in some border states; however, because the impact of changes in racial composition on transportation issues - especially crash data - has not been quantified, this factor will not be included in the projection 
analysis. Distribution of the elderly population by gender and age group for each Census region for 1995-2020 is shown in Figures 3.1-3.4.

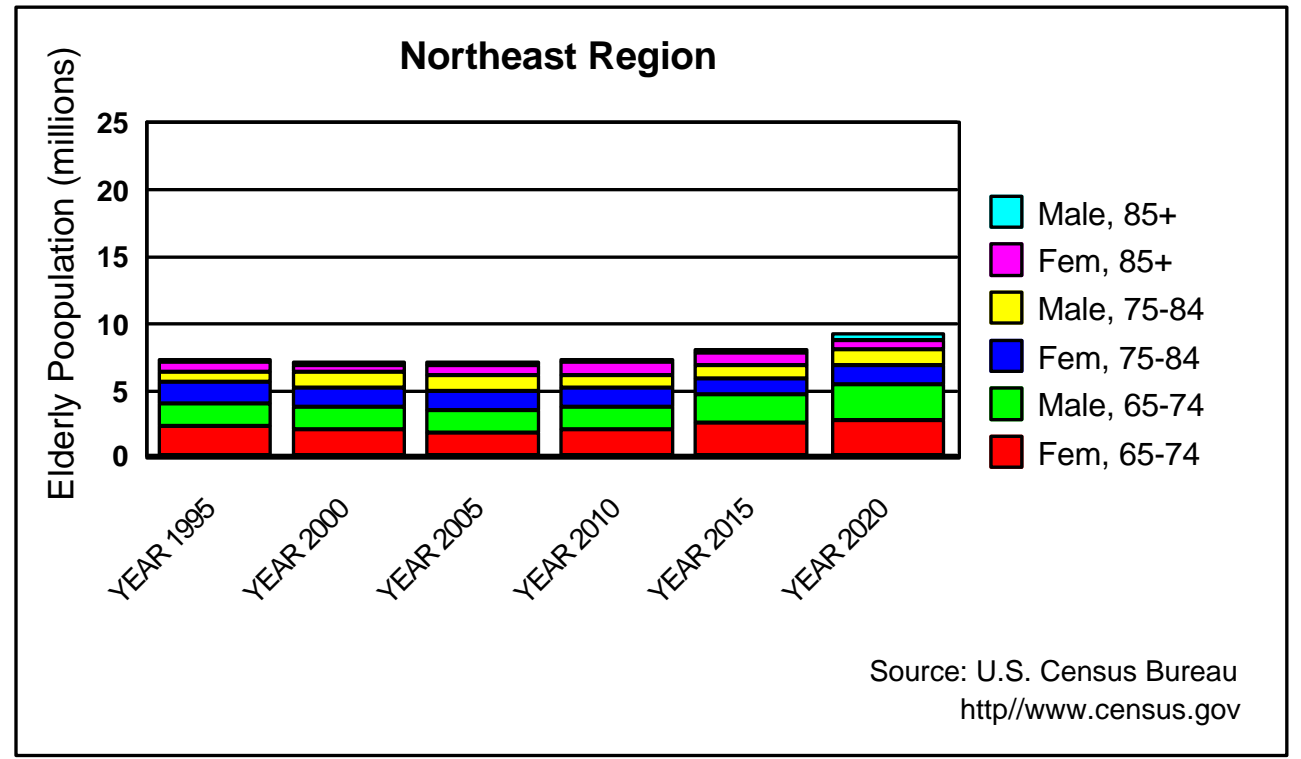

Figure 3.1. Distribution of the Elderly Population in the Northeast Region by Gender and Age Group between 1995 and 2020

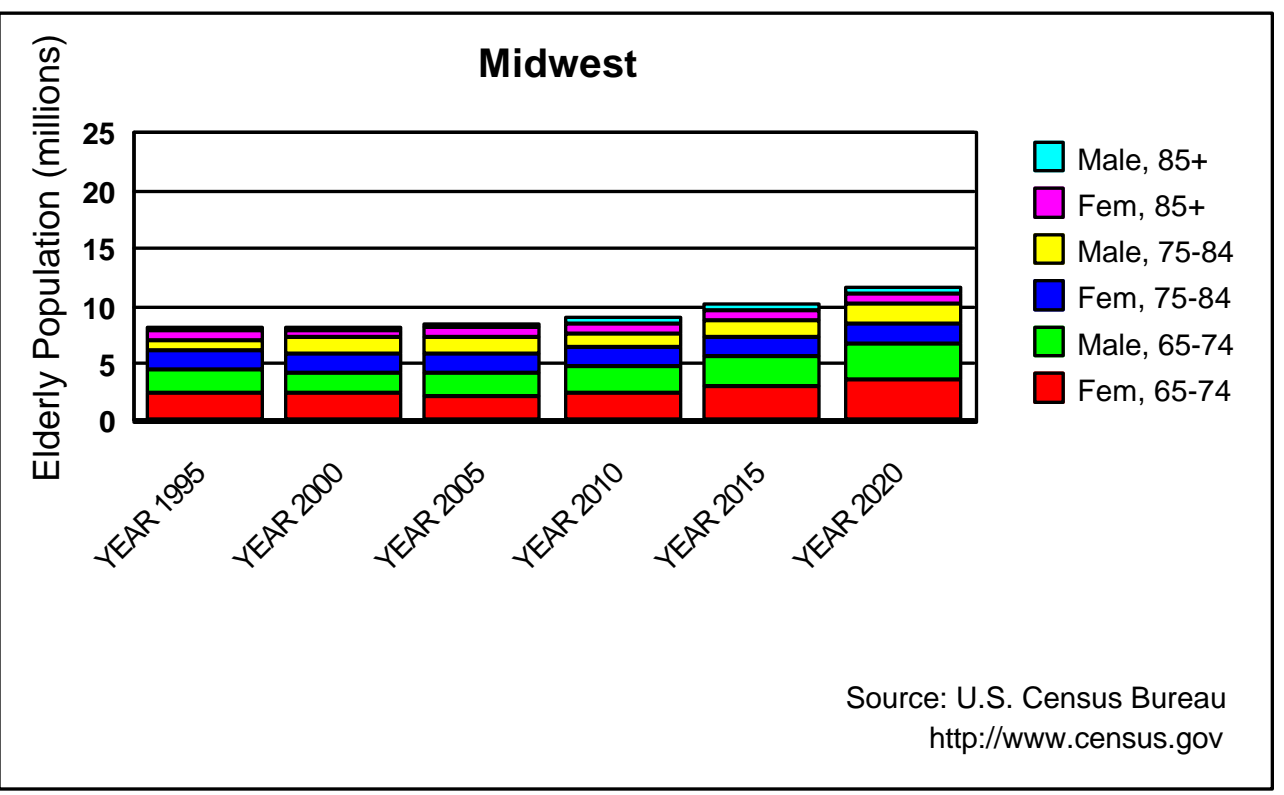

Figure 3.2. Distribution of the Elderly Population in the Midwest Region by Gender and Age Group between 1995 and 2020 


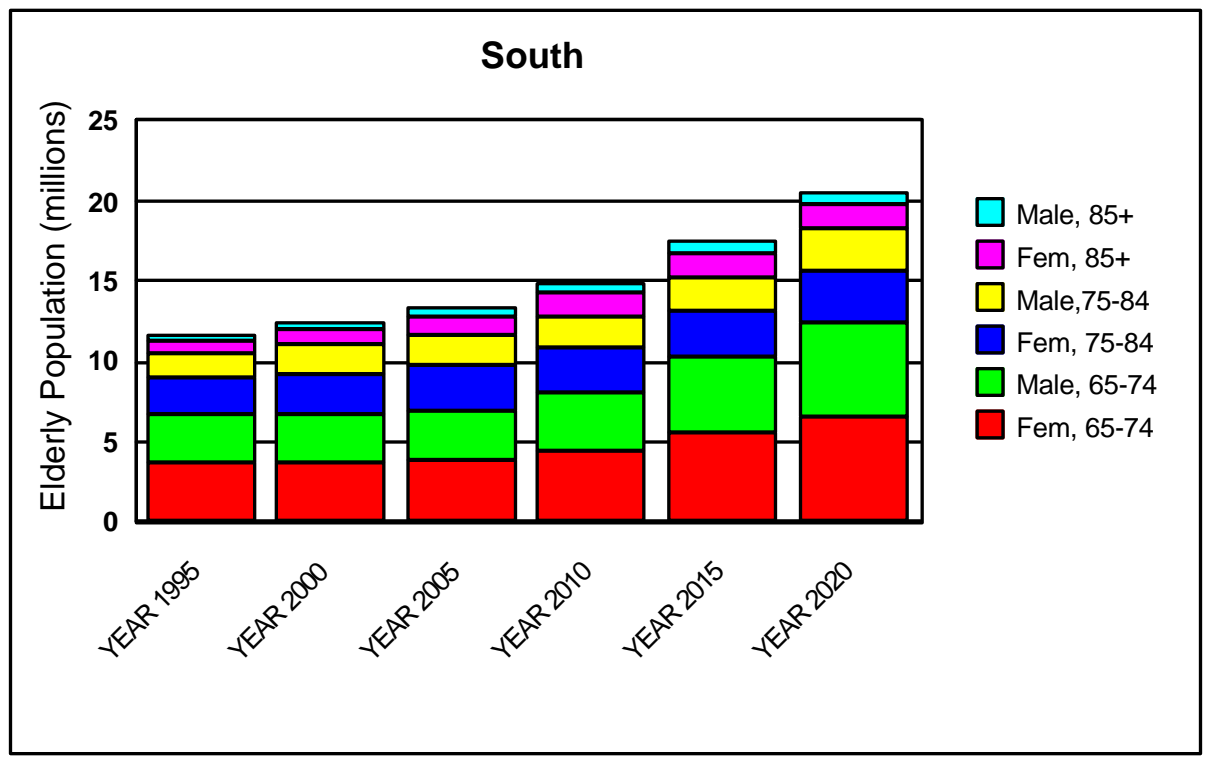

Figure 3.3. Distribution of the Elderly Population in the South Region by Gender and Age Group between 1995 and 2020

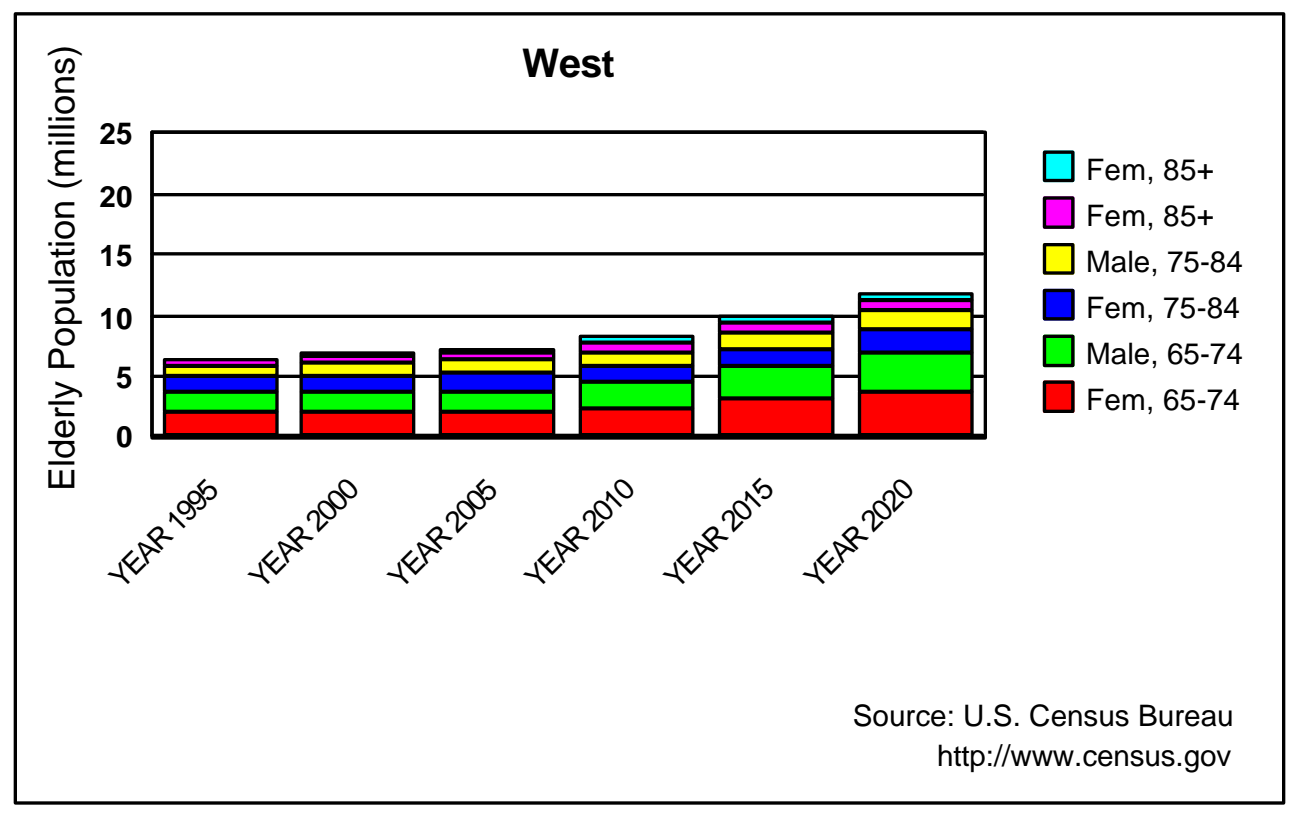

Figure 3.4. Distribution of the Elderly Population in the West Region by Gender and Age Group between 1995 and 2020 
More elderly people live in rural areas than in metropolitan areas. The marked growth of the elderly in rural areas is a result of aging-in-place, out-migration of young people to more urban areas with better paying jobs, and in-migration of retirees from urban areas (Rogers, 1999).The number of older persons varies among the regions. The greatest concentration of the elderly (for both rural and urban areas) is in the South (see Figures 3.1-3.4). Because non-metropolitan America is less economically well off and has fewer public transportation options, the elderly, especially those who do not drive or own an automobile, find it difficult to reach health care facilities, to attend social events, or to meet basic shopping needs (National Association of Development Organizations Research Foundation, 1999).

\subsection{HEALTH ISSUES}

The U.S. Census Bureau has projected the future population of the elderly. These projections, however, do not forecast the health of this population. Physical and cognitive health is directly related to driving abilities as well as to survival in crashes. As seniors age, the occurrences of physical and cognitive impairments and overall frailty increase. Among all elderly, in 1996, 10.5\% were unable to carry on a major activity; this percentage can be compared with $3.5 \%$ of those under 65 years of age. In addition, over $27 \%$ of seniors listed their health as fair or poor, with very little difference between the sexes (Administration on Aging, 1999).

With obvious implications for both safety and mobility, it is especially important to attempt to quantify (1) the numbers of elderly with disabilities that could limit their driving skills and (2) the correlation between health impairments and the decisions of whether to drive and how much to drive.

The elderly are experiencing better health than in the past. Manton, Corder, and Stallard (1997) studied chronic disease trends among the elderly in the United States using 
the National Long Term Care Surveys (NLTCS) and saw much lower chronic disability rates. Freedman and Martin (1998), using data from the Survey of Income and Program Participation (SIPP) also found large health improvements in the elderly. In addition, Freedman and Martin found that these improvements have been greatest among those 80 and older. Manton, Stallard, and Singer (1994, p. 61) explain this trend as due to decreased smoking, increased education, and better life styles (more exercise and better nutrition) among seniors. It should be noted, however, that Wallace and Franc do not concur with these studies and contend that the conclusions need further verification (Wallace and Franc, 1999, p. 18). If, indeed, disability rates are declining, the ability of the elderly to continue to drive to later ages would be extended.

Because of increases in the number of elderly and a decline in mortality, the number of nursing home residents is predicted to approximately double (from 1.67 million residents of nursing facilities in 1990) between 1990 and 2025 (American Health Care Association, 1997, p. 7). Nursing home residents average 3.67 activities of daily living (ADL) limitations each. The typical nursing home resident is an 82-year-old woman who needs assistance with some personal activities (American Health Care Association, 1998).

\subsubsection{Impacts of Failing Health on Driving Abilities}

Older persons are more likely to suffer from health problems (Eby et al., 1998, p. 39). Specific medication taken by older persons to alleviate poor health conditions may affect driving ability. In addition, certain medical conditions may affect driving ability. Although certain drugs (e.g., benzodiazepines) and certain severe health conditions (e.g., Alzheimer's Disease) obviously affect driving ability, research is not clear cut on other drugs and health conditions associated with advancing age.

What is true, however, is that older persons experience increasing medical problems. The problem is how to tie health measures (e.g., "excellent," "poor") to driving measures (e.g., whether to drive, how much to drive). Wolinsky (1990) contends that metric coding of perceived health status (and, by implication, more objective categorical GM Project G.6 $3-11$

October 2000 
assessments of health status) does not optimally exploit the elicited information and is not legitimate. For example, assigning the numerical values of 1, 2, 3, and 4 to perceived individual health conditions of "poor, fair, good, and excellent" assumes that the difference between " 2 " and " 3 "is equal to the difference between " 3 " and " 4 ." There is no direct metric relationship between an individual's ranking of his/her perceived health status and his/her decision to drive or not to drive. Nor is there a direct metric relationship between perceived health status and the decision of how much to drive. As the numbers of older drivers increase, we must consider how perceptual (visual), cognitive, and/or psychomotor impairments of the elderly affect their ability to navigate a vehicle.

In 1998, Eby et al. published an extensive review of the literature on older drivers' capabilities. Age-related changes on visual perception (i.e., anatomical changes, eye movements, sensitivity to light, dark adaptation, visual acuity, spatial contrast sensitivity, visual field, space perception, motion perception, color perception), cognitive factors (i.e., attention, perceptual style - field dependence/independence, short-term and long-term memory, problem solving, spatial cognition), and psychomotor skills (i.e., reaction time, flexibility, and coordination) and their effects on driving abilities are well-documented.

Owsley, McGwin, and Ball (1998) studied visual risk factors among elderly drivers involved in crashes that resulted in injury. In this study, elderly drivers with a useful field of view reduction of more than $40 \%$ were at least 20 times more likely to be involved in a crash involving injury than were those with minor visual limitations. The study suggested "that visual processing impairment, a major cause of disability in older adults, and glaucoma, projected to affect almost 1.6 million older adults in the U.S. by the year 2000, increase older drivers' risk for involvement in an injurious crash" (Owsley, McGwin, and Ball, 1998, p. 112).

In a study to compare predictors of driving fitness, Duchek et al. (1998) examined the results of several vision tests, psychometric tests, and diagnoses of mild Alzheimer's Disease. This study indicated that a diagnosis of mild dementia alone may not be the best predictor of impaired driving and that results of the visual search task may be better \begin{tabular}{lll}
\hline GM Project G.6 & $3-12$ & October 2000
\end{tabular} 
predictors. It should be noted that the visual search task is not the same as visual acuity tests administered at drivers licensing sites. Driver licensing tests are not considered adequate to identify older drivers that might be involved in crashes (Ball, 1997, p. 46).

Several studies have shown that older drivers, in general, recognize their limitations and self-regulate their driving to times and places that they consider safest. Self-regulation may reduce crash risk for older drivers, in that it keeps them from being involved in situations in which they have difficulty maneuvering (Ball et al., 1998, p. 321).

In a literature review on the mobility needs of older women, Wallace and Franc (1999) examined the disability-mortality paradox between men and women and its implications for future gender differences among elderly drivers. According to Wallace and Franc's research, women over age 70 were about twice as likely as men to report health limitations. Although women have a longer life expectancy than men, women report more disabling chronic diseases, such as degenerative arthritis, than men. While studies have documented more chronic heart disease among men than among women, improvements are being made in treatments of heart disease, and it is possible that the health of elderly men will improve. Health conditions such as degenerative arthritis make driving difficult or impossible, but there is no evidence that the rate of degenerative arthritis is declining.

"Although the literature has converged on the finding that visual and cognitive impairments contribute to unsafe driving, there is little agreement across studies about which medical conditions and functional impairments elevate crash risk" (Sims et al., 1998, p. 556). 


\subsubsection{Impacts of Increasing Frailty on Casualty Rates}

Due to increasing frailty, the likelihood of an elderly person being severely or fatally injured in an accident increases (Evans, Gerrish, and Taheri, 1998). That is, in a crash of a particular magnitude, younger victims are more likely to survive than elderly victims. An injury that would kill $10 \%$ of persons $65-79$ years old would kill $50 \%$ of persons aged 80 and above. This higher mortality rate in crash victims over 80 is attributed to post-traumatic complications (U.S. Department of Transportation, 1997A, pp. 10-11). It has been estimated that about a third of health care costs from serious injury crashes are spent on the elderly although the elderly currently only represent about $12 \%$ of the U.S. population. These higher costs are attributable to complications and longer recovery times (U.S. Department of Transportation, 1997A, pp. 10-11).

Many studies have discussed the familiar "U"-shaped curve which compares number of fatalities per vehicle miles driven by age. According to this graph, older drivers and teen-age drivers are the most likely victims of crashes. The over-representation of older drivers in serious crashes is a combined product of frequency in which they are involved in a serious crash and the chance of injury or death resulting from the crash (Hakamies-Blomqvist, 1999).

Studies on in-vehicle design changes to better protect the fragile elderly figure have been conducted. As a result, changes to seat, head rest, and seat belt designs have been incorporated by the automobile industry. However, it is unclear how these design changes will impact the casualty rate of the elderly in the future.

\subsubsection{Health and Education Levels}

It has been noted that higher education levels are correlated with better health and longevity. This relationship may result from improved access to medical care, but it may also result from a better, more health-conscious lifestyle (Manton, Stallard, and Singer, 1994, pp. 70-71). 
Wallace and Franc (1999) noted several striking correlations between higher education and better health. Citing results from the Longitudinal Study of Aging for 1984, they noted significant delays in the onset of disabilities in persons over 70 years of age in comparison with persons of the same age group with slightly less education. Unfortunately, it is difficult to disassociate the education component from income, net economic worth, or other socio-behavioral characteristics when attempting to predict health and functional capabilities. Functional capabilities are definitely related to the decision to cease or continue driving (Wallace and Franc, 1999, pp. 21-23).

\subsubsection{Assessment Tools and Retraining}

Older driver tools for assessing driving abilities (or lack thereof) and for retraining/rehoning driving skills exist in several variations. The most common include self-assessment tools, clinical (physician-completed) assessments, and road tests (Eby et al., 1998, pp. 77-84). If the use of assessment tools becomes more widespread and consistently applied, this may impact the number of older drivers.

Self-assessments largely are limited to an individual's own measures of abilities to carry out activities of daily living (ADLs). These measures are very subjective and are prone to environmental influences (e.g., family opinions, social implications). Thus, a less subjective test is desirable. The American Association of Retired People (AARP) has provided simple performance tests that older drivers can use for self-administration.

Fields and Valtinson (1998) reviewed the literature on the use of neuropsychological tests for predicting driving ability. They concluded that "neuropsychological tests have limited predictive validity."

In 1996, Ball and Owsley developed a test to predict the likelihood of an older driver being involved in a crash. The "Useful Field of View" (UFOV) is a computerized program which measures visual attention and cognitive processing speed. According to Ball's studies, drivers with lower UFOV scores were much more likely to be involved in crashes than those with a "normal" UFOV (Owsley and Ball, 1998). Ball also noted that 
current vision screening tests at drivers licensing sites are insufficient to screen for the useful field of vision (Ball, 1997, pp. 42-47).

In addition to the UFOV being an assessment tool, it may also be an effective training tool. Practice with the UFOV improved the reaction time, expanded the size of the attentional field, and seemed to improve driving ability in a test conducted in 1998 (Roenker, Cissell, and Ball, ND). However, there are no statistics on the long-term effect of UFOV training on driving fitness.

Older driver training programs are being developed to assist older drivers with age-related problems. Three such programs are the 55 Alive/Mature Driving program, sponsored by the AARP, Safe Driving for Mature Operators, sponsored by the American Automobile Association (AAA), and Coaching Mature Drivers, sponsored by the National Safety Council (NSC). Evaluations of these retraining programs have indicated that they provide valuable educational information; however, evaluations have provided inconclusive evidence that these training courses actually decrease crashes. It is almost certain that assessment and, possibly, retraining of the burgeoning population of the elderly in the next two to three decades will be necessary.

Staplin and Hunt (1999) conducted research to identify driver assessment tools, remediation techniques and procedures, and licensing. They documented a wide range of remedial treatments, including adaptive equipment, retraining, physical therapies and exercise programs, instruction in driving skills, and other tests (p. 37).

\subsubsection{Better Health, Extended Life Spans, Later Retirement, and Greater Mobility}

Elderly drivers are taking more trips and driving more miles than they did in the past. They are adapting their travel patterns as needed to maintain an active, social lifestyle. One of the primary fears of the elderly, above personal security or health concerns, is losing mobility, expressed as loss of the ability to drive (Staplin and Hunt, 1999, p. 38). 
Although advancing age brings encroaching frailty, older people are actually improving their functional capabilities. The age for full retirement has been extended, but seniors can still expect to spend many active years as retirees. As healthy, energetic participants in society, the elderly will experience expanded transportation needs as their demand for greater mobility grows.

\subsection{TRANSPORTATION AND MOBILITY}

The 21 st century will see the American population aging. Will greater numbers of persons over 65 be driving, and will the elderly be driving further? What kind of changes will we see in driving habits, travel patterns, and the use of alternative transportation? How will the use of "smart" cars and "smart" highways impact the safety and mobility of the elderly?

\subsubsection{Numbers of Drivers}

According to Table DL-220 from Highway Statistics Summary to 1995, the number of drivers' licenses issued to persons over age 60 increased from 27,838,000 in 1985 to $34,013,000$ in 1995, a 22\% increase (U.S. Department of Transportation, 1997B). The greatest increase in licenses issued was in the age group of 70 and over - an increase of almost 50\%! Figure 3.5 shows the growth of the number of elderly persons holding drivers licenses between 1963 and 1995. 


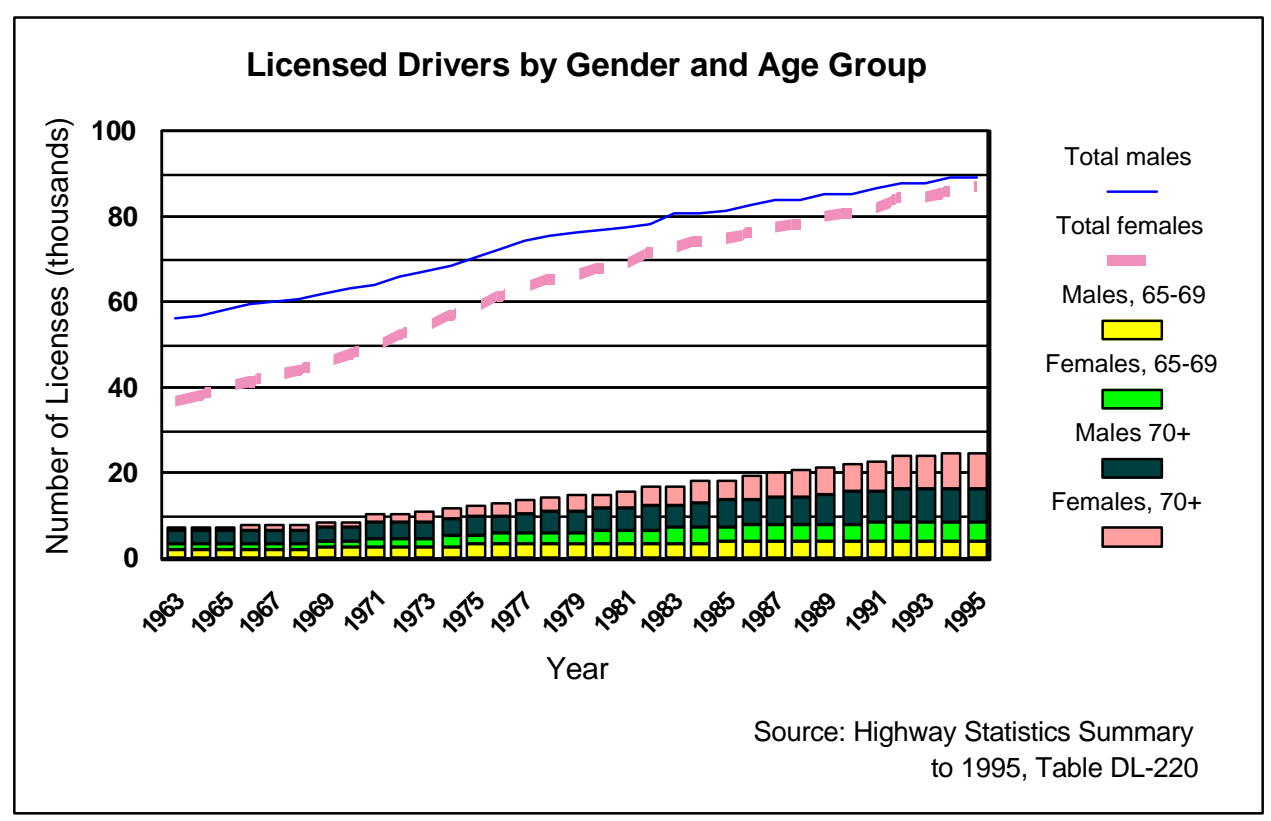

Figure 3.5. Licensed Drivers by Gender and Age Group, 1963-1995.

When Fields and Valtinson contacted the Departments of Motor Vehicles in all 50 states to ascertain state policies for licensing the elder driver, they found that there was no uniformity across the states. Some states require renewal in person after a certain age, as well as a vision test and a road test. Other states require no tests of ability and have lengthened the time intervals between renewals. In some states, doctors are required to report unsafe drivers to the state; other states require the physician to get the patient's written permission before reporting a physical impairment (Fields and Valtinson, 1998).

Some individuals, particularly among the elderly, obtain drivers licenses even though they may not intend to drive a vehicle. Reasons for obtaining a license include identification, "status," or just in case it might be needed. In addition, states may not purge their data sets to account for licensees moving out of state or dying. Therefore, the number of drivers licenses issued is not a valid measure of the actual number of drivers. Eberhard (1996) compared numbers of drivers licenses issued, according to Federal Highway Administration (FHWA) historical data for 1993, with survey data from the 1993 \begin{tabular}{lll}
\hline GM Project G.6 & 3 - 18 & October 2000
\end{tabular} 
Asset and Health Dynamics of the Oldest Old (AHEAD) study. The AHEAD survey documented numbers of persons who actually drove, by age category. In each age group, more people held drivers licenses than actually drove. The likelihood of driving declined with age. Based on historical data, elderly men are more likely to drive than elderly women.

Because of the lack of uniformity of requirements for licensing the older driver and because the possession of a driver's license does not imply that a person actually drives, simply knowing the numbers of licenses issued is not sufficient for determining whether the holder of a drivers license actually drives.

Burkhardt et al. (1998) projected the elderly driver population by age and gender through the year 2030. These projections, which are based on drivers license ratios and licensing patterns, place the number of elderly male drivers in 2030 at 2.28 times the number in 1996. Burkhardt et al. projected the number of elderly females driving in 2030 to be between 2.03 and 2.72 times the number in 1996. The greatest projected increase in the number of elderly drivers was for the oldest old (85+) age category (Burkhardt et al., 1998, pp. 24-38).

Wiggers (1999) projected future drivers to 2030 using FHWA licensed driver counts in combination with the AHEAD driver rates. The AHEAD survey asked respondents to identify their driving status as "drive," "don't drive," and "never drove." Using this information, Wiggers (1999, pp. 39-60) calculated a rate at which former drivers cease to drive when they become elderly. He then calculated the percentages of elderly in each age group who will still be driving in the future (Wiggers, Table 7). (For more information, see Section 10.1, Table 10.3.)

Prior to our model, Burkhardt et al. (1998) and Wiggers (1999) provided two principal alternatives to projecting the number of drivers in the future. In each alternative, the authors stressed that the methodology used assumptions that could be incorrect. 


\subsubsection{Changes in Driving Habits}

In the United States, driving an automobile is critical to achieving independence and mobility. Kostyniuk, Trombley, and Shope (1998) reviewed the literature on driving reduction or cessation among older drivers. They documented that driving habits change as drivers age. For example, after retiring, there is no daily commute to work; in addition, older persons avoid driving at night, in heavy traffic conditions, and during adverse weather conditions; finally, they may drive more slowly than younger drivers. When driving becomes more difficult because of age-related factors, the decision to curtail or stop driving implies dependence on friends and family or on public transportation. Agerelated factors leading to a reduction in driving include declines in vision, cognitive ability, psychomotor ability, and health problems, among other reasons (Kostyniuk, Trombley, and Shope, 1998, p. 23).

Studies have focused on driving reduction and cessation within specific populations of older drivers, and the findings may not be generalizable to other groups of elderly. ... There is a need to examine driving reduction and cessation decisions among representative populations of older people with differing education, income, and living situation characteristics. ... The driving cessation process may have distinct stages, and advice and other interventions from external sources may be perceived differently at each stage. The stages could be a function of an individual's health, age, and the amount of compensatory driving behavior they have implemented (Kostyniuk, Trombley, and Shope, 1998, pp. 32-34).

Marottoli et al. (1993) examined specific risk factors from a driving survey of former participants of the EPESE study group to see if there were specific causes for driving cessation among those who had stopped driving since the earlier study. Factors that were examined included "higher age, lower income, not working, neurologic disease, cataracts, lower physical activity level, and functional disability." Using a multiple logistic regression model, Marottoli found that the elderly continued to drive if no risk factors were present, $17 \%$ stopped driving if one or two factors were present, and $49 \%$ stopped driving if three or more factors were present (Marottoli et al., 1993). 
According to Schatz, Stutts, and Wilkins (1999A), seniors do not plan to stop driving and, indeed, are reluctant to give up the freedom of mobility associated with a personal automobile. Men are especially reluctant to stop driving because they feel a responsibility to provide transportation and are generally more hesitant to ask for help from family or friends. When the elderly do stop driving, they generally depend on family members for transportation needs. Even when seniors have access to public transportation, they often feel that it is not adequate because it does not fit their schedules and they have concerns for personal safety. Seniors feel that they will know when it is time to stop driving; however, some continue driving even after loss of license or at-fault crashes. Other seniors, especially women, may stop driving prematurely. At least one study reported that women are twice as likely to stop driving as men and that men generally cease driving only because of poor health and disability. It is certain that, at least for the current elderly cohorts, a larger percentage of senior men drive than senior women (Schatz, Stutts, and Wilkins, 1999B, pp. 1-2). Women may stop driving because the "man of the family" prefers to drive. Once a senior stops driving, the chance that she will resume driving is $10 \%$ or less. Unfortunately, however, these women may outlive their driverhusbands and may need to reinitiate driving to maintain mobility.

Smiley (1999) discussed adaptive strategies employed by the elderly when they experience declining functional capabilities and changing mobility needs. She noted that the most frequent strategic adaptation of the elderly is to reduce exposure - to drive less and to avoid driving at night or in inclement weather. In addition, older males tend to increase their frequency of use of seat belts, which is a strategic decision. The most frequent tactical adaptation is in speed reduction, increased headway, and lengthened gaps at intersections.

\subsubsection{Driving Distances}

The elderly drive fewer miles annually than persons under age 65. However, their average annual mileage is increasing, especially for women. Based on Nationwide Personal 
Transportation Survey (NPTS) data, Burkhardt et al. (1998) predicted that annual miles driven by the elderly would increase dramatically by 2030. In a separate article, Burkhardt (1998A) estimated that between 1990 and 2020, the total annual mileage driven by male older drivers will increase by $465 \%$ - and, Burkhardt asserted, this estimate is conservative. For senior women drivers, the total annual vehicle miles driven will increase almost $500 \%$.

Although the total annual VMT per person of elderly drivers is predicted to increase (Section 7), it is expected that the elderly will almost certainly continue to drive fewer miles than drivers in the labor force. Persons who drive less generally do most of their driving on local roads, rather than expressways. The crash rate on local streets, which include problems such as congestion, difficult intersections, pedestrians, and other hazards, is higher than that of divided highways with controlled access (See also Section 3.4.1.). Because it is impossible to quantify what percentage of the VMT of older drivers is actually driven on the different types of roads, however, this phenomenon was not factored into the ORNL model.

\subsubsection{Alternative Transportation Modes}

Scott Bogren, editor of Community Transportation, has stated that "Today, senior transportation services are one of the fastest growing segments of the transit industry." (Bogren, 1998, p. 5).

To determine the most appropriate alternative transportation option for the elderly, several criteria must be addressed. First, the physical, functional, and budgetary constraints of the elderly person desiring alternative transportation must be considered. Second is the geographic location. Because most transportation providers need to make a profit, public transportation is more prevalent in urban or more densely populated areas. For areas with limited appeal for "typical" public transportation, alternative service options (e.g., public agencies, volunteer groups, etc.) and other innovative options may be available (Suen, 1999). 
The typical city bus is not the transit service desired by seniors. Many seniors are concerned that they will fall while boarding or departing from the bus or during transit if they must stand while the vehicle is moving. In addition, because they don't want to be considered old and slow, they feel rushed to pay their fares and find a seat. "Smart" fare cards, better on-board displays, auditory cues, and other devices will assist the elderly passenger and perhaps encourage more transit use (Suen, Mitchel, and Henderson, 1998).

An example of an alternative senior transportation service is the Independent Transportation Network (ITN) operating within a 15-mile radius of Portland, Maine. The ITN, which uses automobiles to transport elderly riders at the riders' convenience, is one innovation which seems to have gained approval among its elderly riders.

Additional mobility options in some locations include pedestrian facilities. For seniors, walking is the second most important travel mode after the private vehicle. Pedestrian accommodations to aid elderly pedestrians at intersections include crosswalk lighting and better signs.

For any alternative transportation option, the elderly person must feel safe, secure, and free from harassment while occupying the transit vehicle, while waiting for the transportation vehicle to arrive, and while getting to and from the boarding location (U.S. Department of Transportation, 1997A, p. 50).

\subsection{5 "Intelligent" Technologies and Other Adaptive Equipment}

The Intelligent Transportation System (ITS) is developing highway and in-vehicle devices that would help seniors maneuver better. Current ITS applications include route guidance mechanisms, emergency vehicle location and response systems, adaptive cruise control, vision enhancement, and collision warning systems. Because of their fairly recent incorporation within the market and their relative expense, these systems are not currently widespread among the older driver population (Caird, 1999, p. 3). Hazard warnings, 
tourist services, and "smart" signs are typical highway devices that assist all travelers, including the elderly.

Caird (1999) reviewed several studies of the elderly and ITS applications. He found that the elderly do not want to relinquish their control of the vehicle (as with anticollision devices) and do not want to be startled by loud noises (e.g., warning devices). Women are more reluctant than men to try new technologies. The elderly were, however, enthusiastic about receiving up-to-date information (e.g., road conditions and weather) and appreciative of devices such as breakdown detection and emergency alerts.

The use of head-up displays (HUDs), a technology long used in aviation, is being studied for automobiles. HUDs display certain information to the driver on the windshield; thus drivers can see information (e.g., speed) displayed on the windshield rather than needing to shift their visual focus to a location within the vehicle. The shorter refocusing distance may benefit the elderly driver especially. However, after a critical examination of HUD research literature, Tufano (1997) cautioned that human factors testing of HUDs has been inadequate to determine either the operational benefits or safety-related risks of HUDs in automobiles.

According to Schatz, Stutts, and Wilkins (1999A), seniors do not like "clutter" in their vehicles and prefer to drive a vehicle that is familiar to them. Therefore, some of the in-vehicle guidance mechanisms may be less appealing to seniors. Other in-vehicle systems, such as those to help drivers access emergency assistance, have gained wider popularity.

Seniors approve of improved roadway environment/markings such as protected left turns and more reflective road markings. These vision enhancement systems appear to be promising emerging technologies for assisting the elderly. 
A variety of ITS in-vehicle applications will affect older driver performance. Fear of using technology, difficulty seeing displayed information, ease of use, the need for quick responses to warnings, long auditory or visual messages, and a lack of effective training are significant barriers to large-scale acceptance of ITS applications by older drivers. ... In-vehicle displays must be seen across a wide range of lighting conditions and, more importantly, across age-related changes in the visual system. ... ITS systems offer the potential to increase the mobility and safety of future older drivers. However, these systems are not the only countermeasures available. ... [R] esearch is still needed to determine the degree to which invehicle ITS's can offset declines due to aging processes and whether this objective is realistic. ... [T] he relationships between driving performance with these systems and safety (i.e., accidents) has yet to be determined. ITS applications must, at the minimum, keep preexisting levels of safety constant (Caird, 1999, pp. 23-26).

According to Pike (1999), additional in-vehicle devices that may someday provide protection and/or assistance to seniors include changes in seat belt design, making the belts easier to put on and take off as well as more comfortable; seat belts and air bags that adapt to the condition of a particular crash or the size of the person; seat design to protect the rider from neck injuries; and mechanical devices that assist those with physical limitations when entering/exiting the vehicle. Simple in-vehicle accommodations - for example, making the legibility of the transmission selector positions more pronounced (e.g., ensuring that " $\mathrm{P}$ " is distinguishable from " $\mathrm{R}$ ") might also help. It should be noted that no studies have quantified the impact of these technologies on crashinvolvement rates and they are not factored into ORNL's model.

According to Koppa (1999) visual acuity correction in the form of special eyeglasses may assist some elderly drivers. In addition, hearing losses can be accommodated through after-market addition of in-vehicle visual warning devices to augment auditory warnings. Other add-on devices can make levers and handles easier for arthritic hands to operate. Extensions of pedals and relocations of controls are also possible to help with drivers who have difficulty moving their legs or who have strength limitations. It should be noted that ORNL could find no other data on the crash involvement rates of drivers using these types of after-market devices and did not incorporate the usage of these technologie in the projection model.

\begin{tabular}{lll}
\hline GM Project G.6 & $3-25$ & October 2000
\end{tabular}


Specific highway enhancements to reduce the crash involvement of the elderly have been recommended (Staplin, 1999). These highway design changes include larger and brighter signage and pavement/curb guides (to accommodate problems with nighttime driving); intersection designs and redesigns to improve visibility and ensure standard, consistent positioning of turn/merge lanes and signage (to alleviate the maneuverability problems of the elderly at intersections); improvements in freeway entrance/exit lanes and signage; and improved pedestrian controls and longer crossing times at crosswalks (Staplin, 1999).

ITS technologies and adaptive technologies will certainly impact driving strategies of the elderly and may have a significant impact on their crash involvement in the future. The actual extent of these impacts are impossible to quantify at this time, however, and were not factored into our model.

\subsection{CRASH LITERATURE}

To predict the number of older drivers involved in crashes in the future (e.g., 2020), it is necessary to look at crash data from the past. A discussion of available crash data sets is provided in Chapter 4. Sections 3.4.1-3.4.5, below, provide a brief overview of the current literature providing analyses of crash data.

With increasing age comes increasing frailty. The increasing risk associated with traffic crashes as drivers age was discussed in Section 3.2.2 and will not be addressed further in this chapter. 


\subsubsection{Crash Involvement}

"Crash involvement" may be measured in several different ways. One way is simply to count the number of crashes (or the number of fatal crashes). However, simply counting crashes does not provide an idea of a crash rate. As noted in Hu, Young, and Lu (1993, p. 56), a crash rate can be calculated in several ways, including the following:

- Crashes per capita,

- Crashes per licensed driver,

- Crashes per vehicle miles driven, and

- Crashes based on the proportion of drivers at fault.

Each of these calculations results in a different viewpoint of the older driver's crash involvement. For example, based on numbers of licensed drivers, older drivers have fewer crashes than do younger drivers; however, based on miles driven, drivers over age 75 have the highest crash rate of any age group - even teenagers (Eby et al., 1998, p. 1). These crash rates are examined in greater detail in Section 3.4.2 below, which is a synthesis of research conducted as part of the GM settlement agreement.

A crash rate based on crashes per mile driven has been used frequently as a measure of risk. According to Janke (1991), however, the use of crashes/VMT exaggerates the accident risk of low-mileage groups - such as the elderly. That is, crashes are not a result of some factor times VMT; crashes occur from exposure to crash risk. VMT is only one component of this risk. Another component is type of roadway. Using1984 data compiled by the California Business, Transportation, and Housing Agency, Janke (1991, p. 184) noted that were 2.75 times more crashes/mile driven occurred on non-freeways than on freeways. Because high-mileage drivers generally amass most of their VMT on freeways, they face less risk of being involved in a crash than lowmileage drivers who drive primarily on local streets and roads (e.g., elderly drivers). Therefore, the high crash rate of elderly drivers (as measured by crashes/VMT) is not necessarily an indicator of their being dangerous drivers. 


\subsubsection{Other GM Project Results (Projects G.1 and G.8)}

The settlement agreement between GM and DOT includes other projects that are related to the objectives of this research. The most closely related project is Project G.1, "Changes in Crash Involvement Rates as Drivers Age." The purpose of Project G.1 was to determine how a number of risks vary with driver age from two distinct perspectives. The first problem was to determine how risks change that older drivers themselves face - a matter mainly of concern to the older driver. The second problem was to determine how risks change that older drivers impose on other road users - a matter mainly of concern to the general public.

Evans, Gerrish, and Taheri (1998) used data from the Fatality Analysis Reporting System (FARS) for 1994-1996 and other data sources (same time frame) to compare crashes and crash rates of older drivers to those of other age groups. They arrived at the following preliminary findings:

- During the 1994-96 time frame, the average number of driver fatalities per year (all motorized vehicles) reached its maximum value at age 21.5 for males (593.5 fatalities) and age 18.5 for females (191.7 fatalities) and then generally decreased. Therefore, when looking at a simple count of fatalities, younger drivers are fatally injured in traffic crashes far more often than the older driver.

- When the number of fatalities (by age and gender) is divided by overall population, driver deaths per capita for males are highest among males under 22 and over 80 . Females show a similar but much more muted pattern.

- Driver fatalities per licensed driver show a similar pattern to that of fatalities per population. That is, the fatality rate as measured by the greatest number of fatalities per licensed driver occurs in ages under 22 and over 80.

- Using data from FARS and also the NPTS, driver fatalities per unit distance traveled was computed. This measure shows a similar pattern although even more pronounced at the under 22 and over 80 ages because older and younger drivers drive fewer miles than drivers between the ages of 22 and 80 . 
Evans, Gerrish, and Taheri (1998) went on to examine influences that affect the crash risk - e.g., amount and type of driving, driving capabilities, vehicle type, time of day, alcohol consumption, seat belt use, and driving risks. Results indicated that rates of severe crash involvements per vehicle miles traveled (VMT) were smaller for the elderly than for drivers under 20 years of age.

Evans, Gerrish, and Taheri (1998) compared the risks that elderly drivers impose on others by examining involvements in single-vehicle crashes involving pedestrians. The authors noted that "licensing an older driver (data goes up to age 80) does not pose a greater threat to other road users than licensing younger drivers - indeed it poses substantially less risk than licensing a 20-year-old" (Evans, Gerrish, and Taheri, 1998, p. 12).

GM Project G.8, "Investigations of Crashes and Casualties Associated with Older Drivers," used detailed crash data from North Carolina data sets to compare fault and violation records of drivers over age 65 with fault and violation records for drivers age 45 to 64. Using North Carolina data sets as well as national data, the project investigated the harm rendered by the older driver to self as well as the harm to other drivers. This research resulted in the following highlights:

- The percent of at-fault drivers in two-vehicle crashes increase steadily from $40 \%$ for $45-54$ year olds to approximately $80 \%$ for the oldest drivers in the North Carolina data; very similar trends appear in the FARS data.

- Corresponding odds ratios for chances of being at fault for age categories 55$64,65-74,75-84$, and $85+$ relative to those $45-54$ are $1.22,1.77,3.27$, and 4.57 , respectively.

- Older drivers are increasingly at fault for (1) left-turn maneuver crashes, (2) right-turn crashes, and (3) straight-ahead angle crashes.

- In single-vehicle crashes involving drivers $65+$, a very high $9.2 \%$ resulted in serious injury or fatality.

- The older driver has special problems at non-signalized intersections. 
- As age increased, being struck as a pedestrian became more likely than striking a pedestrian as a motor vehicle driver.

- Poisson regression models developed to predict expected numbers of crashes per driver for specific types of crashes estimated the following: 21.0 crashes/year for every 1,000 male drivers aged 65-74 residing in "urban" counties with populations of 100,000-300,000, of which 1.2 of these would result in a moderate to fatal injury in the other vehicle.

\subsubsection{Gender Effects}

Studies have examined gender differences in fatal crashes. For example, in 1998, male drivers (all ages) were involved in almost three times as many fatal crashes as female drivers (National Highway Traffic Safety Administration, 1999A). Evans, Gerrish, and Taheri (1998) compared gender-based crash rates for elderly drivers and found that the curves of these gender-based crash rates, when plotted, were remarkably similar. In addition, when the rates of traffic deaths to all deaths was plotted, there was very little gender difference between the ages of 20 and 70 .

In 1995, Massie, Campbell, and Williams studied crash data and travel data to produce crash involvement rates per VMT by age and gender. They observed that "men had a higher risk than women of experiencing a fatal crash, while women had higher rates of involvement in injury crashes and all police-reported crashes” (p. 73).

Continuing this line of study in 1997, Massie, Green, and Campbell studied the effects of driver age, driver gender, time of day, and average annual mileage on severe and fatal crashes. Men consistently have a higher risk of crash involvement per mile driven than women. It had been thought that this greater involvement was because they drove more (greater exposure). After adjusting for the greater number of average annual miles driven by men than women, this study suggested that, if women drove similar amounts, women's involvement rates would be lower than men's regardless of crash severity (Massie, Green, and Campbell, 1997). In addition, after adjustment to make average GM Project G.6 
annual miles equal for both genders, men's crash-involvement rates for injury and property-damage-only were higher than women's rates. Although Massie, Green, and Campbell have no definitive explanation for why women's crash rates are so much lower than men's crash rates (after adjustment for equal average annual mileage), they offer some suggestions concerning why the injury and property damage rates (crashes/VMT) are higher for women than men. It is possible that women are involvedin a greater number of injury and property-damage-only crashes per VMT because of driving inexperience, which is due to their lower average annual mileage; therefore, when the rates are adjusted for this lower mileage, the differences in fatal crash rates become even greater and the women's crash rates for non-fatal crashes drop below those of men. Another possible explanation involves the types of streets on which women drive. Persons with low average annual mileage (in this case, women) drive more on urban and local streets and roads than they drive on rural interstates. Urban and local streets have higher crash rates than do rural interstates.

One study identified gender-specific health factors related to crash risks. Factors that place elderly female drivers at risk include living alone and experiencing back pain. Risk factors for men include being employed, scoring low on word-recall tests, having a history of glaucoma, or using antidepressants. The number of miles driven and use of antidepressants were the most significant risk factors for men (Hu et al., 1998, p. 569).

Stamatiadis (1999) examined gender distinctions in crashes involving elderly drivers. He used two-vehicle crash records for Kentucky between 1994 and 1996, eliminating crashes for which he could not determine which one of the two drivers was at fault. He then calculated a crash rate for age-gender groups based on the percent of crashes for which the driver was at fault divided by the percent of crashes for which the driver (same age-gender group) was not at fault. Although there were no significant differences in the crash rates of males and females for ages up to 55, statistically significant (5\% level) gender differences were noted for age groups 55-64, 65-74, and over 75. Females were more often at fault than males for these age groups. Stamatiadis concluded that, while elderly women have higher accident and at-fault rates than elderly \begin{tabular}{lll}
\hline GM Project G.6 & $3-31$ & October 2000
\end{tabular} 
men using mid-1990s data, this gender effect could be caused by a lack of driving experience when younger. He suggested that, because there are no significant gender differences in the at-fault rates for the younger age cohorts, this phenomenon may not continue in the future.

\subsubsection{Crashes Involving Elderly Drivers}

In 1972, traffic fatalities reached a peak when a total of 55,600 persons were killed in highway crashes, a rate of 4.41 fatalities per 100 million annual VMT. In 1998, total fatalities had decreased to 41,471 persons at a fatality rate of only 1.6 fatalities for each 100 million annual VMT (U.S. DOT, 1997B, Table FI-200; National Highway Traffic Safety Administration, 1999A, Table 1). The overall number of fatalities and fatality rates (fatalities per million VMT) have decreased regularly since 1972. This trend has not proved true for the elderly, however. Figure 3.6 shows the steady increase in the number of older driver fatalities annually since 1980 .

As noted in Section 3.4.3, certain factors place older drivers at risk, and these factors differ by gender. As noted in Section 3.2, various health factors associated with aging, especially those involving vision degradation, have been correlated with traffic crashes. In 1988, Evans documented older driver involvement in severe and fatal crashes and noted that the risks faced by older drivers and the risks caused to other drivers are decreased by the reductions in miles driven by older drivers. Evans concluded that the problems of aging drivers are more related to a loss of mobility than to an increase in risks (Evans, 1988). 


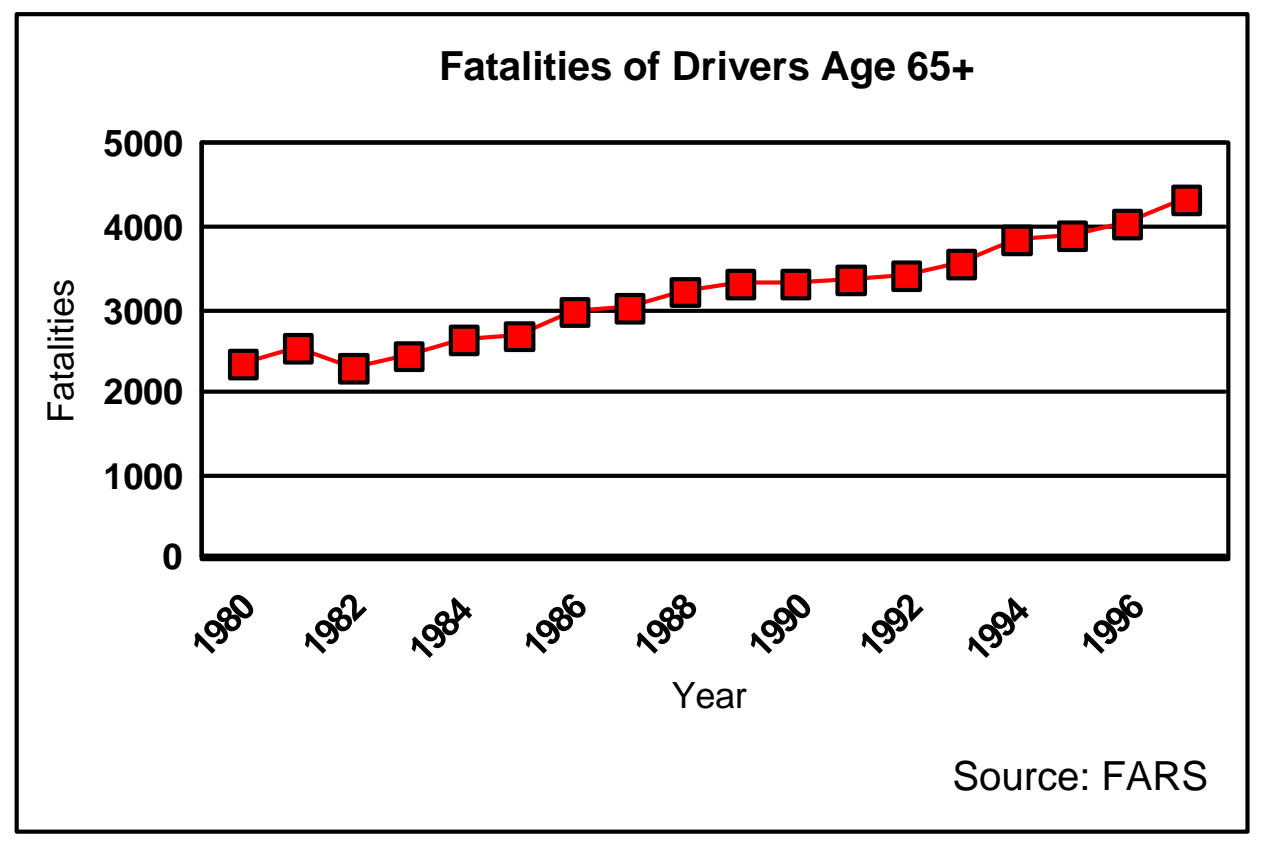

Figure 3.6. Fatalities of Drivers Age 65 or over from 1980-1997.

According to the Older Driver Highway Design Handbook, the "single greatest concern in accommodating older road users, both drivers and pedestrians, is the ability of these persons to safely maneuver through intersections" (U.S. DOT, 1998, p. 3). Intersections present problems for all drivers. About $50 \%$ of all crashes (fatal and nonfatal) of drivers under age 65 occur at intersections, and almost $60 \%$ of all older driver crashes occur at intersections (National Highway Traffic Safety Administration, 1993). However, when statistics for only fatal crashes are compared for elderly and non-elderly drivers, the percentages are not so close. For example, over $50 \%$ of all fatal crashes for drivers age 80 and over occur at intersections, which can be compared with only $24 \%$ of all fatal crashes for drivers under age 50 (U.S. DOT, 1998, p. 3).

Although freeways have lower fatality rates than any other type of U.S. highway, entrance and exit ramps present a distinct problem to older drivers. Older drivers were cited most frequently as being at fault for failure to yield and improper lane use (U.S. DOT, 1998, p. 15). Anecdotal evidence suggests that horizontal curves also present difficulty for older drivers (U.S. DOT, 1998, p. 19). In work zones, failure to yield was a \begin{tabular}{lll}
\hline GM Project G.6 & October 2000
\end{tabular} 
major contributing factor as was driver inattention. Older drivers respond more slowly than younger drivers to unexpected stimuli and tend to be much slower to detect a warning sign, make a decision, and complete a vehicle maneuver (U.S. DOT, 1998, pp. 23-24). All of these traffic conditions contribute to crashes involving the older driver.

\subsubsection{Projections of Crashes and Casualties}

Because of the increasing population of elderly persons (i.e., persons 65 and older) in the next quarter century, historical trends of their increasing mobility (which implied greater exposure to traffic crashes), and historically high fatality "rates"(i.e., fatalities per vehicle miles driven), predictions of a crash problem involving the elderly areimpossible to ignore.

Burkhardt (1998B, pp. 6-7) projects that the number of elderly-driver-involved fatalities will more than triple between 1995 and 2030, from 7,038 to 23,121 (Burkhardt, 1998B, Figure 2). It should be noted that Burkhardt's purpose in this document is not to document his methodology for arriving at this projection. Rather, the purpose of the report is to influence policy decisions for ensuring mobility and independence of older drivers into the future. This report is discussed more fully in Section 10.1.

Wiggers (1999) projects that elderly traffic fatalities will be about 2.5 times greater in 2030 than they were in the mid-1990s. (Wiggers averages the numbers of elderly traffic fatalities between 1993 and 1997 to use as the comparison number.) He estimates an increase in fatalities from 6,326 to 15,889 (Wiggers, 1999, Table 3). Wiggers also notes a dramatic increase in the number of elderly female drivers in the future. The percentage of female drivers killed will increase from 41\% (1993-1997 average) to 59\% (2030 projection) of all elderly female traffic fatalities (Wiggers, 1999, pp. vii-viii). This report is also discussed more fully in Section 10.1.

Both the Burkhardt and Wiggers projections indicate significant increases in elderly crash-involved traffic fatalities in the next three decades. Based on increasing \begin{tabular}{lll}
\hline GM Project G.6 & $3-34$ & October 2000
\end{tabular} 
elderly population numbers and on elderly drivers' increased VMT (crash exposure), these increases in the numbers of crash-related fatalities of the elderly seem inevitable. In addition, as shown in Table 3.5, between 1986 and 1996, the percentages of traffic fatalities that represent persons age 65 and overincreased faster than the proportion of the elderly within the entire population (Hakamies-Blomqvist, 1999).

Table 3.5. Comparison of Changes in Percentages of the Elderly in the General Population and in a Count of Total Traffic Fatalities, 1986-1996

\begin{tabular}{|c|c|c|}
\hline Year & $\begin{array}{c}\text { Population Over } \\
\text { Age 65 (\%) }\end{array}$ & $\begin{array}{c}\text { Traffic Fatalities of Persons } \\
\text { Over Age 65 (\%) }\end{array}$ \\
\hline 1986 & $12.1 \%$ & $13 \%$ \\
\hline 1996 & $12.8 \%$ & $16.9 \%$ \\
\hline
\end{tabular}

Even with the "increases" noted above, the cause ofdeath for the elderly in 1996 was 19.8 times more likely to be caused by heart disease and 12.4 times more likely to be caused by cancer than by a traffic crash (U.S. Census Bureau, 1999). The primary causes of death at various ages are shown in Figure 3.7. As can be seen in this figure, traffic-related fatalities are a more common cause of death for age groups under 65 than for the elderly. For example, motor vehicle crashes account for $14.7 \%$ of all deaths in age group 15-34, but less than $1 \%$ of all deaths for age group 65 and above. 


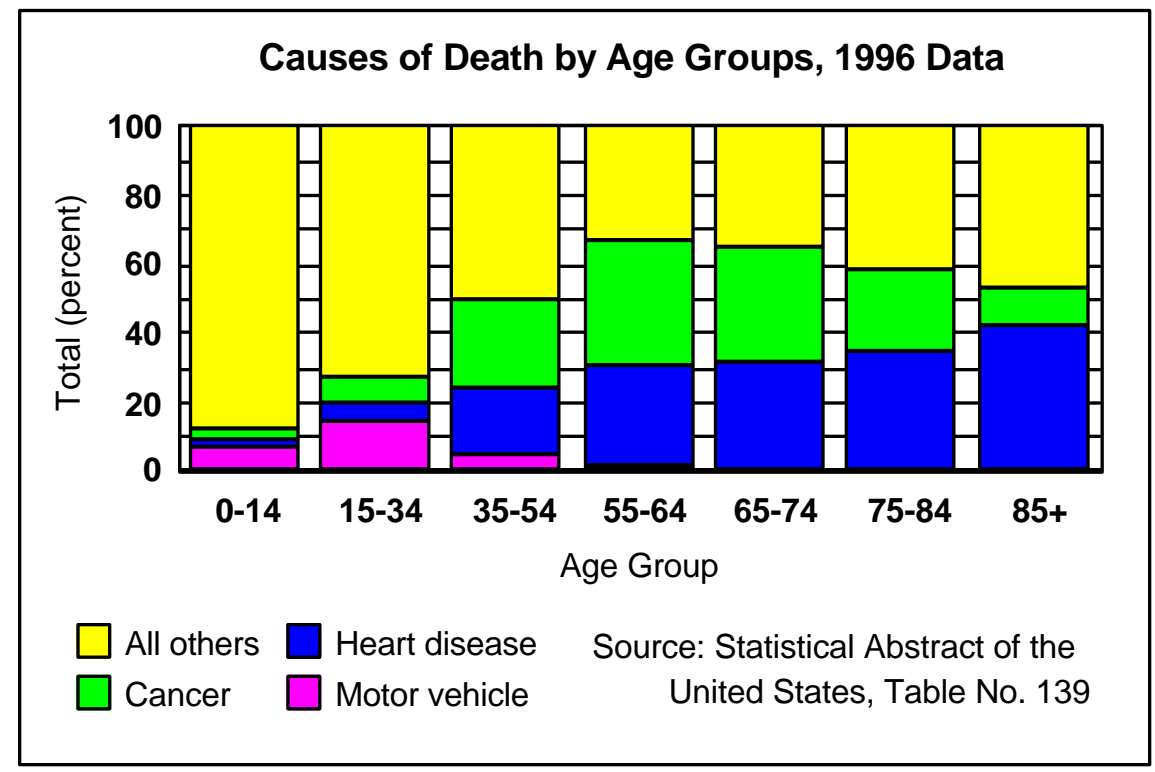

Figure 3.7. Comparison of Selected Causes of Death, by Age Group, 1996 Data. 


\section{ANALYSIS OF DATA SETS}

\subsection{INTRODUCTION}

We concentrated on finding data sources with information on population, income, driver/driving distance, physical/functional limitations, and crashes/fatalities. Because of the need to project results based on age groups, gender, and region, for each five-year time period, we needed specific data elements which could be matched among the various data sets.

Although population projections were available from the U.S. Census Bureau, no other projections were available at the level of detail needed for the other categories. Therefore, we searched for historical data sets in the above categories to establish trends and relationships on which projections could be based. The perfect data source would contain records which could be identified by age group, gender, and region; in addition, it would span a study that had continued for at least 25 years (since that was the time span of the projections).

No single historical data set contained all needed information. For example, the Nationwide Personal Transportation Surveys (NPTSs) contained demographics, driving status, and the availability of other drivers in the household but did not contain a functional/health indicator; the National Health Interview Surveys (NHISs) contained demographics and a functional/health indicator but did not contain data on driving status or the existence of another driver in the household. Neither of these data sets contained crash data.

After a review of the available data sets, we concluded that finding sufficient historical data on which to base projections is difficult. Especially difficult is finding data to describe 
cohort behavior and conditions for the years on which the model is based (i.e., 1977, 1983, 1990, 1995).

\subsection{ASSESSMENT OF DATA SOURCES}

We collected and evaluated data from many sources before determining the most useful and reasonable data sets for use in the model. Data sets were examined for their availability, completeness, quality, and appropriateness for the purposes of the project. Each data set is described briefly below under one or more of the categories of information needed for the projection model. Reasons for inclusion or exclusion of data sets are provided.

\subsubsection{Population Data and Projections (U.S. Census Bureau)}

Population data from the U.S. Census Bureau (http://www.census.gov), with historical data dating back to 1790 and projections through 2100, were the easiest to obtain and most complete data sets available. Appropriate as a measure of the rapid increase in the numbers of elderly after 2010, population projections also included considerations of migration, immigration, emigration, birth/death rates, and other population-changing

influences. Population data could be obtained for every permutation needed by the model. Additional information on how population data were used in the model isgiven in Section 5.3 and Appendix B.1.

\subsubsection{Income Data (Bureau of Economic Analysis, U.S. Census Bureau, and National Health Interview Survey)}

The Bureau of Economic Analysis (BEA) provides historical personal income data from 1969, and makes projections on personal income by states through 2045 . The 
projections are for all age groups. Because of confidentiality and disaggregation issues, however, we were unable to use the BEA income projections.

Census data sources contain historical long-term income data by various "types" of households (i.e., female head of household with no husband present, etc.), and by age groups. There are also historical data sets of median income by states for a "typical" family. Unfortunately, income data from the U.S. Census Bureau contain limited disaggregation capabilities.

The NHIS is a large (about 40,000 households), well-designed, cross-sectional study, conductedannually, of non-institutionalized individuals. We considered using NHIS to derive income projections using either

- Direct projection of elderly cohort-specific income, or

- Separate projections of (a) non-elderly cohort-specific working income and (b) same cohort-specific decline in income during elderly years.

Income data from the NHIS, however, had limited usage within the model because NHIS is not a longitudinal study, and income trends were difficult to project. Because we felt that projections of income were a critical component in the model, ORNL issued a subcontract to a reputable firm (Standard \& Poor's DRI) having experience in using population and income files from the U.S. Census Bureau to obtain income projections in the format and disaggregations desired. The DRI estimates and forecasts are explained in further detail in Appendix B.2.1.1. 


\subsubsection{Drivers and Driving Distance Information (Highway Statistics and Nationwide Personal Transportation Survey)}

The U.S. DOT's FHWA produces annual reports containing highway statistics for the entire United States. These reports provide a dependable, reliable, consistent, long-term (many statistics going back to 1949) data source. Relevant information includes numbers of driver's licenses by age, gender, and state; total VMT; miles of highways of various types; and other potentially useful information (e.g., the transportation budget). There are limitations in this data source, however. For example,Highway Statistics does not contain any projections and does not supply annual VMT per person. In addition, if data from the NPTS are used in the model, it is important to obtain data for 1977 and 1983.Highway Statistics Table DL-22, which provides the number of driver's licenses by age-gender-state, does not exist for oddnumbered years prior to 1990, and it also combines all ages above age 70. Although these constraints could be overcome through interpolation and disaggregation, we determined fairly early in the project that driver totals from the NPTS would be used in the model rather than numbers of drivers licenses as reported in Highway Statistics. We concluded that the driver totals from NPTS more closely approximated the numbers of people who actually drove, as opposed to people who just held a license, particularly among the elderly.

The NPTS, a large (42,000 households in 1995) transportation survey taken in 1977, 1983, 1990, and 1995, contains historical data on personal travel habits (driver/non-driver status, VMT), availability of transit (except for 1983), number of drivers in a household, age, income, and other relevant information. NPTS does not contain projections, is not available for every year, is a survey rather than a census, and consists of self-reported estimates. In addition, the 1983 NPTS does not contain a regional identifier. Because, however, the NPTS has such a wealth of individual travel information, we decided to base projections of driving status and VMT on the NPTS data from the four surveys noted above. Additional information on how the data from NPTS were used in the model is provided in Chapter 7. 
Many factors influence whether, and how much, an individual drives. Although studies have examined the impacts of various factors (see Chapter 3), there are few data sets available. We pursued the use of gasoline prices as an influential factor on VMT. This data set, from the Energy Information Administration, provided average gasoline prices, including taxes, by Census region. The first year for which this data set became available was 1984 . Prices are also forecasted through 2020 (personal communication with Bruce Bawks, Bruce.Bawks@eia.doe.gov). The price of fuel was incorporated in the model (Section 7.2).

Another potential influence on the decision to drive is the availability of alternative transportation. This availability was based on a rural-urban designation from the U.S. Census Bureau. For more information, see Appendix B.2.7 and Table B.11.

Although studies have addressed self-regulation and the decision to stop driving (Chapter 3), there are no data sources that would help predict how this phenomenon will affect elderly decisions in the future. Therefore, this factor was not incorporated in the model.

\subsubsection{Physical/Functional Limitations}

There are speculations and projections about the health conditions of the elderly in the future; however, there is no data source that provides actual data-based health-related projections. Therefore, we attempted to locate historical data sets that provide data on healthrelated limitations to driving, driving cessation based on self-regulation, risks to elderly persons involved in crashes, and other factors that relate physical/functional limitations and driving.

The historical data sets examined included the Health and Retirement Study/Assets and Health Dynamics of the Oldest Old (HRS/AHEAD), NHIS, and the Social Security Administration (SSA)/U.S. Census Bureau. 
The HRS and the AHEAD studies are conducted and maintained by the Institute for Social Research, University of Michigan. HRS is intended to provide data for researchers, policy analysts, and program planners who have to make policy decisions affecting retirement, health insurance, saving and economic well being. AHEAD is intended to provide detailed coverage of the joint dynamics among health (physical, cognitive, and functional), dementia, economic and family resources and care arrangements for the oldest old.

The HRS/AHEAD surveys have been conducted every two years since 1992 (AHEAD began in 1994). HRS and AHEAD data collection efforts merged in 1998. Sampling includes 9,473 households, 11,965 individuals, and 7,447 respondents. This combined data source is a well-documented, longitudinal survey of elderly individuals. (AHEAD studied adults born in 1923 or before; HRS studied adults born in 1931-1941; these dates were adjusted somewhat in 1998 for the joint survey.) Although this would appear to be an excellent source of data on the physical/functional limitations of the elderly, the very limited time ranges (since 1992) of these studies make it difficult to discern time trends from them. In addition, because the surveys did not exist in 1977, 1983, or 1990, the input would be difficult to use with NPTS data from those years. Finally, there were age group gaps in the data. For example, for 1994, the AHEAD data are restricted to adults 72 and older, and the HRS data are restricted to adults between 53 and 63; therefore, adults in the age group of 64-71 are omitted.

In addition to the HRS/AHEAD longitudinal studies, other longitudinal studies, including the Established Populations for Epidemiologic Studies of the Elderly (EPESE), Marin County Study, and the Sonoman studies, were considered. Because of a lack of data or incompatibility with other data sources, these studies were not used in our modeling.

NHIS is described in Section 4.2.2 above. Although not all data elements desired for matching NHIS data with NPTS data were available, we were able to use the Activity Limitation Status (ALS) variable from NHIS to compute an index which was used as a 
surrogate health indicator in the model. For more information on this calculation, see Section 5.4.

The SSA-Census data provides past and projected life expectancies. At one point in time, we considered using life expectancy as a factor; however, the ALS data appeared to be sufficient.

\subsubsection{Crashes, Casualties, and Fatalities (National Center for Statistics and Analysis, National Highway Traffic Safety Administration, and the American Insurance Services Group)}

NHTSA's National Center for Statistics and Analysis (NCSA) maintains data for the Fatality Analysis Reporting System (FARS). FARS data are available for 1975-1998 from ftp://www.nhtsa.dot.gov/FARS . This data set is complete for all fatal crashes in all fifty states, the District of Columbia, and Puerto Rico. Data are collected from police accident reports (PARs), death certificates, hospital records, etc. Data sets include (1) crashes, (2) vehicles/drivers, (3) persons. Because these data represent a census, FARS is especially useful for regional and national vehicle accident mortality tables. We used this data source for developing the crash risk portion of the model. Additional information on data usage is found in Chapter 8.

The NCSA also maintains the National Automotive Sampling System, General Estimation System (NASS GES). Data are collected from a nationally representative sample of police-reported motor vehicle crashes involving property damage, injury, or death. The system began collecting data in 1988. There is a bias due to restriction to police-reported crashes, but the data set is national and is collected by a three-stage weighted probability sample (Stage 1: sample geographic areas; Stage 2: sample police jurisdictions within geographic areas; and Stage 3: sample PARs within jurisdictions). A sample consisting of 55,000 PARs were collected in 1997. Sampling weights are calculated to adjust for variable sampling probability. In addition to estimates, valid standard errors can be calculated from 
these data and weights. Because of the national scope and scientific sampling, the NASS GES data seemed especially appropriate for making regional and national accident projections. The major limitations with GES data were that data were not available on a state/regional level and did not contain injury information prior to 1988. Because of these limitations of the GES data, this data source was not used in development of our model.

The Crash Outcome Data Evaluation System (CODES) is also maintained by NHTSA's NCSA. CODES uses probabilistic data linkage to merge data from eclectic sources such as motor vehicle crash reports, emergency medical services, hospitals, insurance claims, and death certificates. In probabilistic data linkage, data records are merged on the basis of estimates of the probability that they are from the same target (e.g., accident or driver), rather than conventional merging by ID variables that are definite links (and which do not necessarily exist). The probability estimates are computed from data variables such as time, location, and type of vehicle. Although probabilistic data linkage is automated by computers, some case-by-case tuning of the results is still necessary, and the process is laborious. CODES data are from seven states. The primary objective of CODES was to investigate effectiveness of seat belts and motorcycle helmets (and to prepare a report to Congress). Because CODES was limited in scope to only seven states, this data source was not used in development of our model.

The State Crash Data system, available from NCSA, includes a census of all crashes from 17 states. Data, which cover the time period of 1989-1994, are not uniform from state to state in either reporting criteria or coding schemes. Tabular reports are available on (1) trends, (2) crashes, (3) vehicles, and (4) people. Because the State Crash Data was limited in scope to 17 states, this data source was not used in the development of the model.

Index and the Property Insurance Loss Register (PILR) are maintained by the American Insurance Services Group (AISG). Index is a national clearinghouse for bodilyinjury and automobile insurance claims data with a database of over 50 million claims. PILR 
collects first-party property claims data. PILR was merged with Index; together they contain over one billion records and receive 18 million claims each year. Index was used by CODES. Index and PILR are used primarily as tools for preventing insurance fraud. These data sources were not used in our model because of institutional barriers to obtaining the data.

Seat belt use has been shown to reduce the impactand casualty rate of a crash. The projected use of seat belts among the elderly was obtained from NHTSA and incorporated in the model (Section B.2.5 and Table B.10).

\subsubsection{Other Data Categories Considered}

In addition to the obvious impact of population, income, driver status and driving distance, health, and crash risk on projecting numbers of casualties of the elderly for the next 25 years, there were other potential factors that we examined. These included education level, transportation/highway budgets, and the impact of safer infrastructure/vehicles/drivers in the future [including possible impacts of the Intelligent Transportation System (ITS)]. Although these factors were not incorporated within our model, further research is needed to determine how they may impact future casualties (see also Chapters 3 and 10).

\subsection{CONCLUSIONS}

Table 4.1 lists the data sources examined and provides a cross-sectional reference to the data categories. 
Table 4.1. Data Sources Examined

\begin{tabular}{|c|c|c|}
\hline Data source & Type of data available & Notes \\
\hline $\begin{array}{l}\text { U.S. Census Bureau } \\
\text { (http://www.census.gov) }\end{array}$ & $\begin{array}{ll}\text { - } & \text { Population (historical } \\
& \text { data) } \\
\text { - } & \text { Population (projections) } \\
\text { - } & \text { Income } \\
\text { - } & \text { Education } \\
\text { - } & \text { Rural-urban percentages }\end{array}$ & $\begin{array}{l}\text { We used population } \\
\text { projections and rural- } \\
\text { urban percentages in } \\
\text { the model }\end{array}$ \\
\hline $\begin{array}{l}\text { BEA } \\
\text { (http://www.bea.doc.gov/beahome.ht } \\
\text { ml) }\end{array}$ & $\begin{array}{l}\text { - Income (historical) } \\
\text { - Income (projections) }\end{array}$ & \\
\hline NHIS & $\begin{array}{l}\text { - Health } \\
\text { - Income } \\
\text { - Education } \\
\text { - Employment status }\end{array}$ & $\begin{array}{l}\text { We derived a health } \\
\text { index from the ALS } \\
\text { data }\end{array}$ \\
\hline Standard \& Poor's DRI & - Income (projections) & $\begin{array}{l}\text { We used income } \\
\text { projections }\end{array}$ \\
\hline $\begin{array}{l}\text { U.S. DOT, FHWA } \\
\text { (http://www.fhwa.dot.gov/ohim/ohim } \\
\text { stat.htm })\end{array}$ & $\begin{array}{ll}\text { - } & \text { Drivers licenses } \\
\text { - } & \text { Highway mileage } \\
\text { - } & \text { VMT } \\
\text { - } & \text { Transportation budgets }\end{array}$ & \\
\hline $\begin{array}{l}\text { NPTS (conducted by U.S. DOT) } \\
\text { (see, for example, } \\
\text { http://www-cta.ornl.gov/npts/199 } \\
\text { 5/Doc/index.shtml ) }\end{array}$ & $\begin{array}{l}\text { - Driving status/availability } \\
\text { of other driver in } \\
\text { household } \\
\text { - VMT/person } \\
\text { - Income } \\
\text { - Availability of transit }\end{array}$ & $\begin{array}{l}\text { We used driving status, } \\
\text { availability of other } \\
\text { driver in household, } \\
\text { VMT/person }\end{array}$ \\
\hline $\begin{array}{l}\text { EIA } \\
\text { (Bruce.Bawks@eia.doe.gov) }\end{array}$ & - Fuel prices & We used fuel prices \\
\hline $\begin{array}{l}\text { HRS/AHEAD } \\
\text { (http://www.umich.edu/ hrswww/) }\end{array}$ & $\begin{array}{l}\text { - Physical/functional } \\
\text { limitations }\end{array}$ & \\
\hline $\begin{array}{l}\text { SSA } \\
\text { (http://www.ssa.gov/) }\end{array}$ & $\begin{array}{l}\text { - Physical/functional } \\
\text { limitations }\end{array}$ & \\
\hline $\begin{array}{l}\text { U.S. DOT, NHTSA's NCSA } \\
\text { (http://www.nhtsa.dot.gov/people/ncs } \\
\text { a/ ) }\end{array}$ & $\begin{array}{ll}\text { - } & \text { Fatalities } \\
\text { - } & \text { Crashes }\end{array}$ & We used fatalities data \\
\hline $\begin{array}{l}\text { U.S. DOT, NHTSA } \\
\text { (http://www.nhtsa.dot.gov/people/inj } \\
\text { ury/airbags/presbelt/ ) }\end{array}$ & - Seat belt use & We used seat belt data \\
\hline $\begin{array}{l}\text { AISG } \\
\text { (http://www.iso.com/AISG/index } \\
\text { sys/indexsys.html) }\end{array}$ & - Crashes & \\
\hline
\end{tabular}


Based on the requirements of the model and the appropriateness of the data set, the following public-use data sources were chosen for use:

- Population projections and rural-urban projections from the U.S. Census Bureau,

- Historical health data from the NHIS,

- Driver information (driving status, availability of other driver, and VMT/person) from NPTS,

- Fuel prices from EIA,

- Historical fatality data from FARS, and

- Income projections produced by DRI. 


\section{OVERVIEW OF THE MODELING SYSTEM}

\subsection{INTRODUCTION TO MODELING}

Our approach to projecting the number of fatalities involving older drivers used four distinct components:

1. projection of non-institutionalized population,

2. projection of the percentage of that population that drives,

3. the projected average miles driven (VMT) per driver, and

4. the projection of fatal crash risk associated with each mile driven.

The non-institutionalized portion of the elderly population that actually drives represents the population exposed to driving risks. We chose not to use the number of drivers' licenses issued to represent the number of older drivers because many older drivers retain their licenses only for identification purposes. Our methodology for projecting the percentage of elderly drivers is given in Chapter 6. VMT was used to represent the exposure to crash risk as a likelihood of being involved in highway crashes per mile of vehicular travel. Our methodology for projecting VMT is given in Chapter 7, while our methodology for projecting the fatal crash risk is given in Chapter 8 .

The population projections provided by the U.S. Census Bureau indicate that nearly all subgroups of the elderly population will increase from 50 to 150 percent by the year 2025 . This enormous increase will have a substantial effect on the projection of the absolute number of casualties, even when crash risk per mile driven decreases or remains constant.

Beginning with non-institutionalized population as a foundation, we used the four components to derive the fatality projections. First, we took the non-institutionalized population projections, sorted by age groups, gender, and region, and multiplied those 
estimates by the projected percentages of the elderly population that will be driving, which gives us a total number of older drivers in the future.

Then, we took the projected number of older drivers and multiplied it by the average VMT per driver to obtain a total number of miles driven by elderly drivers. Finally, we multiplied the estimated total number of miles driven by the crash risk per mile driven to find our ultimate goal, the projected total number of fatalities (either driver fatalities or total fatalities, as explained in Chapter 8).

The behavior of the individual elderly person was taken into account in projecting two of the final three components of the system - when we look at how much an individual with certain characteristics will drive or whether he or she will be a driver. The behavior underlying each of these components is modeled empirically with regression analysis of data from the NPTS, the NHIS, and several other related sources. The estimated equations serve as predictive models used to project our components into the future as the independent variables of those regressions change predictably. NPTS survey data on individual drivers are available to estimate VMT and the probability that an older person will continue to drive. Our projections, however, are in the form of averages for particular subgroups of drivers (e.g., southern male drivers between 65 and 69 years old). The effects of our independent variables in these two models are also estimated at the individual level, while projections are in the form of averages for subgroups. We make the step from characteristics of the individual to characteristics of the group assuming that such groups will be homogeneous over time, and representative of the "average"driver.

\subsection{BRIEF EXPLANATION OF DEMAND THEORY}

Demand theory underlies the projection of the demand for VMT and the need a person has to be a driver. This theory predicts that the quantities of goods or services chosen by a consumer will respond to changes in the consumer's income and to changes in the prices, 
or acquisition costs, of the goods or services and of closely related goods and services, referred to as substitutes and complements. Consumption will increase in response to decreases in the acquisition cost of the goods or services in question, to decreases in the costs of complementary goods and services (items used in conjunction with the good or service under study), and to increases in the costs of substitute goods and services. Abstracting from changes in acquisition costs, increases in income will lead consumers to increase their consumption of a good or service. In each of the predictive models, data on the acquisition costs of the directly concerned consumption item, and on substitutesand complements, are not readily available. Thus, we rely on surrogates for these costs.

Demand theory for items that involve binary choices (i.e., to buy or not to buy) has been developed in the context of the demand for durable goods for which different varieties are available and for transportation modal choice (automobile or public transit primarily). When several choices are available, a system of demand equations is used, with the dependent variables measuring the probability of choosing one item relative to the probability of choosing another, estimated typically in a logit framework. When there is only one choice, the actual choice is "yes" or "no," with "no" being the default choice and the equation system collapsing to a single equation. In the case of the "driver" model, the choice is whether to drive.

\subsection{POPULATION PROJECTIONS}

Population growth, by 5-year age groups and by gender, was projected by the U.S. Census Bureau (Tables B.1-B.4 in Appendix B, and Figure 5.1). The U.S. Census Bureau also projected population growths at individual Census regions. The regional distribution of population is projected by considering the migration into theSouth and West over the next twenty-five years. This movement results in large percent increases in total older driver fatalities in 2025 over 1995 in those regions. Since elderly persons in nursing homes are much less likely to be drivers than those living alone or with their families in non- 


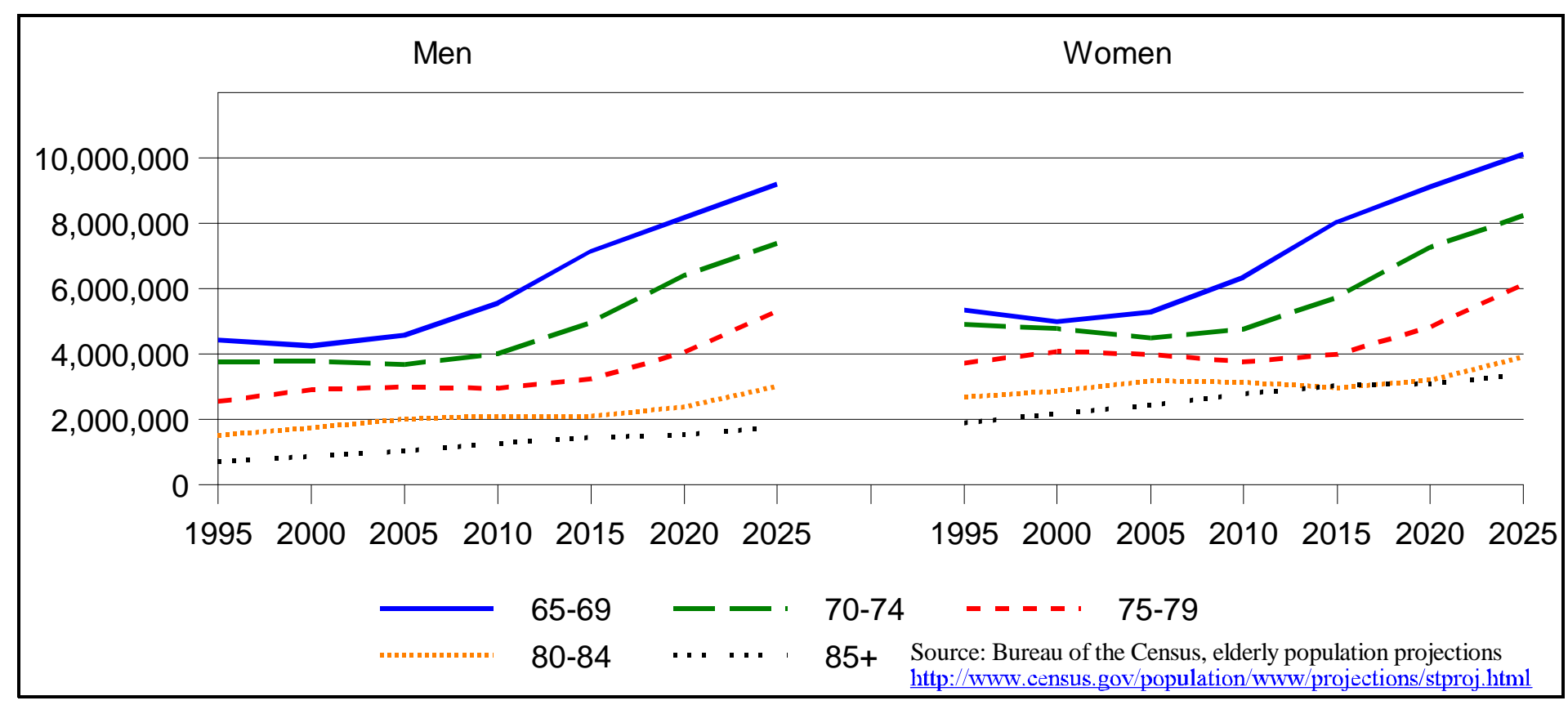

Figure 5.1. Projected National Non-Institutionalized Population 
institutionalized settings, our projections of future elderly populations who will drive exclude those who are projected to be institutionalized (American Health Care Association, 1997, p.7).

The number of people aged 65-69 projected in 2000 is smaller than the actual number of people who are 65-69 in 1995, and some readers may find that decrease in cohort size odd and discomforting. That projection may be a statistical bump to some extent, but it also may reflect the effect of the Great Depression on the number of people born between 1931 and 1935, the group represented by the 65-69 year olds in 2000. Both birth rates and the numbers of births dropped below their trend levels between 1931 and 1941. Of course, the birth rate in the United States had been declining for decades as part of the demographic transition, but even that falling birth rate fell below its trend rate of decrease between 1931 and the beginning of World War II. In a growing population we would expect subsequent cohorts to be larger than earlier ones, but a peak of live births occurred in 1930, a level that was not recovered until 1941 (U.S. Census Bureau, 1975, p. 49). This smaller size of the 1931-35 cohort is likely attributable to a combination of delayed marriage, delayed childbearing within existing marriages, possible reductions in births outside of marriage (likely to have been a small effect in either direction in the 1930s), higher infant and child mortality, and possibly increased adult morbidity rates later in life. Whether immigration could have compensated for this reduction in natural increase among this cohort is an open question, but with tighter immigration restrictions dating from the 1920s, even post-World War II immigration by persons born between 1931 and 1935 may not have compensated for the reduction in U.S. births. 


\subsection{HEALTH STATUS DATA}

The health index included in the probability of continuing to drive and VMT models is constructed using relationships found in the NHIS data. The NHIS' Activity Limitation Status (ALS) variable assumes values 1 to 4, which indicate a subject's health:

1. Unable to perform major activity

2. Limited in kind/amount of major activity

3. Limited in other activities

4. Not limited

Using this original variable, a continuous index was computed where an ALS of 1 remained 1, an ALS of 2 became 3, an ALS of 3 became 25, and an ALS score of 4 was given a value of 40. The log of this continuous predictor was then used as a dependent variable and regressed on factors including region, gender, age, race, marital status, education attainment, and income. Three regressions were run for the years 1983, 1990, and 1995. The coefficients of these models can be found in Table 5.1.

Once these models were complete, we took these coefficients into the NPTS data and calculated predicted ALS scores (on the 1, 3, 25, 40 scale) using the information found in NPTS. At this point, the scores were then broken down by percentiles with each NPTS respondent given a score on a 1 to 4 scale so that the distribution of the total population's scores matched the distribution found in the original NHIS measure. The natural log of these scores on the 1 to 4 scale were then used in the "driver" and VMT demand models as an approximate measure of an individual's health.

While we acknowledge that our method is for integrating health and driving has limitations, we nonetheless feel that an association is necessary. Even for noninstitutionalized persons, health limitations curtail driving. Additional research in the 
relationships between health and the decision to drive and between health and VMT is recommended in Chapter 10.

Table 5.1. NHIS Activity Limitation Status Regression Coefficients and T-Values

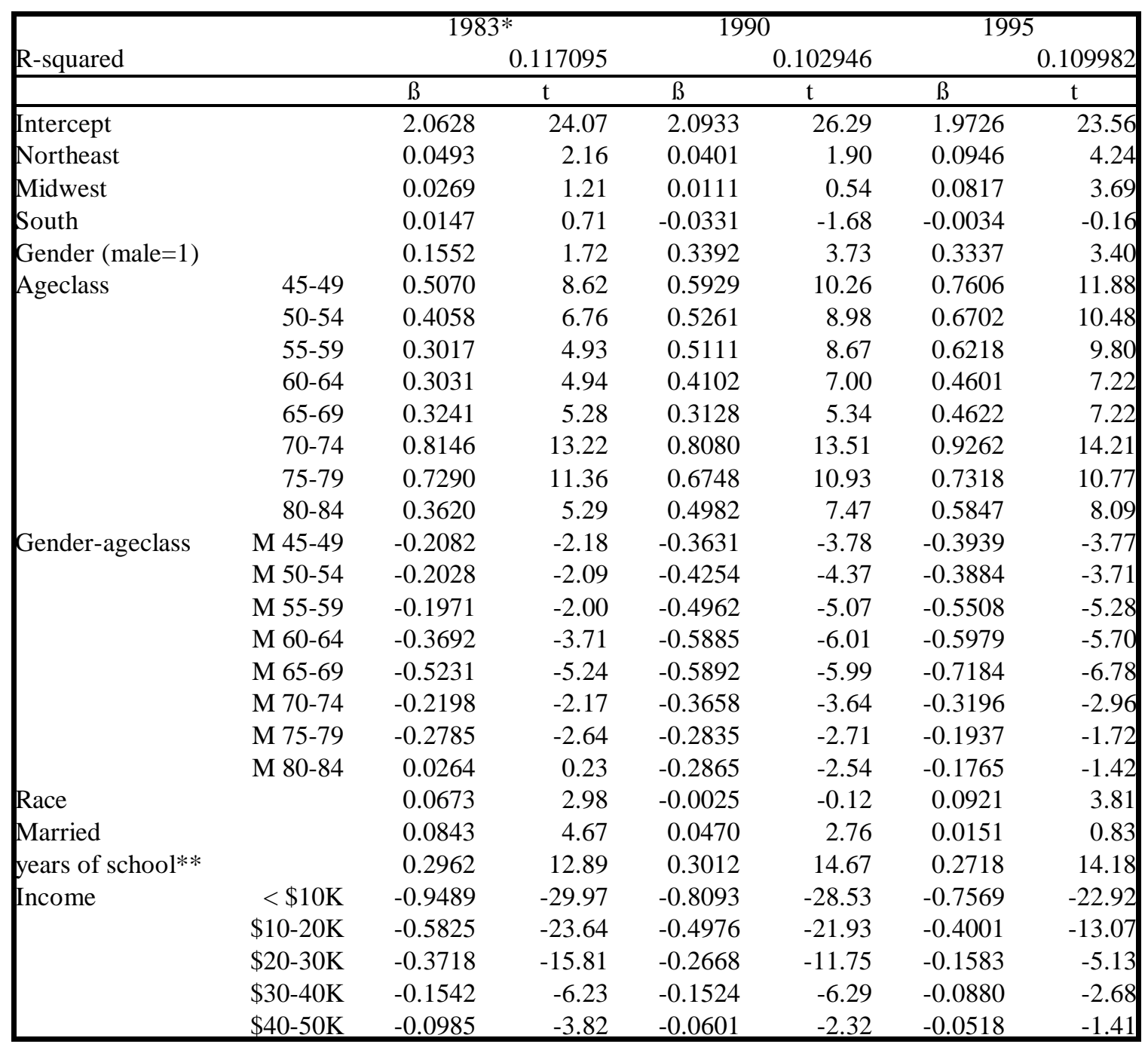

*(Note that the 1983 NPTS does not contain a region variable and thus predictions for that year were obtained omitting the region portion of the model).

** The years of school variable is computed by taking the number of years schooling a given individual had, adding one, and taking the natural $\log$ of the result. 


\subsection{ASSUMPTIONS}

As noted in Section 4, our search for data sets on the elderly which include information on health, income, education, driving status and practices (e.g., seat belt use, driving while intoxicated, use of transit), and VMT/person, while also including variables for gender, age group, and region, concluded that these data sets simply do not exist. In addition, it is not generally possible to form direct links between data sets. Therefore, for the critical missing link of health status, we constructed the surrogate described in the preceding section.

In other cases, we simply excluded a particular projection from our model. One example of such an exclusion is the future impact of technology on the elderly driver. Improved infrastructure, in-vehicle devices, and ITS innovations (see also Sections 3.3.5 and 10.3.1) may have a tremendous impact. We simply do not know how these innovations will impact the older driver (or how they will influence the elderly decision to choose alternative transportation or to walk). We also do not know how public policy will affect the building of new highways or affect our transportation modes. Finally, because of the tremendous influence of this large elderly population in the future, changes in public transportation will almost certainly occur. Predicting the extent of these changes, however, would be mere speculation.

Using traditional regression models on historical data is an effective way to estimate the effects of predictive variables on components of our modeling system. However, assuming that the magnitude of historical trends will continue indefinitely into the future sometimes yields absurd results. In situations where this problem presents itself in our projections, we logically modify coefficients of variables to provide more reasonable estimates of our modeling system components. For example, the probability of driving must be between 0 and 1 and projections of VMT by elderly drivers should not exceed a logical maximum, explored in Chapter 7. 


\section{THE PROPORTION OF THE ELDERLY POPULATION THAT DRIVES}

\subsection{HISTORICAL TRENDS IN ELDERLY DRIVING}

Historical data show that the percentage of the population that drives has increased over time. NPTS data from 1977, 1983, 1990, and 1995 show a general upward trend, excluding the 1995 figures, in the percent of various age groups in the population that drive (Figure 6.1). The numbers in this figure represent those persons who drive, not necessarily those who just have a license. As such, persons who call themselves drivers but did not report any mileage driven in the given survey year were not counted as drivers. This means that known problems with the statistical under-reporting of VMT in the 1995 NPTS may affect our measure of active drivers, and could account for the dip between 1990 and 1995 .

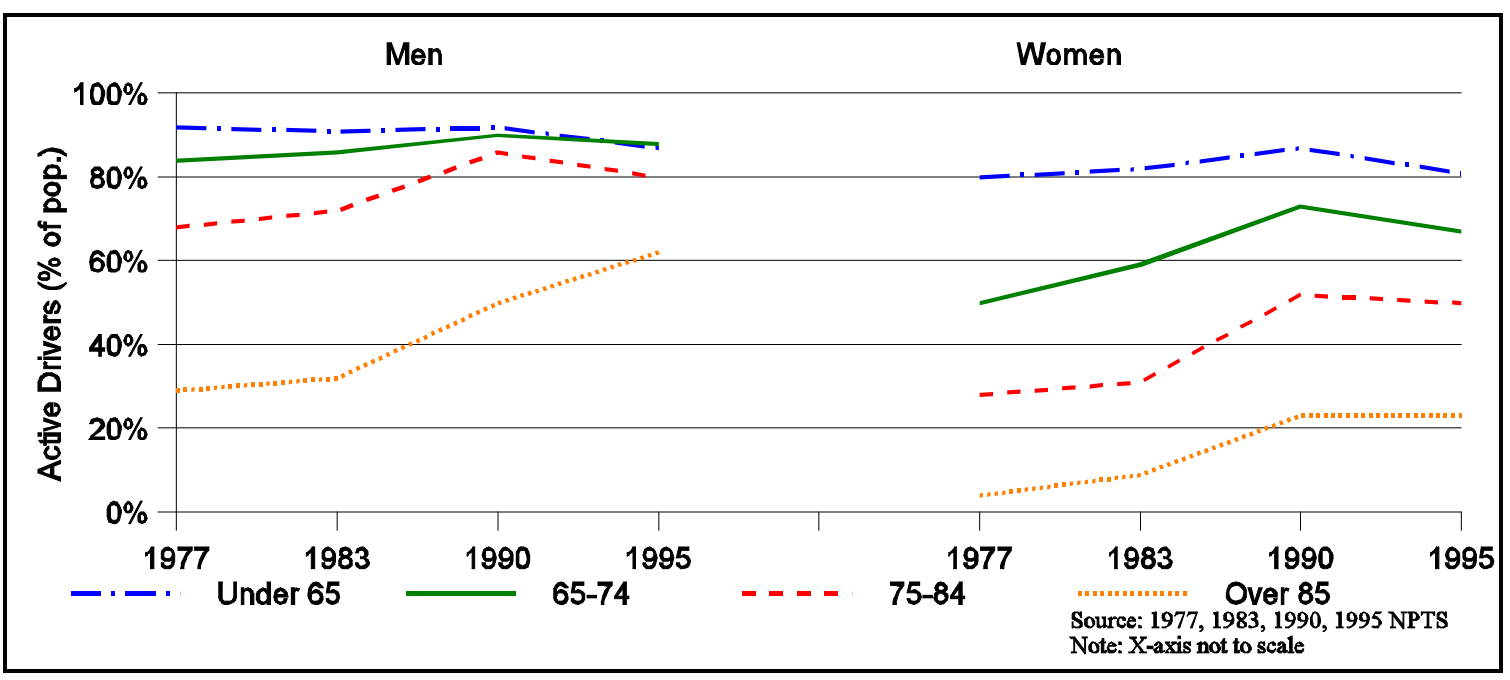

Figure 6.1. Active Drivers as a Percentage of the Population, 1977-1995 
Historically, those age groups with the most room to increase have done so, with $29 \%$ of men over 85 driving in 1977, and 62\% of men in the same age group driving in 1995. Similarly for women, the percentage of women over 85 who drove increased from a mere $4 \%$ in 1977 to $23 \%$ in 1995 . These numbers also show the differences between men and women, which are slight in those under 65, but increase dramatically as men and women age.

Other historical data also show the decrease in the probability that a person will drive as he or she ages. A panel study that followed the same group of people for 13 years showed that as age increases, the likelihood of driving diminishes (Hu, 1995, p. 3-1 to 3-43). In the first year of the study, about $90 \%$ of women and $95 \%$ of men reported that they were active drivers. The percentages declined gradually but steadily over time, and by the thirteenth year, only $70 \%$ of women and $80 \%$ of men continued to drive.

\subsection{MODELING THE DECISION TO DRIVE}

The second component of our projection system involves estimation of the historical determinants of people's decisions to drive. We treat the decision to drive as an economic resource allocation decision, even if it does not involve a simple purchase in a market. This is essentially the demand framework discussed in Section 5.2.

There is no simple, empirically implementable indicator of why one continues to drive, although there are some indicators of substitutes for driving. While the proportion of Americans who are drivers has been quite high over the past several decades, income has played a clear role in determining the rate of "adoption" of driving, and income belongs in this model. We use two measures of substitutes for driving: letting someone else drive 6ther driver) and an indirect indicator of the existence of other means of getting around to one's destinations, a binary variable for an individual's residence in an urban or rural area. Ideally, access to public transportation would have been a more direct measure of the availability of alternative travel modes, but data limitations made the urban variable our best choice. 
Employment status represents a derived demand for the decision to drive. Theyear variable captures a composite measure of the societal changes we are unable to quantify individually. Health status captures a person's ability to drive, as a measure with some degree of continuity, rather than his or her preference for driving.

Because the fraction of the population that can be drivers is bounded above by the value 1.0, we estimated the percentage of the elderly population that continues to drive with a logistic regression with the functional form of:

Prob (continuing to drive) $=\left(1+\mathrm{e}^{-\mathrm{z}}\right)^{-1}$,

where $\mathrm{Z}=$ constant $+\mathrm{a}_{1} \log ($ income $)+\mathrm{a}_{2} \log$ (health status $)+\mathrm{a}_{3}($ urban $)+$ $\mathrm{a}_{4}$ (employment status $)+\mathrm{a}_{5}($ other driver available in household $)+\mathrm{a}_{6}($ year $)$.

This equation was estimated separately for age groups and by gender, with ten regressions in all.

Table 6.1 contains the results of the regressions of the model. The percent of variance in the dependent variable explained by the regressions ranges from .19 to .50 , with these measures showing stronger relationships between the decision to drive and our predictors in women than in men. These adjusted $\mathrm{R}^{21} \mathrm{~s}$, the statistics that report the percent of variance explained in each regression, are satisfactory considering the large sample sizes and the survey character of the data.

Due to the form of equation (1), our regressions, and logistic regressions in general, do not have explicitly interpretable coefficients. Note the coefficients in Table 6.1 for the men aged 65-69 as an example. The $\log$ (income) coefficient of 0.5829 means that for each 
Table 6.1. Regression Results for the Probability of Continuing to Drive

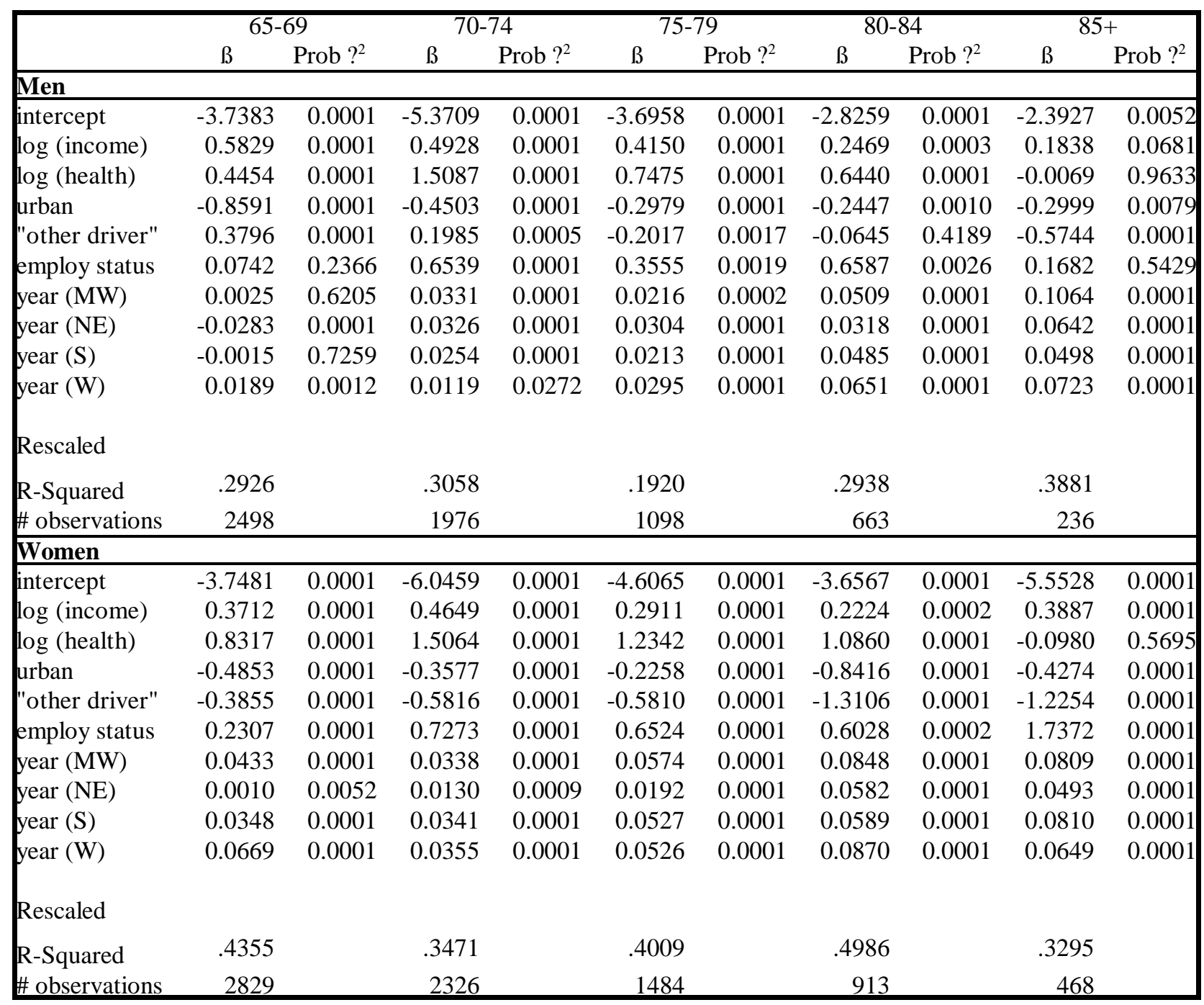

one unit increase in $\log ($ income), the logit function, represented by $\mathrm{Z}$ in equation (1), increases by 0.5829 . While the precise effect of $\log$ (income) on the probability of driving is dependent upon magnitudes of the other effects in the model, onecan say that there is a positive relationship between income and the probability to continue driving. The 0.0001 in the "Prob ?2" column of Table 7.1, being lower than 0.05 (or 5\%), indicates that a strong 
statistical relationship exists between income and the probability of driving. ${ }^{1}$ Similarly, a 0.4454 coefficient for $\log ($ health) signifies that a one unit increase in the log(health) variable will lead to a 0.4454 increase in the logit function, indicating a positive relationship between the probability of driving and health status. The urban variable, as a proxy for the availability of public transportation, has a coefficient of -0.8591 , logically indicating that the availability of public transit decreases the probability of continuing to drive. Since it is a dummy variable, taking on a value of 0 or 1 , there is either no change to the logit model if one lives in a nonurban area, or there is a decrease of 0.8591 to the logit function if one lives in an urban area. The effect of other drivers in the household is also a dummy variable, where having other drivers in the household increases the logit function by 0.3796. Similarly, the employment status coefficient of 0.0742 means that a person who is part of the workforce increases the logit function by 0.0742 . However, the "Prob?" " column shows a value of 0.2366 which, being above our standard cut-off, indicates that there may be no real relationship between being in the workforce and continuing to drive for men aged 65 to 69 . The same lack of a significant statistical relationship is found in the time trends (represented by year in Table 6.1), which capture increases in the probability of continuing to drive not explained by income, health, etc., for the midwestern and southern regions. The time trend for the other two regions indicates that, every year, the logit function of those in the Northeast will decrease by 0.0283 and the function for those in the West will increase by 0.0189 . The negative effect between time and the probability of driving in the northeast region is an anomaly, not being representative of all age groups.

\footnotetext{
${ }^{1}$ The 5\% figure is a standard statistical cut-off for assessing "statistical significance," which is a short-hand expression for whether the true value of an estimated statistic is likely to be different from zero. As such, these confidence levels, or significance levels, tell the probability that the true values of these regression coefficients are different from zero. Thus significance at a $5 \%$ level means that there is only a $5 \%$ chance that the true value of a coefficient is zero. A $1 \%$ confidence level is "better" than a $5 \%$ level in the sense that we can have more confidence that the true value of the coefficient is not zero. While there is no logical reason to pick any particular significance level as a cut-off, with higher percentages leading a researcher to dismiss an estimated coefficient as too imprecisely estimated to support much confidence, $5 \%$ and $1 \%$ are common levels used as separating the variables that are strongly believed to have a relationship with another variable from those that might or might not. Depending on various characteristics of the data available for a statistical study, some researchers might feel uncomfortable dismissing a variable that reaches only the $10 \%$ or even the $15 \%$ significance level. Judgment is unavoidable in using significance levels to screen variables in statistical relationships.
} 
Now, let us look at the general effects ofthe variables in the model. Income has an extremely strong statistical relationship (significant at better than 1\%) with the decision to continue driving in most age/gender groups, while males 85 or older only have a weaker, but still moderately strong statistical relationship (significant at only about 6\%). Income has a tendency to influence the decision to continue driving more for a man than a woman, except in the $85+$ age group where the reverse is true. The coefficients range from 0.18 to 0.58 . For males, the effect of income on the decision to drive declines with age, but there is no clear age pattern among females.

A higher health status increases the probability to continue driving, with strong positive relationships (significant at better than 1\%) for all age and gender groups except in men and women over 85 , where relationships are not statistically significant. Consistent with previous research, poor health influences women not to drive more than men, except among 70-74 year olds, for whom the coefficients are the same at 1.50. For both men and women, health matters least among the 65-69 year-olds. Health status matters most in the next age group (70-74), with the magnitude declining across the 75-79 and 80-84 age groups and becoming statistically insignificant in the $85+$ ages. The coefficients of this effect range from 0.44 to 1.50 .

As a proxy for having public transit available, living in an urban area has a strong depressing effect on the probability of being a driver for both men and women, always with coefficients significant at better than $1 \%$. The magnitude of this effect lessens with age for men with the exception of those over 85 , and falls for women over the youngest three age groups. The effect of urbanization on a woman's probability to continue driving is largest in the 80-84 age group, but falls off among 85+ to a level nearly comparable with that of the 6569 year-olds. Coefficients range from -0.22 to -0.84 .

The presence ofother drivers in the household has strikingly different effects for men and women. These relationships are highly statistically significant (at better than $1 \%$ ) for every age/gender group except 80-84 males. Men in the 65-69 and 70-74 age groups are 
more likely to be drivers if there are other drivers in the household, but men in the 75-79 or $85+$ age groups are less likely to drive under those circumstances. There is effectively no influence of other drivers on 80-84 year old men. Women, on the other hand, are always less likely to continue driving when there are other drivers in the household, and the strength of this effect has a general upward trend with age. Overall, the negative relationship between having other drivers and continuing to drive for women is stronger than the positive relationship for men.

Being in the labor force has a strong positive effect on the probability of women driving, with a the effect roughly increasing with age. For men the effect is always positive but is statistically significant only in the middle three age groups of 70-74, 75-79, and 80-84. Except among 80-84 year olds, being in the workforce influences a woman's decision to drive more than it does for a man. The magnitudes of the significant coefficients range from 0.23 to 0.73 .

The regional time trends are generally positive (significant while negative only for 6569 males in the northeast Census region). They also tend to be somewhat larger for women than for men and get larger for older age groups, indicating that our behavioral variables alone tend to underpredict the growth of driving among the older elderly and among women, neither of which is surprising.

\subsection{PROJECTING THE PROPORTION OF OLDER POPULATIONS THAT WILL DRIVE}

The percentage of each age/gender group who will continue to drive is projected with the originally estimated regression equation (1). Since values of the dependent variable are constrained (the ratio cannot exceed one), it was necessary to retain the asymptotic behavior of the dependent variable imposed by the form of the equation in the projection. For projections of future years' values of the dependent variables, the projected levels of the 
independent variables were substituted into the logistic equation and the new values of the dependent variables calculated.

Projecting with the constant growth rates estimated in the regressions of the probability of continuing to drive would have yielded absurd results. It is well known that projecting constant growth rates from a period in the past into an indefinite future frequently produces untenable results, and this problem was particularly prominent in the cases of these three limited dependent variables. In the projections of the proportion of elderly who will continue to drive, we used thetime trend with an allowance for decreasing growth rates at every five-year interval in the future. The procedure we used is detailed in Appendix C. While this is a complicated set of adjustments to the time effect in the projections, it avoids arbitrarily changing what we consider to be the more basic coefficients relating income, employment status, presence of other drivers in the household, etc., to the driving choice. Furthermore, the basic adjustment to lower the pure time effect represented in the time trend coefficients had its own empirical basis, and the subsequent adjustments on individual coefficient values is based on a combination of how age affects the driving choice and patterns in the base projections themselves.

Aggregate projections of the independent variables were used to project the probability of continuing to drive. The projection of household income, by age, gender, and region, was supplied by DRI's projections in constant 1998 dollars, using their regional forecasting model. Those projections are reported in Tables B.5 and B.6 in the appendix, with further explanation in Appendix B.2.1. Health status was projected to remain at its 1995 level throughout the projection period in the base projection but was projected to grow at $1 / 4 \%$ per year in another projection discussed in Chapter 9 . Theother driver variable was a dummy variable in the regression, taking a value zero or one for absence or presence of other drivers in the household. The value of this variable was projected for each population segment (age/gender, region) by taking the proportion of that population living in a household with other drivers (a fraction between zero and one) and maintaining that level throughout the projection period. Employment status was projected by extrapolating Bureau of Labor 
Statistics (BLS) projections beyond 2008. For 2010-2025, we used predicted values from age/gender-specific regressions using the 1999-2008 projections versus time. The BLS data only cover age groups 65-69, 70-74, and 75+, so for each of the age groups 75-79, 80-84, and $85+$, we used the $75+$ projections.

The urban effect was projected in a manner similar to the projection of other driver and employment status. The percent of the age/gender/region sample living in urban areas in 1995, which approximated the proportions of the overall population living in urbanized areas in those regions, was projected unchanged to 2025. No authoritative projection of urbanization by region was found for the United States, and while some regions' urbanization clearly is expected to increase by 2025 (e.g., the western Census region), those of the other regions had less clear expectations. Rather than attempt either an independent projection of urbanization which was beyond the scope of the present study, or make an arbitrary set of projections which could be subject to considerable difference of opinion themselves, we retained the 1995 regional urbanization levels in the projections to 2025 .

Figure 6.2 offers a graphical depiction of the projections of the proportion of elderly who will continue driving, while Tables A.2.1-A.2.4 in Appendix A report the actual numbers. Historically, the proportions of the male age groups who drive are considerably higher than the corresponding proportions in the female age groups and consequently have less scope for further growth over the twenty-five-year projection period. The percent of men in the 65-69 age group who drive is projected to rise from $84.4 \%$ in 1995 to $91.1 \%$ in 2025 , an increase of 7\% (not percentage points, but percent). The relative growth in ratios in the 70-74 and 75-79 age groups of men is about the same, but the projected increases are more substantial for the $80-84$ and $85+$ groups, rising from $69.1 \%$ to $82.5 \%$ (19.3\%) and from $53.5 \%$ to $65.5 \%$ (22.3\%) respectively. The percent of southern men $85+$ driving is projected to increase by nearly $40 \%$ by 2025 , almost double the national average.

In each age group, the proportion of women driving in 2025 approaches the percentage of men driving in that age group in 1995. Nonetheless, these increases represent 


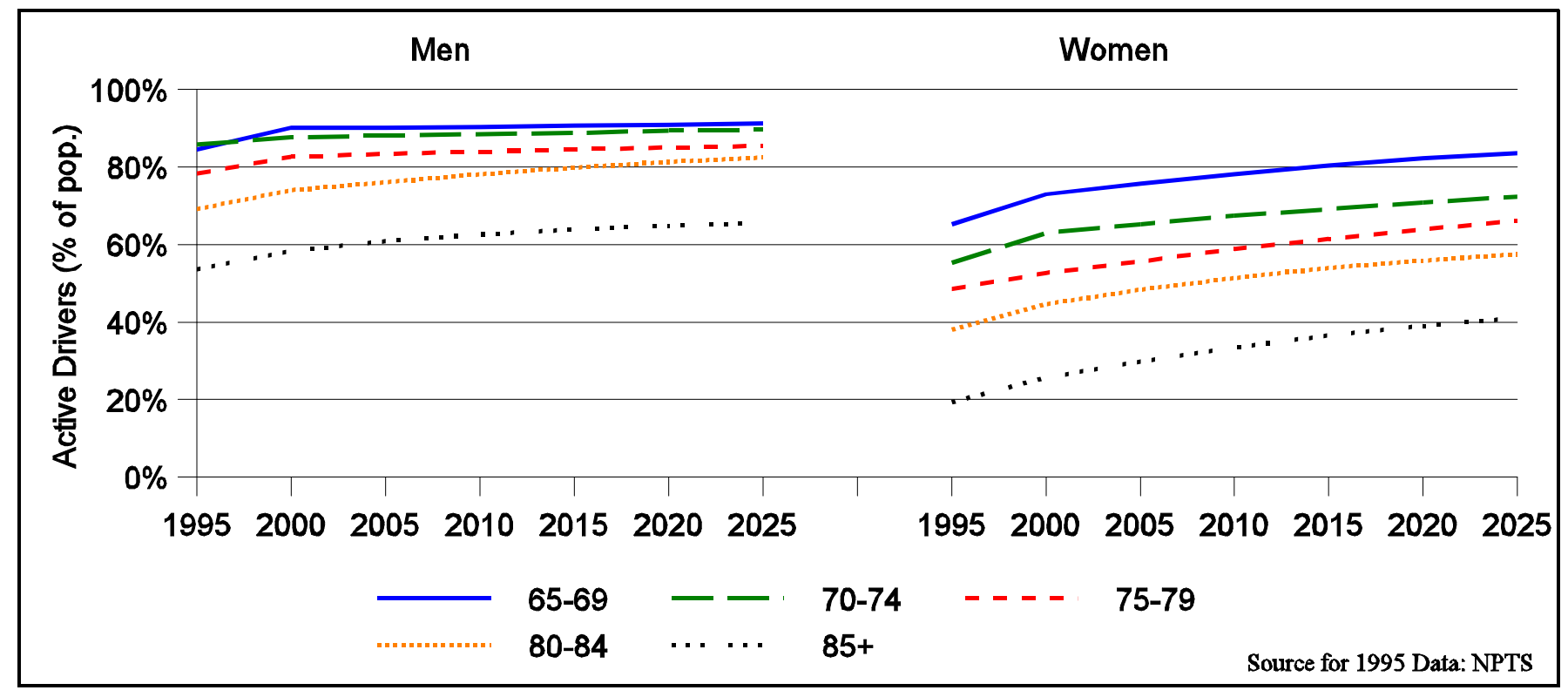

Figure 6.2. Projected Active Drivers as a Percentage of the Population 
considerably greater proportional changes, with national averages in 2025 ranging from $28 \%$ higher (65-69 women) than 1995 levels to $113 \%$ (85+). The greatest proportional increases occur in the $85+$ women in all regions, reaching $122 \%$ and $142 \%$ increases in the Northeast and South respectively. In 1995, 65.1\% of women 65-69 were drivers nationally, with that percentage rising to $83.6 \%$ by 2025 . In the West, $92.9 \%$ of women in that age group are projected to drive by 2025 , but only $64.1 \%$ in the Northeast (which also had the smallest percent increase over the period). Only $19.2 \%$ of women $85+$ drove in 1995 , and nearly $41.1 \%$ are projected to drive by 2025 , with the highest proportion in the Midwest at $52.5 \%$ and the lowest in the Northeast at $22.2 \%$.

Tables 6.2 and 6.3 show the national and regional contributions of growth in income and labor force participation (LFP) to the projected growth in the percentage of drivers between 1995 and 2025. Income is the predominant, identifiable social determinant for men, but the influence of the time trend is dominant for women of all ages. The effect of income declines steadily by age group for men, and generally but not uniformly for women. The effect of LFP growth is minimal on women. In Table 6.3, the contribution of income growth in excess of $100 \%$ and that of LFP growth in the negative range for northeastern and southern men in the 65-69 age group reflects negative time trends in those two groups. These tables also show the enormous contribution of the pure effect of time, an indistinguishable combination of technological and institutional changes extrapolated from the past but dampened to reflect previous slowing trends. The interpretation of these magnitudes and signs is that, if it were not for the effect of the regional time trend, in both cases the driver percentage in 2025 would be substantially higher than it is with the time trend. 
Table 6.2. Determinants of Projected National Driver Growth

\begin{tabular}{|cccc|ccc|}
\hline & \multicolumn{3}{|c|}{ Men, National } & \multicolumn{3}{c|}{ Women, National } \\
\hline Age & Income & $\begin{array}{c}\text { Employment } \\
\text { status }\end{array}$ & $\begin{array}{l}\text { Time } \\
\text { trend }\end{array}$ & Income & $\begin{array}{c}\text { Employment } \\
\text { status }\end{array}$ & $\begin{array}{l}\text { Time } \\
\text { trend }\end{array}$ \\
\hline $65-69$ & $51.21 \%$ & $2.39 \%$ & $43.11 \%$ & $18.08 \%$ & $0.36 \%$ & $82.03 \%$ \\
$70-74$ & $32.98 \%$ & $6.90 \%$ & $59.82 \%$ & $20.42 \%$ & $0.80 \%$ & $79.35 \%$ \\
$75-79$ & $28.46 \%$ & $0.28 \%$ & $70.79 \%$ & $9.76 \%$ & $0.16 \%$ & $90.34 \%$ \\
$80-84$ & $11.06 \%$ & $0.35 \%$ & $88.42 \%$ & $6.26 \%$ & $0.18 \%$ & $93.53 \%$ \\
$85+$ & $4.83 \%$ & $0.06 \%$ & $95.12 \%$ & $8.35 \%$ & $0.04 \%$ & $91.71 \%$ \\
\hline
\end{tabular}

Table 6.3. Determinants of Projected Regional Driver Growth

\begin{tabular}{|c|c|c|c|c|c|c|}
\hline & \multicolumn{3}{|c|}{ Midwest Men } & \multicolumn{3}{|c|}{ Midwest Women } \\
\hline Age & Income & $\begin{array}{c}\text { Employment } \\
\text { status }\end{array}$ & $\begin{array}{l}\text { Time } \\
\text { trend }\end{array}$ & Income & $\begin{array}{c}\text { Employment } \\
\text { status }\end{array}$ & $\begin{array}{l}\text { Time } \\
\text { trend }\end{array}$ \\
\hline 65 & $81.12 \%$ & $3.16 \%$ & $15.72 \%$ & $11.71 \%$ & $0.22 \%$ & $88.07 \%$ \\
\hline 70 & $28.12 \%$ & $7.01 \%$ & $64.88 \%$ & $14.65 \%$ & $0.71 \%$ & $84.64 \%$ \\
\hline 75 & $13.24 \%$ & $0.23 \%$ & $86.52 \%$ & $4.96 \%$ & $0.13 \%$ & $94.91 \%$ \\
\hline 80 & $5.73 \%$ & $0.26 \%$ & $94.01 \%$ & $5.30 \%$ & $0.15 \%$ & $94.55 \%$ \\
\hline $85+$ & $3.92 \%$ & $0.04 \%$ & $96.03 \%$ & $6.75 \%$ & $0.03 \%$ & $93.22 \%$ \\
\hline & \multicolumn{3}{|c|}{ Northeast Men } & \multicolumn{3}{|c|}{ Northeast Women } \\
\hline Age & Income & $\begin{array}{l}\text { Employment } \\
\text { status }\end{array}$ & $\begin{array}{l}\text { Time } \\
\text { trend }\end{array}$ & Income & $\begin{array}{l}\text { Employment } \\
\text { status }\end{array}$ & $\begin{array}{l}\text { Time } \\
\text { trend }\end{array}$ \\
\hline 65 & $106.71 \%$ & $4.67 \%$ & $-211.38 \%$ & $41.43 \%$ & $0.95 \%$ & $57.62 \%$ \\
\hline 70 & $26.06 \%$ & $7.14 \%$ & $66.81 \%$ & $36.69 \%$ & $1.50 \%$ & $61.81 \%$ \\
\hline 75 & $18.59 \%$ & $0.26 \%$ & $81.15 \%$ & $19.65 \%$ & $0.32 \%$ & $80.03 \%$ \\
\hline 80 & $7.02 \%$ & $0.34 \%$ & $92.64 \%$ & $5.98 \%$ & $0.25 \%$ & $93.77 \%$ \\
\hline \multirow[t]{2}{*}{$85+$} & $3.80 \%$ & $0.05 \%$ & $96.15 \%$ & $12.23 \%$ & $0.06 \%$ & $87.71 \%$ \\
\hline & \multicolumn{3}{|c|}{ Southern Men } & \multicolumn{3}{|c|}{ Southern Women } \\
\hline Age & Income & $\begin{array}{l}\text { Employment } \\
\text { status }\end{array}$ & $\begin{array}{l}\text { Time } \\
\text { trend }\end{array}$ & Income & $\begin{array}{l}\text { Employment } \\
\text { status }\end{array}$ & $\begin{array}{l}\text { Time } \\
\text { trend }\end{array}$ \\
\hline 65 & $128.96 \%$ & $6.06 \%$ & $-35.02 \%$ & $13.24 \%$ & $0.26 \%$ & $86.50 \%$ \\
\hline 70 & $46.43 \%$ & $7.83 \%$ & $45.74 \%$ & $20.71 \%$ & $0.66 \%$ & $78.63 \%$ \\
\hline 75 & $43.52 \%$ & $0.34 \%$ & $56.14 \%$ & $9.44 \%$ & $0.12 \%$ & $90.44 \%$ \\
\hline 80 & $20.30 \%$ & $0.48 \%$ & $79.22 \%$ & $7.77 \%$ & $0.17 \%$ & $92.05 \%$ \\
\hline $85+$ & $7.79 \%$ & $0.08 \%$ & $92.13 \%$ & $9.71 \%$ & $0.03 \%$ & $90.26 \%$ \\
\hline
\end{tabular}


Table 6.3 (continued)

\begin{tabular}{|rrrr|rrr|}
\hline \multicolumn{4}{|c|}{ Western Men } & \multicolumn{3}{c|}{ Western Women } \\
\hline Age & Income & $\begin{array}{c}\text { Employment } \\
\text { status }\end{array}$ & $\begin{array}{l}\text { Time } \\
\text { trend }\end{array}$ & Income & $\begin{array}{c}\text { Employment } \\
\text { status }\end{array}$ & $\begin{array}{l}\text { Time } \\
\text { trend }\end{array}$ \\
\hline 65 & $27.70 \%$ & $1.14 \%$ & $71.16 \%$ & $11.28 \%$ & $0.17 \%$ & $88.55 \%$ \\
70 & $21.68 \%$ & $4.86 \%$ & $73.45 \%$ & $9.12 \%$ & $0.48 \%$ & $90.40 \%$ \\
75 & $29.98 \%$ & $0.28 \%$ & $69.75 \%$ & $5.26 \%$ & $0.10 \%$ & $94.64 \%$ \\
80 & $5.78 \%$ & $0.24 \%$ & $93.98 \%$ & $5.04 \%$ & $0.13 \%$ & $94.83 \%$ \\
$85+$ & $2.10 \%$ & $0.04 \%$ & $97.87 \%$ & $3.35 \%$ & $0.04 \%$ & $96.61 \%$ \\
\hline
\end{tabular}




\section{VEHICLE MILES TRAVELED}

\subsection{HISTORICAL TRENDS IN ELDERLY DRIVING}

The total person miles of travel for all drivers in the United States increased from 2,026 billion miles in 1983 to 2,141 billion miles in 1990 to 2,663 billion miles in 1995, a total increase of 31.4\% (U.S. Department of Transportation, 1997B). Historical driving trends among the elderly also show a general increase in the annual amount of VMT per person ${ }^{1}$ (Figure 7.1). The age group of persons over 85 have seen the largest increases. Men over 85 drove an average of 1933 miles per year in 1983, a number which more than doubled to 5166 in 1995. Women also saw a sharp increase in VMT per person in that time frame, tripling their driving miles from 1828 in 1990 to 2781 miles in 1995. Insufficient VMT data for women over 85 in 1977 and for all persons over 85 in 1983 prevented us from obtaining comparisons over a longer time frame. Increases in other elderly groups were less dramatic, but still substantial, with men between the ages of 65 and 84 increasing the number of miles driven by $35 \%$, and women in that same age group increasing their average numbers from $35 \%(65-74)$ to $75 \%(75-84)$. This increases show changes in the driving habits of older women, who are clearly driving a substantial amount more than women of similar ages in the past. However, as shown in Figure 7.1, the rate of increase for the elderly between ages 65 and 84 was greater between 1983 and 1990 than it was between 1990 and 1995 . Note that statistical changes in the 1995 VMT measures of the NPTS are believed to understate actual VMT for that time period.

Travel habits of the elderly are different from those of younger age groups. In 1995, the average person over 65 took fewer trips for every trip purpose than those under 65 , with the most substantial decline, logically, in trips to earn a living (Figure 7.2). The smallest

\footnotetext{
${ }^{1}$ Person miles of travel includes travel by any mode or means; VMT/person implies that the person is driving the vehicle.
} 


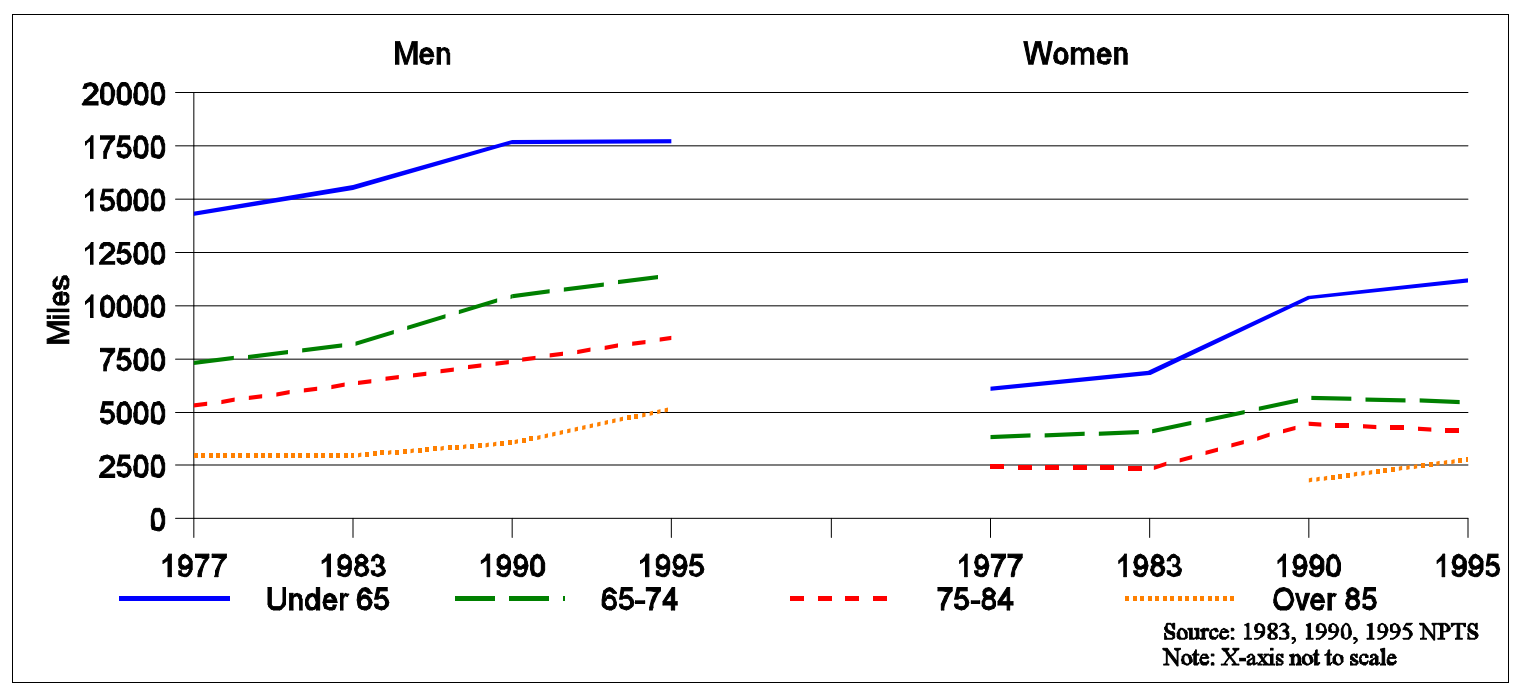

Figure 7.1. Annual Vehicle Miles of Travel per Driver, 1977-1995

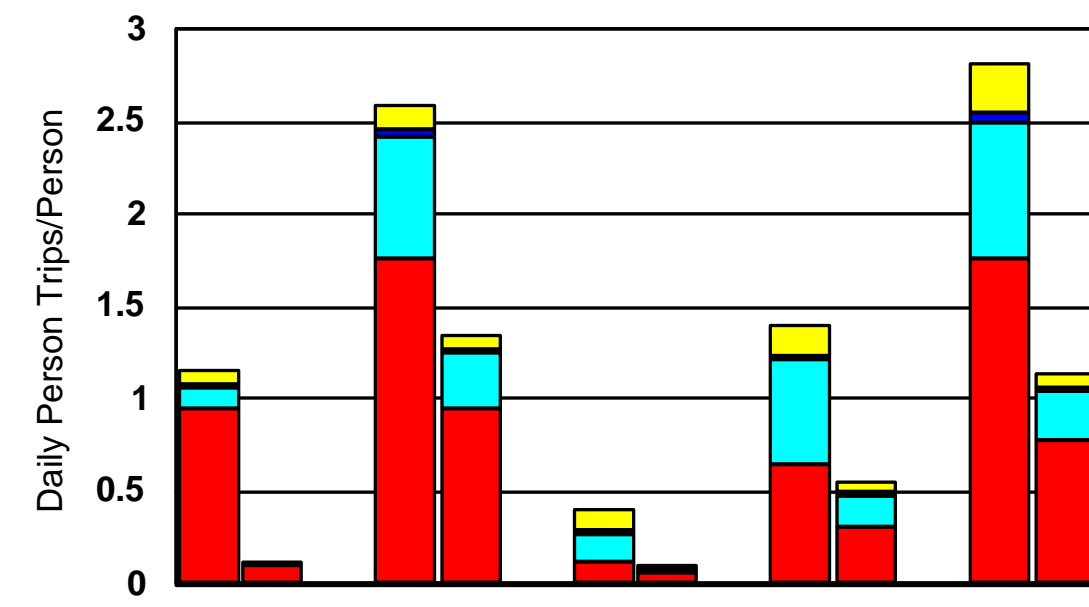

$\square$ Other

Public

Transit

$\square$ Pov,

Passenger

$\square$ POV,

Driver

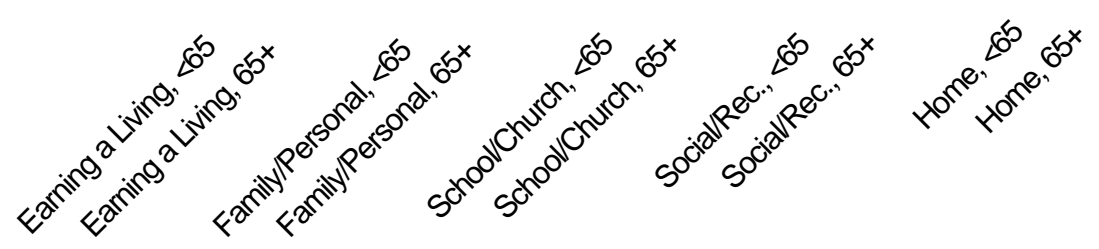

POV $=$ Privately Owned Vehcile Source: 1995 NPTS

Figure 7.2. Average Person Trips per Person by Mode of Transportation and Trip Purpose, for Individuals under 65 and Individuals 65 and Over 
decline in number of person trips was for the trip purpose of family and personal business. Now that we have shown how much and in what ways elderly driving has increased in the last two decades, we examine historical determinants of VMT that can be used to project VMT into the future.

\subsection{EMPIRICAL MODELING OF VMT}

We estimate the average VMT per driver using data from the 1977, 1983, 1990, and 1995 NPTS. This relationship is an economic one derived from demand theory, discussed in Section 5.2. The demand for mileage driven derives ultimately from a person's preferences, conditioned by his or her personal and external circumstances.

The demand for VMT is complicated by two factors. First, with the exception of leisure driving, VMT generally has a derived demand and is not something people would consume for its own sake. For instance, people drive to work to earn their income and they drive to the store to buy goods they want to consume, not simply for the sake of the respective trip. Thus, people's demand for VMT is derived from their demands to get to their jobs, to have the goods they purchase, to see their doctors, etc. One of the factors that creates differences in the driving patterns, and overall demands for VMT, between elderly drivers and those in the prime working ages of 25-60, is that some of the important activities from which the demand for VMT is derived are different. Particularly, the proportion of the population working declines substantially. Many of the other consumption oriented determinants of VMT demand, such as shopping trips and service-related trips, change less (US DOT, 1993, p.4-37)2. However, having fewer hours spent working does free up the elderly, particularly the younger elderly, to consume more recreation that may demand VMT. This at least partially compensates for the reduction in work trips.

\footnotetext{
${ }^{2}$ Table 4.20 shows that retired individuals and couples have a far sharper decline in travel related to earning a living than for other purposes.
} 
Second, VMT as a consumption item is something that consumers must produce themselves with combinations of their time and purchased inputs, not an item like clothing that can be purchased and consumed directly. The household production model of demand handles this aspect of the demand for VMT quite well, specifying that the consumer of VMT produces that service with a combination of time and purchased inputs (Becker, 1965, pp. 493-517). In the case of VMT, the purchased inputs are the vehicle (or at least the depreciation on the vehicle), fuel, and insurance. Both depreciation and insurance have at least theoretical relationships to VMT. Empirically, depreciation would parallel VMT more closely than would insurance payments, if for no other reason than that people have the opportunity to understate their mileage to their automobile insurance companies. Empirical observations of both depreciation and insurance costs are difficult to come by, as are observations of the amount of time drivers spend producing their VMT. The fact that time is required to produce VMT complicates the empirical interpretation of income in a demand equation of the form "VMT $=\mathrm{f}$ (income, prices)" because income also influences the "price" of VMT. People who earn higher incomes face a higher cost of using their time driving than do people who earn lower incomes, so the income variable in a regular demand equation contains both the ordinary income effect and a price effect. For the elderly, the price effect of income may be lessened somewhat by virtue of the fact that much of their income will come from asset sources such as retirement plans and earnings from various types of investments and savings. Consequently, their time spent driving is less likely, across all elderly in any one age group, to come out of marginal working time. Nonetheless, even with zero working time, higher incomes will cause people to value their leisure more highly, and time spent driving will come out of leisure.

The preferred strategy for estimating the demand for VMT would be a simultaneous equations approach jointly estimating the supply of VMT (meaning the maximum amount of VMT possible, given time constraints) and the demand for it. Data limitations, and possibly the diminished price effect of income for the elderly, precluded deriving useful results from that approach. Consequently, the regression model with which we implemented our VMT demand estimation used a specification closer to the ordinary demand equation, although we 
included variables to account for the derived-demand effect of working and for one substitute for driving (the availability of someone else in the household who can drive). Our basic VMT demand regression equation is:

$$
\begin{aligned}
& \log (\mathrm{VMT})=\mathrm{constant}+\mathrm{a}_{1} \log (\text { income })+\mathrm{a}_{2} \log (\text { fuel price })+\mathrm{a}_{3} \log (\text { health status }) \\
& +\mathrm{a}_{4}(\text { employment status })+\mathrm{a}_{5}(\text { other drivers available in household })+\mathrm{a}_{6}(\text { year }) .
\end{aligned}
$$

The logarithmic specification of the regression permits interpretation of the estimated regression coefficients as elasticities, i.e., the percent change in VMT induced by a $1 \%$ change in an independent variable. Thus the estimated value of $\mathrm{a}_{2}$ is a fuel price elasticity of demand for VMT and that of $\mathrm{a}_{1}$ is an income elasticity of demand for VMT. Much is known about relative magnitudes of price and income elasticities of demand, which helps in the assessment of the reasonability of the current estimates.

The health status variable is an NPTS representation of activity limitation status. This variable, whose construction is described in Section 5.3, is based on the ALS ranking from NHIS. This variable indicates an individual's capacity to drive, and is actually a supply-side influence used in this demand equation as a control. Employment status is a binary variable for in or out of the work force, and other drivers available in household is another binary variable indicating the presence or absence of other drivers in the elderly person's household.

The impact of the fuel price variable on the amount of driving was quite large $(-1.5$ to -2.2) relative to what is known about fuel-price elasticities (Pickerell and Simek, 1999, pp.1-17). ${ }^{3}$ This variable caused other estimation problems, particularly in the effect of income, so the final specification omitted fuel price. The year variable is a measure of the changes in American society and the geography of its infrastructure over the past quarter

\footnotetext{
${ }^{3}$ Pickerell and Simek estimate price elasticities of VMT per vehicle (our measure is VMT per person) ranging from -0.09 to -0.34 , using the 1995 NPTS and the same source for fuel price data that we use. While we can reproduce their results, the fuel price elasticities we can obtain for VMT/person do not fall below -1.5.
} 
century on which we are unable to obtain direct, quantitative information. Some of these changes include changing family roles that have caused more women to drive; changing urban-suburban relationships that have affected shopping behavior, recreational travel, and the journey to work; and changing labor market conditions that have interacted with both of the previous changes.

In the VMT models, a separate regression was estimated for each age group, as shown in Table 7.1. The percents of variance explained by the regressions, also know as the $\mathrm{R}^{2}$ statistic, are in a satisfactory range for regressions on large sample-size survey data, centering around a range from 0.17 to 0.29 .

Let us use the men aged 65 to 69 as an example of how to interpret the coefficient results in Table 7.1. Thelog(income) coefficient of 0.3050 means that, for each $1 \%$ increase in income, VMT will increase by $0.3050 \%$. Similarly for the health status variable, a $1 \%$ increase in the health status measure will cause a $0.0868 \%$ increase in VMT. Having other drivers in the household will lead to a decrease of 0.1279 in $\log (\mathrm{VMT})$, not VMT in its standard scale since the other drivers effect was not estimated in log-form. Being part of the workforce will lead to an increase in $\log (\mathrm{VMT})$ of 0.4991 . Finally, for each additionalyear, the increase in $\log (\mathrm{VMT})$ not attributable to previously accounted for effects like income and health status is 0.0218 .

Turning to overall trends in the results, the income elasticities of VMT are in the range of 0.20 to 0.46 , meaning that each $1 \%$ increase inincome will lead to an increase in VMT of $0.20 \%$ to $0.46 \%$. This range of increase was not consistently higher across age groups for men or women. The elasticity estimate for $85+$ men is 0.80 and -0.69 for $85+$ women, with both being statistically significant at $5 \%$ or better. The male estimate is somewhat high to be entirely credible and the large negative estimate for the women surely is a fluke of some sort, either statistical or involving peculiarities of income in this age group of women. Section 7.3 contains an explanation of how we handle such odd estimates. 
Table 7.1. VMT Regression Results

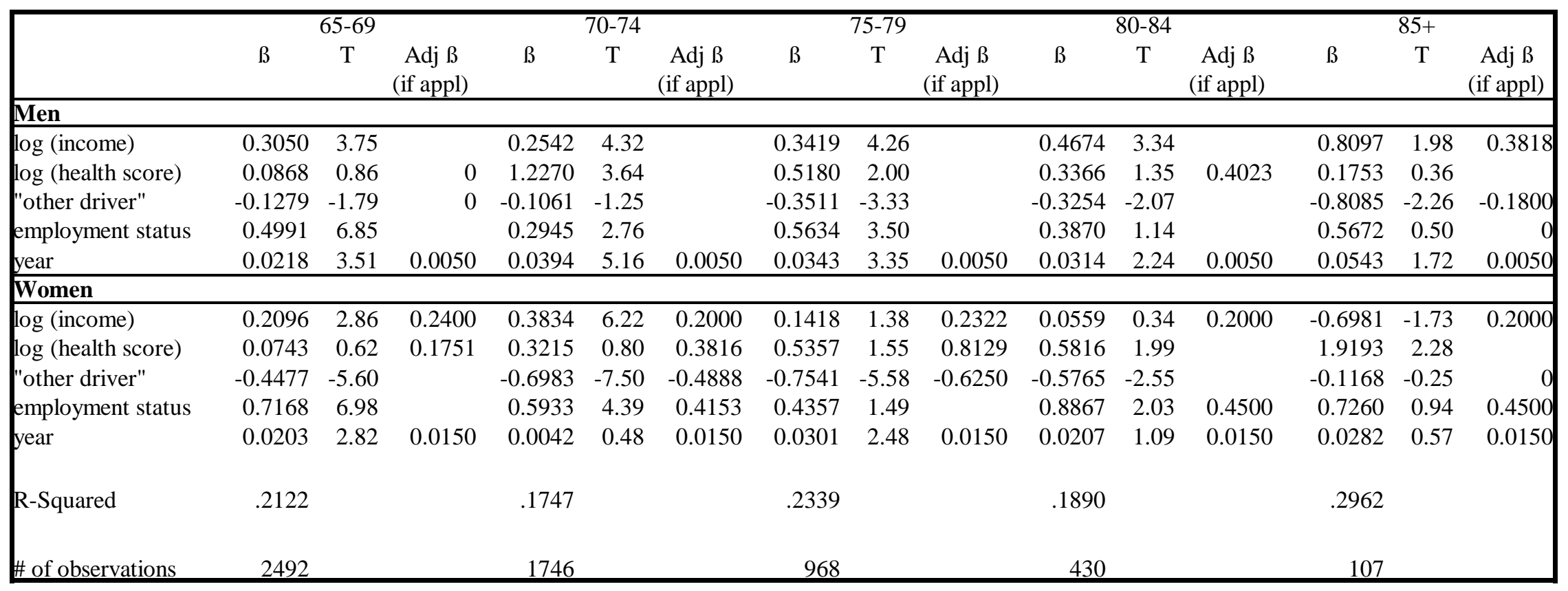


The health status effects are positive as expected, showing that better health status permits more driving. However, these effects are highly significant statistically for men only in the 70-74 and 75-79 age groups (marginally significant for the 80-84 group) and for women only in the 80-84 and 85+ age groups (with a marginally significant effect for the 7579 group). It seems as if this measure of health status only has a material effect among the older women, while its effect seems restricted to men in the middle periods of old age. The magnitudes of the significant effects for both men and women are rather large, with elasticities of 1.23 and 0.52 for the men 70-74 and 75-79 and 0.58 and 1.92 for the women $80-84$ and $85+$.

Having other drivers in an elderly person's household generally has a stronger dampening effect on VMT for women than for men, but no clear pattern of effect by age emerges, suggesting that the impact of having other drivers in the household on the amount of driving does not change by age. However, that gender effect is reversed in the 85+ age group where there is no identifiable effect on women and the dampening effect on men is substantial, with its coefficient of -0.81 being larger than in any other age group.

Being in the work force generally has a stronger positive effect on women's VMT than on men's, but as with the effect of other driver, there is no clear age pattern among the magnitudes of that effect. For 75-79 year olds, the effect is stronger for men than for women. Otherwise, the effects are always larger for females than males, and the differences are statistically significant for all age groups except the 85+ group, for which both the male and female effects are not statistically significant.

The increases in VMT captured by our time trend variable, which is a proxy for other differential changes between cohort groups, are about the same for men and women among the 65-69 and 75-79 age groups. In other cases, these effects are roughly twice as large for men at any age. 


\subsection{PROJECTING VMT}

For projection of VMT, we used our previously developed model (2) based on data from 1977, 1983, and 1990, and substituted the actual means of 1995 VMT for the constant term in the regression equation. This substitution was done in order to ensure our 2000 projections did not represent an unrealistically large departure from actual 1995 levels. We used the remaining regression coefficients to projectchanges in VMT according to projected percent changes in the values of the independent variables. The logarithms of VMT,income and health status were used in the regression, yielding regression coefficients with the forms of elasticities: the percent change in the dependent variable (VMT) per one-percent change in the independent variable (income and health status). Employment status and other driver were projected as changes in the percentages of the population in each age/gender group in the labor force (essentially a labor force participation rate for employment status) and living in a household with other drivers — changesrelative to the group percentages in 1995 . The regression coefficients of these variables, given the log transformation of VMT, yielded percent change in VMT caused by one-percent changes in these two variables. This projection is essentially an add-to-base method. In the absence of changes in the independent variables and exogenous growth determining annual VMT per driver, VMT would continue into the future at its 1995 rate. Only changes in those determinantsof VMT, or any added time trend, will affect VMT in future years.

As explained in Section 7.2, the final VMT regressions generally were very good in terms of showing significant relationships of the expected signs of independent variables, and even explanation of the variance in VMT, considering the individual survey character of the data. Nevertheless, some of the coefficients for individual variables for specific age/gender groups showed non-significant relationships or relationships that were significant but of unusual magnitude. Rather than project VMT using these coefficients mechanically, we altered some of the coefficient values, which can be identified in the "Adjß" column of Table 7.1. Where possible, we used information from regressions estimated under different specifications when searching for a significant coefficient value to use in place of a non- 
significant one in the final set of regressions. When we decided to not accept a significant coefficient value (as in the cases of the odd income effect for men and women over 85), or when no significant value was obtained in any regression, we looked for patterns of magnitudes across age groups and endeavored to use a magnitude that fit into such a pattern. Because of these substitutions, there are no consequences to any unusual coefficients found in the regressions.

Of particular importance among the altered coefficients is the exogenous growth factor (the time trend variable), which incorporates historical increases in VMT caused by factors unaccounted for in the model. Linear extrapolation of historical growth trends is a notoriously unsatisfactory projection procedure since it presumes previous behavior will continue unchanged throughout the future. Therefore, the value of the time trend coefficient was modified in the projection to be that valuewhich would restrict the 2025 VMT for the age group consisting of 65 to 69 year-olds to the approximate levels that same group traveled as 35 to 39 year-olds in 1995. Our reasoning is that since VMT requires people to use their time, and total time available is limited, there is some upper limit to VMT as long as average travel speeds do not increase. Some ITS innovations could yield modest increases in average travel speeds, but the growth of population and natural restrictions on the increase of lane mileage can be expected to limit any such increases. In the absence of firm knowledge regarding the maximum amount of time the American population is willing to spend traveling, we take the age group with the current greatest average VMT as representing the plausible maximum time people can be expected to spend traveling in the future. It could be argued that the elderly in the future (this very cohort, in fact, displaced twenty years into their future) would be unwilling to spend as much time driving as they did when they were twenty years

\footnotetext{
${ }^{4}$ The importance of time in the demand for VMT goes back to the household production aspect of that demand. It takes time to consume most goods. Time is a major input to VMT, and time spent traveling is a major allocation of Americans' time budgets today. It may be intuitive to think of the demand for VMT as reflecting the number of destinations for which people have a demand to reach, but when the total time spent traveling during the week reaches some number of hours-we do not have an empirical clue to what that number of hours actually is - people will begin to think twice about the "necessity" of some of their proposed, or even their traditional, destinations; they will combine some trips (trip chaining), postpone others, and possibly even drop some. While people may think in terms of destinations, their travel behavior is equally powerfully conditioned by the constraints on their time.
} 
younger. In that case, our VMT projections can be considered as a maximum likely scenario. However, in light of all the changes in the past twenty years in characteristics of drivers, employment, technology, and infrastructure, we are unable to derive a satisfactory, purely empirical estimate of how much time the future elderly will devote to driving. Hence we suggest that a healthier and wealthier elderly population driving in safer vehicles on improved highways and possibly greater distances with urban sprawl might devote as much of their time to driving as they did when they were thirty years younger, but probably not more. This maximum level of VMT allows for expected growth in the demand for VMT for specific age/gender groups while maintaining a reasonableness in the projections. While this anchors the maximum likely driving by the 65-69 age cohort in 2025 , the proportional decreases in driving among older cohorts at that date depend strictly on the proportionalities in the

\footnotetext{
${ }^{5}$ Modeling the demand for VMT with a linear regression may inadequately capture the effects of the time it takes to travel. A person's time is, of course, limited to twenty-four hours in a day, and people typically devote blocks of time to particular types of activity: sleep, work, eating, recreation, and so on. The fact that driving takes time puts an upper limit on the amount of VMT that a person would demand, regardless of his or her income. Modeling the demand for and supply of VMT simultaneously, in a household production framework, as we suggested above would be an excellent procedure, could account for the increasing scarcity value of a person's driving time as VMT increased, imposing a cap on VMT naturally, according to the valuation a person puts on his or her time. As the valuation of the time spent driving increases as more VMT is undertaken, the cost of VMT will rise considerably, choking off thedemand for it. It may be possible to develop some other methods to account for the increasing effective cost of time made available to driving which would be less demanding of data. It would not be appropriate to simply reduce the magnitudes of the income elasticities of demand for VMT estimated in our ordinary least squares regressions on the grounds that the negative effect of income on VMT, acting as the cost of driving time, is excluded, because our current specification may be allowing some part of the negative component to enter the currently estimated coefficient.

In the present research, we did not have the data to implement any form of a natural capping of the demand for VMT, hence our resort to the arbitrary capping of VMT for 65-69 year old males at the maximum VMT of any age group in 1995, which happened by circumstance to be 35-39 yearolds. Picking the VMT of any other particular age group might have been preferable in some intuitive sense, but not in any empirically determinable manner; since our admittedly arbitrary method of capping the VMT projection uses only one arbitrary decision, we consider it preferable to picking a specific age group's VMT as a cap without reason to prefer that group over any other, which would involve at least two arbitrary decisions.

We are aware of one study that has addressed the demand for VMT as a household production problem, although less than fully satisfactorily. Greening et al. estimated the demand for fuel efficiency in vehicles, gasoline, and vehicle mile traveled with the seemingly unrelated regressions technique (a Generalized Least Squares technique for use in equations with correlated error terms but not with endogenous variables of one equation used as independent variables in another equation). Income appears as an independent variable in all three of their equations, but it never appears in an equation as an indicator of the cost of time spent driving. Hence there remains a specification problem in their implementation of the household production approach to estimating the demand for VMT.
} 
empirically derived regression coefficients, and similarly with the rate of growth of VMT for each age group over the period 2000 to 2025.

The income, health status, other driver, and employment status variables, and the year trend were projected identically to their projections for the proportion of elderly that drives. The year trend variable was a simple count, beginning with $1977=1$ and increasing by one in each subsequent year.

We present the projections of VMT in several formats. We offer a graphical presentation of aggregate national projections of VMT per capita, by age and gender, in Figure 7.3. The numbers underlying the graphs are contained in the tables of Appendix A, Tables A.1.1 through A.1.4, which present Census region as well as national projections. In a pattern of tabular presentations that will carry through each of our projections, the first pair of tables presents projections for males, the second for females. In each pair of tables by gender, the first (Tables A.1.1 and A.1.3 for VMT) presents the actual mileage projections and the second (Tables A.1.2 and A.1.4 for VMT) presents those projections as percents of 1995 actual levels.

The national average VMT for the groups of elderly men are projected to rise by 27\%-51\% over their 1995 levels. VMT in the 65-69 group is projected to experience the largest increase, rising from around 12,400 miles per year in 1995 to a projected 18,800 by 2025. The oldest age group of men, those $85+$, experience the smallest increase, from around 5,100 miles in 1995 to 6,500 in 2025 . The 2025 VMT projection drops off rather sharply as we move to the 70-74 group of males, with a projected 13,700 miles in that year, while the 75-79 group is close behind with 12,700 projected miles. The drop-off is sharp again as we move to the 80-84 group, with some 8,600 projected miles in 2025. Table A.1.2 presents these mileages as percents of 1995 actual mileage.

The elderly women begin from a much smaller base of VMT in 1995, but have greater relative projected increases than men in each age group. The 65-69 women are projected to 
reach a national average of nearly 11,300 miles, $93 \%$ above their 1995 average. The $85+$ group is projected to increase its VMT by nearly 78\% over 1995 levels, to over 4,900 miles per person in 2025. The smallest increase for any age group is 70\% over the 1995 level, among the 75-79 group. These increases put the women's groups' VMT by 2025 at levels approximating the VMT of the corresponding groups of men in 1995.

The regional patterns of increase are generally not uniform. That is, a percent increase higher than the national average in the VMT of one age group does not necessarily imply that VMT of all age groups in that region will grow more rapidly than the national average. Having offered that rule of thumb, however, VMT growth for all age groups of men in the West and women in the Midwest is lower than the national average, and not simply because their starting (1995) levels were all higher than the national average. ${ }^{6}$ Projected VMT growth for the youngest group of elderly men, the 65-69 year olds, is greatest in the Midwest and least in the South, although the differences of 53\% over 1995 levels in the Midwest contrasted with only $48.3 \%$ in the South are not terribly great. The oldest men's VMT is projected to grow the most in the South (32.8\% over 1995 levels) and the least in the West (23.6\%). Among women, the greatest projectedVMT growth for 65-69 women occurs in the West (96.0\% over 1995) and the lowest in the Northeast and South (88.5\% and 89.6\%). Among the oldest women, the 85+, the greatest growth occurs in the South $(77.0 \%)$ and the lowest in the West (64.9\%).

\footnotetext{
${ }^{6}$ Only in the South were 1995 VMT levels higher than the national average for each male age group; no region had 1995 VMT uniformly lower than the national average. Among the elderly women, no region had either higher- or lower-than-national-average VMT in 1995 in all age groups.
} 


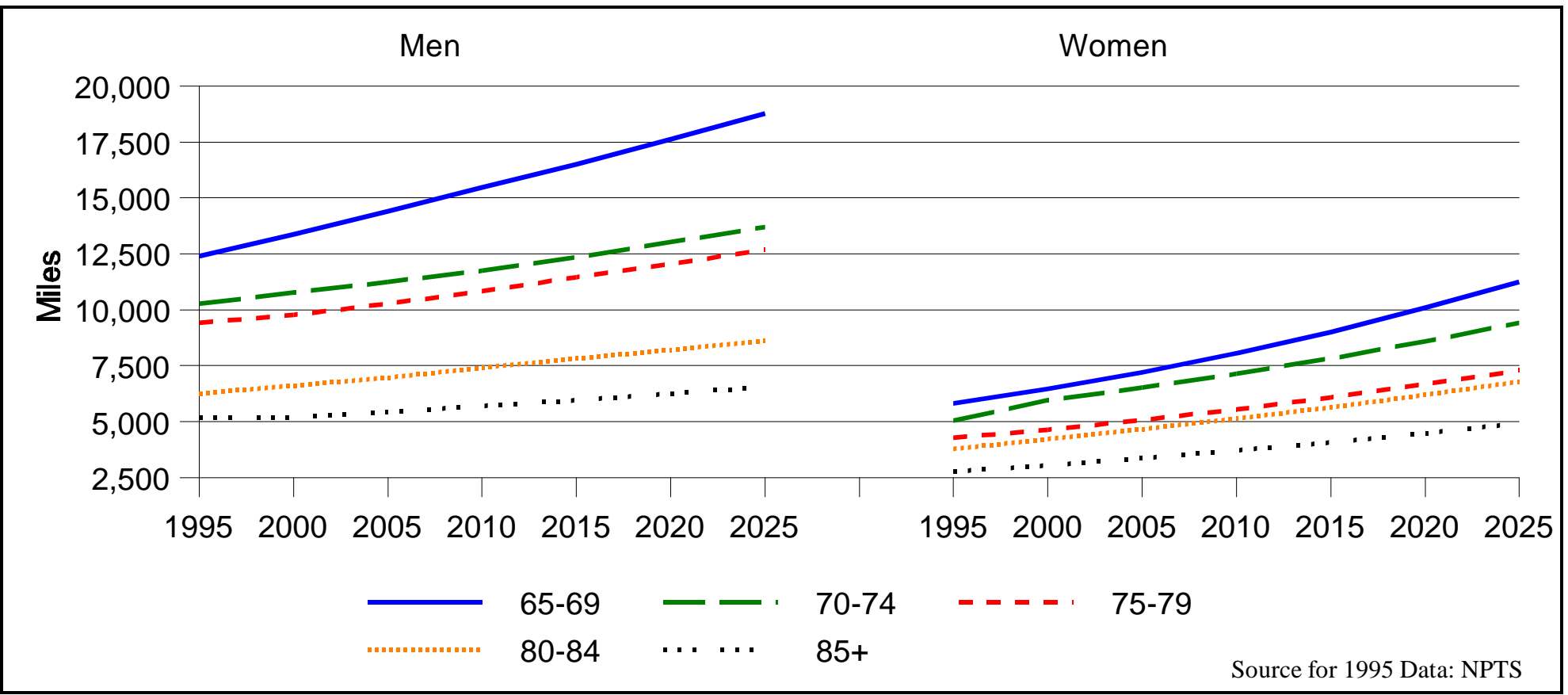

Figure 7.3. Annual Projected Vehicle Miles of Travel Per Driver 
Three forces are actually operating in the projections of VMT, in the sense that their values are changing over the projection period relative to their 1995 values: income, labor force participation (LFP), and the pure time effect. The contributions of these three forces differ between men and women, among age groups, and between regions, as shown in Tables 7.2 and 7.3. These contributions reflect both the sensitivity of the driver percentage to the variable in question, as determined empirically in the regression, and the projected growth of each independent variable. ${ }^{7}$

Among 65-69 year old men, changes in the proportion of households participating in the labor force contributes the largest proportion of projected VMT growth. The pure effect of time, dampened as it has been between the original regressions and the projections, contributes the second-largest growth to this age group. Income contributes the least, accounting for between 22 and $27 \%$ of the increase in mileage. Among most of the older age groups, the pure effect of time contributes the most mileage growth. Income has the largest effect among 75-79 and 80-84 men in the South. In these older groups, the contribution of income growth usually exceeds the contribution of LFP growth, and the differential increases with age, as is reasonable to expect. In the oldest age groups in all regions, LFP growth has no effect because its projection coefficient was zero.

Table 7.2. Determinants of Projected National VMT Growth, 1995-2025

\begin{tabular}{|cccc|rcc|}
\hline \multicolumn{3}{|c|}{ Men } & \multicolumn{3}{c|}{ Women } \\
\hline Age & Income & $\begin{array}{c}\text { Employment } \\
\text { status }\end{array}$ & Time & Income & $\begin{array}{c}\text { Employment } \\
\text { Status }\end{array}$ & Time \\
\hline $65-69$ & $24.23 \%$ & $39.62 \%$ & $36.15 \%$ & $13.75 \%$ & $18.46 \%$ & $67.42 \%$ \\
$70-74$ & $24.64 \%$ & $20.02 \%$ & $55.34 \%$ & $10.07 \%$ & $17.78 \%$ & $72.27 \%$ \\
$75-79$ & $39.90 \%$ & $8.76 \%$ & $51.34 \%$ & $10.23 \%$ & $7.47 \%$ & $82.23 \%$ \\
$80-84$ & $44.01 \%$ & $9.38 \%$ & $46.61 \%$ & $12.66 \%$ & $7.45 \%$ & $79.68 \%$ \\
$85+$ & $42.25 \%$ & $0.00 \%$ & $57.75 \%$ & $11.25 \%$ & $7.51 \%$ & $80.85 \%$ \\
\hline
\end{tabular}

\footnotetext{
${ }^{7}$ The method of assessing these contributions is to take the total differential of the VMT regression equation to obtain the expression for each variable's percent contribution to the value of the dependent variable. The differentials of the dependent and independent variables were the differences between their 2025 projected values and their 1995 actual values. The estimated regression coefficients form the basis of the coefficients on the individual contribution terms.
} 
Table 7.3. Determinants of Projected Regional VMT Growth

\begin{tabular}{|c|c|c|c|c|c|c|}
\hline \multirow{2}{*}{ Midwest } & \multicolumn{3}{|c|}{ Men } & \multicolumn{3}{|c|}{ Women } \\
\hline & & & & & & \\
\hline Age & Income & Employment & Time & Income & Employment & Time \\
\hline $65-69$ & $27.05 \%$ & $38.18 \%$ & $34.77 \%$ & $13.40 \%$ & $18.68 \%$ & $67.91 \%$ \\
\hline $70-74$ & $20.01 \%$ & $21.30 \%$ & $58.68 \%$ & $8.02 \%$ & $18.19 \%$ & $73.79 \%$ \\
\hline $75-79$ & $26.22 \%$ & $10.79 \%$ & $62.99 \%$ & $6.24 \%$ & $7.79 \%$ & $85.97 \%$ \\
\hline $80-84$ & $36.30 \%$ & $10.62 \%$ & $53.07 \%$ & $11.98 \%$ & $7.54 \%$ & $80.48 \%$ \\
\hline $85+$ & $44.07 \%$ & $0.00 \%$ & $55.93 \%$ & $11.55 \%$ & $7.58 \%$ & $80.88 \%$ \\
\hline \multicolumn{7}{|l|}{ Northeast } \\
\hline Age & Income & Employment & Time & & & \\
\hline $65-69$ & $24.11 \%$ & $39.72 \%$ & $36.17 \%$ & Income & Employment & Time \\
\hline $70-74$ & $19.92 \%$ & $21.34 \%$ & $58.74 \%$ & $9.61 \%$ & $17.82 \%$ & $72.57 \%$ \\
\hline $75-79$ & $34.31 \%$ & $9.63 \%$ & $56.06 \%$ & $10.74 \%$ & $7.43 \%$ & $81.83 \%$ \\
\hline $80-84$ & $34.33 \%$ & $10.94 \%$ & $54.73 \%$ & $8.93 \%$ & $7.80 \%$ & $83.26 \%$ \\
\hline $85+$ & $41.12 \%$ & $0.00 \%$ & $58.88 \%$ & $10.95 \%$ & $7.63 \%$ & $81.43 \%$ \\
\hline \multicolumn{7}{|l|}{ South } \\
\hline Age & Income & Employment & Time & Income & Employment & Time \\
\hline $65-69$ & $22.14 \%$ & $40.76 \%$ & $37.10 \%$ & $13.06 \%$ & $18.76 \%$ & $68.18 \%$ \\
\hline $70-74$ & $30.30 \%$ & $18.60 \%$ & $51.10 \%$ & $12.30 \%$ & $17.23 \%$ & $70.47 \%$ \\
\hline $75-79$ & $46.28 \%$ & $7.89 \%$ & $45.83 \%$ & $12.81 \%$ & $7.25 \%$ & $79.94 \%$ \\
\hline $80-84$ & $55.26 \%$ & $7.50 \%$ & $37.24 \%$ & $14.75 \%$ & $7.30 \%$ & $77.95 \%$ \\
\hline $85+$ & $47.96 \%$ & $0.00 \%$ & $52.04 \%$ & $15.29 \%$ & $7.26 \%$ & $77.45 \%$ \\
\hline \multicolumn{7}{|l|}{ West } \\
\hline Age & Income & Employment & Time & Income & Employment & Time \\
\hline $65-69$ & $24.75 \%$ & $39.39 \%$ & $35.86 \%$ & $16.92 \%$ & $17.94 \%$ & $65.14 \%$ \\
\hline $70-74$ & $21.61 \%$ & $20.88 \%$ & $57.51 \%$ & $7.73 \%$ & $18.23 \%$ & $74.03 \%$ \\
\hline $75-79$ & $41.11 \%$ & $8.63 \%$ & $50.26 \%$ & $9.41 \%$ & $7.54 \%$ & $83.06 \%$ \\
\hline $80-84$ & $39.83 \%$ & $10.04 \%$ & $50.13 \%$ & $13.27 \%$ & $7.43 \%$ & $79.29 \%$ \\
\hline $85+$ & $30.45 \%$ & $0.00 \%$ & $69.55 \%$ & $3.47 \%$ & $8.26 \%$ & $88.27 \%$ \\
\hline
\end{tabular}

The time trend accounts for the greatest proportion of VMT growth by far among women in all age groups and regions. In the 70-74 and 75-79 age groups, LFP growth contributes more to VMT growth than does income, but those relative proportions reverse in the two oldest age groups. In the 85+ age groups, other-driver growth continues to contribute to VMT growth between half and three-quarters the mileage income growth contributes with the exception of the West, where the proportions are reversed between income and LFP. 
The magnitude of what we call "the pure effect of time" for want of a more precise term is striking. This effect is a combination of technological and institutional changes, and its magnitude reflects the relative contribution of this set of factors to VMT growth in the recent past. Even though we have dampened the strength of this effect from what it would have been with a linear extrapolation, its contribution is still large. One implication of this result is that if one finds our VMT projections unbelievably high, it is possible to lower them without altering the effects of either income growth or changes in elderly labor force participation, although such changes would imply particular beliefs about the progress and consequences of future technological and institutional change. 


\section{FATAL CRASH RATES}

\subsection{MODELING FATALITY RATES FOR OLDER DRIVERS}

Data limitations impeded direct, reliable observation of all accidents, but accidents in which a fatality occurs are reported considerably more thoroughly and consistently than crashes not involving a fatality. Accordingly, our principal measure of fatalities is older driver fatalities, meaning the exact number of older drivers killed in accidents. We also developed another fatality measure which captured the total number of deaths involved in crashes involving an older driver, but its interpretability lacks clarity because of insufficient information on assignment of fault in crashes.

The first of the two fatal crash rate concepts we call "driver risk," or the driver fatality rate. It is the fatality rate, per mile driven, of older drivers alone, regardless of any other deaths that occur in a crash involving an older driver. The driver fatality risk rate is measured by dividing the number of older drivers in a given age-gender-region group killed in automobile accidents by the number of miles driven in a year for the particular group of drivers. This rate is essentially the number of annual driver fatalities per mile driven. Because of the VMT magnitude, these rates are presented in terms of number of annual fatalities per 100 million miles driven.

Figure 8.1 shows that almost all of the rates of elderly "driver risk" have been declining over time, with the exception of men between 80 and 84 years old. The biggest declines are found in the groups with the highest historical risk - those persons over the age of 85 . Figure 8.2 illustrates that those elderly persons in the South generally have a higher risk than those in other regions of the country. 


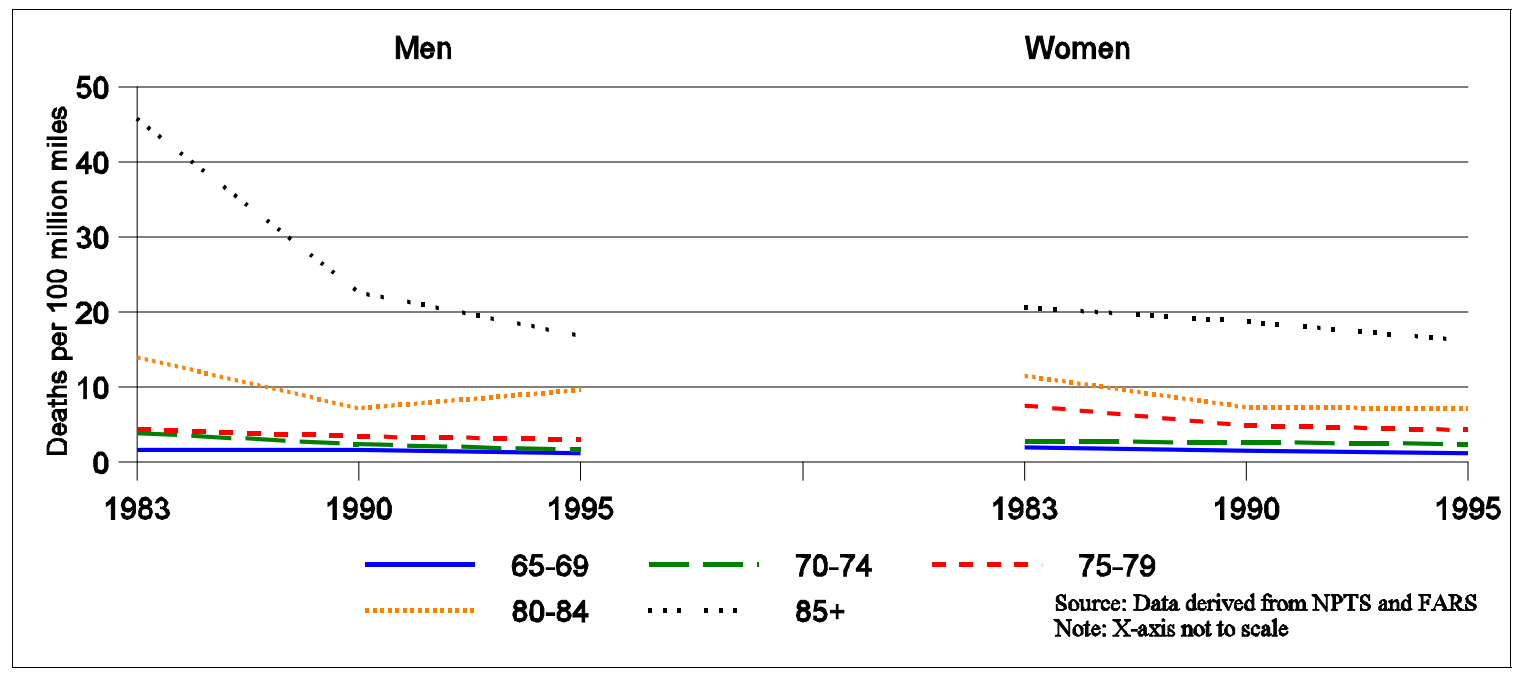

Figure 8.1. Historical Elderly Driver Fatality Rate By Age (deaths per 100 million miles)

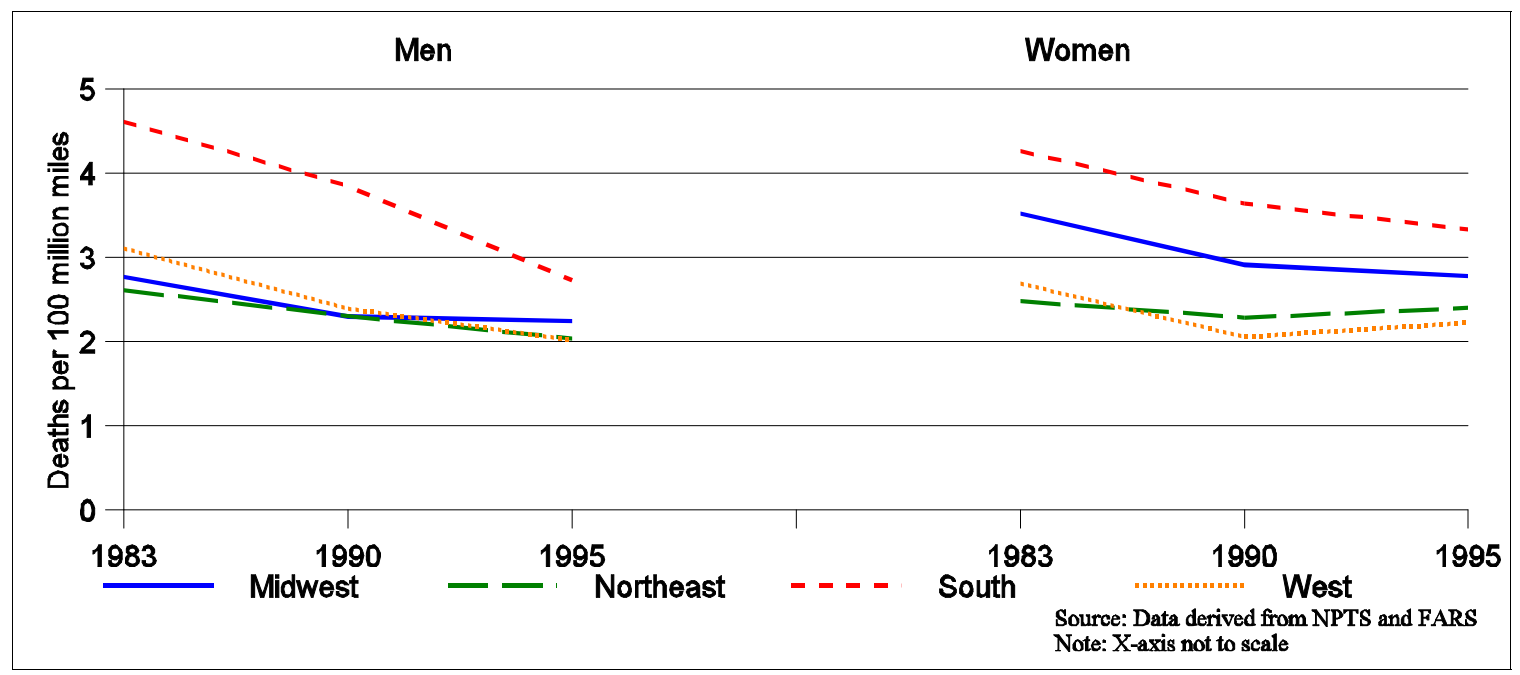

Figure 8.2. Historical Elderly Driver Fatality Rate By Region (deaths per 100 million miles) 
The other fatality risk concept we project is the "total fatality crash rate," which is the total number of fatalities, regardless of age or occupant status, associated with a crash in which at least one older driver is involved. The rate of total fatality risk is measured in a more complex fashion than the driver crash rate. Each driver in a fatal crash which involves an older driver is assigned equal responsibility for each fatality. Then, the sum of the fatalities attributed to each driver is found for a driver's age-gender-regiongroup. For example, if a crash involving three fatalities occurs between a man aged 65 and a woman aged 72, 1.5 fatalities would be attributed to the 65-69 age group for men, and 1.5 fatalities would be attributed to the 70-74 age group for women, both in the respective region of the accident. If a two-vehicle crash involving a 67 year old woman and a 45 year old man resulted in four deaths, two of them would be attributed tothe 65-69 female age group, and two would be excluded from the measure as attributable to an age group outside the study. In assigning responsibility in general, an individual older driver's contribution to age/gender/region total equals the number of fatalities divided by the number of drivers involved. The total number of fatalities attributed to each age-gender-region group is then divided by the annual number of aggregate miles driven in that group, in similar fashion to the driver fatality risk measure. Total fatality risk is also presented in terms of number of annual fatalities per 100 million miles driven. Historical trends in our measure of "total risk" mirrored trends in the "driver risk" measure.

The casualty data from the 1983, 1990, and 1995 FARS were used. FARS reports information on fatal crashes by state, disaggregated by age in one-year increments and by gender. We aggregated the individuals to 5-year age groups and the states to Census regions. Corresponding variables on income, health status, VMT, etc., were created as age/gender/region averages from NPTS and NHIS data.

The availability of automobile seat belts, beginning in the 1960s and growing relatively slowly until well into the 1970s, represents one independent variable used in this equation. Seat belt use can be viewed as an indicator of technology that shifts the degree of safety 
available, given income and an array of related prices. This effect on safety, as proxied by the seatbelt usage variable, was the same for all people at any given time. The income effect on safety choices had a differential effect across individuals both at any point in time, as individuals (actually groups in the aggregation required for this regression) with higher incomes purchased vehicles that provide greater safety at a given time, and over time, as the general level of incomes for all people rose, leading themto choose greater levels of safety across the board.

Empirical evidence indicated that regional effects were important as well, so presence in one of the four Census regions was also used as a set of binary variables. Seat belt use and time were highly correlated, as is to be expected with the market penetration of this innovation, along with the passage of legislation mandating seatbelt use. We experimented with combinations of one of the two variables and the residual of the regression of the other variable on the variable entered in untransformed version. The final version of the model interacted seatbelt use with age, ${ }^{1}$ but the residual of the regression of time on seat belt use as a variable was never significant. Consequently, we excluded time from both estimated models. Interacting seatbelt use with age permits the identification of differential effectiveness of seatbelt use in preventing fatalities across age groups.

Thus the full array of independent variables for this equation included income, health status, seat belt use, age, gender, and time. As we explain below, we did not use all of these variables in the final estimation used in the projection model. The smaller sample size available for these models forced several choices between variables that, in a more perfect world, would have been retained in the regression model. We estimated this regressiorfor all age groups and both genders, but we accounted for individuals' 5-year age groups and gender with binary variables instead of estimating separate regressions. The effect of seat belt use was virtually identical between men and women, so the gender-seat belt interaction was

\footnotetext{
${ }^{1}$ That is, a separate variable was created for seatbelt use for each of our 5-year age groups: e.g., a variable for seatbelt use among 65-69 year olds, another for 70-74 year olds, etc.
} 
dropped. Since these measures have asymptotic minima at zero (in practice, probably well above zero: the fatal crash rates cannot fall below zero andare unlikely in practice to reach zero), we again chose the logistic specification for the regression equations.

Income had a highly statistically significant relationship with the fatality rate (significant at $1 \%$ ), indicating that people with higher income were purchasing more safety. One such route is in the form of newer vehicles, which are more likely to have the most current safety technology incorporated into them. Other routes, such as more careful driving and ability to drive at less dangerous times of the day, are more open to debate and should be subjected to more direct, empirical examination. Income also affects the fatality rate in that individuals with higher incomes are generally healthier to begin with, and may receive better health care after a crash. This point is expanded upon later in the report.

The health status variable, either as a direct variable or as a residual from the regression of health status on income, had a positive relationship with the older driver fatality rate, and it substantially reduced the significance of income. The expectation for that variable was that it represented a measure of capacity for driving and should have a negative relationship to the crash rate. The only apparent explanation for a positive relationship is that people with greater physical limitations drive more carefully and actually overcompensate for their disabilities. While this explanation could be the case, it seemed like any extraordinarily conscientious driving could easily be mitigated by slower reaction time. The health status variable has been rather problematic, in terms of the data within the NHIS being able to explain only small proportions of the variance in that measure, through its transfer via model coefficients from the NHIS to the NPTS, and finally to its aggregation to Census region averages with the values calculated from the NPTS. Thus, we prefer to suggest that we simply do not understand the negative health coefficient. The crash rates projected with and without the health status variable are not vastly different, so we preferred to use the model without health status for the projections. 
We did not include employment status in the crash rate models because it was not expected to exert an influence on crash rates, or fatal crashes per mile driven. Of course, being in the labor force is likely to put a person on the road more than not being employed, but that should have affected the total number of fatal crashes, not the rate. Accordingly, the employment status effect exerted its influence on total fatal crashes through its effect on VMT.

The final logistic regression specification is as follows:

Prob (driving a mile with an older driver fatality) $=\left(1+\mathrm{e}^{-\mathrm{Z}}\right)^{-1}$,

where $\mathrm{Z}=$ constant $+\mathrm{a}_{1} \log ($ income $)+\mathrm{a}_{2}($ age $)+\mathrm{a}_{3}($ seat belt use $*$ age $)+\mathrm{a}_{4}($ region $)$.

The regression equation used as independent variables income, the categorical 5-year age variable; seat belt use interacted withage (meaning that the effect of seat belt use varies with age), and Census region dummy variables. The regression also included dummy variables to account for specific age/gender/region groups that did not adhere to general age, gender, or region effects. We did not estimate separate regressions for age, gender, and region because of the small sample size available for this model-120 observations in contrast to several thousand for the VMT and driver models.

Table 8.1 reports the regression model for the elder driver crash rate. All variables but two region dummy variables and one region/gender/age dummy variable indicated strong statistical relationships. The income coefficient of the driver crash rate was negative, as theory leads us to expect, and was of substantial size at 0.46. As in the logistic regressions modeling the probability of continuing to drive, this 0.46 means that for each additional one unit of $\log ($ income $)$, the logit function, $\mathrm{Z}$ in equation (3), increases by 0.46 . The seatbelt effectiveness variables also had the anticipated effect of decreasing the fatality rate, but do not 
have a regular pattern over the age groups. The effectiveness of the protection given by seatbelt usage was greatest for people in the 85+ age group, as might be expected, with a coefficient of -1.36 . This coefficient of -1.36 means that, for those 85 and olderonly, each one unit increase in the seatbelt rate will decrease the logit function by 1.36 . The coefficients for the $65-69,75-79$ were virtually the same size, -0.63 , and that for the $80-84$ group is quite close in magnitude, -0.57 . The effect for the 70-74 group was intermediate in magnitude at -1.01. The age dummy variables indicated that as age increases, so does the risk of being involved in a fatal crash. Regional variables showed no relationship between the Midwest and Northeast regions and the fatality rate, but the fatality rate in the southern Census region was somewhat higher than in other regions. The southern regional dummy variable added 0.30 to the overall intercept term of -10.01 , not an especially large effect but a statistically significant one. Several other interacted dummy variables also captured differential fatality rates: the rate for western males in the $85+$ age group rose over time, $85+$ women in the South and West had a slightly lower fatality rate, and 80-84 men in the South a slightly higher rate. Women in the 80-84 age group in the Northeast had a small, statistically weak, negative differential in their fatality rates.

Table 8.1. Driver Crash Rate Regression

\begin{tabular}{|lrr|}
\hline & \multicolumn{1}{c}{$\beta$} & Prob ? \\
\hline Intercept & -10.0123 & 0.0001 \\
log (income) & -0.4620 & 0.0001 \\
Sb*age65 & -0.6255 & 0.0001 \\
Sb*age70 & -1.0080 & 0.0001 \\
Sb*age75 & -0.6279 & 0.0001 \\
Sb*age80 & -0.5729 & 0.0001 \\
Sb*age85 & -1.3596 & 0.0001 \\
Age65 & -3.0419 & 0.0001 \\
Age70 & -2.4238 & 0.0001 \\
Age75 & -2.1552 & 0.0001 \\
Age80 & -1.4633 & 0.0001 \\
Midwest & -0.0305 & 0.3974 \\
Northeast & -0.0601 & 0.1148 \\
South & 0.3005 & 0.0001 \\
W 85 M * time & -0.0303 & 0.0023 \\
NE 80 F & -0.1714 & 0.1567 \\
S 85 F & -0.4718 & 0.0001 \\
W 85 F & -0.5550 & 0.0003 \\
S 80 M & 0.4098 & 0.0001 \\
\hline
\end{tabular}


Table 8.2 reports the regression results for the model of the total fatal crash rate. The total fatal crash rate is far more complex than the total driver fatality rate. Thus, while a factor such as income of the driver in the elder driver fatal crash rate is directly relevant, it is not clear whose income would affect the total crash rate: the elder driver, who may or may not have died in the crash, a passenger who died in any of the vehicles involved, or the nonelder driver of another vehicle. The only information we have is the income of the elder driver involved in the crash, and he or she may not be the fatality. Consequently while the income of the elder driver involved in the crash may affect his or her safety, other people are involved, and we do not have the data to model the choices that led them to be on the scene. Thus the appropriateness of the income of the elder driver in one of these crashes is open to question. Not surprisingly, income performed oddly in these regressions, obtaining positive and significant regression coefficients. Our lack of understanding as to why higher income would lead to a higher probability of total fatal crashes in an age/gender population led to our omission of the variable from the regression specification. Thehealth status variable also had a positive significant regression coefficient when used in the same regression with income of the elder driver involved. Not understanding why superiorhealth status would lead to a higher fatal crash rate, we also omitted that variable from the specification. While higher levels of income and better health status may increase the total number of fatalities through increased VMT and increased probability of driving, there is no directly logical effect of these two variables on the total fatality rate per mile driven.

Altogether, it was not clear that variables thought to influence individual choices should be in this regression. Accordingly, the regression model for total fatal crash risk contains only age and region dummy variables, the seatbelt variable interacted with age to account for the differential frailty of elderly persons of different ages, and some more specific age/gender/region interacted dummy variables to account for idiosyncratic effects in the aggregate crash statistics. Nevertheless, no differentials on the basis of gender alone were found, so the only gender dummy variables used were those interacted with the occasional age group and region. 
Table 8.2. Total Risk Crash Rate Regression

\begin{tabular}{|lrr|}
\hline & \multicolumn{1}{c}{$\beta$} & Prob ? $^{2}$ \\
\hline Intercept & -14.6373 & 0.0001 \\
Age65 & -2.8306 & 0.0001 \\
Age70 & -2.1929 & 0.0001 \\
Age75 & -2.0658 & 0.0001 \\
Age80 & -1.1724 & 0.0001 \\
Midwest & -0.1186 & 0.0002 \\
Northeast & -0.1213 & 0.0008 \\
South & 0.2505 & 0.0001 \\
Sb*age65 & -0.7053 & 0.0001 \\
Sb*age70 & -1.2005 & 0.0001 \\
Sb*age75 & -0.6562 & 0.0001 \\
Sb*age80 & -0.7641 & 0.0001 \\
Sb*age85 & -1.5809 & 0.0001 \\
NE 80 M & -0.2824 & 0.0013 \\
S 80 85 F & -0.5416 & 0.0001 \\
W 85M*Time & -0.0329 & 0.0018 \\
W 65 F & -0.102 & 0.1840 \\
W 75 80 F & -0.2289 & 0.0018 \\
W 85 F & -0.7147 & 0.0001 \\
\hline
\end{tabular}

The great majority of the variables had an extremely highly significant effect on the total fatal crash rate. The age dummy variables indicate higher fatality rates for this measure in older age groups. As in the elder driver crash risk model, this measured rate was somewhat higher in the southern Census region, with a coefficient on the southern region dummy variable of 0.25 to be added to the general constant term of -14.64. Also as in the case of the driver crash risk, no clear age pattern emerged in the effect of seatbelt use, but the greatest effectiveness of seatbelt use also emerged for the 85+ and 70-74 age groups, as in the driver crash risk regression. And as in that other crash rate, the time trend on $85+$ men in the western Census region was negative.

We acknowledge that the use ofsimple crash per mile measures to characterize the risk facing drivers has been criticized on the grounds, among others, that the crashrate per mile does not appear to be constant for drivers who average substantially different annual mileages (Janke 1991). Janke notes that drivers with low annualVMT tend to have higher crash rates per mile than do drivers with high annual mileage, to a considerable extent because 
the low-mileage drivers are driving disproportionately on city streets as opposed to expressways. For example, crash rates per mile from California in the 1980s were 2.75 times as high on open-access streets as on expressways. One of the important implications of this empirical finding is that mileage by itself may not be a satisfactory measure of the exposure to crashes. For example, Janke notes that part of the linearly measured crash risk of, say, elder drivers should be attributed to where they drive, and only part of it to their age. Stratification of driver populations according to various criteria is one recommended strategy for reducing this nonlinearity in the mileage-accident relationship.

Our analysis of crash risk begins with a stratification of the elderly as opposed to all age groups and continues the stratification with the interacted age-seatbelt use variable, which permits crash risk to vary within elderly age groups. Data on the predominant use of one type of roadway were not available in observational units compatible with the state-wide FARS data used in the crash rate regressions. Even if such roadway data had been available, projecting the values of those variables (possibly as the percent of driving on one or the other type of roadway) to 2025 would have been a major challenge. Overall, we believe the combined effect of driver age and roadways driven in our measure of age-specific crash risk to be satisfactory: if older drivers tend to drive proportionally more on city streets than do mid-career drivers (ages 35-55) and consequently have higher crash rates per mile, that is an acceptable indicator of the crash rates expected for older drivers, even if some of the differential between their rates and those of younger drivers is attributable to driving location.

\subsection{FATAL CRASH RATE PROJECTIONS}

Two variants of older driver fatality rates, the older driver fatality rate and the total fatality rate from crashes involving an older driver, are projected with the originally estimated regression equation (3). Since the values both of these dependent variables can take are constrained (neither fatality rate can go below zero), it was necessary to retain in the 
projection the asymptotic behavior of the dependent variable imposed by the form of the equation. For projections of future years' values of the dependent variables, the projected levels of the independent variables were substituted into the respective logistic equations and the new values of the dependent variables calculated. We did not use the time trend in the projection of older driver fatality rates.

The projection of household income to support projection of both fatal crash rates was identical to its projection for the previous components. The age and region variables were dummy variables, and they simply took values of 1 in each projection year, to be multiplied by the estimated regression coefficients. This is also the case with the interacted dummy variables age/gender/region and West/men. The doubly interacted dummy variable West/male/year was projected as the time trend variable was projected, but only for the group of males in the western Census region. The seatbelt use variable was projected using predicted values of a regression on time of 1991-1996 NHTSA rates and the U.S. DOT's 2025 expected rate of use at 85\%, on time. Data were available from 1983-1996, but inconsistent data due to a change in methodology in 1991 required us to use only the 19911996 data and 2025 projection in the regression (Appendix B.2.5). The interaction of these projections with age used the same percent use with each age group but multiplied that usage by a separate regression coefficient in the projection.

Finally, the projection of the numbers of fatal crashes required the use of population projections, which were furnished by U.S. Census Bureau projections. The modification of total projected population by the fraction projected to be institutionalized (AHCA, taken from Statistical Abstract of the United States) yielded the projected non-institutionalized population. Projections of all other independent variables were embodied in the projections of the other components.

Figure 8.3 illustrates the projected decline in fatal crash rates among elderly drivers. One can observe that the oldest age group (85+) has the highest historical crash rates per 100 
million miles driven, with the 1995 national averages being 16.83 deaths per 100 million miles driven for men and 16.23 per 100 million miles driven for women. Additionally, the positive relationship between age and fatal crash risk holds for both genders and all regions. The oldest age groups have also had much sharper rates of historical decline in these rates than some of the younger elderly groups. Our projections reflect this information, with the oldest age groups declining at a much sharper rate (to 66\% of their observed 1995 rates in 2025) than the younger groups, which decline to around 85\% of their observed 1995 rates in the 2025 projections. These projected national trends are virtually identical between the two genders at the youngest (65-69) and oldest (85+) age groups, but vary to some degree among the middle groups, with men generally declining at a slower rate. Fatal crash rates among drivers were fairly consistent among regions, except for those drivers in the South, who had higher fatality rates across virtually all age groups and both genders. Tables A.3.1-A.3.4 in Appendix A show these age and regional differences in greater detail.

Our total fatality rate from crashes involving an older driver follows similar trends, with the oldest age groups having rates that start higher and drop relatively more dramatically than the youngest elderly age groups. We also see the same positive relationship between age and risk as we do in the fatal crash rate of drivers, as well as the similarity between genders. As with the driver fatal crash rate, southern men have higher absolute rates per 100 million miles than men in other regions. Tables A.5.1-A.5.4 in the Appendix show these differences in greater detail.

Income growth and projected growth in seatbelt use contribute roughly equally to these projected declines in driver risk ranging from around $60 \%-40 \%$ to $50 \%-50 \%$, depending on age/gender group. Tables 8.3 and 8.4 show these contributions at the national and regional levels. Differences are more substantial across age groups than between genders within any particular age group, primarily because the regression coefficient on the 


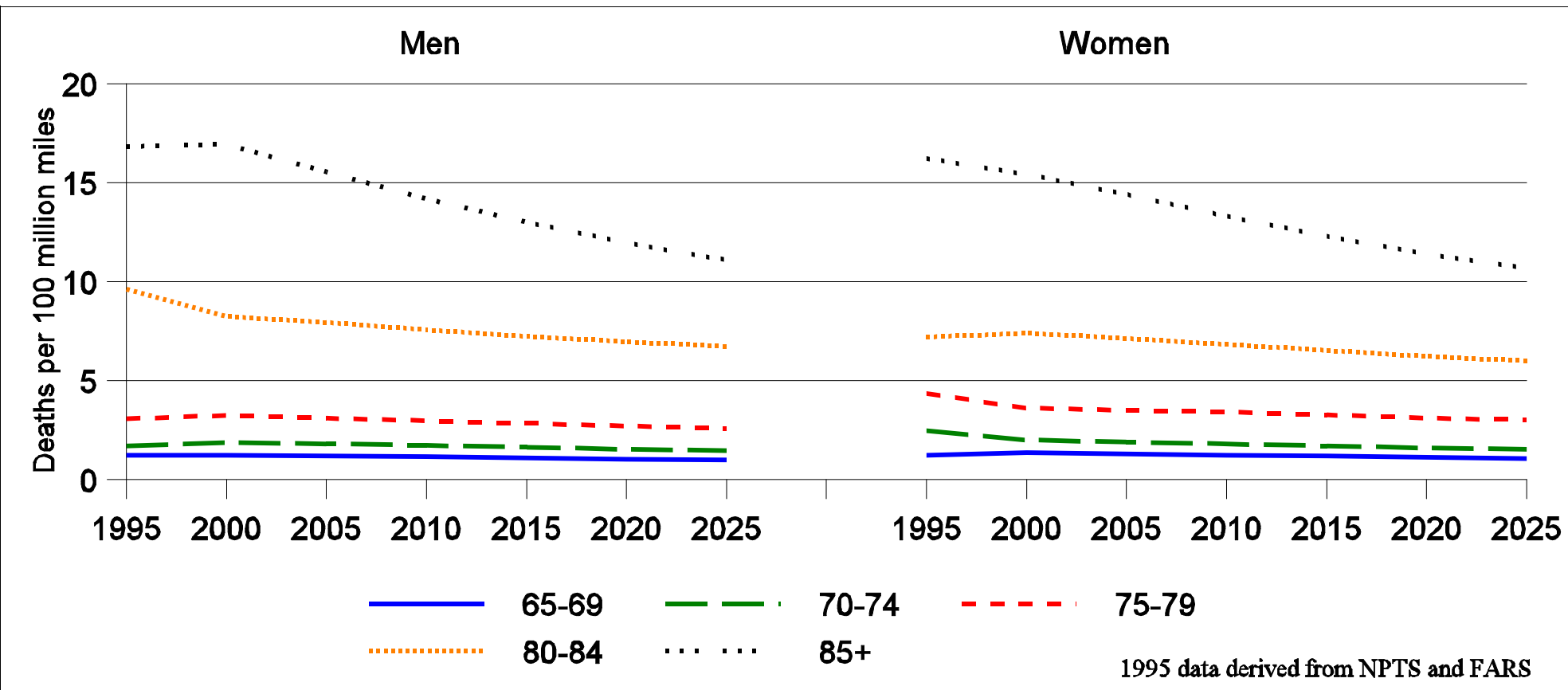

Figure 8.3. Projected Driver Risk By Age (deaths per 100 million miles) 
seatbelt use variable was invariant across gender. There is no smooth pattern of increase or decrease in the contribution of either variable as we move up the age groups. Among men, seatbelt use contributes the most among the $70-74$ and $85+$ groups, $60 \%$ to $63 \%$, and the least to decreases in driver crash risk among 65-69, 75-79, and 80-84 year olds, from $40 \%$ to $42 \%$. Growth in seatbelt use contributes the most to decreases in women's driver crash risk among the 65-69 year olds, around 37\%, the least among the 80-84 group, and at an intermediate level among the 70-74 and 75-79 year olds, at 55\% and $49 \%$.

Table 8.3. The Determinants of Projected Changes in Driver Risk, National Level

\begin{tabular}{|ccr|cr|}
\hline \multicolumn{3}{|c|}{ Men } & \multicolumn{2}{c|}{ Women } \\
\hline Age & Income & Seatbelt & Income & Seatbelt \\
\hline $65-69$ & $58.09 \%$ & $41.94 \%$ & $62.46 \%$ & $37.44 \%$ \\
$70-74$ & $39.92 \%$ & $59.90 \%$ & $44.13 \%$ & $55.78 \%$ \\
$75-79$ & $57.71 \%$ & $42.19 \%$ & $50.54 \%$ & $49.37 \%$ \\
$80-84$ & $59.19 \%$ & $40.68 \%$ & $62.40 \%$ & $37.40 \%$ \\
$85+$ & $37.17 \%$ & $62.93 \%$ & $38.69 \%$ & $61.42 \%$ \\
\hline
\end{tabular}

While seatbelt use is a traditional focus of concern, the substantial contribution of income growth to decreasing crash risk in these projections is importantas $40 \%$ to $60 \%$ of the decrease in this risk indicator is attributable to increasing income. Our modeling has not specified the routes of effect of higher real, elderly income, but we have pointed to the most likely possibilities as ability to afford safer equipment and generally higher valuation of safety which may spill over into driving practices as well as equipment purchases. Income and health are generally positively correlated, although in the regressions underlying these projections, better health, as measured by our indicator, would have elevated crash rates. The health-income-crash rate relationship needs further research.

Regional variations in the different variables' contributions to the crash rate decline are not as striking as they have been in some of the other projections, as Table 8.4 clearly shows. The seatbelt contribution to crash rate decline is largest among western women 85+, at $83 \%$ (followed by western men in the same age group, at $74 \%$ ), and the lowest is among 


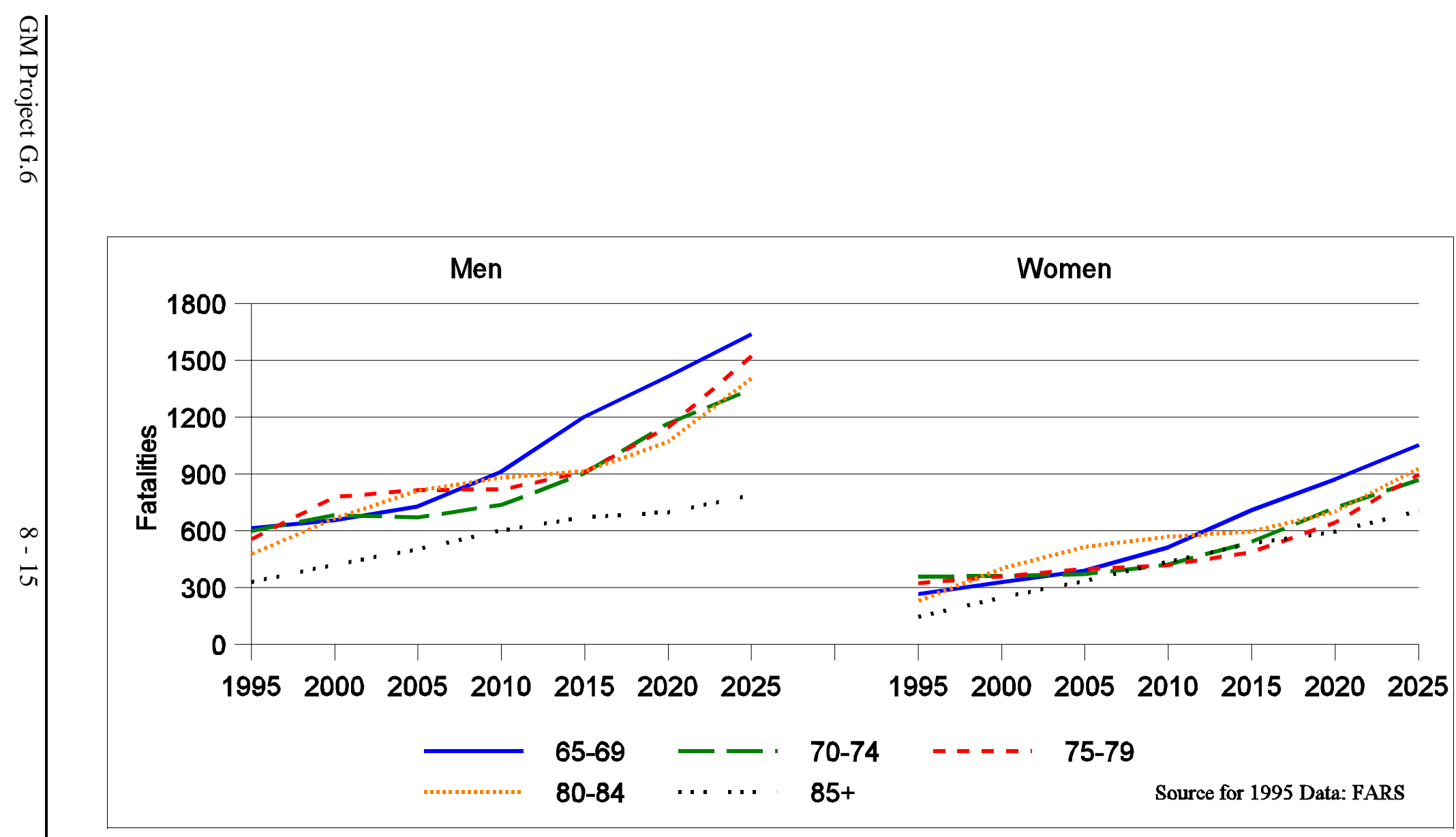

Figure 8.4. Projected Driver Fatalities By Age 
80-84 men in the South, at 30\%, accompanied by southern women $80-84$, at $31 \%$. Of course, these groups have the highest contribution of income to crash risk decrease.

Table 8.4. The Determinants of Projected Changes in Driver Risk, Regional Level

\begin{tabular}{|ccr|cc|}
\hline \multicolumn{3}{|c|}{ Men } & \multicolumn{2}{c|}{ Women } \\
\hline Midwest & & & \multicolumn{2}{c|}{} \\
\hline Age & Income & Seatbelt & Income & Seatbelt \\
$65-69$ & $61.78 \%$ & $38.22 \%$ & $62.62 \%$ & $37.38 \%$ \\
$70-74$ & $35.70 \%$ & $64.30 \%$ & $38.93 \%$ & $61.07 \%$ \\
$75-79$ & $45.01 \%$ & $54.99 \%$ & $39.55 \%$ & $60.45 \%$ \\
$80-84$ & $53.41 \%$ & $46.59 \%$ & $61.59 \%$ & $38.41 \%$ \\
$85+$ & $39.32 \%$ & $60.68 \%$ & $39.71 \%$ & $60.29 \%$ \\
\hline Northeast & & & \multicolumn{2}{|c|}{} \\
\hline Age & Income & Seatbelt & Income & Seatbelt \\
$65-69$ & $57.05 \%$ & $42.95 \%$ & $57.48 \%$ & $42.52 \%$ \\
$70-74$ & $33.33 \%$ & $66.67 \%$ & $43.96 \%$ & $56.04 \%$ \\
$75-79$ & $50.98 \%$ & $49.02 \%$ & $51.75 \%$ & $48.25 \%$ \\
$80-84$ & $51.51 \%$ & $48.49 \%$ & $51.63 \%$ & $48.37 \%$ \\
$85+$ & $35.65 \%$ & $64.35 \%$ & $39.48 \%$ & $60.52 \%$ \\
\hline South & & & \multicolumn{2}{|c}{} \\
\hline Age & Income & Seatbelt & Income & Seatbelt \\
$65-69$ & $55.81 \%$ & $44.19 \%$ & $61.79 \%$ & $38.21 \%$ \\
$70-74$ & $47.64 \%$ & $52.36 \%$ & $50.95 \%$ & $49.05 \%$ \\
$75-79$ & $67.31 \%$ & $32.69 \%$ & $58.91 \%$ & $41.09 \%$ \\
$80-84$ & $69.89 \%$ & $30.11 \%$ & $68.94 \%$ & $31.06 \%$ \\
$85+$ & $43.63 \%$ & $56.37 \%$ & $48.99 \%$ & $51.01 \%$ \\
\hline West & & & \multicolumn{3}{|c}{} \\
\hline Age & Income & Seatbelt & Income & Seatbelt \\
$65-69$ & $58.89 \%$ & $41.11 \%$ & $68.60 \%$ & $31.40 \%$ \\
$70-74$ & $37.82 \%$ & $62.18 \%$ & $37.70 \%$ & $62.30 \%$ \\
$75-79$ & $62.52 \%$ & $37.48 \%$ & $47.11 \%$ & $52.89 \%$ \\
$80-84$ & $55.58 \%$ & $44.42 \%$ & $63.81 \%$ & $36.19 \%$ \\
$85+$ & $25.73 \%$ & $74.27 \%$ & $16.70 \%$ & $83.30 \%$ \\
\hline
\end{tabular}

\subsection{DRIVER FATALITY PROJECTIONS}

The total number of driver fatalities, represented in Figure 8.4 and presented in greater detail in Tables A.4.1-A.4.4 in the appendix, is projected to increase in a less stable way. This is due to the conflicting influences of increased population, VMT, and 
percentages of people driving, and decreases in the fatal crash rate of drivers. For male older drivers aged 65-69, the number of annual driver fatalities is projected to increase $166.6 \%$, from 614 to 1637 . For females of the same age group, fatalities are projected to increase by $294 \%$, from 267 to 1051 . This greater increase is due in large part to greater projected increases for women in VMT and the percent of women who drive. Note that, although the rate of increase in the number of fatalities is expected to be higher for women during 19952025 , the absolute number of female driver fatalities will remain lower than that of male drivers.

In the regional breakdown of driver fatalities, the greatest number occurs, as expected, in the South. In 1995, 42\% of all driver fatalities, nationally, occurred in the South. In 2025, our projections indicate that this number will rise to $51 \%$, mostly due to higher than average expected population growth of the elderly in this region.

The projections of our total fatalities measure mirrors the trends found in driver fatalities, from the higher rate of increase in total fatalities attributed to women, to the increase in the already high proportion of fatalities occurring in the South. We do not present the numbers for those projections in either tables or graphs since they were so similar to the driver fatality results. Additionally the implicit attribution of fault in that measure lends those numbers to easy misinterpretation. 


\section{ANALYSIS OF THE FATALITY PROJECTIONS}

In this chapter, we offer two views on the importance of various determinants of elderly driver fatalities. The first takes the perspective of the four major components of the projections: growths in population, increases in VMT, growth in the percent of the elderly population driving, and decreases in crash risk. We report these contributions to the fatality projections in Section 9.1. None of these major components is directly amenable to policy instruments, but many of the variables in the equations used to project those components do have some susceptibility to adjustment by public policy. In Section 9.2 we report the sensitivity of driver fatalities in 2025 to alternative scenarios based on alternative growth assumptions of each of the independent variables in the component equations, one at a time. Thus, we can see how sensitive the driver fatality projections are to slight changes in, say, income or health status. Pursuing the findings of the contributions and sensitivity analyses of this chapter, Section 9.3 reports the consequences of suppressing the effects of unspecified technological and institutional changes on VMT and on driver fatalities. A spreadsheet tool was developed to let users conduct scenario analyses of particular interest to themselves by modifying growth assumptions used in our projections. The guide to use this tool is in Section 9.4.

\subsection{CONTRIBUTIONS OF INDIVIDUAL COMPONENTS TO DRIVER FATALITY PROJECTIONS}

Before reporting the contributions of the major projection components to driver fatalities in 2025, we detail the method of calculating these contributions. Section 9.1.2 offers a graphical presentation of the various components' percentage contributions to driver fatalities. 


\subsubsection{Computations}

The projection of fatalities is a function of the projections of non-institutionalized population, the percent of the population that will drive, the average miles driven per year by an older driver, and the fatal crash rate per hundred million miles driven. To calculate the percentage contributions of thefour major components to the projections of total fatalities it is necessary to take account of the multiplicative structure of the projections. The general method of making these calculations is to compare the number of fatalities projected under different circumstances. It is possible to hold the projection of any one of these components, or any combination of them, at their 1995 levels, which we call "flat-lining" in the following explanation. Let $A$ be the projected fatalities derived from the full projection (i.e., when no component projection is flat-lined), and let $B$ be the projected fatalities when all four projection components are held at their 1995 values (i.e., when all four are flat-lined). Then $A / B$ is the ratio of the full contribution of all four projection components to the flat-lined figures. Next, define a separate variable for the fatality projection derived under the flat-lining of three of the four contributing projections. Let $C$ be the projection obtained flat-lining all components but the projected elderly population; let $D$ be the corresponding projection derived from flat-lining everything but the projected older drivers $E$ the projection flat-lining all but VMT, and $F$ the projection from flat-lining all but crash risk.

Dividing $C, D, E$, and $F$ by $B$ gives each component's contribution to the full projection: $A / B=(C / B)(D / B)(E / B)(F / B)$. To simplify the notation, let $C / B=G, D / B=H$, $E / B=I, F / B=J$, and $A / B=X$. Using this new notation, the expression for the projection in terms of the contributions of individual components is $X=G H I J$. To express the total projection as a sum of the components, express the equation in logarithmic form: $\log X=\log$ $\mathrm{G}+\log \mathrm{H}+\log \mathrm{I}+\log \mathrm{J}$. Finally, to express the individual contributions as shares of the full projection, divide the entire equation by $\log X: 1=(\log G) /(\log X)+(\log H) /(\log X)+(\log$ $\mathrm{I}) /(\log \mathrm{X})+(\log \mathrm{J}) /(\log \mathrm{X})$, where $(\log !) /(\log \mathrm{X})$ is the percent contribution of factor! , which, of course, will be population, VMT, driver, and risk. 


\subsubsection{Contributions to Driver Fatalities}

The dampening effect on projected fatalities of falling crash risk over time simply yields a negative contribution to the risk projection, which means that if risk were flat-lined, the projected fatalities would be larger than they are when the decrease in crash risk is factored into the projection. Thisnegative contribution of crash risk also means that, while the sum of the component contributions to driver fatalities will always be 1 , the components themselves have the potential of attaining values greater than one, with the sum of the positive terms, or more simply, those components (VMT, driver, and population) whose changes over time increase the number of fatalities will always sum to a value greater than one.

As we can observe in Figure 9.1, by far the largest contributor to the growth in male driver fatalities is population. This should come as no great surprise given that the elderly male non-institutionalized population is expected to double over the projected time frame, while VMT and percentages of people who drive are projected to increase at less substantial rates. The driver projections show up as a mere blip for the younger age groups simply because these groups already have driver rates near $100 \%$. As such, no substantial increases in these rates were possible when projecting, meaning that any increase in fatalities over the projected time frame cannot be attributed in great part to an increase in the percent of the male population that drives. This effect lessens as we move to the oldest age groups. VMT is somewhat similar to driver, with the younger groups already approaching a theoretical limit on the feasible amount of annual VMT, translating into a smaller relative contribution to fatalities.

The relative component contributions to female driver fatalities vary greatly from those of male fatalities. Non-institutionalized female population is expected to increase dramatically, but it is not expected to double as it is for men. In addition, projections of VMT and percentage of the population that drives are slightly higher for women then for men when comparing the ratio of 2025 projections to 1995 observed values. As one can see in 
Figure 9.2, the combination of these effects presents a picture that is different from that presented by the component contributions of male fatalities. Population plays a far lesser role, while the roles of VMT and driver are much more prominent. Overall, while the contributions of risk and driver are relatively small for some age groups, no one component truly dominates the projection of female driver fatalities in the way that population dominates the projection of male fatalities.

\section{2 SENSITIVITY ANALYSIS}

This section addresses how alternative projected pathsof the independent variables in the independent component equations (VMT, percent of drivers, crash risk) affect the projections of older driver fatalities. Those variables are household income, employment status, health status, presence of other drivers in the household, location in an urban area, and seat belt use. Although we projected fatalities for each fifth year in the projection period, we considered it sufficient to study the sensitivity of the fatalities at the terminal date. Alternative scenarios were generated by altering the projected growth path of each independent variable, one at a time. Table 9.1 reports the total impacts on the number of elder driver fatalities in 2025 of changes in each of the independent variables, through all of the components by which they have their effects. The numbers in Table 9.1 are in the form of elasticities, which identify the percent change in the dependent variable, elder driver fatalities in this case, per onepercent change in the independent variable. Since elasticities are dimensionless numbers they are comparable across cases involving greatly differing magnitudes. Consequently these elasticities are directly comparable across independent variables and across projection components. 


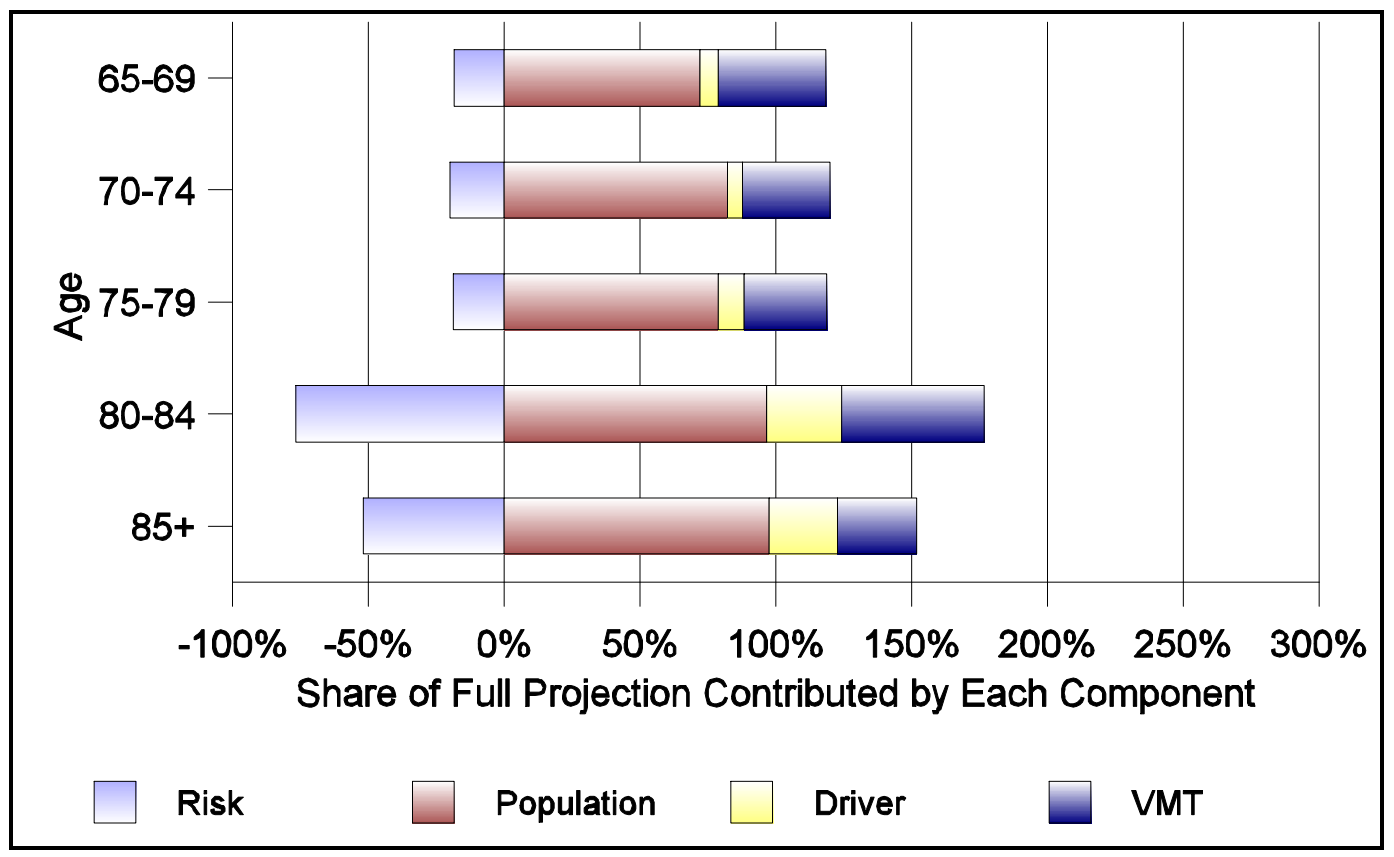

Figure 9.1. Component Contributions to 2025 Driver Fatality Projections, Men

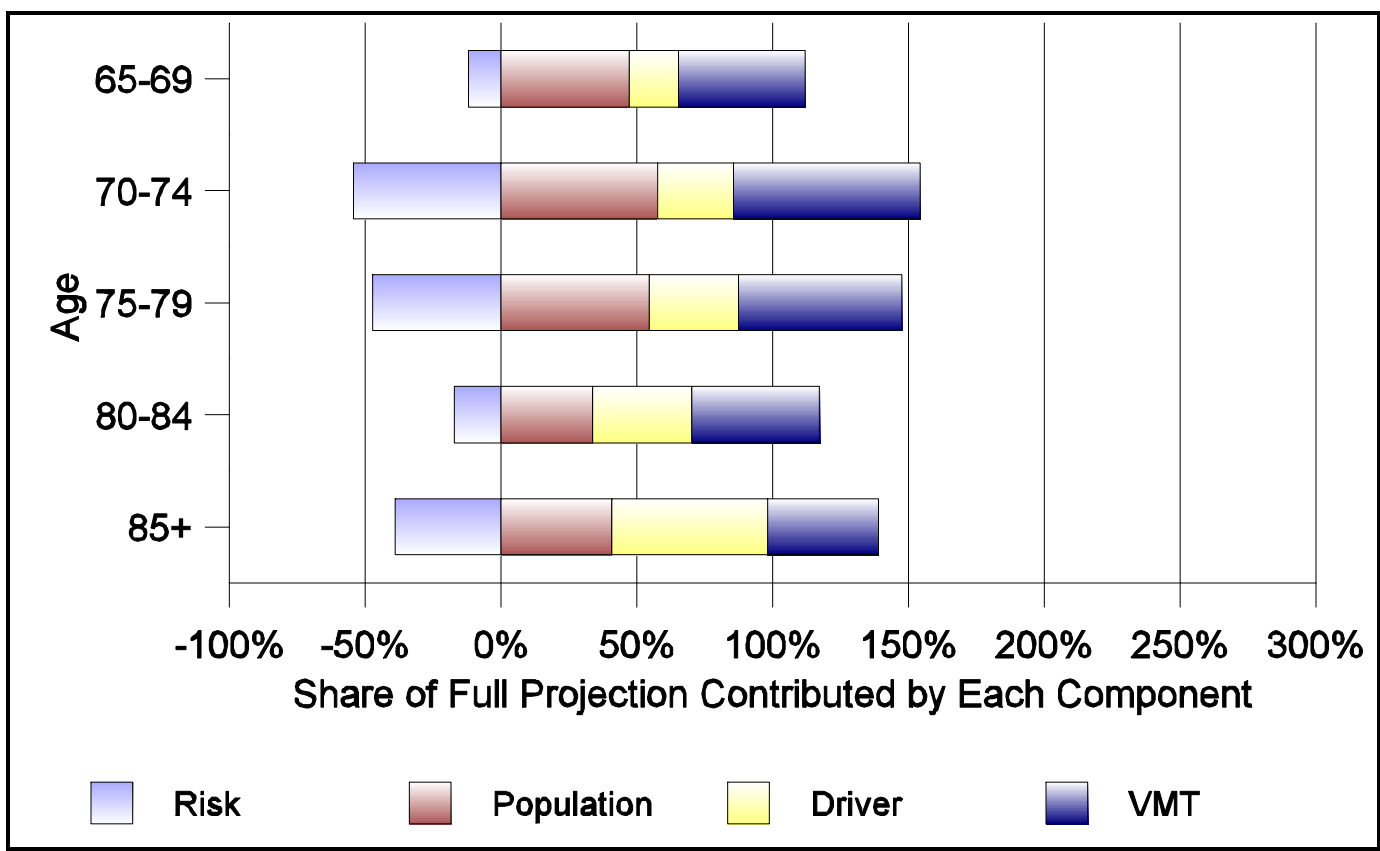

Figure 9.2. Component Contributions to 2025 Driver Fatality Projections, Women 
Table 9.1. Sensitivity of Total Driver Fatalities to Perturbations in Independent Variables: Elasticities of Projected Driver Fatalities in 2025

\begin{tabular}{|lcccccc|}
\hline Age Group & Income & $\begin{array}{c}\text { Employment } \\
\text { status }\end{array}$ & $\begin{array}{c}\text { Presence of } \\
\text { other drivers } \\
\text { in household }\end{array}$ & $\begin{array}{c}\text { Health } \\
\text { status }\end{array}$ & $\begin{array}{c}\text { Urban } \\
\text { location }\end{array}$ & $\begin{array}{c}\text { Seat belt } \\
\text { use }\end{array}$ \\
\hline $65-69$ & -0.06 & 0.50 & 0.03 & 0.02 & -0.06 & -0.57 \\
$70-74$ & -0.14 & 0.31 & -0.09 & 1.39 & -0.04 & -0.91 \\
$75-79$ & -0.04 & 0.55 & -0.36 & 0.43 & -0.03 & -0.57 \\
$80-84$ & 0.02 & 0.64 & -0.32 & 0.35 & -0.03 & -0.52 \\
$85+$ & -0.003 & 0.005 & -0.26 & 0.12 & -0.08 & -1.23 \\
\hline & & & Men & & & \\
\hline $65-69$ & -0.08 & 0.66 & -0.44 & 0.17 & -0.06 & -0.57 \\
$70-74$ & -0.09 & 0.79 & -0.53 & 0.44 & -0.07 & -0.91 \\
$75-79$ & -0.04 & 0.43 & -0.65 & 0.73 & -0.06 & -0.57 \\
$80-84$ & -0.55 & 0.44 & -0.70 & 0.60 & -0.28 & -0.52 \\
$85+$ & -0.02 & 0.46 & -0.17 & 1.24 & -0.19 & -1.23 \\
\hline
\end{tabular}

Some of the independent variables have effects on more than one component, so Tables 9.2 through 9.7 report the underlying elasticity structure of the individual component equations. Thus, while the reader can see the final impact of each of the independent variables in Table 9.1, the routes of effect can be traced with the elasticities reported in Tables 9.2 through 9.7. As an example of the difference between an independent variable's effect on the components of the fatality projection and on the final fatality projection, consider how an increase in income works: it increases VMT and the percent of the population driving, both of which increase exposure to traffic crashes, but it reduces crash risk by more than it increases the other two components, leaving a small, negative effect on fatalities. 


\subsubsection{Total Impacts on Older Driver Fatalities}

As we noted in the example in the section introduction, income has a small, dampening effect on older driver fatalities, although the impact for 80-84 women is sizeable. Thinking primarily of the effect of income on the demand for VMT and for being a driver, this result is a surprise, but it arises through the route of income's dampening effect on crash risk. It just happens, for every age/gender group except 80-84 men, that the direct effect of income on crash risk outweighs the indirect effects on the two components of exposure to crashes. Considering the error bounds on theoriginal regression coefficients, an income elasticity of fatal driver crashes of -0.02 is not a great concern however; its "true value" could be +0.01 .

The elasticities reported in the column labeled "employment status" in Table 9.1 show the effect on an entire population of an increase in labor force participation among that group. Thus, if the percent of the 65-69 year-old men in the labor force were to increase by one percent (a percent of a percent, note), the projection is for a $0.50 \%$ increase in the number of driver fatalities among that group. With the exception of $85+$ men, these elasticities are large (that for 70-74 men, at 0.31 , some readers might consider not particularly large). These sensitivities take on added significance when we consider that the Social Security retirement age for men born in 1960 and later recently has been increased from 65 to 67 . This result says to expect a consequence in terms of additional driver fatalities associated with additional work trips among this cohort. This effect works through both the VMT and driver percentage components, operating in the same direction.

Perturbing "having another driver in the household" is equivalent to changing the proportion of elderly households that have more than one driver. Thus, if male life expectancies were to increase relative to female, bringing their expectancies closer to women's, we would see a larger percentage of women with another driver in the household, and possibly the same effect among the male age groups. This change has a small, positive effect on 65-69 males, again plausible as a statistical error phenomenon, but otherwise has a 
material, dampening effect on driver fatalities among all age groups and both genders. Many of the elasticities are of substantial magnitude, particularly among the female age groups.

Improved health status has the counterintuitive effect of increasing older driver fatalities, and by substantial percentages per unit improvement in health as reported by these elasticity values. There is an equally natural intuitive understanding of this result inasmuch as people with fewer activity limitations are more likely to be mobile and thence experience greater exposure to traffic crashes. Again, this operates through both VMT and the percent of elderly that continue driving.

Urban location has a small, but rather consistent, dampening effect on driver fatalities, although the magnitudes for the two oldest groups of women are considerably larger. Clearly this reflects the greater availability of substitutes for driving in cities. One can interpret these elasticities as the impact of a $1 \%$ increase in the percent of the total (or regional) population living in cities on the number of elder driver fatalities. As the projection model is structured, this effect derives strictly from the driver percentage component of exposure, without an additional channel through VMT.

The seat-belt-use elasticities are encouraging in that they are sizeable as well as negative. They are the same magnitude for both gendersbecause no gender difference was detectable in the regression coefficients of seat belt use in the crash rate model. Whether this effect would survive more detailed, individual information on seat belt use by age, we cannot say, but it certainly is worth exploration.

\footnotetext{
${ }^{1}$ Recall that the exclusion of a substitute-for-driving variable in the VMT demand equation was the consequence of data limitations in an early NPTS. Location in a SMA was not considered an adequate indicator of substitutes for VMT, and information on proximity to, or otherwise availability of, public transit was unavailable in the 1983 NPTS. Location in a SMA was considered an adequate indicator of substitutes for driving at all.
} 


\subsubsection{Sensitivity of the Projection Components to Individual Variables}

In Section 9.2.1 we noted that some independent variables worked their effects on total driver fatalities through several routes. The best example of this is income, which affects

all three of the projection components constructed in this research (population growth projections, of course, being supplied by the U.S. Census Bureau). Each of the following six tables reports the sensitivity of the projections of each major component to one of the independent variables. A final column at the right of each table reports the total effect of the variable on driver fatalities. Having alluded to the differential effects of some independent variables on the separate projection components in the discussion of the sensitivity of driver fatalities, we provide no further examination of the elasticities of Tables 9.2 through 9.7.

\subsection{A LOWER BOUND FOR DRIVER FATALITIES AND VMT}

We have noted that we believe our driver fatality projections to be as high as is reasonable, principally because the elderly VMT projections are as high as could be expected. We do not believe that annual VMT per capita will exceed the projections in Figure 7.3 and the accompanying appendix tables. The contributions of income growth and growth in elderly labor force participation are solidly established, but the time trend terms in the projection equations, as noted in Chapter 7, contribute substantial, in some age/gender groups even dominant, proportions of the growth in VMT projected to 2020. Although the empirical basis of the magnitude of the time trend coefficients is indisputably comprised of 
Table 9.2. Sensitivity of 2025 Projections to Perturbations in Income Growth

\begin{tabular}{|lcccr|}
\hline Age group & \multicolumn{5}{c|}{ Arc Elasticity } \\
\cline { 2 - 5 } & VMT & $\begin{array}{c}\text { Percent of } \\
\text { population } \\
\text { driving }\end{array}$ & $\begin{array}{c}\text { Fatal accident } \\
\text { rate }\end{array}$ & $\begin{array}{c}\text { Total } \\
\text { fatalities }\end{array}$ \\
\hline \multicolumn{5}{c}{ Men } \\
\hline $65-69$ & 0.18 & 0.03 & -0.26 & -0.06 \\
$70-74$ & 0.23 & 0.04 & -0.42 & -0.14 \\
$75-79$ & 0.24 & 0.04 & -0.32 & -0.04 \\
$80-84$ & 0.12 & 0.01 & -0.13 & 0.02 \\
$85+$ & 0.27 & 0.04 & -0.35 & -0.003 \\
\hline & \multicolumn{5}{c}{ Women } & -0.21 & -0.08 \\
\hline $65-69$ & 0.11 & 0.02 & -0.29 & -0.09 \\
$70-74$ & 0.12 & 0.08 & -0.14 & -0.04 \\
$75-79$ & 0.07 & 0.03 & -1.45 & -0.55 \\
$80-84$ & 0.60 & 0.28 & -0.14 & -0.02 \\
$85+$ & 0.06 & 0.06 & & \\
\hline
\end{tabular}

Perturbation: $10 \%$ increase in the rate of increase

Table 9.3. Sensitivity of 2025 Projections to Perturbations in Projected Employment Status

\begin{tabular}{|c|c|c|c|c|}
\hline \multirow[b]{2}{*}{ Age group } & \multicolumn{4}{|c|}{ Arc Elasticity } \\
\hline & VMT & $\begin{array}{l}\text { Percent of } \\
\text { population } \\
\text { driving }\end{array}$ & $\begin{array}{l}\text { Fatal accident } \\
\text { rate }\end{array}$ & $\begin{array}{l}\text { Total driver } \\
\text { fatalities }\end{array}$ \\
\hline \multicolumn{5}{|c|}{ Men } \\
\hline $65-69$ & 0.49 & 0.002 & & 0.50 \\
\hline $70-74$ & 0.29 & 0.01 & & 0.31 \\
\hline $75-79$ & 0.55 & 0.004 & & 0.55 \\
\hline $80-84$ & 0.63 & 0.01 & & 0.64 \\
\hline $85+$ & - & 0.004 & & 0.005 \\
\hline \multicolumn{5}{|c|}{ Women } \\
\hline $65-69$ & 0.66 & 0.01 & & 0.67 \\
\hline $70-74$ & 0.78 & 0.01 & & 0.79 \\
\hline $75-79$ & 0.42 & 0.01 & & 0.43 \\
\hline $80-84$ & 0.43 & 0.01 & & 0.44 \\
\hline $85+$ & 0.43 & 0.03 & & 0.46 \\
\hline
\end{tabular}

Perturbation: $10 \%$ increase in the rate of growth 
Table 9.4. Sensitivity of 2025 Projections to Perturbations in Projected Percentage of Elderly Households with Other Drivers

\begin{tabular}{|c|c|c|c|c|}
\hline \multirow[b]{2}{*}{ Age group } & \multicolumn{4}{|c|}{ Arc Elasticity } \\
\hline & VMT & $\begin{array}{l}\text { Percent of } \\
\text { population } \\
\text { driving }\end{array}$ & $\begin{array}{c}\text { Fatal accident } \\
\text { rate }\end{array}$ & $\begin{array}{l}\text { Total driver } \\
\text { fatalities }\end{array}$ \\
\hline \multicolumn{5}{|c|}{ Men } \\
\hline $65-69$ & - & 0.03 & & 0.03 \\
\hline $70-74$ & -0.10 & 0.01 & & -0.09 \\
\hline $75-79$ & -0.34 & -0.02 & & -0.36 \\
\hline $80-84$ & -0.31 & -0.01 & & -0.32 \\
\hline $85+$ & -0.17 & -0.07 & & -0.26 \\
\hline \multicolumn{5}{|c|}{ Women } \\
\hline $65-69$ & -0.41 & -0.04 & & -0.44 \\
\hline $70-74$ & -0.45 & -0.08 & & -0.53 \\
\hline $75-79$ & -0.58 & -0.08 & & -0.65 \\
\hline $80-84$ & -0.53 & -0.16 & & -0.70 \\
\hline $85+$ & - & -0.17 & & -0.17 \\
\hline
\end{tabular}

Perturbation: $1.67 \%$ increase per 5 year period

Table 9.5. Sensitivity of 2025 Projections to Perturbations in Projected Trend in Health Status

\begin{tabular}{|c|c|c|c|c|}
\hline \multirow[b]{2}{*}{ Age group } & \multicolumn{4}{|c|}{ Arc Elasticity } \\
\hline & VMT & $\begin{array}{c}\text { Percent of } \\
\text { population } \\
\text { driving }\end{array}$ & $\begin{array}{c}\text { Fatal accident } \\
\text { rate }\end{array}$ & $\begin{array}{l}\text { Total driver } \\
\text { fatalities }\end{array}$ \\
\hline \multicolumn{5}{|c|}{ Men } \\
\hline $65-69$ & - & 0.02 & & 0.02 \\
\hline $70-74$ & 1.23 & 0.13 & & 1.39 \\
\hline $75-79$ & 0.36 & 0.07 & & 0.43 \\
\hline $80-84$ & 0.28 & 0.07 & & 0.35 \\
\hline $85+$ & 0.12 & -0.001 & & 0.12 \\
\hline \multicolumn{5}{|c|}{ Women } \\
\hline $65-69$ & 0.12 & 0.06 & & 0.17 \\
\hline $70-74$ & 0.25 & 0.19 & & 0.44 \\
\hline $75-79$ & 0.54 & 0.19 & & 0.73 \\
\hline $80-84$ & 0.39 & 0.21 & & 0.60 \\
\hline $85+$ & 1.27 & -0.03 & & 1.24 \\
\hline
\end{tabular}

Perturbation: $1.25 \%$ increase per 5-year period 
Table 9.6. Sensitivity of 2025 Projections to Perturbations in Projected Urbanization

\begin{tabular}{|c|c|c|c|c|}
\hline \multirow[b]{2}{*}{ Age group } & \multicolumn{4}{|c|}{ Arc Elasticity } \\
\hline & VMT & $\begin{array}{l}\text { Percent of } \\
\text { population } \\
\text { driving }\end{array}$ & $\begin{array}{l}\text { Fatal accident } \\
\text { rate }\end{array}$ & $\begin{array}{l}\text { Total driver } \\
\text { fatalities }\end{array}$ \\
\hline \multicolumn{5}{|c|}{ Men } \\
\hline $65-69$ & & -0.06 & & -0.06 \\
\hline $70-74$ & & -0.04 & & -0.04 \\
\hline $75-79$ & & -0.03 & & -0.03 \\
\hline $80-84$ & & -0.03 & & -0.03 \\
\hline $85+$ & & -0.08 & & -0.08 \\
\hline \multicolumn{5}{|c|}{ Women } \\
\hline $65-69$ & & -0.06 & & -0.06 \\
\hline $70-74$ & & -0.07 & & -0.07 \\
\hline $75-79$ & & -0.06 & & -0.06 \\
\hline $80-84$ & & -0.28 & & -0.28 \\
\hline $85+$ & & -0.19 & & -0.19 \\
\hline
\end{tabular}

Perturbation: $10 \%$ increase from 1995 to 2025

Table 9.7. Sensitivity of 2025 Projections to Perturbations in Projected Seat Belt Use

\begin{tabular}{|c|c|c|c|c|}
\hline \multirow[b]{2}{*}{ Age group } & \multicolumn{4}{|c|}{ Arc Elasticity } \\
\hline & VMT & $\begin{array}{l}\text { Percent of } \\
\text { population } \\
\text { driving }\end{array}$ & $\begin{array}{l}\text { Fatal accident } \\
\text { rate }\end{array}$ & $\begin{array}{c}\text { Total driver } \\
\text { fatalities }\end{array}$ \\
\hline \multicolumn{5}{|c|}{ Men } \\
\hline $65-69$ & & & -0.57 & -0.57 \\
\hline $70-74$ & & & -0.91 & -0.91 \\
\hline $75-79$ & & & -0.57 & -0.57 \\
\hline $80-84$ & & & -0.52 & -0.52 \\
\hline $85+$ & & & -1.23 & -1.23 \\
\hline \multicolumn{5}{|c|}{ Women } \\
\hline $65-69$ & & & -0.57 & -0.57 \\
\hline $70-74$ & & & -0.91 & -0.91 \\
\hline $75-79$ & & & -0.57 & -0.57 \\
\hline $80-84$ & & & -0.52 & -0.52 \\
\hline $85+$ & & & -1.23 & -1.23 \\
\hline
\end{tabular}

Perturbation: $96 \%$ seat belt usage in 2025 
the changes in vehicle technology, transportation infrastructure, the spatial structure of American cities, changes in family structure, and changing individual roles in society over the period from 1977 to 1995 , we were unable to separate those effects into distinct, quantitative variables. Extrapolating from historical time trends is notoriously dangerous, although such practice probably yields under-estimates as often as over-estimates, depending on the subject. Our method of avoiding simple, linear extrapolation of historical time trends was to cap the VMT projection of the group reasonably expected to have the largest annual VMT, 65-69 year-old males, at their lifetime peak, and let all other time trends be adjusted proportionally to the adjustment required in the 65-69 male time trend coefficient to create the cap on VMT. We recognize that this is likely to yield a high estimate of VMT, but the procedure is the least judgmental adjustment that can be made on the time trends without further information on the distinct forces those trends represent. It seems reasonable to label these projections of VMT and the corresponding driver fatality projections as upper bounds.

A logical lower bound, using the information available to us, is to eliminate the "blackbox" time effect altogether. The implications of this move are very strong: no further technological change that would encourage more driving, no infrastructure changes that would do the same, no further effects of changing urban/suburban spatial configurations, no further effects of social changes other than the presence of another driver in the household. All of these assumptions are probably wrong, but by how much we cannot know with current information. But, knowing that some effects coming from these sources are likely to increase elderly VMT over the next quarter century, and setting them to zero offers a logically defensible lower bound on both VMT and on fatalities.

Section 9.3.1 projects VMT without time effects and offers several comparisons with the previous projections. This is also a convenient place to examine the effect of improving health status on VMT, inasmuch as the previous projection held health status at 1995 levels. Section 9.3.2 uses the lower-bound VMT projection to project a corresponding lower bound on driver fatalities. 


\subsubsection{The Effect of Time on VMT Projections}

The substantial contribution of the technological and institutional changes represented in the time effect of the projections of VMT makes it worthwhile to derive a lower bound case in which none of those changes occur, particularly since we cannot attribute the effects of time to specific developments. Table 9.8 reports the 2025 projections of VMT, at the national level, for men and women with and without any time effects. Eliminating the time effects drops the men's VMT projections by about $13 \%$ and those of women by $35 \%$. Figures 9.3 and 9.4 show the upper and lower bounds of VMT, graphically depicting the difference time makes in these projections.

This is a useful opportunity to compare the effects of improving elderly health on VMT relative to the effects of the undifferentiated technical and institutional changes represented by time. Table 9.8 also reports the 2025 VMT for the scenario with no time effects but the health status indicator increasing at $1 \frac{2}{2} \%$ per year from 1995 through 2025 . The base-case projections developed otherwise have kept the value of the health status variable constant at its 1995 level. Because the 65-69 year-old men's coefficient forhealth status was zero (statistically), there is no effect on that group. The remaining age groups of men show a declining impact of improving health status, beginning with over a $9 \%$ impact on the 2025 VMT projection for 70-74 men and falling to somewhat over $1 \%$ for the $85+$ group, relative to a no-time effects projection for 2025 . For women, the pattern by age is much the opposite, with a $1 \%$ increase in 2025 VMT attributable to improvement in health status among 65-69 women, increasing to a $15 \%$ difference in the $85+$ group. 
Table 9.8. VMT Projections for 2025 With and Without Pure Time Effects and with Improving Health Status, National Level

Men

\begin{tabular}{|ccccccc|}
\hline Age group & $\begin{array}{c}\text { Observed } \\
1995\end{array}$ & $\begin{array}{c}\text { With time } \\
2025\end{array}$ & $\begin{array}{c}\text { Without time } \\
2025\end{array}$ & Change & $\begin{array}{c}\text { Health improvements, no } \\
\text { time effect, 2025 }\end{array}$ & Change \\
\hline $65-69$ & $12,419.43$ & $18,787.30$ & $16,279.84$ & $-13.35 \%$ & $16,279.84$ & $0.00 \%$ \\
$70-74$ & $10,291.61$ & $13,706.88$ & $11,836.52$ & $-13.65 \%$ & $12,945.25$ & $9.37 \%$ \\
$75-79$ & $9,422.77$ & $12,709.24$ & $10,981.64$ & $-13.59 \%$ & $11,404.77$ & $3.85 \%$ \\
$80-84$ & $6,269.21$ & $8,622.38$ & $7,455.89$ & $-13.53 \%$ & $7,677.05$ & $2.97 \%$ \\
$85+$ & $5,165.97$ & $6,558.96$ & $5,662.48$ & $-13.67 \%$ & $5,735.99$ & $1.30 \%$ \\
\hline
\end{tabular}

Women

\begin{tabular}{|ccccccc|}
\hline Age group & $\begin{array}{c}\text { Observed } \\
1995\end{array}$ & $\begin{array}{c}\text { With time } \\
2025\end{array}$ & $\begin{array}{c}\text { Without time } \\
2025\end{array}$ & Change & $\begin{array}{c}\text { Health improvements, no } \\
\text { time effect, 2025 }\end{array}$ & Change \\
\hline $65-69$ & $5,841.61$ & $11,275.70$ & $7,324.45$ & $-35.04 \%$ & $7,417.75$ & $1.27 \%$ \\
$70-74$ & $5,054.79$ & $9,435.52$ & $6,118.64$ & $-35.15 \%$ & $6,290.24$ & $2.80 \%$ \\
$75-79$ & $4,288.47$ & $7,317.29$ & $4,713.94$ & $-35.58 \%$ & $5,003.88$ & $6.15 \%$ \\
$80-84$ & $3,805.26$ & $6,818.64$ & $4,398.60$ & $-35.49 \%$ & $4,590.16$ & $4.36 \%$ \\
$85+$ & $2,780.62$ & $4,946.91$ & $3,188.68$ & $-35.54 \%$ & $3,667.11$ & $15.00 \%$ \\
\hline
\end{tabular}

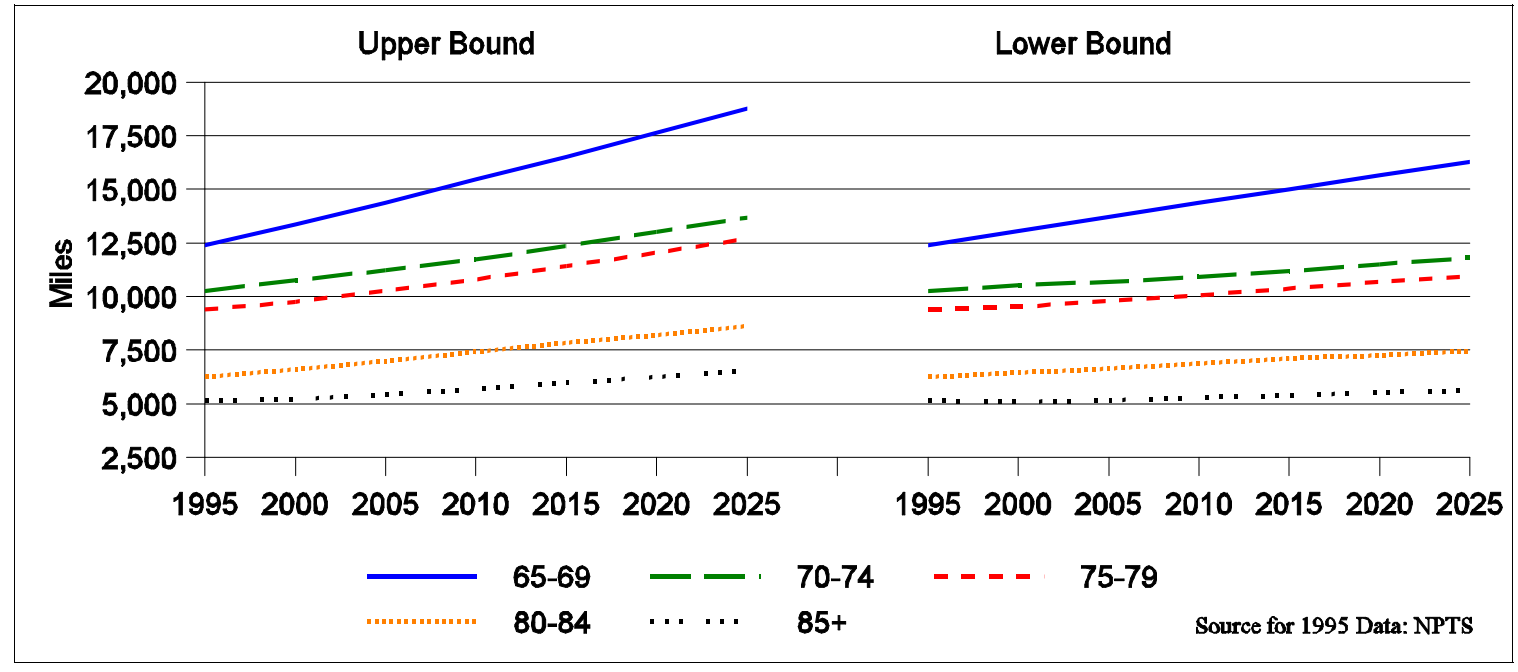

Figure 9.3. Projected VMT, Men (Upper and Lower Bounds) 


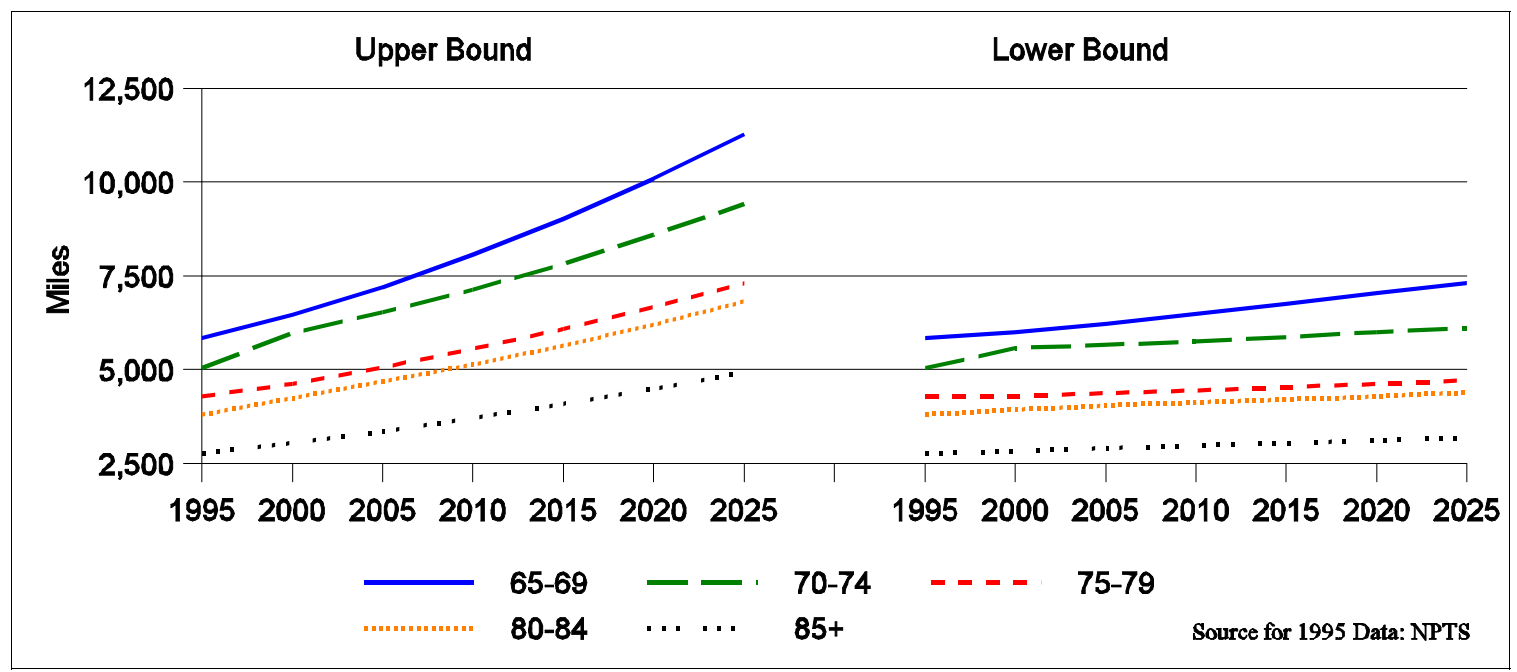

Figure 9.4. Projected VMT, Women (Upper and Lower Bounds)

\subsubsection{Driver Fatalities with Lower Bounded VMT}

A lower bound on driver fatality projections uses the lower-bounded VMT projections with no time effects. Table 9.9 reports 2025 driver fatality projections with and without time effects in VMT. Compared to the 1995 reported fatalities, the inclusion or exclusion of time effects makes a second-order difference, at least for men. Without time effects, total male driver fatalities increase by $151 \%$ by 2025 , compared to $190 \%$ with those effects. For women the difference is greater: $143 \%$ increase without time versus $275 \%$ with.

Using the lower-bounded VMT has interesting effects on the relative contributions of the major components to driver fatalities, as depicted in Figures 9.5 and 9.6, compared with Figures 9.1 and 9.2. Eliminating the time effect on VMT alone substantially affects the contribution of driver risk, in both men and women. The greatest dampening effect on male fatalities made by risk, with time effects on VMT, are in the two oldest age groups; without time effects, the greatest effect is on the two youngest groups. With women, the pattern is less easily summarized, but by eliminating the time effect in VMT, the effect of risk rises in 
the youngest group and drops in the next-youngest group. The effect of risk stays about the same in 75-79 group, shoots even farther up in 80-84, and drops sharply in the 85+ group.

Table 9.9. Comparison of Driver Fatality Projections for 2025, with Upper-bounded and Lower-bounded VMT Projections, National Level

\begin{tabular}{|crrrrrr|}
\hline Age group & $\begin{array}{c}\text { Men, with } \\
\text { upper- } \\
\text { bounded } \\
\text { VMT }\end{array}$ & $\begin{array}{c}\text { Men, with } \\
\text { lower- } \\
\text { bounded } \\
\text { VMT }\end{array}$ & $\begin{array}{c}\text { Men, 1995 } \\
\text { reported }\end{array}$ & $\begin{array}{c}\text { Women, } \\
\text { with upper- } \\
\text { bounded } \\
\text { VMT }\end{array}$ & $\begin{array}{c}\text { Women, } \\
\text { with lower- } \\
\text { bounded } \\
\text { VMT }\end{array}$ & $\begin{array}{c}\text { Women, } \\
1995 \\
\text { reported }\end{array}$ \\
\hline $65-69$ & 2424 & 2101 & 805 & 1446 & 940 & 316 \\
$70-74$ & 1735 & 1498 & 733 & 1067 & 692 & 362 \\
$75-79$ & 1996 & 1725 & 613 & 957 & 616 & 322 \\
$80-84$ & 1545 & 1336 & 469 & 865 & 558 & 196 \\
$85+$ & 706 & 610 & 270 & 559 & 361 & 106 \\
Total & $\mathbf{8 4 0 6}$ & $\mathbf{7 2 7 0}$ & $\mathbf{2 8 9 0}$ & $\mathbf{4 8 9 4}$ & $\mathbf{3 1 6 7}$ & $\mathbf{1 3 0 2}$ \\
\hline
\end{tabular}

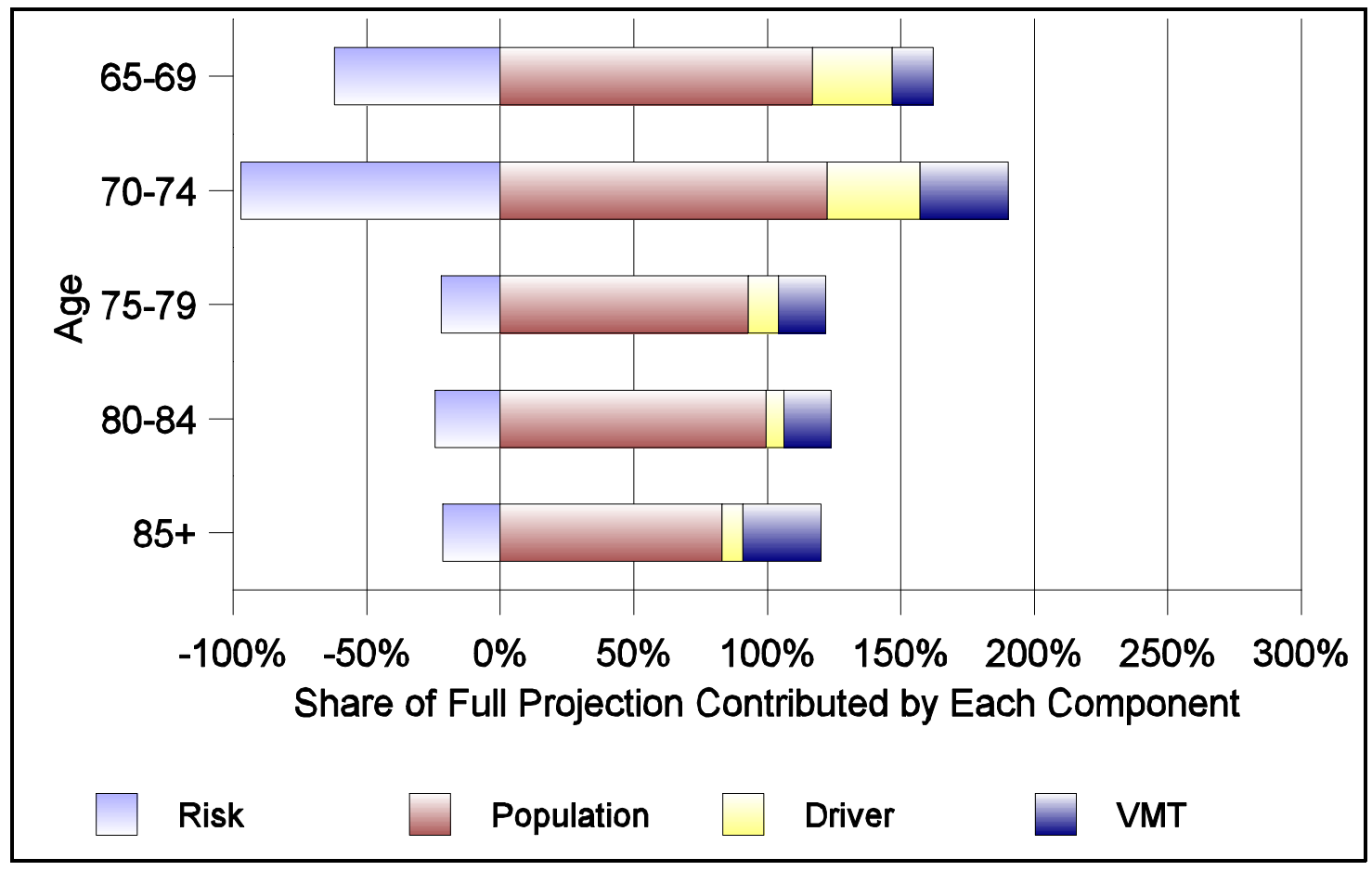

Figure 9.5. Component Contributions to Driver Fatality Projections Using Lower-bounded VMT, Men 


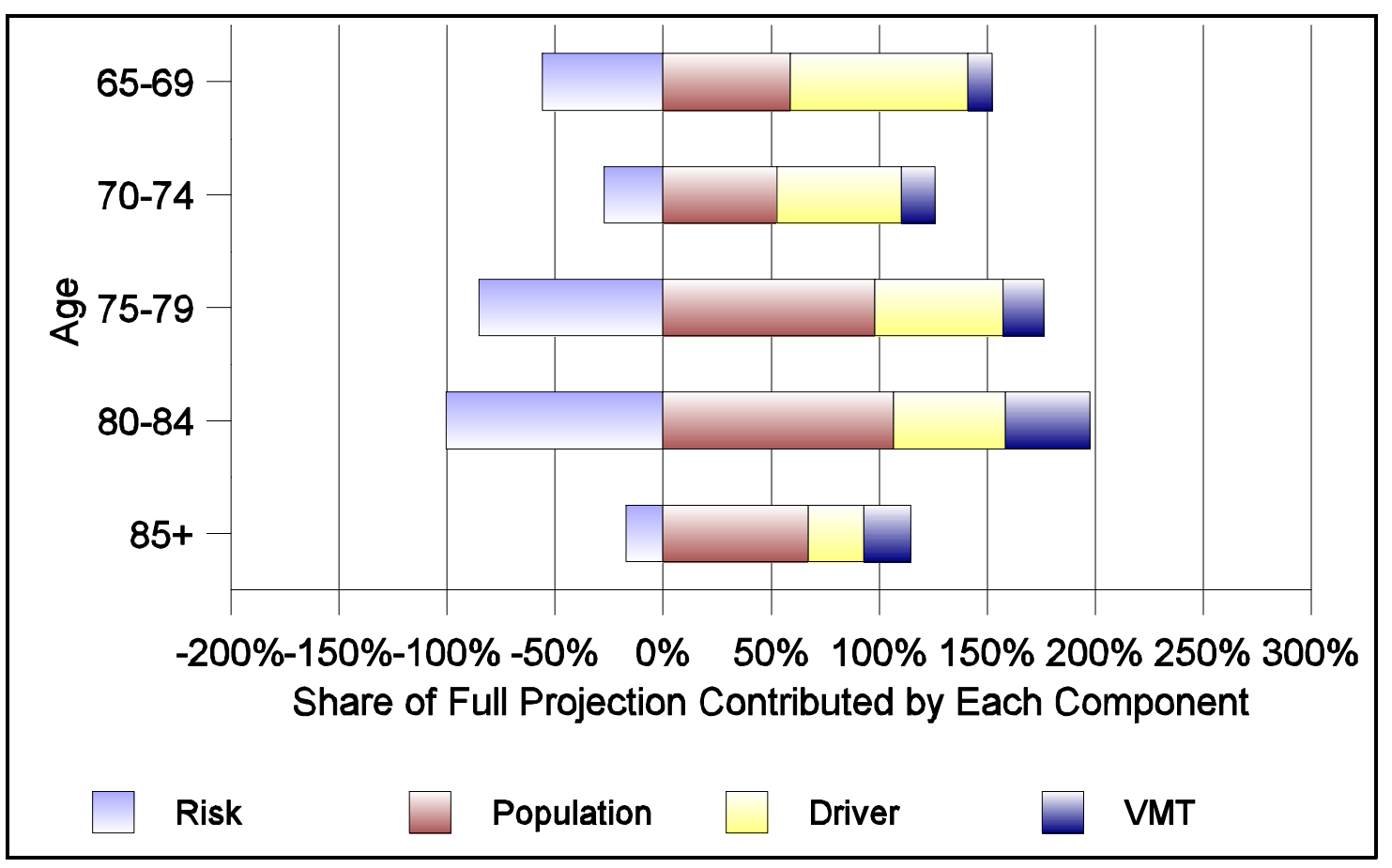

Figure 9.6. Component Contributions to Driver Fatality Projections Using Lower-bounded VMT, Women

\subsection{USER INTERFACE FOR “WHAT-IF” ANALYSIS}

The tool for performing "what-if" analysis on the elder driver projections is an Excel 97/2000 spreadsheet. A copy of the spreadsheet can be obtained on the internet via the older drivers link at http://www-cta.ornl.govor by contacting Tim Reuscher at (865) 574-8690. This spreadsheet utilizes Visual Basic macros, which guide the user through decisions to alter the levels of independent variables used in driver, VMT, and risk projections. The main sheet that the user sees upon opening the spreadsheet is presented below. 


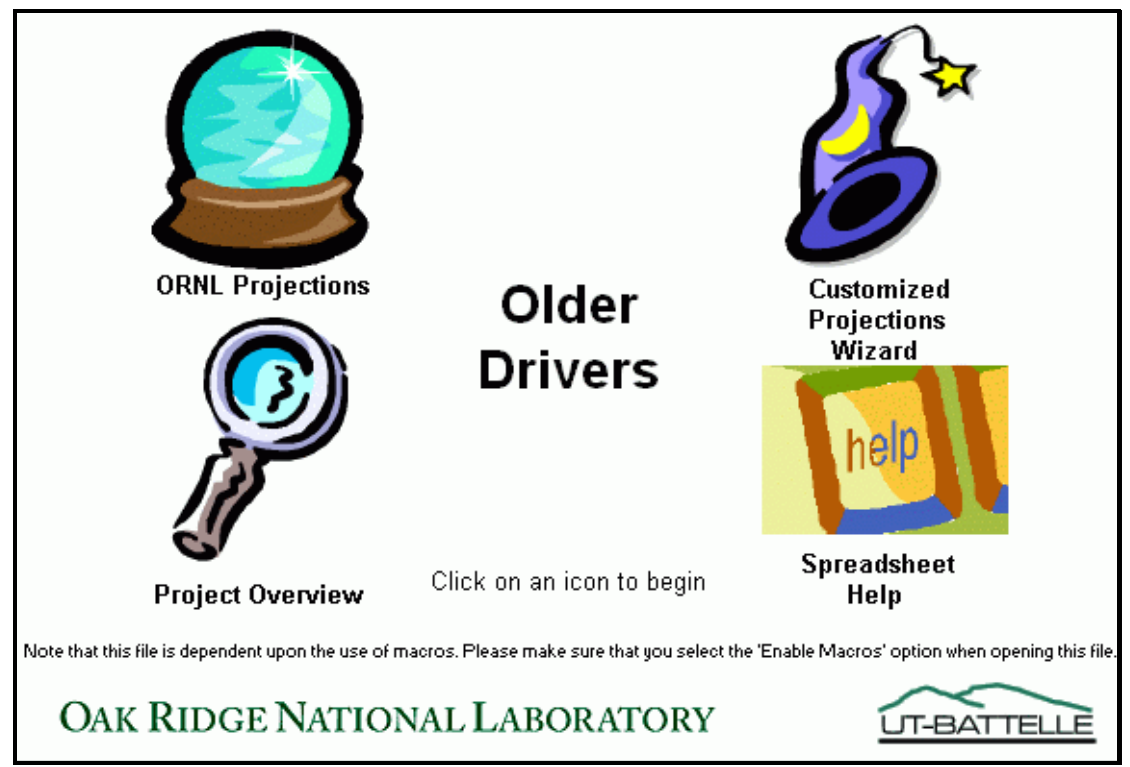

Clicking on the "ORNL Projections" link will give the user the option to view the projections presented in the Appendices of this report, displayed by projection type, region, or age group. The "Customized Projections Wizard," discussed in more detail later, will let the user perform the "what-if" analysis previously described. The "Project Overview" and "Spreadsheet Help" links provide the user with background information on the project and basic help in using the older drivers spreadsheet.

\subsubsection{Customized Projections Wizard}

The "Customized Projections Wizard" is a simple, step-by-step procedure for altering the levels of independent variables (income, "other driver," employment status, urban population percentages, health status, and seatbelt usage levels) used in projecting the percentage of the population that drives, how much the elderly drive, and their fatality risk per mile driven. Step 1 is a simple introduction to the process. Step 2 requires the user to name the new file which will be created as a result of the wizard, and allows the user to define how the output will be presented. 


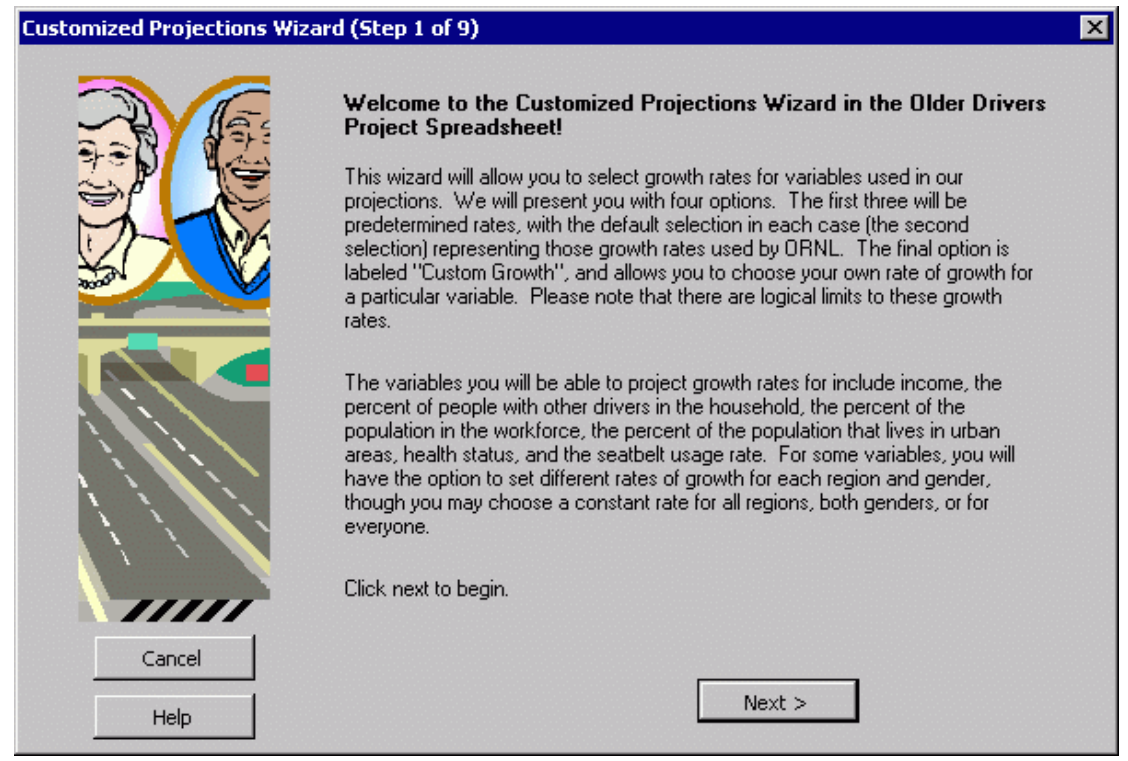

Step 1: Introduction

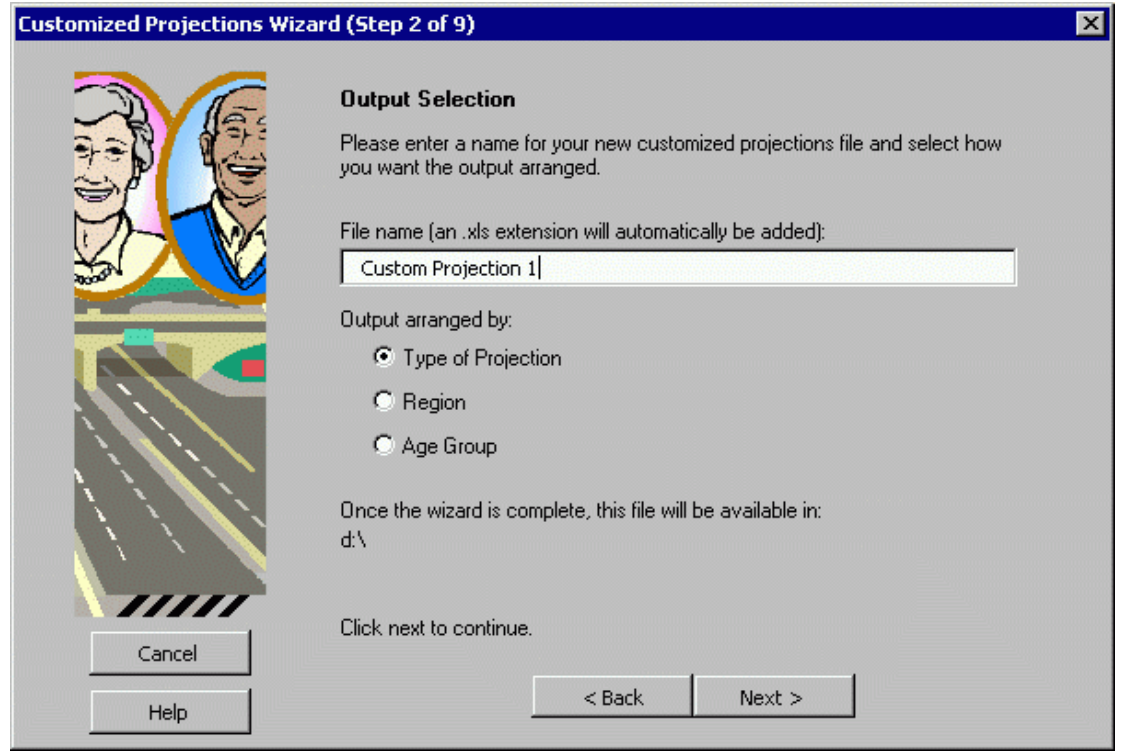

Step 2: Decisions on file naming and arrangement of output

The next six screens in the wizard allow the user to change the levels of independent variables. These variables can be changed to allow for three pre-determined levels of growth 
or decline, with the second option always representing the level ORNL chose. The variables can also be changed at a "Custom Growth" rate chosen by the user. In addition, the nature of some variables allows for them to be changed at the regional and gender levels, meaning the user can select different levels of growth for each gender orregion. Income and health status can have different levels for region and/or gender, while "other driver" and employment status can only differ by gender, with urban status only allowed to differ by region. These patterns follow the data used by ORNL for our projections. The following screens show how one can modify the various levels of the independent variables. The first screen shows what the user first sees in step 3. Clicking on the check boxes that say "Same growth for all regions" and "Same growth for both genders" will give the user the second screen below (Step 3a), which lets one change income at different levels for region and gender. Selecting the option "Custom Growth" from one of the drop-down lists will give the user the third screen (Step 3b), and clicking on the up or down arrows increases or decreases the value of the growth rate while the text below the box illustrates the effects of such a change.

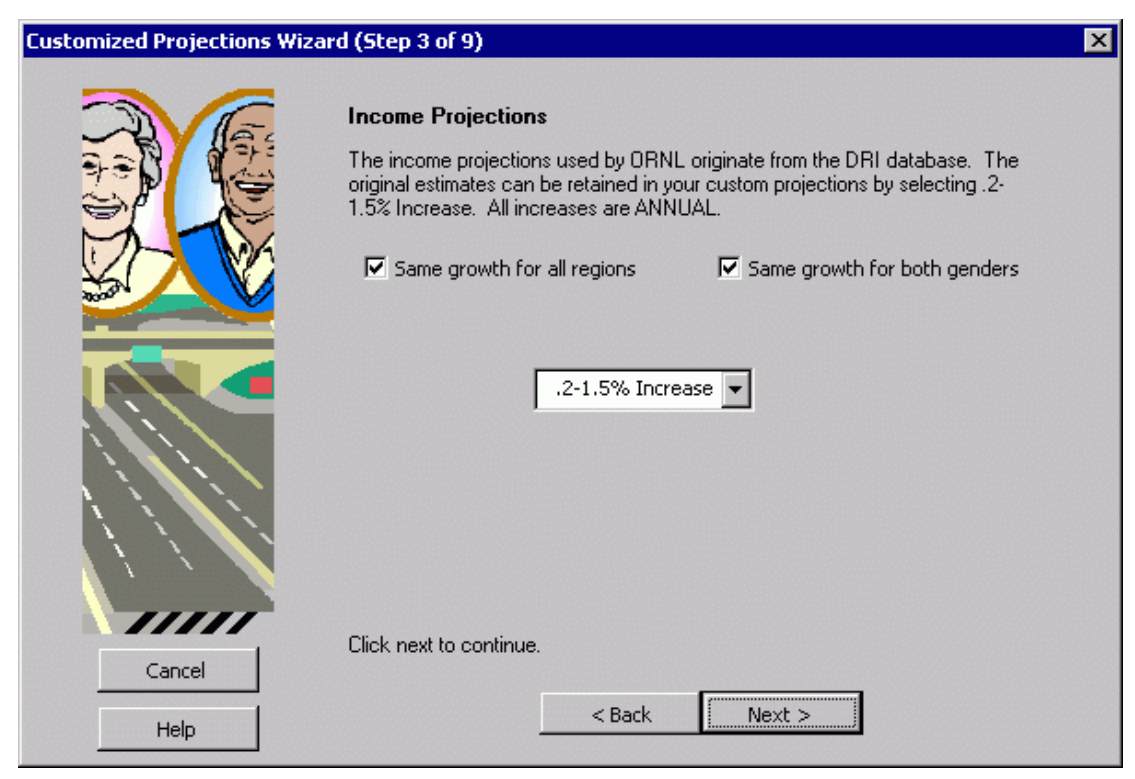

Step 3: Modifying Income levels 


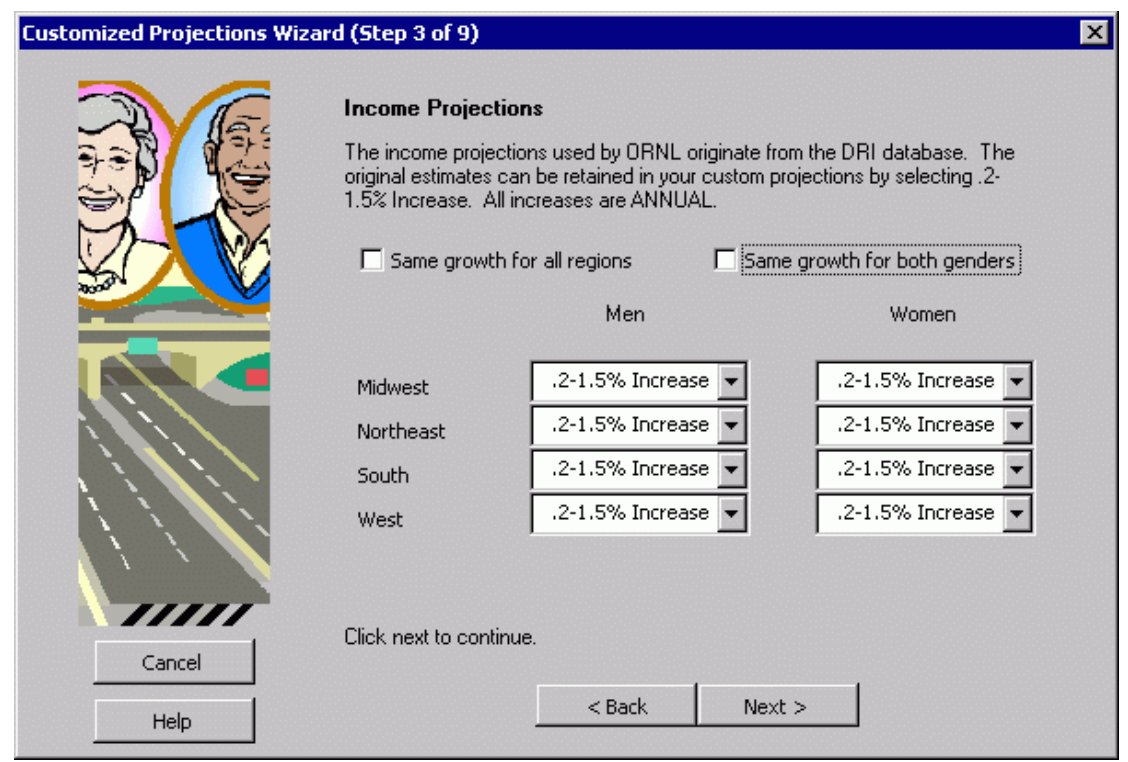

Step 3a: Modifying Income at different levels for regions and genders

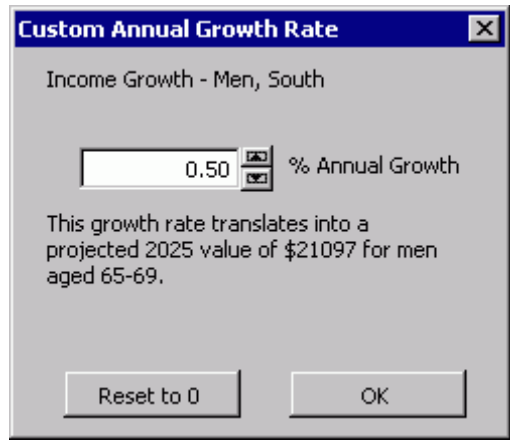

Step 3b: An example of choosing a "Custom Growth" rate

The steps are similar for "other driver," employment status, urban population, health status, and seatbelt use (Steps 4-8). When one clicks on the "Next" button of the health status screen, Excel, using the older driver spreadsheet macro instructions, calculates the effects of the user's modifications on the various projections and creates a file with the name given by the user in step two. Once Excel is finished, which usually takes a minute or two (and perhaps longer depending on the speed of the computer), a "Congratulations" screen 
(Step 9) will pop up, indicating that the process is complete. This screen will indicate where one can find the file just created on his or her computer.

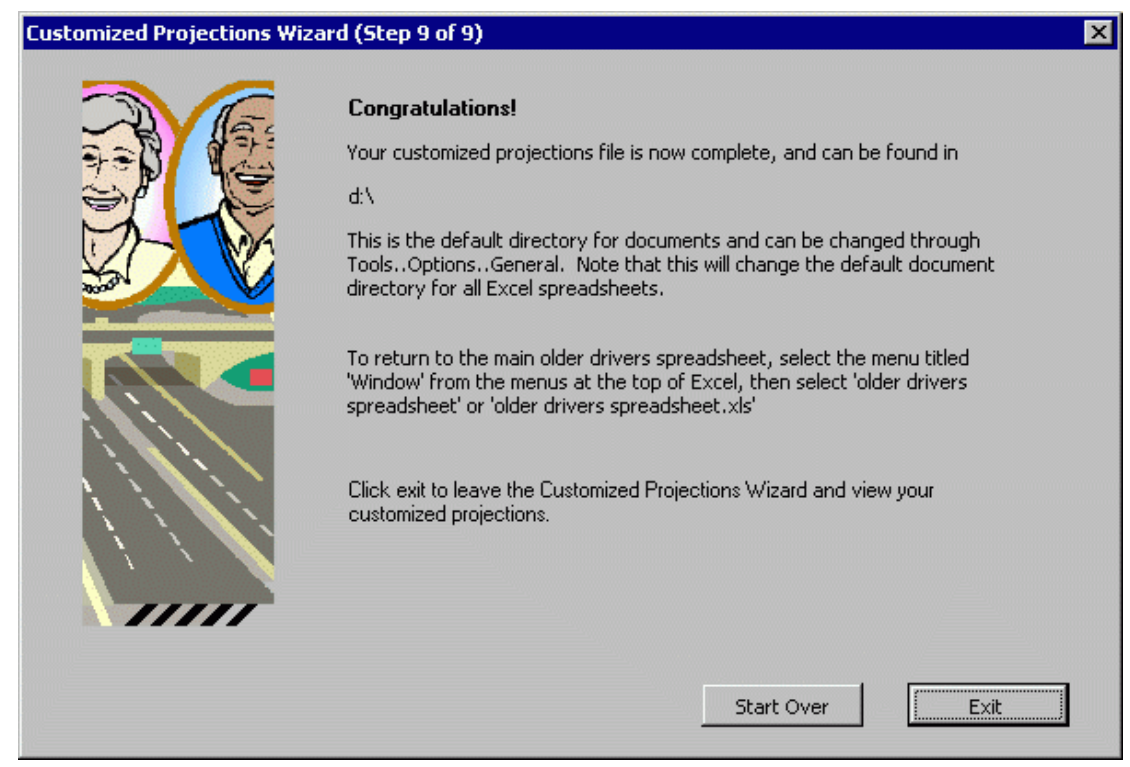

Step 9: The final confirmation

Clicking the Exit button will finish the wizard and will take the user into the newly created "Customized Projections" file. The first sheet one sees is the Summary sheet (below) which details exactly which modifications were made to produce the projections contained in the file. 


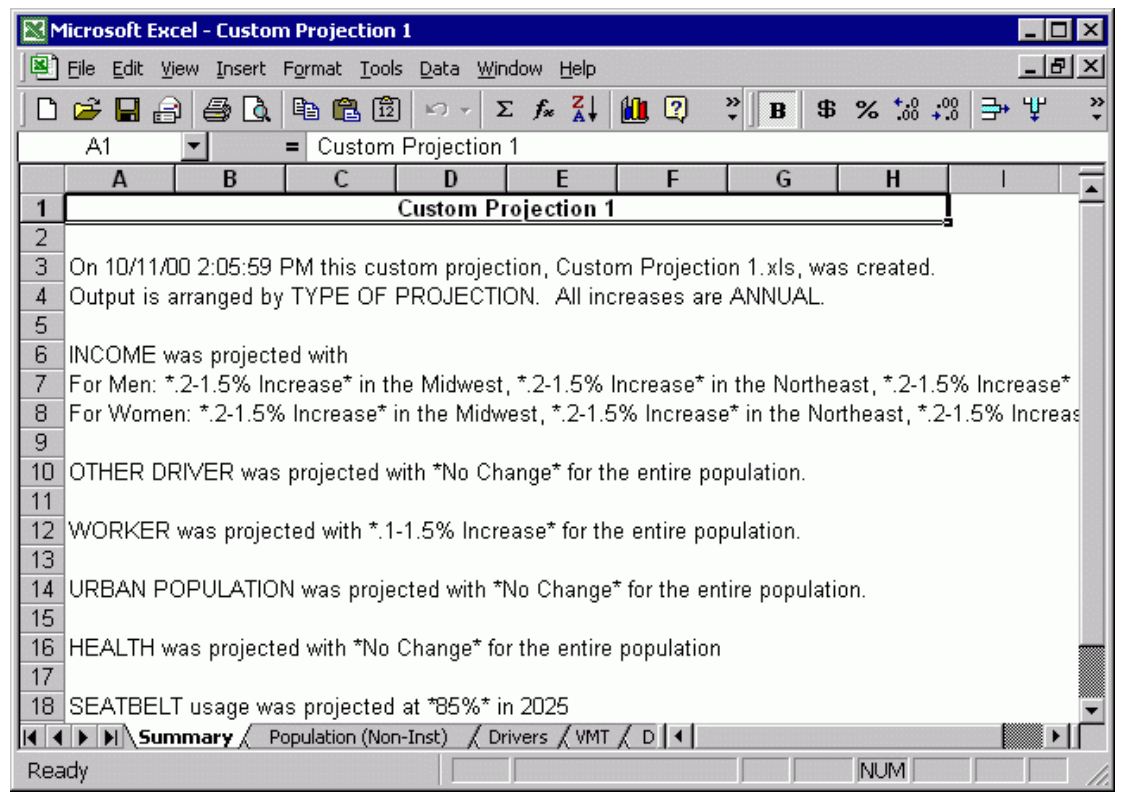

Clicking on one of the sheet tabs will let the user view the various projections made as a result of the wizard. Since this particular projection specified the output arranged by "Type of Projection," the visible tabs include Population, Drivers, VMT, and the risk and fatality measures. 


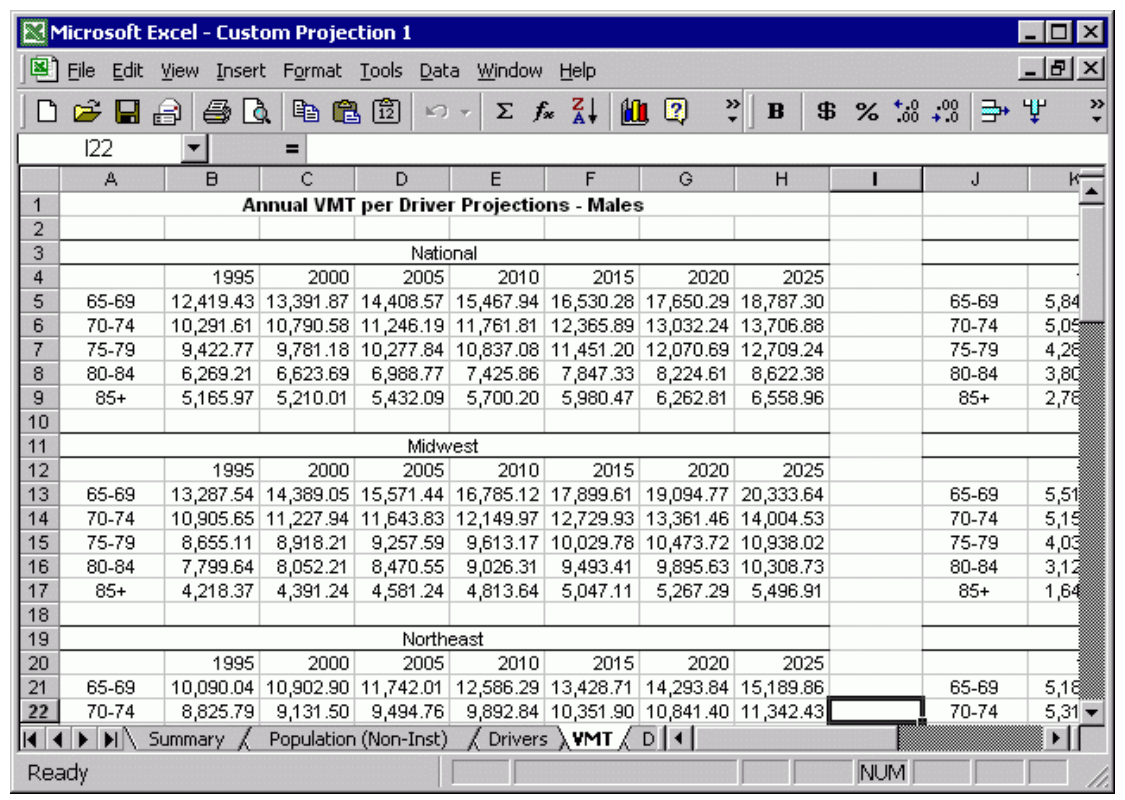

Customized Projections file 


\section{SUMMARY, CONCLUSIONS, AND RECOMMENDATIONS}

\subsection{SUMMARY OF FINDINGS}

As part of this research effort, we developed a new methodology for projecting elderly traffic crash fatalities. This methodology separates exposure to crashes from crash risk per se, and further divides exposure into two components, the number of miles driven and the likelihood of being a driver. This component structure permits conceptually different determinants of traffic fatalities to be projected separately and has thorough motivation in behavioral theory. It also permits finer targeting of particular aspects of projections that need improvement and closer linking of projections to possible policy instruments for influencing them.

\subsubsection{Aggregate Fatality Projections}

Tables 10.1 and 10.2 summarize ORNL's projections of the two fatality measures used in this study, older driver fatalities and the pro-rated total fatalities. Table 10.1 includes fatalities of older drivers only. It is important to recall that our measurement of "total fatalities" (Table 10.2), which extends to passengers in an elder driver's vehicle and to drivers and passengers of other vehicles as well as non-occupants in such a crash, divides the total number of fatalities among the number of vehicles involved in the crash. This procedure effectively excludes some deaths from these crashes from the final measure of total fatalities assigned to elder drivers. The concept was adopted as a concession to the absence of information on which driver in a crash was at fault. Others' definitions of "total" fatalities sometimes include the deaths that we have excluded by our pro-rating procedure. 
Table 10.1. Older Driver Fatality Projections by Age Group, Male and Female

\begin{tabular}{|lrrrrrrr|}
\hline Age Group & \multicolumn{1}{c}{1995} & \multicolumn{1}{c}{2000} & \multicolumn{1}{c}{2005} & 2010 & 2015 & 2020 & \multicolumn{1}{c|}{2025} \\
\hline $65-69$ & 881 & 983 & 1115 & 1425 & 1911 & 2287 & 2688 \\
$70-74$ & 956 & 1045 & 1040 & 1158 & 1447 & 1888 & 2216 \\
$75-79$ & 876 & 1136 & 1212 & 1235 & 1398 & 1793 & 2419 \\
$80-84$ & 704 & 1064 & 1325 & 1448 & 1511 & 1770 & 2329 \\
$85+$ & 474 & 670 & 838 & 1039 & 1202 & 1294 & 1489 \\
Total & $\mathbf{3 8 9 1}$ & $\mathbf{4 8 9 8}$ & $\mathbf{5 5 3 0}$ & $\mathbf{6 3 0 5}$ & $\mathbf{7 4 6 9}$ & $\mathbf{9 0 3 2}$ & $\mathbf{1 1 1 4 1}$ \\
\hline
\end{tabular}

Table 10.2. Total Fatality Projections by Age Group, Male and Female

\begin{tabular}{|lrrrrrrr|}
\hline & 1995 & 2000 & 2005 & 2010 & 2015 & 2020 & 2025 \\
\hline $65-69$ & 1121 & 1267 & 1464 & 1917 & 2628 & 3221 & 3871 \\
$70-74$ & 1094 & 1221 & 1219 & 1369 & 1744 & 2333 & 2802 \\
$75-79$ & 935 & 1240 & 1342 & 1400 & 1627 & 2139 & 2953 \\
$80-84$ & 665 & 1022 & 1282 & 1429 & 1518 & 1803 & 2410 \\
$85+$ & 377 & 530 & 666 & 840 & 990 & 1082 & 1265 \\
Total & $\mathbf{4 1 9 2}$ & $\mathbf{5 2 7 9}$ & $\mathbf{5 9 7 3}$ & $\mathbf{6 9 5 5}$ & $\mathbf{8 5 0 8}$ & $\mathbf{1 0 5 7 9}$ & $\mathbf{1 3 3 0 1}$ \\
\hline
\end{tabular}

\subsubsection{Comparison of ORNL Aggregate Fatality Projections to Other Studies}

Comparison of our projections with two other recent sets of projections for elderly traffic fatalities in the United States (Burkhardt et al. 1998; Wiggers 1999) is instructive. The three studies differ in their methodologies and consequently in their projections. To facilitate the comparison we begin with a recapitulation of the ORNL projection methodology.

\section{The ORNL Projection}

The structure of the ORNL projections is a base of exposure to crash risk, multiplied by a measure of the risk per unit of exposure, multiplied in turn by the population expected to drive. VMT by elderly drivers by gender and age group is the exposure base chosen as representing the most proximate measure of the exposure to the risk of a fatal vehicle crash. The projection of VMT was based on a behavioral regression of the demand for VMT in the previous quarter century (1977-1990/1995), with adjustments made to time trend coefficients used in the projections. The projection of the fatal crash risk per hundred million miles driven 
similarly relied on a regression model embodying driver behavior. The proportion of the various age/gender groups driving also was expected to be important in the future. Analogously to the projection models for VMT and crash risk, these proportions of drivers were modeled as behavioral decisions with regressions on the previous quarter century of data. These expected proportions of drivers were multiplied by the non-institutional populations in each age/gender group (U.S. Census Bureau projections) to derive the total number of drivers who would drive the miles projected by the VMT projection.

Prominent among the advantages of this projection methodology are its flexibility and its indirectness. Its flexibility derives from separately projecting the major components of future elderly driver fatalities: the exposure, the risk, and the proportion of the population expected to be exposed. Its indirectness lies in the fact that the projections of each of these components of driver fatalities depends on the evolution of variables that are known to affect each component, but the projected magnitude of each component itself is not directly manipulated. The difficulty with an indirect procedure is that the estimates of the behavioral relationships between the directly projected variables such as income, health status, employment status, seat belt use, etc., and the magnitude of the associated components of the fatality projections may turn out to be inaccurate. On a more positive note, however, the projected variables generally are phenomena that would be involved directly in policy efforts to manage elderly traffic fatalities.

Table 10.1 reports ORNL's driver fatality projections for men and women combined.

\section{The Burkhardt et al. Projection}

Burkhardt et al. (1998, Figure 2-8, p. 47) project single, total (i.e., male and female) elder driver fatality figures for 2020 and 2030. They do not describe their methodology in detail, but their projections appear to have been based on a linear regression of male VMT on time and possibly other unreported variables over 1968 (or 1983)-1995, with female VMT projected as a constant 1995 fraction of male VMT. Fatality rates per mile were assumed to 
remain constant at 1995 rates and were multiplied by projected VMT, then multiplied by population projections (presumably U.S. Census Bureau projections). This projection method yielded projections of 18,934 and 23,121 elder driver fatalities in 2020 and 2025, compared with 9,032 and 11,140 projected by ORNL for those years. For 2020 the Burkhardt projection is $210 \%$ of the ORNL projection, and that study's 2030 projection is $208 \%$ of ORNL's 2025 projection.

Table 10.3. Burkhardt et al. and ORNL Projections of Elderly Driver Fatalities as a Percent of 1995 Traffic Fatalities

\begin{tabular}{|lccc|}
\hline & 2020 & 2025 & 2030 \\
\hline Burkhardt et al. & $487 \%$ & - & $594 \%$ \\
ORNL & $232 \%$ & $286 \%$ & - \\
\hline
\end{tabular}

The Burkhardt et al. methodology tends to elevate fatality projections by several routes. First, the projection of VMT, whichthey reasonably use as the base of exposure to the risk of a crash, appears to be a straight-line extrapolation of VMT growth over a period during which American travel increased substantially. VMT cannot continue to grow indefinitely for several reasons. First, traveling takes time, more traveling can be expected to take more time, and eventually the projected travel will reach a point beyond which people would no longer be willing to devote their time. Second, highway congestion would reach unacceptable levels which could no longer be alleviated by new construction. The regression from which the VMT is extrapolated apparently does not contain variables that would tend to dampen the growth in VMT as these forces begin to prevail.

The second route by which the Burkhardt et al. methodology gives elevated projections is the assumption of a fixed fatality rate per mile of VMT. Of the three possibilities for the progress of this rate-increasing, constant, or decreasing — their choice eliminates the potential for improvements in safety technology or behavior to depress the 
trend of fatal crashes in the future. Our own empirical examination of the fatal driver crash rate per mile (per hundred million miles, more precisely) showed negative relationships between the crash rate and two important variables that are widely expected to increase over time, elderly income and seat belt use.

Pegging female VMT to 1995 male VMT dampened the growth of female elderly VMT over the ensuing thirty-five years, which in turn would have dampened the projection of female driver fatalities. Evidently this source of under-projection did not compensate for the two sources of over-projection - the straight-line extrapolation of VMT growth and the constant crash rate per mile.

\section{The Wiggers Projection}

Wiggers (1999, Table 2) separately projected elder driver and passenger fatalities by the same age groups used here, and by gender, for 2020 and 2030. Wiggers's methodology assumed that VMT and all other driving behavior would remain constant (1999, p. 4), and he projected driver fatalities as a linear extrapolation of elderly fatality rates per 100,000 population, times population growth. To obtain the trend of elderly fatality rates, Wiggers regressed fatality rates calculated from FARS data on time over the period 1975-1997. To avoid the possibility of projecting negative fatalities for some timein the future, he rejected regressions that yielded negative regression coefficients (1999, p. 4, n. 5). Another motivation for this exclusion of negative coefficients was to represent a diminishing effect of safety improvements on fatalities, but a negative regression coefficient on time would not necessarily imply a non-diminishing effect of safety improvements. (The use of time and the square of time as separate regressors could have accounted for diminishing effectiveness of safety improvements while still permitting them to contribute to reductions of fatalities. A negative coefficient on the time variable and a positive coefficient on time squared would be interpreted as a positive effect of safety technology with diminishing effects over time.) 
Wiggers' projections do not show a simple pattern relative to the ORNL projections. We summarize the out-year projections for Wiggers and ORNL in Table 10.4, which compares the ORNL driver fatality projections for 2025 with Wiggers' two years, as percents of actual historical driver fatalities. As the first row of Table 10.4 shows, ORNL's projections are considerably higher than Wiggers' for 2020 for each male age group except $85+$ but are slightly lower than Wiggers' for 70-74 and 75-79 females. Although ORNL's 2025 projection and Wiggers' 2030 projection are not directly comparable, the implied growth trends nonetheless can be compared. Wiggers' 2030 projections for the three younger male age groups are substantially lower than ORNL's 2025 projections for those groups and considerably higher for the two oldest male age groups. Wiggers' 2030 projection for 65-69 females is nearly half again the magnitude of ORNL's 2025 projection for that group, his projections for 70-74 and 75-79 women are considerably higher than ORNL's, and the Wiggers 2030 projections for the two oldest groups of women are virtually the same as ORNL's 2025 projections for those age groups.

Table 10.4. Wiggers' and ORNL's Projections of Elderly Driver Fatalities as a Percent of Historical Fatalities

\begin{tabular}{|c|c|c|c|c|c|}
\hline \multicolumn{6}{|c|}{ Males } \\
\hline Projection & $65-69$ & $70-74$ & $75-79$ & $80-84$ & $85+$ \\
\hline 2020 Wiggers* & $149 \%$ & $145 \%$ & $151 \%$ & $198 \%$ & $319 \%$ \\
\hline 2020 ORNL** & $230 \%$ & $195 \%$ & $208 \%$ & $225 \%$ & $213 \%$ \\
\hline 2025 ORNL*** & $267 \%$ & $225 \%$ & $275 \%$ & $295 \%$ & $240 \%$ \\
\hline 2030 Wiggers* & $157 \%$ & $179 \%$ & $228 \%$ & $360 \%$ & $514 \%$ \\
\hline \multicolumn{6}{|c|}{ Females } \\
\hline Projection & $65-69$ & $70-74$ & 75-79 & $80-84$ & $85+$ \\
\hline 2020 Wiggers* & $241 \%$ & $223 \%$ & $215 \%$ & $220 \%$ & $320 \%$ \\
\hline 2020 ORNL** & $327 \%$ & $202 \%$ & $200 \%$ & $306 \%$ & $408 \%$ \\
\hline 2025 ORNL*** & $394 \%$ & $243 \%$ & $277 \%$ & $405 \%$ & $481 \%$ \\
\hline 2030 Wiggers* & $299 \%$ & $320 \%$ & $361 \%$ & $414 \%$ & $491 \%$ \\
\hline
\end{tabular}

* Numbers are given as a percentage of 1993-97 average fatalities

** Numbers are given as a percentage of 1995 average fatalities 
The base of exposure to crash risk in Wiggers' methodology is the elderly population rather than any measure of their behavior. As Wiggers himself notes, this choice of exposure base forces an assumption of several dimensions of unchanged driving behavior - not only VMT but the choice of whether to be a driver or not. Neither of these assumptions is reasonable when considering American elderly driving during the first quarter of the twentyfirst century.

The consequences of Wiggers' systematic exclusion of a declining fatality rate for his projections are not entirely clear-cut. Assuming that the fatality rate per mile did not decline clearly would have biased the projections upward, but Wiggers buried any changes in VMT within the growing elderly population, which he assumed to not change its driving behavior. Consequently he projected a fatality rate per population that is a combination of safer driving and more driving, and he forced it to yield a net effect reflecting more driving. This empirical result of VMT dominating the fatality projections runs counter to what ORNL learned about the net effect of growing real income on fatalities. Income growth was a major determinant of projected VMT growth and of the driver percentage, and both of those components had a major influence on projected fatalities. However, income was negatively related to the fatal driver crash rate, and its influence on the projected number of driver fatalities through that route outweighed its combined effects throughVMT growth and "driver" growth: overall, income growth among the elderly population had a slight, dampening effect on the projection of elder driver fatalities.

\section{Summary}

The inability to determine an endogenous asymptote on VMT growth required an exogenous supplementation in the ORNL projection: adjusting the time trend on 65-69 male VMT in 2025 to be no greater than 35-39 male VMT in 1995, but letting all other age-gender groups' VMT grow in empirically determined proportion to VMT in that age-gender group. This is a feature of the ORNL projection worth trying to improve, but it probably leaves our projection of VMT at the high end of what is reasonable and consequently makes our elder 
driver fatality projections at the high end of what are reasonable. Another possible source of upward bias in the ORNL driver fatality projections resides in the projections of female crash rates. Our regression-based projections show a declining driver crash rate, based largely on income growth and more extensive seat belt use. However, many of the elderly women in the statistical sample on which these relationships are based began driving at later ages whereas the women in, say, the 70-75 age group in 2020 and 2025 well may have nearly 60 years of driving experience. This longer driving experience for the elderly women of the future may further reduce their fatal crash rates. We reiterate that we consider the ORNL projections of elder driver fatal crashes to be at the high end of what are reasonable projections.

The Burkhardt et al. projections are substantially higher than the ORNL projections, for reasons that are clearly traceable in their methodology: upward bias in VMT growth (the exposure base) and a constant fatal crash rate per mile (risk per unit of exposure). Wiggers' projections, using population as the exposure base, do not offer as clear insights into the sources of their differences from the ORNL projections, but that choice of exposure base probably is responsible for the relatively unsystematic differences between his and ORNL's projections, depending on age-gender group. However, it would not be appropriate to declare Wiggers' age-gender specific driver fatality projections superior to ORNL's when they are lower because of the behavioral rigidities built into his projections by his methodology.

\subsubsection{Disaggregated Projection Results}

Table 10.4 shows ORNL fatality projections as percents of 1995 driver fatalities. Men and women in aggregate, and by age groups, have widely different fatality projections for 2025. The male driver fatalities overall grow by less than the female fatalities, but male driver fatalities for ages 75-79 are projected to grow by more than females in that age group. The female driver fatalities in the $85+$ age group are projected to grow by more than twice the male fatalities. The results of that particular age group are attributable to much greater growth in the female driver population and VMT when compared to the male driver 
population, and a slightly smaller reduction in women's crash risk than men's, which outweighed the effects of substantially larger effect of population growth among males.

Table 10.5. Elder Driver Fatality Projections for 2025 (as Percentages of 1995 Driver Fatalities)

\begin{tabular}{|ccc|}
\hline Age Group & Male & Female \\
\hline $65-69$ & $301.3 \%$ & $457.8 \%$ \\
$70-74$ & $236.7 \%$ & $295.0 \%$ \\
$75-79$ & $325.5 \%$ & $297.0 \%$ \\
$80-84$ & $329.3 \%$ & $441.5 \%$ \\
$85+$ & $261.1 \%$ & $526.1 \%$ \\
Total & $290.8 \%$ & $375.9 \%$ \\
\hline
\end{tabular}

The forces behind the growth of driver fatalities among men and women also differ. In general, population growth had the greatest effect on growth in male driver fatality projections, and growth of driver populations and VMT were the largest influences on the growth of female driver fatalities. Reductions in crash risk were more influential in retarding the growth of female driver fatalities in the 70-74 and 75-79 age groups, and the greatest impact on males ages 80-84. Growth of driver population contributed very little to the growth in male driver fatalities, although it was larger in the 80-84 and 85+ age groups than in the younger groups. Correspondingly, growth of driver population contributed more to growth of female driver fatalities in the two oldest age groups than in the three younger groups. Reductions in crash risk were more important in dampening female fatality growth among the 70-74 and 75-79 age groups than among any other female age group and more than among the corresponding male age groups. 


\subsection{CONCLUSIONS}

The increases in the numbers of elderly fatal traffic crashes will likely be large, but much of the growth will simply be a consequence of population growth. Much of the remaining increase will be a consequence of social changes, particularly the growing similarity in male and female social roles. The outlook would be worse, however, were it not for projections of substantial decreases in crash risks.

Laying the responsibility for this growth in traffic fatalities at the door of population growth and greater mobility does little to offer constructive public policy to address the problem. However, examination of the forces contributing to the growth of VMT per driver, driver percentages, and crash risks offers some insights into constructing policies. First, through its influence on VMT and driver populations, employment status has a relatively important influence on driver fatality projections. A one percent larger fraction of 65-69 yearold men in the labor force would entail a $1 \frac{1}{2} \%$ increase in the number of driver fatalities in that group in 2025. This is a comparison of alternative labor force participation rates in 2025 for this age group of men, not a comparison of their labor force participation rates in 1995 and 2025. For 65-69 year-old women, the same change in labor force participation would be associated with a $b \%$ increase in driver fatalities. We consider this a serious sensitivity to the labor force participation rate. Social Security retirement ages have risen by as much as two years for people born in 1960 or later, which definitely will increase the labor force participation rate in this youngest five-year age group of elderly. Many of these people will want to continue working, and keeping them from the labor force would be counterproductive not only from the perspective of the financial viability of the Social Security program but in terms of their own satisfaction with life. Nonetheless, alternatives such as remote working, working fromhome, and related developments made viable by the current and future revolutions in communications technologies couldbe exploited to target this group for effective mobility with lower exposure to traffic crashes. 
Second, improvements in health status, as captured by our construct in this study, are projected to lead to an increase in elder driver fatalities. Had we been able to find a satisfactory relationship of health status in our crash risk models, this effect might have been attenuated, but as far as we were able to ascertain, the most reliable consequences of improved health status were to encourage greater mobility—larger driver percentages and more VMT. However, much medical research is being directed to specific ailments that retard such driving-related capabilities as vision fields and depression. Our findings underscore the importance of such research.

A third major influence on driver fatalities, of comparable magnitude to those of employment and health status, was seat belt use. Higher rates of seat belt use can be encouraged, and education among today's younger age groups can build durable habits.

A fourth finding of particular interest is the relative unimportance of income growth in the growth of elder driver fatalities. Since income growth is an important influence on both VMT growth and the growth of driver populations, it would not have been surprising had income growth been a major determinant of elderly fatalities. However, income growth is projected to make even greater contributions to the reduction in crash rates. This retarding effect of income on crash rates has a net lowering effect on total fatalities, although its effects on VMT and driver populations contribute to the growth of elder driver fatalities. Increases in elderly income do suggest, on the positive side, that older drivers in the future will be better equipped financially to purchase new vehicles with newer safety technology and correspondingly that education programs about the availability and effectiveness of such equipment targeted to them could be funds well spent.

\footnotetext{
${ }^{1}$ For only one example of this type of targeted research, see Rubin et al., 1998, especially Section 13, "Preliminary Study of the Relationship between Vision and Crash Involvement."
} 


\subsection{DIRECTIONS FOR FUTURE RESEARCH}

\subsubsection{The Role of Infrastructure and Equipment}

Our approach to projection of elderly traffic fatalities permits us to attribute those changes over the next twenty-five years to specific causes, such as better health putting more elderly drivers on the roads. With the data available, however, we have been unable to identify the effects of specific technological and infrastructure changes over the past quarter century and are hence unable to incorporate projections of how they could be expected to affect elderly fatalities in the future. The best we have been able to do so far is to identify time trends in VMT and the percentage of drivers which are not otherwise explained by the variables in the model. To project effects of, say, ITS innovations or further vehicle safety improvements on elderly fatalities we could vary the time trends in the VMT and driver componentsof our projection (time trends were not successful in the fatality rate regressions), but the magnitude of the effects would be hypothetical. More direct study of the effects of equipment and infrastructure changes on the components of elderly fatalities could permit more precise projections of the direct and indirect consequences of improvements in those elements of the transportation system. Study of these improvements, coupled with investigations of negative effects such as deteriorations of certain infrastructure components and the increasing negative impact of driver distractions such as cellular phones, can offer more informative guidance for policy choices. See also Section 3.3.5 on current research on these technologies.

\subsubsection{Asymptotic Projection of VMT}

The regression model underlying the projection of VMT does not contain any internal mechanism that would tend to limit the growth of VMT as its various determinants increase in value, a phenomenon we should expect because driving requires people to use their time. Although we have imposed an asymptote on the projections of VMT, we still consider our fatalities projections to be at the high end of what is reasonable, since we think that the base 
projections of VMT may be high. Our attempts to estimate a household production model of VMT were hampered by lack of data. This production model could help account for the fact that higher income would give people a higher cost of using their time to drive as well as directly increasing their demand for driving. It may be possible to combine data on time use from other surveys with NPTS data to better account for the dampening effect of time requirements on increasing VMT. Other, complementary approaches to estimating a household production model could examine interactions of vehicle fuel efficiency, fuel,and vehicle safety features simultaneously with the demand for VMT.

\subsubsection{Additional and Improved Measures of Health Status}

A third area that needs further research is the construction of a measure of health status. In the present effort we developed a method to transfer structural relationships regarding the ALS construct from the NHIS survey on health to the NPTS survey data base on driving behavior. It would be useful to identify other health indicators relevant to driving behavior for such cross-data base transfer. Even more useful would be to combine questions about driving and health status directly in a single survey, but that would lead to research capabilities only well in the future. Other more comprehensive data bases that link health status with VMT, driving vs non-driving, or crash information—or any combination of the three travel behaviors-should be examined for the possibilities of behavioral modeling to further identify choice relationships. The relative frailty of older cohorts, meaning the likelihood that a crash that a younger driver would survive could kill an older driver, is lost within the age-specific crash risks estimated in our crash risk regressions and projected from those equations. Identifying the contribution of such frailty to elderly fatalities or crash risks would be empirically demanding. Such identification would require individual-level observations on crashes with information on type of crash (head-on, side, single-vehicle,

multiple-vehicle), estimated speed of impact, make/model/year of vehicles of each party to the crash, and age of driver (or of each passenger killed). These information requirements might be met from some state records if not at the national level. As a policy issue such 
frailty may be reduced by improving elderly health trends or through general technological improvements in safety equipment that can help a frail person survive a crash.

\subsubsection{Comparison of Younger and Older Drivers' Behavior}

This study's finding of the importance of employment status as a determining force in elder driver fatalities points to the question of how much of this effect is a pure age effect and how much is comparable to the exposure to crash risk faced by all working drivers. This issue can be addressed to some extent with currently available information, but projection of younger fatalities into the future would require income projections for the younger age groups, which may behave quite differently from those of the elderly living between 2000 and 2025. Another issue that bears further investigation is age-specific seat belt use. The seat belt use information available for this study was population-wide. If age- and/or genderspecific seat belt use information were made available, it might be possible to study seat belt use as a choice made simultaneously with other driving choices such as VMT, driving, and crash rate.

\subsubsection{Alternative Transportation Options for the Elderly}

As noted in Section 10.3.1, there are several uncertainties regardingmobility of the elderly in the future. The impacts of smart cars, infrastructure enhancements, and innovative safety programs and/or components can simply not be quantified at this time. However, current trends are to solve the problems of traffic congestion, air pollution, and safety through better engineering and creative approaches to public transportation rather than by building new roads. The need for alternative mobility options for the elderly is well recognized, and various concepts for making transit use more acceptable to elderly riders are being explored.

Additional research is needed in the areas of public transportation as well as other alternative mobility options. For example, more information on public transit is needed (1) to identify the features that the elderly desire in a transit system (price/method of payment, ease 
of entry/exit, safety, security, etc.), (2) to determine where and when and for what purposes the elderly would use transit, (3) to describe potential options for rural conditions, and (4) to develop a methodology for predicting transit success. In addition, public comment would be helpful to quantify the appeal and/or value of elderly communities that encourage pedestrian trails or "golf-cart" types of transportation within the community. Other approaches to achieving mobility and an acceptable quality of life for the elderly should also be explored. Although many of these research components have been considered in part (as noted in Section 3), there has been no attempt to consolidate all of the research into a single data repository. 


\section{REFERENCES}

Administration on Aging. 1997.Demographic Changes. U.S. Department of Health and $\mathrm{H} \mathrm{u} \mathrm{m} \mathrm{a} \quad \mathrm{S}$ e r v i e s. W a s h i g t o n, D. C. http://pr.aoa.dhhs.gov/aoa/stats/aging21/demography.html.

Administration on Aging. 1999. Profile of Older Americans: 1999. U.S. Department of Health and Human Services. Washington, D.C. http://pr.aoa.dhhs.gov/aoa/stats/profile/.

Administration on Aging. 2000. Transportation and the Elderly. U.S. Department of Health and Human Services. Washington, D.C. http://www.aoa.gov/factsheets/Transportation.html

American Health Care Association. 1997. The Nursing Home Facility Sourcebook: Facts and Trends - 1997. p. 7.

American Health Care Association. 1998. "The Looming Crisis." http://www.ahca.org/secure/nfres.htmand http://ahca.org/secure/alres.htm.

American Psychological Association. 1996. "Touch-Screen Computer Program Predicts Crash Risk in Older Drivers," APA Public Communications. http://www.apa.org/releases/drivers.html

American Psychological Association (Scott Sleek, Monitor staff). 1996. "Gauging When Drivers Are Too Old," APA Public Communications. http://www.apa.org/monitor/sep96/drivingd.html

Asher, Cheryl Carleton. 1992. "Hedonic Analysis of Reliability and Safety for New Automobiles," Journal of Consumer Affairs. Vol. 26, pp. 377-396.

Ball, Karlene. 1997. "Attentional Problems and Older Drivers." Alzheimer Disease and Associated Disorders. Vol. 11, Suppl. 1, pp. 42-47.

Ball, Karlene, Cynthia Owsley, Beth Stalvey, Daniel L. Roenker, Michael E. Sloane, and Mark Graves. 1998. "Driving Avoidance and Functional Impairment in Older Drivers." Accident Analysis and Prevention. Vol. 30, No. 3, pp. 313-22.

Bawks, Bruce. Personal communication.Bruce.Bawks@eia.doe.gov.

Becker, Gary S. 1965. "A Theory of the Allocation of Time.” Economic Journal. Vol. 75, pp. 493-517. 
Blincoe, Lawrence. 1994. Estimating the Benefits from Increased Safety Belt Use. NHTSA Technical Report.

Bogren, Scott. 1998. "From the Editor: Mobility. It Makes a Big Difference."Community Transportation: Meeting the Needs of Seniors. Vol. 17, No. 7, p. 5.

Burkhardt, J. 1998A. "Safe Mobility for Life." Community Transportation: Meeting the Needs of Seniors. Vol. 17, No. 7, p. 20.

Burkhardt, Jon E. 1998B. "Mobility and Independence: Changes and Challenges for Older Drivers." Prepared for the Older Driver Conference: Policy Challenges for a New Age, Sponsored by the Illinois Department on Aging.

Burkhardt, Jon, Arlene M. Berger, Michael Creedon, and Adam T. McGavock 1998. Mobility and Independence: Changes and Challenges for Older Drivers. Ecosometrics Inc., Bethesda, Maryland.

Burkhardt, J., A. Berger, and A. McGavock. 1996. "The Mobility Consequences of the Reduction or Cessation of Driving by Older Women." Pp. 441-453 in Women's Travel Issues: Proceedings from the Second National Conference, October 1996. U.S. Department of Transportation. FHWA-PL-97-024.

Burkhauser, Richard V., and Paul J. Gertler (Eds.). 1995. "The Health and Retirement Study, Data Quality and Early Results," in Journal of Human Resources (Special Issue), 30 (Supplement), University of Wisconsin Press.

Caird, J. K. 1999. "In-Vehicle Intelligent Transportation Systems (ITS) and Older Drivers' Safety and Mobility," prepared for the Transportation Research Board Conference on Transportation in an Aging Society, Bethesda, Maryland.

Carr, Deborah, Anu Pemmarazu, and Dorothy P. Rice (Eds). 1996. Improving Data on America's Aging Population: Summary of a Workshop. National Academy Press, Washington, D.C.

Coroni-Huntley, J., D.B. Brock, A. Ostfeld, et al. 1986. "Established Populations of Epidemiologic Studies of the Elderly." NIH Pub. No. 86-2443. National Institute on Aging, U.S. Dept. of Health and Human Services.

Day, Jennifer Cheeseman. 1996. Population Projections of the United States by Age, Sex, Race, and Hispanic Origin: 1995 to 2050. U.S. Bureau of the Census, Current Population Reports, P25-1130, U.S. Government Printing Office, Washington, D.C. 
Duchek, Janet M., Linda Hunt, Karlene Ball, Virginia Buckles, and John C. Morris. 1998. "Attention and Driving Performance in Alzheimer's Disease." Journal of Gerontology: Psychological Sciences. Vol. 53B, No. 2, pp. 130-141.

Eberhard, J. W. 1996. "Safe Mobility for Senior Citizens,"pp. 27-37 in Journal of International Association of Traffic and Safety Sciences. Vol. 20(1).

Eby, David W., Deborah A. Trombley, Lisa J. Molnar, and Jean T. Shope. 1998. The Assessment of Older Drivers' Capabilities: A Review of the Literature. UMTRI 98-24. The University of Michigan Transportation Research Institute.

Evans, Leonard. 1988. "Older Driver Involvement in Fatal and Severe Traffic Crashes." Journal of Gerontology: Social Sciences. Vol. 43, No. 6, S186-193.

Evans, Leonard, Peter H. Gerrish, and Bahram Taheri. 1998. "Epidemiology of the Older Driver: Some preliminary findings from data through 1996." Paper No. 98-S6-W49. Proceedings of the $16^{\text {th }}$ International Technical Conference on the Enhanced Safety of Vehicles, Windsor, Canada, June 1-4, 1998. [based on GM/DOT study G.1]

Fields, Robert, and Gale Valtinson. 1998. "The Assessment of Older Drivers: Neuropsychological Predictors and State Laws." [poster presentation at 1998 meeting of the American Psychological Association, San Francisco]

Foley, D. J., R.B. Wallace, and J. Eberhard. 1995. "Risk Factors for Motor Vehicle Crashes among Older Drivers in a Rural Community." Journal of the American Geriatrics Society. Vol. 43, No.7. Pp. 776-781.

Freedman, Vicki, and Linda G. Martin. 1998. "Understanding Trends in Functional Limitations Among Older Americans." American Journal of Public Health. Vol. 88, No. 10. Pp. 1457-1462.

Gerontological Society of America. 1997. The Journals of Gerontology: Series B: Psychological and Social Sciences. Vol. 52B. Special Issue: "Asset and Health Dynamics Among the Oldest Old (AHEAD): Initial Results from the Longitudinal Study."

Gilford, Dorothy M. (Ed.). 1988. The Aging Population in the Twenty-First Century: Statistics for Health Policy. National Academy Press, Washington, D.C.

Greening, Lorna A., Hann Tarn Jeng, John P. Formby, and David C. Cheng, 1994. "Use of Region, Life-Cycle, and Role Variables in the Short-Run Estimation of the Demand for Gasoline and Miles Traveled," Division of Research and Service, 
College of Commerce and Business Administration, University of Alabama, WP 94-01.

Hakamies-Blomqvist, Liisa. 1999. "Safety of Older Persons in Traffic," prepared for the Transportation Research Board Conference on Transportation in an Aging Society, Bethesda, Maryland.

Hersch, Susan Winter. 1997. "Older Drivers: License Restriction vs. Revocation." Research Notes. http://www.dmv.ca.gov/profile/rd/resnotes/older.htm

Hobbs, Frank B., and Bonnie L. Damon. 1996. 65+ in the United States. U.S. Bureau of the Census. Current Population Reports, Special Studies, P23-190. U.S. Government Printing Office, Washington, D.C.

Hu, P.S., Jennifer R. Young, and An Lu. 1993. Highway Crash Rates and Age-Related Driver Limitations: Literature Review and Evaluation of Data Bases. ORNL/TM12456. Oak Ridge National Laboratory.

Hu, P.S., David Trumble, and An Lu. 1995. "Driving Decisions and Vehicle Crashes among Older Drivers.” ORNL/M-4620. Oak Ridge National Laboratory.

Hu, Patricia S., David A. Trumble, Daniel J. Foley, John W. Eberhard, and Robert B. Wallace. 1998. "Crash Risks of Older Drivers: A Panel Data Analysis," Accident Analysis and Prevention. Vol. 30, No. 5, pp. 569-581.

Janke, Mary K. 1991. "Accidents, Mileage, and the Exaggeration of Risk," Accident Analysis and Prevention Vol. 23, Nos. 2-3, pp. 183-188.

Janke, Mary K. 1997. "Dementia/Frailty Study - Where Are We Now?" Research Notes. http://www.dmv.ca.gov/profile/rd/resnotes/dfstudy.htm

Jeff, G., and R. McElroy. 1996. “Women's Travel: Consequences and Opportunities.” Pp. 81-93 in Women's Travel Issues: Proceedings from the Second National Conference, October 1996. U.S. Department of Transportation. FHWA-PL-97024.

Johnson, Kenneth M., and Calvin L. Beale. 1999. "The Continuing Population Rebound in Nonmetro America," Rural Development Perspectives. Vol. 13(3), http://www.ers.usda.gov/epubs/pdf/rdp/rdp1098/index.htm

Koppa, Rodger. 1999. "Motor Vehicle Adaptive Equipment and Modifications," prepared for the Transportation Research Board Conference on Transportation in an Aging Society, Bethesda, Maryland. 
Kostyniuk, Lidia P., Deborah A. Trombley, and Jean T. Shope. 1998. The Process of Reduction and Cessation of Driving Among Older Drivers: A Review of the Literature. UMTRI-98-23. The University of Michigan Transportation Research Institute.

Manton, Kenneth G., Larry Corder, and Eric Stallard. 1997. "Chronic Disability Trends in Elderly United States Populations: 1982-1994,” pp. 2593-2598 in Proceedings of the National Academy of Sciences USA. March 1997

Manton, Kenneth G., Eric Stallard, and Burton H. Singer. 1994. "Methods for Projecting the Future Size and Health Status of the U.S. Elderly Population,"pp. 44-77 in Studies in the Economics of Aging, David A. Wise, Ed., University of Chicago Press, Chicago.

Marottoli, Richard A., Adrian M. Ostfeld, Susan S. Merrill, Gary D. Perlman, Daniel J. Foley, and Leo M. Cooney, Jr. 1993. "Driving Cessation and Changes in Mileage Driven Among Elderly Individuals." Journal of Gerontology: Social Sciences. Vol. 48, No. 5, pp. S255-S260.

Massie, Dawn L., Paul E. Green, and Kenneth L. Campbell. 1997. "Crash Involvement Rates by Driver Gender and the Role of Average Annual Mileage." Accident Analysis and Prevention. Vol. 29, No. 5, pp. 675-685.

Massie, Dawn L., Kenneth L. Campbell, and Allan F. Williams. 1995. "Traffic Accident Involvement Rates by Driver Age and Gender." Accident Analysis and Prevention. Vol. 27, No. 1, pp. 73-87.

McGwin, Gerald, Jr., Cynthia Owsley, and Karlene Ball. ND. "Identifying Crash Involvement Among Older Drivers: Agreement Between Self-report and Staterecords." Paper submitted to Accident Analysis and Prevention.

Murray, Christopher J. L., and Alan D. Lopez. 1997. "Alternative Projections of Mortality and Disability by Cause 1990-2020: Global Burden of Disease Study." The Lancet. Harvard School of Public Health. Vol. 349, pp. 1498-1504.

Myers, George C., Ed. 1997. "Asset and Health Dynamics Among the Oldest Old (AHEAD): Initial Results From the Longitudinal Study," The Journals of Gerontology, Series B: Psychological and Social Sciences, 52B (Special Issue).

Myers, Renee S., Karlene K. Ball, Thomas D. Kalina, David L. Roth, and Kathryn T. Goode. ND. "The Relationship of Useful Field of View and Other Screening Instruments to On-Road Driving Performance." [draft paper] 
National Association of Development Organizations Research Foundation. 1999. "Focus on Rural America," Economic Development Digest. Vol. 10, No. 6, pp. 1-3.

National Highway Traffic Safety Administration. 1999A. "Traffic Safety Facts 1998: Overview." http://www.nhtsa.dot.gov/people/ncsa/pdf/Overview98.pdf.

National Highway Traffic Safety Administration. 1999B. "Research Note: Observed Safety Belt Use in 1998." http://www.nhtsa.dot.gov/people/ncsa/98obbelt.html.

Owsley, Cynthia, Gerald McGwin, Jr., and Karlene Ball. 1998. "Vision Impairment, Eye Disease, and Injurious Motor Vehicle Crashes in the Elderly." Ophthalmic Epidemiology. Vol. 5, No. 2. Pp. 101-113.

Owsley, Cynthia, Karlene Ball, Gerald McGwin, Jr., Michael E. Sloane, Daniel L. Roenker, Milton F. White, and E. Todd Overley. 1998. "Visual Processing Impairment and Risk of Motor Vehicle Crash Among Older Adults." The Journal of the American Medical Association. Vol. 279, No. 14, pp. 1083-1088.

Pickerell, Don, and Paul Simek. 1999. "Growth in Motor Vehicle Ownership and Use: Evidence from the Nationwide Personal Transportation Survey," Journal of Transportation and Statistics. Vol. 2, pp. 1-17.

Pike, Jeffrey A. 1999. "Protecting the Older Driver - Vehicle Concepts," prepared for the Transportation Research Board Conference on Transportation in an Aging Society, Bethesda, Maryland.

Roenker, Daniel L., Gayla M. Cissell, and Karlene K. Ball. ND. "The Effects of Useful Field of View and Driving Simulator Training on Driving Performance." [draft paper]

Rogers, Carolyn C. 1999. "Growth of the Oldest Old Population and Future Implications for Rural Areas," Rural Development Perspectives. Vol. 14, No. 3, http://www.ers.usda.gov/epubs/pdf/rdp/rdpoct99/rdpoct99d.pdf.

Rubin, Gary S., Sheila K. West, and Kathleen Turano, Claudia Kawas, Scott Zeger, Beatriz Muñoz, Jennifer Istre, and Janet O'Conner. 1998. "Salisbury Eye Evaluation Study," mimeo, Johns Hopkins University.

Schatz, Sally, Jane Stutts, and Jean Wilkins. 1999A. "The Decision to Stop Driving: Results of Focus Groups with Seniors and Family Members." Proceedings, Transportation Research Board, $78^{\text {th }}$ Annual Meeting.

Schatz, Sally, Jane Stutts, and Jean Wilkins. 1999B. "The Premature Reduction and Cessation of Driving: A Preliminary Study of Women Who Choose Not to Drive 
or to Drive Infrequently." Proceedings, Transportation Research Board, $78^{\text {th }}$ Annual Meeting.

Sarmiento, S. 1996. "Household, Gender, and Travel." Pp. 37-52 in Women's Travel Issues: Proceedings from the Second National Conference, October 1996. U.S. Department of Transportation. FHWA-PL-97-024.

Sims, Richard V., Cynthia Owsley, Richard M. Allman, Karlene Ball, and Tonya M. Smoot. 1998. "A Preliminary Assessment of the Medical and Functional Factors Associated with Vehicle Crashes by Older Adults." Journal of the American Geriatrics Society. Vol. 46, pp. 556-561.

Smiley, Alison. 1999. "Adaptive Strategies of Older Drivers," prepared for the Transportation Research Board Conference on Transportation in an Aging Society, Bethesda, Maryland.

Social Security Administration. 1999. "Social Security Retirement Benefits," Pub. No. 0510035, http://www.ssa.gov/pubs/10035.html.

Stamatiadis, Nikiforos. 1999. "Gender Effect on the Accident Patterns of Elderly Drivers," Proceedings of the 9th International Conference on Traffic Safety on Two Continents.

Staplin, Loren, and Linda Hunt. 1999. "Driver Programs," prepared for the Transportation Research Board Conference on Transportation in an Aging Society, Bethesda, Maryland.

Staplin, Loren. 1999. "Highway Enhancements to Improve the Safety and Mobility of Older Road Users: Practical Applications of Current Devices," prepared for the Transportation Research Board Conference on Transportation in an Aging Society, Bethesda, Maryland.

Stewart, R.B., M.T. Moore, R.G. Marks, F.E. May, and W.E. Hale. 1993. "Driving Cessation and Accidents in the Elderly: An Analysis of Symptoms, Diseases, Cognitive Dysfunction and Medications," AAA Foundation for Traffic Safety, Washington, D.C.

Straight, Audrey. 1997. Community Transportation Survey. Public Policy Institute, American Association of Retired Persons. Washington, D.C.

Suen, Ling. 1999. "Mobility Alternatives for Seniors," prepared for the Transportation Research Board Conference on Transportation in an Aging Society, Bethesda, Maryland. 
Suen, S. Ling, C. G. B. Mitchell, and Steve Henderson. 1998. "Application of Intelligent Transportation Systems to Enhance Vehicle Safety for Elderly and Less Able Travellers," Paper No. 98-S2-O-03. Transportation Development Centre, Transport, Canada.

Teets, Mary K. (Ed.). 1997. Highway Statistics Summary to 1995. FHWA-PL-97-009, U.S. Department of Transportation, Federal Highway Administration, Washington, D.C.

Tufano, Daniel R. 1997. "Automotive HUDs: The Overlooked Safety Issues," Human Factors. Vol 39, No. 2, pp. 303-311.

U.S. Census Bureau, U.S. Department of Commerce. 1999. Statistical Abstract of the United States. http://www.census.gov/prod/www/statistical-abstract-us.html.

U.S. Census Bureau, U.S. Department of Commerce. 1975. Historical Statistics of the United States, Colonial Times to 1970. U.S. Government Printing Office, Washington, D.C.

U.S. Census Bureau, U.S. Department of Commerce. http://www.census.gov.

U.S. Department of Transportation, Federal Highway Administration. 1997A. Improving Transportation for a Maturing Society. DOT-P10-97-01.

U.S. Department of Transportation, Federal Highway Administration. 1993. 1990 NPTS Databook Volume I, p. 4-37.

U.S. Department of Transportation, Federal Highway Administration. 1997B. Highway Statistics Summary to 1995. FHWA-PL-97-009.

U.S. Department of Transportation, Federal Highway Administration. 1998. Older Driver Highway Design Handbook.FHWA-RD-97-135.

Van Nostrand, J.F., Sylvia E. Furner, and Richard Suzman (Eds.). 1993. Vital and Health Statistics: Health Data on Older Americans: United States, 1992. U.S. Department of Health and Human Services, Centers for Disease Control and Prevention. National Center for Health Statistics. Series 3, No. 27.

Wallace, Robert B., and Daniel Franc. 1999. Literature Review of the Status of Research on the Transportation and Mobility Needs of Older Women. DOT HS 808949.

Wiggers, George F. 1999. Projection of Elderly Population Traffic Fatalities. DRAFT Final Report. 
Wolinsky, Fredric D. 1990. Health and Health Behavior Among Elderly Americans: An Age-Stratification Perspective. Springer Publishing Company, New York. 


\section{GLOSSARY}

Baby boomers

Dementia

Elasticity

Elderly

Endogenous

Exogenous
Persons born from 1946 to 1964.

The loss of cognitive abilities (e.g., memory, perception, judgment); the most common dementia is Alzheimer's disease).

A measure of sensitivity or responsiveness, defined as the percent change in one variable (the dependent variable) in response to a onepercent change in another variable (the independent variable).

Persons aged 65 and over (including the young old, 65-74; the aged, 75-84; and oldest old, 85 and over).

A variable in a model whose value is determined by the solution to the model.

A variable in a model whose value is determined outside the model. 


\section{APPENDIX A. ENDOGENOUS VARIABLE PROJECTIONS}

Table A.1.1. Projections of Vehicle Miles of Travel, Males, in Miles Driven

\begin{tabular}{|c|c|c|c|c|c|c|c|}
\hline \multicolumn{8}{|c|}{ National } \\
\hline & 1995 & 2000 & 2005 & 2010 & 2015 & 2020 & 2025 \\
\hline $65-69$ & $12,419.43$ & $13,391.87$ & $14,408.57$ & $15,467.94$ & $16,530.28$ & $17,650.29$ & $18,787.30$ \\
\hline $70-74$ & $10,291.61$ & $10,790.58$ & $11,246.19$ & $11,761.81$ & $12,365.89$ & $13,032.24$ & $13,706.88$ \\
\hline $75-79$ & $9,422.77$ & $9,781.18$ & $10,277.84$ & $10,837.08$ & $11,451.20$ & $12,070.69$ & $12,709.24$ \\
\hline $80-84$ & $6,269.21$ & $6,623.69$ & $6,988.77$ & $7,425.86$ & $7,847.33$ & $8,224.61$ & $8,622.38$ \\
\hline $85+$ & $5,165.97$ & $5,210.01$ & $5,432.09$ & $5,700.20$ & $5,980.47$ & $6,262.81$ & $6,558.96$ \\
\hline \multicolumn{8}{|c|}{ Midwest } \\
\hline & 1995 & 2000 & 2005 & 2010 & 2015 & 2020 & 2025 \\
\hline $65-69$ & $13,287.54$ & $14,389.05$ & $15,571.44$ & $16,785.12$ & $17,899.61$ & $19,094.77$ & $20,333.64$ \\
\hline $70-74$ & $10,905.65$ & $11,227.94$ & $11,643.83$ & $12,149.97$ & $12,729.93$ & $13,361.46$ & $14,004.53$ \\
\hline $75-79$ & $8,655.11$ & $8,918.21$ & $9,257.59$ & $9,613.17$ & $10,029.78$ & $10,473.72$ & $10,938.02$ \\
\hline $80-84$ & $7,799.64$ & $8,052.21$ & $8,470.55$ & $9,026.31$ & $9,493.41$ & $9,895.63$ & $10,308.73$ \\
\hline $85+$ & $4,218.37$ & $4,391.24$ & $4,581.24$ & $4,813.64$ & $5,047.11$ & $5,267.29$ & $5,496.91$ \\
\hline \multicolumn{8}{|c|}{ Northeast } \\
\hline & 1995 & 2000 & 2005 & 2010 & 2015 & 2020 & 2025 \\
\hline $65-69$ & $10,090.04$ & $10,902.90$ & $11,742.01$ & $12,586.29$ & $13,428.71$ & $14,293.84$ & $15,189.86$ \\
\hline $70-74$ & $8,825.79$ & $9,131.50$ & $9,494.76$ & $9,892.84$ & $10,351.90$ & $10,841.40$ & $11,342.43$ \\
\hline $75-79$ & $7,843.85$ & $8,222.43$ & $8,602.90$ & $8,951.16$ & $9,367.02$ & $9,787.95$ & $10,220.92$ \\
\hline $80-84$ & $6,594.43$ & $6,787.63$ & $7,112.44$ & $7,533.15$ & $7,916.27$ & $8,267.41$ & $8,634.32$ \\
\hline $85+$ & $4,562.94$ & $4,751.45$ & $4,946.74$ & $5,173.66$ & $5,409.26$ & $5,635.13$ & $5,869.98$ \\
\hline \multicolumn{8}{|c|}{ South } \\
\hline & 1995 & 2000 & 2005 & 2010 & 2015 & 2020 & 2025 \\
\hline $65-69$ & $13,585.74$ & $14,541.74$ & $15,542.88$ & $16,660.85$ & $17,781.16$ & $18,977.10$ & $20,193.32$ \\
\hline $70-74$ & $10,909.42 *$ & $11,366.05$ & $11,851.00$ & $12,383.89$ & $13,051.91$ & $13,787.01$ & $14,534.15$ \\
\hline $75-79$ & $10,909.42 *$ & $11,435.23$ & $12,086.27$ & $12,810.11$ & $13,548.13$ & $14,277.48$ & $15,045.40$ \\
\hline $80-84$ & $5,335.76^{*}$ & $5,711.24$ & $6,123.98$ & $6,537.83$ & $7,006.61$ & $7,452.95$ & $7,924.09$ \\
\hline $85+$ & $5,335.76^{*}$ & $5,565.42$ & $5,818.98$ & $6,135.49$ & $6,458.65$ & $6,765.26$ & $7,086.30$ \\
\hline \multicolumn{8}{|c|}{ West } \\
\hline & 1995 & 2000 & 2005 & 2010 & 2015 & 2020 & 2025 \\
\hline $65-69$ & $11,646.94$ & $12,533.98$ & $13,434.20$ & $14,386.11$ & $15,410.01$ & $16,464.56$ & $17,552.55$ \\
\hline $70-74$ & $10,623.54$ & $10,942.75$ & $11,325.25$ & $11,812.28$ & $12,394.12$ & $13,047.22$ & $13,703.34$ \\
\hline $75-79$ & $9,152.65$ & $9,502.94$ & $9,918.66$ & $10,414.53$ & $10,996.84$ & $11,611.76$ & $12,247.12$ \\
\hline $80-84$ & $6,106.40$ & $6,355.69$ & $6,693.20$ & $7,085.57$ & $7,469.86$ & $7,825.59$ & $8,198.57$ \\
\hline $85+$ & $5,843.41$ & $6,026.66$ & $6,177.43$ & $6,380.49$ & $6,638.30$ & $6,932.11$ & $7,223.09$ \\
\hline
\end{tabular}

"See Appendix C.2 regarding adjustment of the 1995 VMT estimates for Southern men in these age categories. 
Table A.1.2. Projections of Vehicle Miles of Travel, Males, as Percents of 1995 Averages

\begin{tabular}{|c|c|c|c|c|c|c|c|}
\hline \multicolumn{8}{|c|}{ National } \\
\hline & 1995 & 2000 & 2005 & 2010 & 2015 & 2020 & 2025 \\
\hline $65-69$ & $100.0 \%$ & $107.8 \%$ & $116.0 \%$ & $124.5 \%$ & $133.1 \%$ & $142.1 \%$ & $151.3 \%$ \\
\hline 70-74 & $100.0 \%$ & $104.8 \%$ & $109.3 \%$ & $114.3 \%$ & $120.2 \%$ & $126.6 \%$ & $133.2 \%$ \\
\hline $75-79$ & $100.0 \%$ & $103.8 \%$ & $109.1 \%$ & $115.0 \%$ & $121.5 \%$ & $128.1 \%$ & $134.9 \%$ \\
\hline $80-84$ & $100.0 \%$ & $105.7 \%$ & $111.5 \%$ & $118.4 \%$ & $125.2 \%$ & $131.2 \%$ & $137.5 \%$ \\
\hline $85+$ & $100.0 \%$ & $100.9 \%$ & $105.2 \%$ & $110.3 \%$ & $115.8 \%$ & $121.2 \%$ & $127.0 \%$ \\
\hline \multicolumn{8}{|c|}{ Midwest } \\
\hline & 1995 & 2000 & 2005 & 2010 & 2015 & 2020 & 2025 \\
\hline $65-69$ & $100.0 \%$ & $108.3 \%$ & $117.2 \%$ & $126.3 \%$ & $134.7 \%$ & $143.7 \%$ & $153.0 \%$ \\
\hline $70-74$ & $100.0 \%$ & $103.0 \%$ & $106.8 \%$ & $111.4 \%$ & $116.7 \%$ & $122.5 \%$ & $128.4 \%$ \\
\hline $75-79$ & $100.0 \%$ & $103.0 \%$ & $107.0 \%$ & $111.1 \%$ & $115.9 \%$ & $121.0 \%$ & $126.4 \%$ \\
\hline $80-84$ & $100.0 \%$ & $103.2 \%$ & $108.6 \%$ & $115.7 \%$ & $121.7 \%$ & $126.9 \%$ & $132.2 \%$ \\
\hline $85+$ & $100.0 \%$ & $104.1 \%$ & $108.6 \%$ & $114.1 \%$ & $119.6 \%$ & $124.9 \%$ & $130.3 \%$ \\
\hline \multicolumn{8}{|c|}{ Northeast } \\
\hline & 1995 & 2000 & 2005 & 2010 & 2015 & 2020 & 2025 \\
\hline $65-69$ & $100.0 \%$ & $108.1 \%$ & $116.4 \%$ & $124.7 \%$ & $133.1 \%$ & $141.7 \%$ & $150.5 \%$ \\
\hline 70-74 & $100.0 \%$ & $103.5 \%$ & $107.6 \%$ & $112.1 \%$ & $117.3 \%$ & $122.8 \%$ & $128.5 \%$ \\
\hline $75-79$ & $100.0 \%$ & $104.8 \%$ & $109.7 \%$ & $114.1 \%$ & $119.4 \%$ & $124.8 \%$ & $130.3 \%$ \\
\hline $80-84$ & $100.0 \%$ & $102.9 \%$ & $107.9 \%$ & $114.2 \%$ & $120.0 \%$ & $125.4 \%$ & $130.9 \%$ \\
\hline $85+$ & $100.0 \%$ & $104.1 \%$ & $108.4 \%$ & $113.4 \%$ & $118.5 \%$ & $123.5 \%$ & $128.6 \%$ \\
\hline \multicolumn{8}{|c|}{ South } \\
\hline & 1995 & 2000 & 2005 & 2010 & 2015 & 2020 & 2025 \\
\hline $65-69$ & $100.0 \%$ & $107.0 \%$ & $114.4 \%$ & $122.6 \%$ & $130.9 \%$ & $139.7 \%$ & $148.6 \%$ \\
\hline $70-74$ & $100.0 \%$ & $104.2 \%$ & $108.6 \%$ & $113.5 \%$ & $119.6 \%$ & $126.4 \%$ & $133.2 \%$ \\
\hline $75-79$ & $100.0 \%$ & $104.8 \%$ & $110.8 \%$ & $117.4 \%$ & $124.2 \%$ & $130.9 \%$ & $137.9 \%$ \\
\hline $80-84$ & $100.0 \%$ & $107.0 \%$ & $114.8 \%$ & $122.5 \%$ & $131.3 \%$ & $139.7 \%$ & $148.5 \%$ \\
\hline $85+$ & $100.0 \%$ & $104.3 \%$ & $109.1 \%$ & $115.0 \%$ & $121.0 \%$ & $126.8 \%$ & $132.8 \%$ \\
\hline \multicolumn{8}{|c|}{ West } \\
\hline & 1995 & 2000 & 2005 & 2010 & 2015 & 2020 & 2025 \\
\hline $65-69$ & $100.0 \%$ & $107.6 \%$ & $115.3 \%$ & $123.5 \%$ & $132.3 \%$ & $141.4 \%$ & $150.7 \%$ \\
\hline 70-74 & $100.0 \%$ & $103.0 \%$ & $106.6 \%$ & $111.2 \%$ & $116.7 \%$ & $122.8 \%$ & $129.0 \%$ \\
\hline $75-79$ & $100.0 \%$ & $103.8 \%$ & $108.4 \%$ & $113.8 \%$ & $120.1 \%$ & $126.9 \%$ & $133.8 \%$ \\
\hline $80-84$ & $100.0 \%$ & $104.1 \%$ & $109.6 \%$ & $116.0 \%$ & $122.3 \%$ & $128.2 \%$ & $134.3 \%$ \\
\hline $85+$ & $100.0 \%$ & $103.1 \%$ & $105.7 \%$ & $109.2 \%$ & $113.6 \%$ & $118.6 \%$ & $123.6 \%$ \\
\hline
\end{tabular}


Table A.1.3. Projections of Vehicle Miles of Travel, Females, in Miles Driven

\begin{tabular}{|c|c|c|c|c|c|c|c|}
\hline \multicolumn{8}{|c|}{ National } \\
\hline & 1995 & 2000 & 2005 & 2010 & 2015 & 2020 & 2025 \\
\hline $65-69$ & $5,841.61$ & $6,469.73$ & $7,207.58$ & $8,062.62$ & $9,022.63$ & $10,102.36$ & $11,275.70$ \\
\hline $70-74$ & $5,054.79$ & $5,989.04$ & $6,537.90$ & $7,147.67$ & $7,831.89$ & $8,603.26$ & $9,435.52$ \\
\hline $75-79$ & $4,288.47$ & $4,638.78$ & $5,085.04$ & $5,554.26$ & $6,089.60$ & $6,680.07$ & $7,317.29$ \\
\hline $80-84$ & $3,805.26$ & $4,252.43$ & $4,690.89$ & $5,145.03$ & $5,655.51$ & $6,209.56$ & $6,818.64$ \\
\hline $85+$ & $2,780.62$ & $3,055.74$ & $3,373.67$ & $3,719.86$ & $4,096.97$ & $4,503.36$ & $4,946.91$ \\
\hline \multicolumn{8}{|c|}{ Midwest } \\
\hline & 1995 & 2000 & 2005 & 2010 & 2015 & 2020 & 2025 \\
\hline $65-69$ & $5,515.17$ & $6,074.43$ & $6,726.88$ & $7,507.64$ & $8,395.19$ & $9,393.56$ & $10,478.21$ \\
\hline $70-74$ & $5,152.59$ & $6,060.79$ & $6,597.72$ & $7,209.33$ & $7,898.13$ & $8,674.27$ & $9,508.81$ \\
\hline $75-79$ & $4,034.03$ & $4,345.09$ & $4,744.21$ & $5,174.98$ & $5,653.74$ & $6,178.32$ & $6,742.60$ \\
\hline $80-84$ & $3,122.46$ & $3,401.80$ & $3,745.11$ & $4,099.42$ & $4,500.43$ & $4,936.49$ & $5,408.45$ \\
\hline $85+$ & $1,640.07$ & $1,780.83$ & $1,954.92$ & $2,135.83$ & $2,345.64$ & $2,577.12$ & $2,828.30$ \\
\hline \multicolumn{8}{|c|}{ Northeast } \\
\hline & 1995 & 2000 & 2005 & 2010 & 2015 & 2020 & 2025 \\
\hline $65-69$ & $5,182.14$ & $5,733.13$ & $6,370.35$ & $7,085.14$ & $7,892.20$ & $8,789.68$ & $9,770.73$ \\
\hline $70-74$ & $5,311.19$ & $6,267.71$ & $6,845.26$ & $7,499.25$ & $8,220.52$ & $9,033.87$ & $9,909.71$ \\
\hline $75-79$ & $4,545.07$ & $4,950.97$ & $5,451.21$ & $5,965.21$ & $6,525.90$ & $7,142.80$ & $7,810.98$ \\
\hline $80-84$ & $4,348.77$ & $4,731.74$ & $5,197.44$ & $5,664.51$ & $6,195.68$ & $6,775.43$ & $7,403.78$ \\
\hline $85+$ & $3,074.19$ & $3,336.27$ & $3,675.17$ & $4,042.26$ & $4,434.01$ & $4,847.66$ & $5,296.02$ \\
\hline \multicolumn{8}{|c|}{ South } \\
\hline & 1995 & 2000 & 2005 & 2010 & 2015 & 2020 & 2025 \\
\hline $65-69$ & $6,208.98$ & $6,837.53$ & $7,573.93$ & $8,444.19$ & $9,438.10$ & $10,553.63$ & $11,769.26$ \\
\hline $70-74$ & $5,297.19$ & $6,282.94$ & $6,884.63$ & $7,547.35$ & $8,296.86$ & $9,144.90$ & $10,062.47$ \\
\hline $75-79$ & $3,918.65$ & $4,253.23$ & $4,675.10$ & $5,134.73$ & $5,647.50$ & $6,202.55$ & $6,802.69$ \\
\hline $80-84$ & $4,378.41$ & $4,772.09$ & $5,274.12$ & $5,815.45$ & $6,405.91$ & $7,034.19$ & $7,717.74$ \\
\hline $85+$ & $3,207.43$ & $3,505.66$ & $3,881.74$ & $4,278.36$ & $4,714.14$ & $5,175.27$ & $5,678.42$ \\
\hline \multicolumn{8}{|c|}{ West } \\
\hline & 1995 & 2000 & 2005 & 2010 & 2015 & 2020 & 2025 \\
\hline $65-69$ & $6,252.37$ & $6,980.89$ & $7,819.96$ & $8,772.16$ & $9,800.14$ & $10,973.97$ & $12,255.83$ \\
\hline $70-74$ & $4,283.68$ & $5,044.84$ & $5,502.99$ & $6,017.41$ & $6,581.31$ & $7,216.38$ & $7,900.55$ \\
\hline $75-79$ & $4,941.45$ & $5,368.45$ & $5,881.23$ & $6,400.80$ & $7,009.10$ & $7,681.64$ & $8,410.64$ \\
\hline $80-84$ & $3,524.51$ & $3,842.27$ & $4,214.57$ & $4,598.92$ & $5,058.71$ & $5,577.30$ & $6,138.18$ \\
\hline $85+$ & $3,437.32$ & $3,690.90$ & $4,017.76$ & $4,367.58$ & $4,759.88$ & $5,197.05$ & $5,667.40$ \\
\hline
\end{tabular}


Table A.1.4. Projections of Vehicle Miles of Travel, Females, as Percents of 1995 Averages

\begin{tabular}{|c|c|c|c|c|c|c|c|}
\hline \multicolumn{8}{|c|}{ National } \\
\hline & 1995 & 2000 & 2005 & 2010 & 2015 & 2020 & 2025 \\
\hline $65-69$ & $100.0 \%$ & $110.8 \%$ & $123.4 \%$ & $138.0 \%$ & $154.5 \%$ & $172.9 \%$ & $193.0 \%$ \\
\hline $70-74$ & $100.0 \%$ & $118.5 \%$ & $129.3 \%$ & $141.4 \%$ & $154.9 \%$ & $170.2 \%$ & $186.7 \%$ \\
\hline $75-79$ & $100.0 \%$ & $108.2 \%$ & $118.6 \%$ & $129.5 \%$ & $142.0 \%$ & $155.8 \%$ & $170.6 \%$ \\
\hline $80-84$ & $100.0 \%$ & $111.8 \%$ & $123.3 \%$ & $135.2 \%$ & $148.6 \%$ & $163.2 \%$ & $179.2 \%$ \\
\hline $85+$ & $100.0 \%$ & $109.9 \%$ & $121.3 \%$ & $133.8 \%$ & $147.3 \%$ & $162.0 \%$ & $177.9 \%$ \\
\hline \multicolumn{8}{|c|}{ Midwest } \\
\hline & 1995 & 2000 & 2005 & 2010 & 2015 & 2020 & 2025 \\
\hline $65-69$ & $100.0 \%$ & $110.1 \%$ & $122.0 \%$ & $136.1 \%$ & $152.2 \%$ & $170.3 \%$ & $190.0 \%$ \\
\hline $70-74$ & $100.0 \%$ & $117.6 \%$ & $128.0 \%$ & $139.9 \%$ & $153.3 \%$ & $168.3 \%$ & $184.5 \%$ \\
\hline $75-79$ & $100.0 \%$ & $107.7 \%$ & $117.6 \%$ & $128.3 \%$ & $140.2 \%$ & $153.2 \%$ & $167.1 \%$ \\
\hline $80-84$ & $100.0 \%$ & $108.9 \%$ & $119.9 \%$ & $131.3 \%$ & $144.1 \%$ & $158.1 \%$ & $173.2 \%$ \\
\hline $85+$ & $100.0 \%$ & $108.6 \%$ & $119.2 \%$ & $130.2 \%$ & $143.0 \%$ & $157.1 \%$ & $172.4 \%$ \\
\hline \multicolumn{8}{|c|}{ Northeast } \\
\hline & 1995 & 2000 & 2005 & 2010 & 2015 & 2020 & 2025 \\
\hline $65-69$ & $100.0 \%$ & $110.6 \%$ & $122.9 \%$ & $136.7 \%$ & $152.3 \%$ & $169.6 \%$ & $188.5 \%$ \\
\hline 70-74 & $100.0 \%$ & $118.0 \%$ & $128.9 \%$ & $141.2 \%$ & $154.8 \%$ & $170.1 \%$ & $186.6 \%$ \\
\hline $75-79$ & $100.0 \%$ & $108.9 \%$ & $119.9 \%$ & $131.2 \%$ & $143.6 \%$ & $157.2 \%$ & $171.9 \%$ \\
\hline $80-84$ & $100.0 \%$ & $108.8 \%$ & $119.5 \%$ & $130.3 \%$ & $142.5 \%$ & $155.8 \%$ & $170.2 \%$ \\
\hline $85+$ & $100.0 \%$ & $108.5 \%$ & $119.5 \%$ & $131.5 \%$ & $144.2 \%$ & $157.7 \%$ & $172.3 \%$ \\
\hline \multicolumn{8}{|c|}{ South } \\
\hline & 1995 & 2000 & 2005 & 2010 & 2015 & 2020 & 2025 \\
\hline $65-69$ & $100.0 \%$ & $110.1 \%$ & $122.0 \%$ & $136.0 \%$ & $152.0 \%$ & $170.0 \%$ & $189.6 \%$ \\
\hline $70-74$ & $100.0 \%$ & $118.6 \%$ & $130.0 \%$ & $142.5 \%$ & $156.6 \%$ & $172.6 \%$ & $190.0 \%$ \\
\hline $75-79$ & $100.0 \%$ & $108.5 \%$ & $119.3 \%$ & $131.0 \%$ & $144.1 \%$ & $158.3 \%$ & $173.6 \%$ \\
\hline $80-84$ & $100.0 \%$ & $109.0 \%$ & $120.5 \%$ & $132.8 \%$ & $146.3 \%$ & $160.7 \%$ & $176.3 \%$ \\
\hline $85+$ & $100.0 \%$ & $109.3 \%$ & $121.0 \%$ & $133.4 \%$ & $147.0 \%$ & $161.4 \%$ & $177.0 \%$ \\
\hline \multicolumn{8}{|c|}{ West } \\
\hline & 1995 & 2000 & 2005 & 2010 & 2015 & 2020 & 2025 \\
\hline $65-69$ & $100.0 \%$ & $111.7 \%$ & $125.1 \%$ & $140.3 \%$ & $156.7 \%$ & $175.5 \%$ & $196.0 \%$ \\
\hline 70-74 & $100.0 \%$ & $117.8 \%$ & $128.5 \%$ & $140.5 \%$ & $153.6 \%$ & $168.5 \%$ & $184.4 \%$ \\
\hline $75-79$ & $100.0 \%$ & $108.6 \%$ & $119.0 \%$ & $129.5 \%$ & $141.8 \%$ & $155.5 \%$ & $170.2 \%$ \\
\hline $80-84$ & $100.0 \%$ & $109.0 \%$ & $119.6 \%$ & $130.5 \%$ & $143.5 \%$ & $158.2 \%$ & $174.2 \%$ \\
\hline $85+$ & $100.0 \%$ & $107.4 \%$ & $116.9 \%$ & $127.1 \%$ & $138.5 \%$ & $151.2 \%$ & $164.9 \%$ \\
\hline
\end{tabular}


Table A.2.1. Projections of Drivers in Age Groups, Males, Percentages

\begin{tabular}{|c|c|c|c|c|c|c|c|}
\hline \multicolumn{8}{|c|}{ National } \\
\hline & 1995 & 2000 & 2005 & 2010 & 2015 & 2020 & 2025 \\
\hline $65-69$ & $84.46 \%$ & $90.11 \%$ & $90.08 \%$ & $90.41 \%$ & $90.67 \%$ & $90.94 \%$ & $91.15 \%$ \\
\hline 70-74 & $85.83 \%$ & $87.74 \%$ & $88.06 \%$ & $88.43 \%$ & $88.90 \%$ & $89.39 \%$ & $89.82 \%$ \\
\hline $75-79$ & $78.36 \%$ & $82.59 \%$ & $83.32 \%$ & $83.95 \%$ & $84.50 \%$ & $84.96 \%$ & $85.38 \%$ \\
\hline $80-84$ & $69.19 \%$ & $73.91 \%$ & $76.13 \%$ & $78.10 \%$ & $79.80 \%$ & $81.26 \%$ & $82.53 \%$ \\
\hline $85+$ & $53.56 \%$ & $58.18 \%$ & $60.84 \%$ & $62.62 \%$ & $63.88 \%$ & $64.80 \%$ & $65.52 \%$ \\
\hline \multicolumn{8}{|c|}{ Midwest } \\
\hline & 1995 & 2000 & 2005 & 2010 & 2015 & 2020 & 2025 \\
\hline $65-69$ & $84.27 \%$ & $91.76 \%$ & $90.67 \%$ & $91.05 \%$ & $91.27 \%$ & $91.51 \%$ & $91.73 \%$ \\
\hline 70-74 & $87.50 \%$ & $88.00 \%$ & $88.24 \%$ & $88.51 \%$ & $88.82 \%$ & $89.14 \%$ & $89.42 \%$ \\
\hline $75-79$ & $79.46 \%$ & $84.06 \%$ & $85.16 \%$ & $86.12 \%$ & $86.96 \%$ & $87.68 \%$ & $88.30 \%$ \\
\hline $80-84$ & $75.46 \%$ & $78.14 \%$ & $80.75 \%$ & $83.01 \%$ & $84.78 \%$ & $86.19 \%$ & $87.35 \%$ \\
\hline $85+$ & $61.47 \%$ & $66.02 \%$ & $68.41 \%$ & $69.73 \%$ & $70.49 \%$ & $70.93 \%$ & $71.24 \%$ \\
\hline \multicolumn{8}{|c|}{ Northeast } \\
\hline & 1995 & 2000 & 2005 & 2010 & 2015 & 2020 & 2025 \\
\hline $65-69$ & $80.62 \%$ & $86.97 \%$ & $86.87 \%$ & $86.83 \%$ & $86.80 \%$ & $86.81 \%$ & $86.87 \%$ \\
\hline 70-74 & $84.87 \%$ & $87.61 \%$ & $88.09 \%$ & $88.50 \%$ & $88.95 \%$ & $89.38 \%$ & $89.74 \%$ \\
\hline $75-79$ & $79.65 \%$ & $83.62 \%$ & $84.59 \%$ & $85.31 \%$ & $85.94 \%$ & $86.44 \%$ & $86.84 \%$ \\
\hline $80-84$ & $63.94 \%$ & $72.80 \%$ & $75.35 \%$ & $77.86 \%$ & $80.11 \%$ & $82.14 \%$ & $84.00 \%$ \\
\hline $85+$ & $58.03 \%$ & $58.62 \%$ & $62.05 \%$ & $64.33 \%$ & $65.85 \%$ & $66.85 \%$ & $67.56 \%$ \\
\hline \multicolumn{8}{|c|}{ South } \\
\hline & 1995 & 2000 & 2005 & 2010 & 2015 & 2020 & 2025 \\
\hline $65-69$ & $85.50 \%$ & $89.02 \%$ & $89.18 \%$ & $89.44 \%$ & $89.63 \%$ & $89.85 \%$ & $90.03 \%$ \\
\hline 70-74 & $84.16 \%$ & $86.28 \%$ & $86.77 \%$ & $87.27 \%$ & $87.95 \%$ & $88.65 \%$ & $89.28 \%$ \\
\hline $75-79$ & $75.66 \%$ & $80.63 \%$ & $81.16 \%$ & $81.72 \%$ & $82.21 \%$ & $82.62 \%$ & $83.02 \%$ \\
\hline $80-84$ & $59.83 \%$ & $66.94 \%$ & $69.01 \%$ & $70.99 \%$ & $72.93 \%$ & $74.72 \%$ & $76.41 \%$ \\
\hline $85+$ & $38.82 \%$ & $43.30 \%$ & $46.31 \%$ & $48.89 \%$ & $51.00 \%$ & $52.69 \%$ & $54.09 \%$ \\
\hline \multicolumn{8}{|c|}{ West } \\
\hline & 1995 & 2000 & 2005 & 2010 & 2015 & 2020 & 2025 \\
\hline $65-69$ & $86.97 \%$ & $93.20 \%$ & $93.83 \%$ & $94.38 \%$ & $94.86 \%$ & $95.26 \%$ & $95.60 \%$ \\
\hline 70-74 & $87.57 \%$ & $90.16 \%$ & $90.19 \%$ & $90.33 \%$ & $90.58 \%$ & $90.89 \%$ & $91.15 \%$ \\
\hline $75-79$ & $79.59 \%$ & $83.22 \%$ & $83.74 \%$ & $84.24 \%$ & $84.73 \%$ & $85.16 \%$ & $85.54 \%$ \\
\hline $80-84$ & $81.65 \%$ & $81.76 \%$ & $83.66 \%$ & $84.99 \%$ & $85.89 \%$ & $86.50 \%$ & $86.94 \%$ \\
\hline $85+$ & $65.60 \%$ & $72.76 \%$ & $74.32 \%$ & $74.99 \%$ & $75.37 \%$ & $75.63 \%$ & $75.81 \%$ \\
\hline
\end{tabular}


Table A.2.2. Projections of Drivers in Age Groups, Males, as Percentages of 1995 Percentages

\begin{tabular}{|c|c|c|c|c|c|c|c|}
\hline \multicolumn{8}{|c|}{ National } \\
\hline & 1995 & 2000 & 2005 & 2010 & 2015 & 2020 & 2025 \\
\hline $65-69$ & $100.0 \%$ & $106.7 \%$ & $106.6 \%$ & $107.0 \%$ & $107.4 \%$ & $107.7 \%$ & $107.9 \%$ \\
\hline 70-74 & $100.0 \%$ & $102.2 \%$ & $102.6 \%$ & $103.0 \%$ & $103.6 \%$ & $104.1 \%$ & $104.6 \%$ \\
\hline $75-79$ & $100.0 \%$ & $105.4 \%$ & $106.3 \%$ & $107.1 \%$ & $107.8 \%$ & $108.4 \%$ & $109.0 \%$ \\
\hline $80-84$ & $100.0 \%$ & $106.8 \%$ & $110.0 \%$ & $112.9 \%$ & $115.3 \%$ & $117.4 \%$ & $119.3 \%$ \\
\hline $85+$ & $100.0 \%$ & $108.6 \%$ & $113.6 \%$ & $116.9 \%$ & $119.3 \%$ & $121.0 \%$ & $122.3 \%$ \\
\hline \multicolumn{8}{|c|}{ Midwest } \\
\hline & 1995 & 2000 & 2005 & 2010 & 2015 & 2020 & 2025 \\
\hline $65-69$ & $100.0 \%$ & $108.9 \%$ & $107.6 \%$ & $108.1 \%$ & $108.3 \%$ & $108.6 \%$ & $108.9 \%$ \\
\hline 70-74 & $100.0 \%$ & $100.6 \%$ & $100.8 \%$ & $101.2 \%$ & $101.5 \%$ & $101.9 \%$ & $102.2 \%$ \\
\hline $75-79$ & $100.0 \%$ & $105.8 \%$ & $107.2 \%$ & $108.4 \%$ & $109.4 \%$ & $110.3 \%$ & $111.1 \%$ \\
\hline $80-84$ & $100.0 \%$ & $103.6 \%$ & $107.0 \%$ & $110.0 \%$ & $112.3 \%$ & $114.2 \%$ & $115.8 \%$ \\
\hline $85+$ & $100.0 \%$ & $107.4 \%$ & $111.3 \%$ & $113.4 \%$ & $114.7 \%$ & $115.4 \%$ & $115.9 \%$ \\
\hline \multicolumn{8}{|c|}{ Northeast } \\
\hline & 1995 & 2000 & 2005 & 2010 & 2015 & 2020 & 2025 \\
\hline $65-69$ & $100.0 \%$ & $107.9 \%$ & $107.8 \%$ & $107.7 \%$ & $107.7 \%$ & $107.7 \%$ & $107.8 \%$ \\
\hline 70-74 & $100.0 \%$ & $103.2 \%$ & $103.8 \%$ & $104.3 \%$ & $104.8 \%$ & $105.3 \%$ & $105.7 \%$ \\
\hline $75-79$ & $100.0 \%$ & $105.0 \%$ & $106.2 \%$ & $107.1 \%$ & $107.9 \%$ & $108.5 \%$ & $109.0 \%$ \\
\hline $80-84$ & $100.0 \%$ & $113.9 \%$ & $117.8 \%$ & $121.8 \%$ & $125.3 \%$ & $128.5 \%$ & $131.4 \%$ \\
\hline $85+$ & $100.0 \%$ & $101.0 \%$ & $106.9 \%$ & $110.8 \%$ & $113.5 \%$ & $115.2 \%$ & $116.4 \%$ \\
\hline \multicolumn{8}{|c|}{ South } \\
\hline & 1995 & 2000 & 2005 & 2010 & 2015 & 2020 & 2025 \\
\hline $65-69$ & $100.0 \%$ & $104.1 \%$ & $104.3 \%$ & $104.6 \%$ & $104.8 \%$ & $105.1 \%$ & $105.3 \%$ \\
\hline 70-74 & $100.0 \%$ & $102.5 \%$ & $103.1 \%$ & $103.7 \%$ & $104.5 \%$ & $105.3 \%$ & $106.1 \%$ \\
\hline $75-79$ & $100.0 \%$ & $106.6 \%$ & $107.3 \%$ & $108.0 \%$ & $108.7 \%$ & $109.2 \%$ & $109.7 \%$ \\
\hline $80-84$ & $100.0 \%$ & $111.9 \%$ & $115.3 \%$ & $118.7 \%$ & $121.9 \%$ & $124.9 \%$ & $127.7 \%$ \\
\hline $85+$ & $100.0 \%$ & $111.5 \%$ & $119.3 \%$ & $125.9 \%$ & $131.4 \%$ & $135.7 \%$ & $139.3 \%$ \\
\hline \multicolumn{8}{|c|}{ West } \\
\hline & 1995 & 2000 & 2005 & 2010 & 2015 & 2020 & 2025 \\
\hline $65-69$ & $100.0 \%$ & $107.2 \%$ & $107.9 \%$ & $108.5 \%$ & $109.1 \%$ & $109.5 \%$ & $109.9 \%$ \\
\hline $70-74$ & $100.0 \%$ & $103.0 \%$ & $103.0 \%$ & $103.2 \%$ & $103.4 \%$ & $103.8 \%$ & $104.1 \%$ \\
\hline 75-79 & $100.0 \%$ & $104.6 \%$ & $105.2 \%$ & $105.8 \%$ & $106.5 \%$ & $107.0 \%$ & $107.5 \%$ \\
\hline $80-84$ & $100.0 \%$ & $100.1 \%$ & $102.5 \%$ & $104.1 \%$ & $105.2 \%$ & $105.9 \%$ & $106.5 \%$ \\
\hline $85+$ & $100.0 \%$ & $110.9 \%$ & $113.3 \%$ & $114.3 \%$ & $114.9 \%$ & $115.3 \%$ & $115.6 \%$ \\
\hline
\end{tabular}


Table A.2.3. Projections of Drivers in Age Groups, Females, Percentages

\begin{tabular}{|c|c|c|c|c|c|c|c|}
\hline \multicolumn{8}{|c|}{ National } \\
\hline & 1995 & 2000 & 2005 & 2010 & 2015 & 2020 & 2025 \\
\hline $65-69$ & $65.14 \%$ & $72.82 \%$ & $75.63 \%$ & $78.10 \%$ & $80.28 \%$ & $82.17 \%$ & $83.65 \%$ \\
\hline 70-74 & $55.30 \%$ & $62.91 \%$ & $65.26 \%$ & $67.34 \%$ & $69.14 \%$ & $70.88 \%$ & $72.36 \%$ \\
\hline $75-79$ & $48.45 \%$ & $52.56 \%$ & $55.67 \%$ & $58.75 \%$ & $61.54 \%$ & $63.94 \%$ & $66.09 \%$ \\
\hline $80-84$ & $38.06 \%$ & $44.57 \%$ & $48.38 \%$ & $51.38 \%$ & $53.90 \%$ & $55.91 \%$ & $57.45 \%$ \\
\hline $85+$ & $19.23 \%$ & $25.65 \%$ & $29.78 \%$ & $33.38 \%$ & $36.44 \%$ & $39.00 \%$ & $41.07 \%$ \\
\hline \multicolumn{8}{|c|}{ Midwest } \\
\hline & 1995 & 2000 & 2005 & 2010 & 2015 & 2020 & 2025 \\
\hline $65-69$ & $66.24 \%$ & $74.66 \%$ & $78.01 \%$ & $81.24 \%$ & $84.15 \%$ & $86.70 \%$ & $88.86 \%$ \\
\hline 70-74 & $55.39 \%$ & $66.23 \%$ & $67.76 \%$ & $68.95 \%$ & $69.91 \%$ & $70.80 \%$ & $71.47 \%$ \\
\hline $75-79$ & $56.61 \%$ & $55.60 \%$ & $58.73 \%$ & $61.48 \%$ & $63.77 \%$ & $65.67 \%$ & $67.20 \%$ \\
\hline $80-84$ & $45.36 \%$ & $51.95 \%$ & $55.21 \%$ & $57.27 \%$ & $58.66 \%$ & $59.59 \%$ & $60.25 \%$ \\
\hline $85+$ & $26.79 \%$ & $33.09 \%$ & $38.58 \%$ & $43.12 \%$ & $46.95 \%$ & $50.04 \%$ & $52.48 \%$ \\
\hline \multicolumn{8}{|c|}{ Northeast } \\
\hline & 1995 & 2000 & 2005 & 2010 & 2015 & 2020 & 2025 \\
\hline $65-69$ & $59.40 \%$ & $61.68 \%$ & $62.14 \%$ & $62.61 \%$ & $63.13 \%$ & $63.67 \%$ & $64.15 \%$ \\
\hline 70-74 & $51.30 \%$ & $54.89 \%$ & $55.56 \%$ & $56.26 \%$ & $56.89 \%$ & $57.64 \%$ & $58.28 \%$ \\
\hline $75-79$ & $42.42 \%$ & $44.27 \%$ & $44.66 \%$ & $45.02 \%$ & $45.33 \%$ & $45.65 \%$ & $45.95 \%$ \\
\hline $80-84$ & $33.43 \%$ & $36.05 \%$ & $38.27 \%$ & $39.84 \%$ & $41.03 \%$ & $41.91 \%$ & $42.56 \%$ \\
\hline $85+$ & $9.98 \%$ & $15.38 \%$ & $17.16 \%$ & $18.86 \%$ & $20.24 \%$ & $21.32 \%$ & $22.20 \%$ \\
\hline \multicolumn{8}{|c|}{ South } \\
\hline & 1995 & 2000 & 2005 & 2010 & 2015 & 2020 & 2025 \\
\hline $65-69$ & $62.76 \%$ & $73.47 \%$ & $76.19 \%$ & $78.63 \%$ & $80.73 \%$ & $82.51 \%$ & $83.96 \%$ \\
\hline $70-74$ & $54.10 \%$ & $62.58 \%$ & $65.05 \%$ & $67.02 \%$ & $68.71 \%$ & $70.25 \%$ & $71.49 \%$ \\
\hline $75-79$ & $44.51 \%$ & $52.38 \%$ & $56.13 \%$ & $59.68 \%$ & $62.86 \%$ & $65.64 \%$ & $68.05 \%$ \\
\hline $80-84$ & $30.08 \%$ & $40.64 \%$ & $44.89 \%$ & $48.59 \%$ & $51.61 \%$ & $54.02 \%$ & $56.00 \%$ \\
\hline $85+$ & $19.72 \%$ & $27.07 \%$ & $32.34 \%$ & $37.19 \%$ & $41.40 \%$ & $44.86 \%$ & $47.77 \%$ \\
\hline \multicolumn{8}{|c|}{ West } \\
\hline & 1995 & 2000 & 2005 & 2010 & 2015 & 2020 & 2025 \\
\hline $65-69$ & $74.28 \%$ & $80.69 \%$ & $84.31 \%$ & $87.26 \%$ & $89.56 \%$ & $91.43 \%$ & $92.90 \%$ \\
\hline 70-74 & $61.80 \%$ & $68.28 \%$ & $72.23 \%$ & $75.98 \%$ & $79.36 \%$ & $82.48 \%$ & $85.16 \%$ \\
\hline $75-79$ & $52.10 \%$ & $58.35 \%$ & $62.77 \%$ & $66.82 \%$ & $70.61 \%$ & $74.00 \%$ & $76.97 \%$ \\
\hline $80-84$ & $49.38 \%$ & $52.18 \%$ & $57.40 \%$ & $61.40 \%$ & $64.61 \%$ & $67.14 \%$ & $69.07 \%$ \\
\hline $85+$ & $18.04 \%$ & $24.62 \%$ & $27.23 \%$ & $29.29 \%$ & $30.84 \%$ & $32.06 \%$ & $32.94 \%$ \\
\hline
\end{tabular}


Table A.2.4. Projections of Drivers in Age Groups, Females, as Percentages of 1995 Percentages

\begin{tabular}{|c|c|c|c|c|c|c|c|}
\hline \multicolumn{8}{|c|}{ National } \\
\hline & 1995 & 2000 & 2005 & 2010 & 2015 & 2020 & 2025 \\
\hline $65-69$ & $100.0 \%$ & $111.8 \%$ & $116.1 \%$ & $119.9 \%$ & $123.2 \%$ & $126.1 \%$ & $128.4 \%$ \\
\hline 70-74 & $100.0 \%$ & $113.8 \%$ & $118.0 \%$ & $121.8 \%$ & $125.0 \%$ & $128.2 \%$ & $130.8 \%$ \\
\hline $75-79$ & $100.0 \%$ & $108.5 \%$ & $114.9 \%$ & $121.3 \%$ & $127.0 \%$ & $132.0 \%$ & $136.4 \%$ \\
\hline $80-84$ & $100.0 \%$ & $117.1 \%$ & $127.1 \%$ & $135.0 \%$ & $141.6 \%$ & $146.9 \%$ & $150.9 \%$ \\
\hline $85+$ & $100.0 \%$ & $133.4 \%$ & $154.9 \%$ & $173.6 \%$ & $189.5 \%$ & $202.8 \%$ & $213.6 \%$ \\
\hline \multicolumn{8}{|c|}{ Midwest } \\
\hline & 1995 & 2000 & 2005 & 2010 & 2015 & 2020 & 2025 \\
\hline $65-69$ & $100.0 \%$ & $112.7 \%$ & $117.8 \%$ & $122.6 \%$ & $127.0 \%$ & $130.9 \%$ & $134.1 \%$ \\
\hline 70-74 & $100.0 \%$ & $119.6 \%$ & $122.3 \%$ & $124.5 \%$ & $126.2 \%$ & $127.8 \%$ & $129.0 \%$ \\
\hline $75-79$ & $100.0 \%$ & $98.2 \%$ & $103.7 \%$ & $108.6 \%$ & $112.6 \%$ & $116.0 \%$ & $118.7 \%$ \\
\hline $80-84$ & $100.0 \%$ & $114.5 \%$ & $121.7 \%$ & $126.3 \%$ & $129.3 \%$ & $131.4 \%$ & $132.8 \%$ \\
\hline $85+$ & $100.0 \%$ & $123.5 \%$ & $144.0 \%$ & $161.0 \%$ & $175.2 \%$ & $186.8 \%$ & $195.9 \%$ \\
\hline \multicolumn{8}{|c|}{ Northeast } \\
\hline & 1995 & 2000 & 2005 & 2010 & 2015 & 2020 & 2025 \\
\hline $65-69$ & $100.0 \%$ & $103.8 \%$ & $104.6 \%$ & $105.4 \%$ & $106.3 \%$ & $107.2 \%$ & $108.0 \%$ \\
\hline 70-74 & $100.0 \%$ & $107.0 \%$ & $108.3 \%$ & $109.7 \%$ & $110.9 \%$ & $112.4 \%$ & $113.6 \%$ \\
\hline $75-79$ & $100.0 \%$ & $104.4 \%$ & $105.3 \%$ & $106.1 \%$ & $106.8 \%$ & $107.6 \%$ & $108.3 \%$ \\
\hline $80-84$ & $100.0 \%$ & $107.8 \%$ & $114.5 \%$ & $119.2 \%$ & $122.7 \%$ & $125.4 \%$ & $127.3 \%$ \\
\hline $85+$ & $100.0 \%$ & $154.1 \%$ & $172.0 \%$ & $189.0 \%$ & $202.8 \%$ & $213.6 \%$ & $222.5 \%$ \\
\hline \multicolumn{8}{|c|}{ South } \\
\hline & 1995 & 2000 & 2005 & 2010 & 2015 & 2020 & 2025 \\
\hline $65-69$ & $100.0 \%$ & $117.1 \%$ & $121.4 \%$ & $125.3 \%$ & $128.6 \%$ & $131.5 \%$ & $133.8 \%$ \\
\hline $70-74$ & $100.0 \%$ & $115.7 \%$ & $120.2 \%$ & $123.9 \%$ & $127.0 \%$ & $129.9 \%$ & $132.1 \%$ \\
\hline $75-79$ & $100.0 \%$ & $117.7 \%$ & $126.1 \%$ & $134.1 \%$ & $141.2 \%$ & $147.5 \%$ & $152.9 \%$ \\
\hline $80-84$ & $100.0 \%$ & $135.1 \%$ & $149.3 \%$ & $161.5 \%$ & $171.6 \%$ & $179.6 \%$ & $186.2 \%$ \\
\hline $85+$ & $100.0 \%$ & $137.3 \%$ & $164.0 \%$ & $188.6 \%$ & $210.0 \%$ & $227.5 \%$ & $242.2 \%$ \\
\hline \multicolumn{8}{|c|}{ West } \\
\hline & 1995 & 2000 & 2005 & 2010 & 2015 & 2020 & 2025 \\
\hline $65-69$ & $100.0 \%$ & $108.6 \%$ & $113.5 \%$ & $117.5 \%$ & $120.6 \%$ & $123.1 \%$ & $125.1 \%$ \\
\hline 70-74 & $100.0 \%$ & $110.5 \%$ & $116.9 \%$ & $122.9 \%$ & $128.4 \%$ & $133.5 \%$ & $137.8 \%$ \\
\hline $75-79$ & $100.0 \%$ & $112.0 \%$ & $120.5 \%$ & $128.2 \%$ & $135.5 \%$ & $142.0 \%$ & $147.7 \%$ \\
\hline $80-84$ & $100.0 \%$ & $105.7 \%$ & $116.2 \%$ & $124.3 \%$ & $130.8 \%$ & $136.0 \%$ & $139.9 \%$ \\
\hline $85+$ & $100.0 \%$ & $136.5 \%$ & $151.0 \%$ & $162.4 \%$ & $170.9 \%$ & $177.7 \%$ & $182.6 \%$ \\
\hline
\end{tabular}


Table A.3.1. Elder Driver Fatality Rate Projections, Males, Deaths per 100 Million Miles Driven

\begin{tabular}{|c|c|c|c|c|c|c|c|}
\hline \multicolumn{8}{|c|}{ National } \\
\hline & 1995 & 2000 & 2005 & 2010 & 2015 & 2020 & 2025 \\
\hline $65-69$ & 1.23 & 1.26 & 1.21 & 1.16 & 1.11 & 1.06 & 1.02 \\
\hline $70-74$ & 1.71 & 1.88 & 1.82 & 1.74 & 1.65 & 1.55 & 1.47 \\
\hline $75-79$ & 3.09 & 3.25 & 3.12 & 2.99 & 2.85 & 2.72 & 2.60 \\
\hline $80-84$ & 9.63 & 8.26 & 7.94 & 7.57 & 7.26 & 6.99 & 6.76 \\
\hline $85+$ & 16.83 & 16.94 & 15.57 & 14.21 & 13.01 & 11.98 & 11.11 \\
\hline \multicolumn{8}{|c|}{ Midwest } \\
\hline & 1995 & 2000 & 2005 & 2010 & 2015 & 2020 & 2025 \\
\hline $65-69$ & 1.23 & 1.08 & 1.02 & 0.96 & 0.93 & 0.89 & 0.85 \\
\hline $70-74$ & 1.56 & 1.65 & 1.59 & 1.52 & 1.44 & 1.36 & 1.30 \\
\hline $75-79$ & 2.84 & 2.87 & 2.79 & 2.70 & 2.60 & 2.50 & 2.41 \\
\hline $80-84$ & 8.25 & 5.93 & 5.72 & 5.42 & 5.21 & 5.06 & 4.93 \\
\hline $85+$ & 16.95 & 15.67 & 14.67 & 13.61 & 12.66 & 11.85 & 11.18 \\
\hline \multicolumn{8}{|c|}{ Northeast } \\
\hline & 1995 & 2000 & 2005 & 2010 & 2015 & 2020 & 2025 \\
\hline $65-69$ & 0.89 & 1.02 & 0.97 & 0.93 & 0.89 & 0.85 & 0.82 \\
\hline 70-74 & 1.87 & 1.59 & 1.52 & 1.46 & 1.39 & 1.32 & 1.26 \\
\hline $75-79$ & 2.84 & 2.73 & 2.63 & 2.53 & 2.43 & 2.33 & 2.25 \\
\hline $80-84$ & 5.87 & 5.80 & 5.62 & 5.36 & 5.16 & 5.00 & 4.86 \\
\hline $85+$ & 14.51 & 15.23 & 14.29 & 13.34 & 12.45 & 11.68 & 11.05 \\
\hline \multicolumn{8}{|c|}{ South } \\
\hline & 1995 & 2000 & 2005 & 2010 & 2015 & 2020 & 2025 \\
\hline $65-69$ & 1.39 & 1.60 & 1.54 & 1.47 & 1.41 & 1.35 & 1.30 \\
\hline $70-74$ & 1.90 & 2.35 & 2.24 & 2.14 & 2.01 & 1.87 & 1.77 \\
\hline $75-79$ & 3.65 & 4.08 & 3.87 & 3.64 & 3.44 & 3.27 & 3.12 \\
\hline $80-84$ & 20.03 & 12.61 & 11.93 & 11.30 & 10.67 & 10.14 & 9.68 \\
\hline $85+$ & 24.92 & 23.31 & 21.77 & 20.12 & 18.63 & 17.35 & 16.31 \\
\hline \multicolumn{8}{|c|}{ West } \\
\hline & 1995 & 2000 & 2005 & 2010 & 2015 & 2020 & 2025 \\
\hline $65-69$ & 1.18 & 1.07 & 1.02 & 0.98 & 0.93 & 0.89 & 0.85 \\
\hline 70-74 & 1.46 & 1.64 & 1.58 & 1.52 & 1.43 & 1.35 & 1.28 \\
\hline $75-79$ & 2.66 & 2.79 & 2.69 & 2.57 & 2.43 & 2.30 & 2.19 \\
\hline $80-84$ & 6.50 & 6.14 & 5.91 & 5.64 & 5.42 & 5.23 & 5.06 \\
\hline $85+$ & 9.43 & 9.77 & 8.03 & 6.54 & 5.28 & 4.24 & 3.45 \\
\hline
\end{tabular}


Table A.3.2. Elder Driver Fatality Rate Projections, Males, Deaths per 100 Million Miles Driven, as Percentage of 1995 Rates

\begin{tabular}{|c|c|c|c|c|c|c|c|}
\hline \multicolumn{8}{|c|}{ National } \\
\hline & 1995 & 2000 & 2005 & 2010 & 2015 & 2020 & 2025 \\
\hline $65-69$ & $100.0 \%$ & $102.6 \%$ & $98.5 \%$ & $94.2 \%$ & $90.4 \%$ & $86.6 \%$ & $83.5 \%$ \\
\hline $70-74$ & $100.0 \%$ & $110.4 \%$ & $106.6 \%$ & $102.2 \%$ & $96.6 \%$ & $90.8 \%$ & $86.0 \%$ \\
\hline $75-79$ & $100.0 \%$ & $105.1 \%$ & $101.1 \%$ & $96.7 \%$ & $92.2 \%$ & $88.0 \%$ & $84.3 \%$ \\
\hline $80-84$ & $100.0 \%$ & $85.9 \%$ & $82.5 \%$ & $78.7 \%$ & $75.4 \%$ & $72.6 \%$ & $70.2 \%$ \\
\hline $85+$ & $100.0 \%$ & $100.6 \%$ & $92.5 \%$ & $84.4 \%$ & $77.3 \%$ & $71.2 \%$ & $66.0 \%$ \\
\hline \multicolumn{8}{|c|}{ Midwest } \\
\hline & 1995 & 2000 & 2005 & 2010 & 2015 & 2020 & 2025 \\
\hline $65-69$ & $100.0 \%$ & $88.2 \%$ & $83.3 \%$ & $78.8 \%$ & $75.6 \%$ & $72.4 \%$ & $69.7 \%$ \\
\hline $70-74$ & $100.0 \%$ & $105.4 \%$ & $101.8 \%$ & $97.3 \%$ & $92.2 \%$ & $87.1 \%$ & $82.9 \%$ \\
\hline $75-79$ & $100.0 \%$ & $100.9 \%$ & $98.2 \%$ & $95.0 \%$ & $91.4 \%$ & $87.9 \%$ & $84.8 \%$ \\
\hline $80-84$ & $100.0 \%$ & $71.8 \%$ & $69.3 \%$ & $65.7 \%$ & $63.2 \%$ & $61.3 \%$ & $59.7 \%$ \\
\hline $85+$ & $100.0 \%$ & $92.5 \%$ & $86.5 \%$ & $80.3 \%$ & $74.7 \%$ & $69.9 \%$ & $66.0 \%$ \\
\hline \multicolumn{8}{|c|}{ Northeast } \\
\hline & 1995 & 2000 & 2005 & 2010 & 2015 & 2020 & 2025 \\
\hline $65-69$ & $100.0 \%$ & $114.7 \%$ & $109.1 \%$ & $104.1 \%$ & $99.8 \%$ & $95.9 \%$ & $92.6 \%$ \\
\hline 70-74 & $100.0 \%$ & $85.0 \%$ & $81.6 \%$ & $78.3 \%$ & $74.3 \%$ & $70.5 \%$ & $67.3 \%$ \\
\hline $75-79$ & $100.0 \%$ & $95.9 \%$ & $92.3 \%$ & $89.1 \%$ & $85.4 \%$ & $82.0 \%$ & $79.1 \%$ \\
\hline $80-84$ & $100.0 \%$ & $99.0 \%$ & $95.8 \%$ & $91.4 \%$ & $88.0 \%$ & $85.2 \%$ & $82.8 \%$ \\
\hline $85+$ & $100.0 \%$ & $105.0 \%$ & $98.5 \%$ & $91.9 \%$ & $85.8 \%$ & $80.5 \%$ & $76.1 \%$ \\
\hline \multicolumn{8}{|c|}{ South } \\
\hline & 1995 & 2000 & 2005 & 2010 & 2015 & 2020 & 2025 \\
\hline $65-69$ & $100.0 \%$ & $115.1 \%$ & $110.8 \%$ & $105.6 \%$ & $101.3 \%$ & $96.9 \%$ & $93.4 \%$ \\
\hline $70-74$ & $100.0 \%$ & $123.8 \%$ & $118.3 \%$ & $112.8 \%$ & $105.8 \%$ & $98.7 \%$ & $93.0 \%$ \\
\hline $75-79$ & $100.0 \%$ & $111.7 \%$ & $106.1 \%$ & $99.8 \%$ & $94.4 \%$ & $89.6 \%$ & $85.4 \%$ \\
\hline $80-84$ & $100.0 \%$ & $63.0 \%$ & $59.6 \%$ & $56.4 \%$ & $53.2 \%$ & $50.6 \%$ & $48.3 \%$ \\
\hline $85+$ & $100.0 \%$ & $93.5 \%$ & $87.3 \%$ & $80.7 \%$ & $74.7 \%$ & $69.6 \%$ & $65.4 \%$ \\
\hline \multicolumn{8}{|c|}{ West } \\
\hline & 1995 & 2000 & 2005 & 2010 & 2015 & 2020 & 2025 \\
\hline $65-69$ & $100.0 \%$ & $90.7 \%$ & $86.9 \%$ & $83.0 \%$ & $79.1 \%$ & $75.6 \%$ & $72.6 \%$ \\
\hline 70-74 & $100.0 \%$ & $112.2 \%$ & $108.7 \%$ & $104.1 \%$ & $98.3 \%$ & $92.3 \%$ & $87.6 \%$ \\
\hline $75-79$ & $100.0 \%$ & $104.9 \%$ & $101.3 \%$ & $96.5 \%$ & $91.4 \%$ & $86.6 \%$ & $82.4 \%$ \\
\hline $80-84$ & $100.0 \%$ & $94.5 \%$ & $91.0 \%$ & $86.9 \%$ & $83.4 \%$ & $80.5 \%$ & $78.0 \%$ \\
\hline $85+$ & $100.0 \%$ & $103.6 \%$ & $85.2 \%$ & $69.4 \%$ & $56.0 \%$ & $45.0 \%$ & $36.6 \%$ \\
\hline
\end{tabular}


Table A.3.3. Elder Driver Fatality Rate Projections, Females, Deaths per 100 Million Miles Driven

\begin{tabular}{|c|c|c|c|c|c|c|c|}
\hline \multicolumn{8}{|c|}{ National } \\
\hline & 1995 & 2000 & 2005 & 2010 & 2015 & 2020 & 2025 \\
\hline $65-69$ & 1.24 & 1.37 & 1.32 & 1.26 & 1.20 & 1.14 & 1.09 \\
\hline $70-74$ & 2.49 & 2.01 & 1.92 & 1.83 & 1.73 & 1.63 & 1.54 \\
\hline $75-79$ & 4.35 & 3.64 & 3.54 & 3.42 & 3.28 & 3.14 & 3.03 \\
\hline $80-84$ & 7.22 & 7.40 & 7.16 & 6.85 & 6.55 & 6.26 & 6.00 \\
\hline $85+$ & 16.23 & 15.43 & 14.43 & 13.33 & 12.32 & 11.42 & 10.70 \\
\hline \multicolumn{8}{|c|}{ Midwest } \\
\hline & 1995 & 2000 & 2005 & 2010 & 2015 & 2020 & 2025 \\
\hline $65-69$ & 1.26 & 1.16 & 1.12 & 1.07 & 1.01 & 0.95 & 0.91 \\
\hline $70-74$ & 2.27 & 1.73 & 1.67 & 1.59 & 1.50 & 1.42 & 1.35 \\
\hline $75-79$ & 4.97 & 3.17 & 3.11 & 3.00 & 2.89 & 2.79 & 2.70 \\
\hline $80-84$ & 6.85 & 6.54 & 6.30 & 6.04 & 5.75 & 5.49 & 5.27 \\
\hline $85+$ & 22.07 & 17.31 & 16.36 & 15.34 & 14.22 & 13.17 & 12.33 \\
\hline \multicolumn{8}{|c|}{ Northeast } \\
\hline & 1995 & 2000 & 2005 & 2010 & 2015 & 2020 & 2025 \\
\hline $65-69$ & 1.04 & 1.12 & 1.08 & 1.03 & 0.98 & 0.94 & 0.90 \\
\hline 70-74 & 2.23 & 1.68 & 1.61 & 1.52 & 1.44 & 1.35 & 1.28 \\
\hline $75-79$ & 3.36 & 3.02 & 2.91 & 2.79 & 2.68 & 2.57 & 2.49 \\
\hline $80-84$ & 5.59 & 5.42 & 5.25 & 5.08 & 4.88 & 4.69 & 4.53 \\
\hline $85+$ & 28.34 & 17.15 & 16.08 & 14.83 & 13.79 & 12.92 & 12.23 \\
\hline \multicolumn{8}{|c|}{ South } \\
\hline & 1995 & 2000 & 2005 & 2010 & 2015 & 2020 & 2025 \\
\hline $65-69$ & 1.54 & 1.74 & 1.68 & 1.60 & 1.52 & 1.44 & 1.37 \\
\hline 70-74 & 2.74 & 2.50 & 2.37 & 2.24 & 2.10 & 1.96 & 1.85 \\
\hline $75-79$ & 5.99 & 4.60 & 4.44 & 4.23 & 4.02 & 3.83 & 3.68 \\
\hline $80-84$ & 8.93 & 9.68 & 9.23 & 8.69 & 8.21 & 7.82 & 7.48 \\
\hline $85+$ & 15.22 & 16.03 & 14.85 & 13.63 & 12.54 & 11.63 & 10.90 \\
\hline \multicolumn{8}{|c|}{ West } \\
\hline & 1995 & 2000 & 2005 & 2010 & 2015 & 2020 & 2025 \\
\hline $65-69$ & 0.91 & 1.17 & 1.10 & 1.04 & 0.99 & 0.93 & 0.88 \\
\hline 70-74 & 2.54 & 1.75 & 1.68 & 1.59 & 1.52 & 1.43 & 1.37 \\
\hline 75-79 & 2.52 & 3.11 & 3.03 & 2.94 & 2.82 & 2.70 & 2.60 \\
\hline $80-84$ & 6.32 & 6.59 & 6.40 & 6.18 & 5.86 & 5.52 & 5.24 \\
\hline $85+$ & 10.16 & 9.51 & 9.18 & 8.71 & 8.23 & 7.74 & 7.36 \\
\hline
\end{tabular}


Table A.3.4. Elder Driver Fatality Rate Projections, Females, Deaths per 100 Million Miles Driven, as Percentage of 1995 Rates

\begin{tabular}{|c|c|c|c|c|c|c|c|}
\hline \multicolumn{8}{|c|}{ National } \\
\hline & 1995 & 2000 & 2005 & 2010 & 2015 & 2020 & 2025 \\
\hline $65-69$ & $100.0 \%$ & $110.3 \%$ & $106.7 \%$ & $101.9 \%$ & $96.8 \%$ & $91.7 \%$ & $87.7 \%$ \\
\hline 70-74 & $100.0 \%$ & $80.6 \%$ & $77.3 \%$ & $73.5 \%$ & $69.5 \%$ & $65.3 \%$ & $62.0 \%$ \\
\hline $75-79$ & $100.0 \%$ & $83.7 \%$ & $81.5 \%$ & $78.6 \%$ & $75.4 \%$ & $72.3 \%$ & $69.6 \%$ \\
\hline $80-84$ & $100.0 \%$ & $102.5 \%$ & $99.2 \%$ & $94.9 \%$ & $90.7 \%$ & $86.7 \%$ & $83.2 \%$ \\
\hline $85+$ & $100.0 \%$ & $95.1 \%$ & $88.9 \%$ & $82.2 \%$ & $75.9 \%$ & $70.4 \%$ & $65.9 \%$ \\
\hline \multicolumn{8}{|c|}{ Midwest } \\
\hline & 1995 & 2000 & 2005 & 2010 & 2015 & 2020 & 2025 \\
\hline $65-69$ & $100.0 \%$ & $92.0 \%$ & $89.1 \%$ & $84.7 \%$ & $80.3 \%$ & $75.8 \%$ & $72.3 \%$ \\
\hline $70-74$ & $100.0 \%$ & $76.4 \%$ & $73.5 \%$ & $70.0 \%$ & $66.3 \%$ & $62.4 \%$ & $59.4 \%$ \\
\hline $75-79$ & $100.0 \%$ & $63.8 \%$ & $62.6 \%$ & $60.4 \%$ & $58.2 \%$ & $56.1 \%$ & $54.4 \%$ \\
\hline $80-84$ & $100.0 \%$ & $95.6 \%$ & $92.1 \%$ & $88.2 \%$ & $84.0 \%$ & $80.1 \%$ & $76.9 \%$ \\
\hline $85+$ & $100.0 \%$ & $78.4 \%$ & $74.1 \%$ & $69.5 \%$ & $64.4 \%$ & $59.7 \%$ & $55.9 \%$ \\
\hline \multicolumn{8}{|c|}{ Northeast } \\
\hline & 1995 & 2000 & 2005 & 2010 & 2015 & 2020 & 2025 \\
\hline $65-69$ & $100.0 \%$ & $108.0 \%$ & $103.9 \%$ & $99.6 \%$ & $95.0 \%$ & $90.6 \%$ & $87.0 \%$ \\
\hline 70-74 & $100.0 \%$ & $75.5 \%$ & $72.0 \%$ & $68.1 \%$ & $64.5 \%$ & $60.6 \%$ & $57.6 \%$ \\
\hline $75-79$ & $100.0 \%$ & $90.0 \%$ & $86.7 \%$ & $83.2 \%$ & $79.9 \%$ & $76.7 \%$ & $74.1 \%$ \\
\hline $80-84$ & $100.0 \%$ & $96.9 \%$ & $93.8 \%$ & $90.8 \%$ & $87.3 \%$ & $83.9 \%$ & $81.0 \%$ \\
\hline $85+$ & $100.0 \%$ & $60.5 \%$ & $56.7 \%$ & $52.3 \%$ & $48.7 \%$ & $45.6 \%$ & $43.2 \%$ \\
\hline \multicolumn{8}{|c|}{ South } \\
\hline & 1995 & 2000 & 2005 & 2010 & 2015 & 2020 & 2025 \\
\hline $65-69$ & $100.0 \%$ & $112.9 \%$ & $109.3 \%$ & $104.2 \%$ & $98.8 \%$ & $93.4 \%$ & $89.1 \%$ \\
\hline $70-74$ & $100.0 \%$ & $91.5 \%$ & $86.7 \%$ & $81.9 \%$ & $77.0 \%$ & $71.8 \%$ & $67.7 \%$ \\
\hline $75-79$ & $100.0 \%$ & $76.8 \%$ & $74.3 \%$ & $70.7 \%$ & $67.2 \%$ & $64.0 \%$ & $61.4 \%$ \\
\hline $80-84$ & $100.0 \%$ & $108.4 \%$ & $103.4 \%$ & $97.4 \%$ & $92.0 \%$ & $87.5 \%$ & $83.8 \%$ \\
\hline $85+$ & $100.0 \%$ & $105.3 \%$ & $97.5 \%$ & $89.5 \%$ & $82.4 \%$ & $76.4 \%$ & $71.6 \%$ \\
\hline \multicolumn{8}{|c|}{ West } \\
\hline & 1995 & 2000 & 2005 & 2010 & 2015 & 2020 & 2025 \\
\hline $65-69$ & $100.0 \%$ & $127.8 \%$ & $120.9 \%$ & $113.9 \%$ & $108.1 \%$ & $102.0 \%$ & $97.0 \%$ \\
\hline 70-74 & $100.0 \%$ & $69.0 \%$ & $66.0 \%$ & $62.8 \%$ & $59.7 \%$ & $56.4 \%$ & $53.9 \%$ \\
\hline $75-79$ & $100.0 \%$ & $123.6 \%$ & $120.3 \%$ & $116.8 \%$ & $112.0 \%$ & $107.2 \%$ & $103.2 \%$ \\
\hline $80-84$ & $100.0 \%$ & $104.2 \%$ & $101.3 \%$ & $97.7 \%$ & $92.6 \%$ & $87.3 \%$ & $82.9 \%$ \\
\hline $85+$ & $100.0 \%$ & $93.5 \%$ & $90.3 \%$ & $85.7 \%$ & $81.0 \%$ & $76.1 \%$ & $72.4 \%$ \\
\hline
\end{tabular}


Table A.4.1. Projected Elderly Driver Fatalities, Males, Total Number of Fatalities

\begin{tabular}{|c|c|c|c|c|c|c|c|}
\hline \multicolumn{8}{|c|}{ National } \\
\hline & 1995 & 2000 & 2005 & 2010 & 2015 & 2020 & 2025 \\
\hline $65-69$ & 614 & 655 & 728 & 912 & 1203 & 1414 & 1637 \\
\hline $70-74$ & 598 & 682 & 669 & 736 & 906 & 1166 & 1347 \\
\hline $75-79$ & 553 & 779 & 815 & 817 & 911 & 1149 & 1524 \\
\hline $80-84$ & 475 & 664 & 810 & 880 & 915 & 1069 & 1402 \\
\hline $85+$ & 328 & 423 & 504 & 601 & 670 & 699 & 786 \\
\hline Total & 2568 & 3203 & 3526 & 3946 & 4605 & 5497 & 6696 \\
\hline \multicolumn{8}{|c|}{ Midwest } \\
\hline & 1995 & 2000 & 2005 & 2010 & 2015 & 2020 & 2025 \\
\hline $65-69$ & 157 & 144 & 152 & 181 & 234 & 273 & 310 \\
\hline $70-74$ & 147 & 146 & 142 & 150 & 177 & 223 & 257 \\
\hline $75-79$ & 125 & 147 & 155 & 155 & 167 & 203 & 266 \\
\hline $80-84$ & 131 & 154 & 184 & 199 & 204 & 230 & 289 \\
\hline $85+$ & 84 & 97 & 114 & 133 & 147 & 152 & 168 \\
\hline Total & 644 & 689 & 746 & 817 & 928 & 1081 & 1290 \\
\hline \multicolumn{8}{|c|}{ Northeast } \\
\hline & 1995 & 2000 & 2005 & 2010 & 2015 & 2020 & 2025 \\
\hline $65-69$ & 73 & 81 & 83 & 100 & 127 & 144 & 166 \\
\hline $70-74$ & 105 & 99 & 90 & 92 & 110 & 137 & 154 \\
\hline $75-79$ & 85 & 113 & 115 & 107 & 112 & 137 & 176 \\
\hline $80-84$ & 67 & 103 & 123 & 130 & 127 & 141 & 180 \\
\hline $85+$ & 41 & 77 & 92 & 110 & 123 & 126 & 138 \\
\hline Total & 371 & 473 & 503 & 540 & 599 & 685 & 815 \\
\hline \multicolumn{8}{|c|}{ South } \\
\hline & 1995 & 2000 & 2005 & 2010 & 2015 & 2020 & 2025 \\
\hline $65-69$ & 273 & 324 & 369 & 470 & 625 & 736 & 857 \\
\hline $70-74$ & 234 & 314 & 315 & 353 & 441 & 572 & 661 \\
\hline $75-79$ & 235 & 386 & 408 & 416 & 469 & 598 & 798 \\
\hline $80-84$ & 198 & 291 & 361 & 398 & 424 & 505 & 675 \\
\hline $85+$ & 149 & 169 & 212 & 267 & 312 & 340 & 399 \\
\hline Total & 1089 & 1484 & 1666 & 1904 & 2271 & 2752 & 3390 \\
\hline \multicolumn{8}{|c|}{ West } \\
\hline & 1995 & 2000 & 2005 & 2010 & 2015 & 2020 & 2025 \\
\hline $65-69$ & 111 & 106 & 124 & 161 & 217 & 261 & 303 \\
\hline $70-74$ & 112 & 123 & 122 & 140 & 178 & 233 & 274 \\
\hline $75-79$ & 108 & 133 & 137 & 140 & 162 & 210 & 284 \\
\hline $80-84$ & 79 & 116 & 143 & 153 & 160 & 193 & 258 \\
\hline $85+$ & 54 & 80 & 86 & 91 & 88 & 81 & 82 \\
\hline Total & 464 & 558 & 612 & 684 & 806 & 978 & 1202 \\
\hline
\end{tabular}


Table A.4.2. Projected Elderly Driver Fatalities, Males, Total Number of Fatalities as Percent of 1995 Fatalities

\begin{tabular}{|c|c|c|c|c|c|c|c|}
\hline \multicolumn{8}{|c|}{ National } \\
\hline & 1995 & 2000 & 2005 & 2010 & 2015 & 2020 & 2025 \\
\hline $65-69$ & $100.0 \%$ & $106.7 \%$ & $118.5 \%$ & $148.5 \%$ & $195.9 \%$ & $230.3 \%$ & $266.6 \%$ \\
\hline $70-74$ & $100.0 \%$ & $114.0 \%$ & $111.9 \%$ & $123.1 \%$ & $151.5 \%$ & $194.9 \%$ & $225.3 \%$ \\
\hline $75-79$ & $100.0 \%$ & $140.9 \%$ & $147.4 \%$ & $147.8 \%$ & $164.6 \%$ & $207.8 \%$ & $275.6 \%$ \\
\hline $80-84$ & $100.0 \%$ & $139.9 \%$ & $170.6 \%$ & $185.2 \%$ & $192.6 \%$ & $225.0 \%$ & $295.2 \%$ \\
\hline $85+$ & $100.0 \%$ & $128.9 \%$ & $153.7 \%$ & $183.2 \%$ & $204.4 \%$ & $213.1 \%$ & $239.7 \%$ \\
\hline Total & $100.0 \%$ & $124.7 \%$ & $137.3 \%$ & $153.6 \%$ & $179.3 \%$ & $214.0 \%$ & $260.7 \%$ \\
\hline \multicolumn{8}{|c|}{ Midwest } \\
\hline & 1995 & 2000 & 2005 & 2010 & 2015 & 2020 & 2025 \\
\hline $65-69$ & $100.0 \%$ & $92.0 \%$ & $96.5 \%$ & $115.3 \%$ & $148.8 \%$ & $174.0 \%$ & $197.3 \%$ \\
\hline $70-74$ & $100.0 \%$ & $99.3 \%$ & $96.7 \%$ & $102.0 \%$ & $120.2 \%$ & $151.8 \%$ & $174.8 \%$ \\
\hline $75-79$ & $100.0 \%$ & $117.8 \%$ & $123.8 \%$ & $123.8 \%$ & $133.4 \%$ & $162.3 \%$ & $212.5 \%$ \\
\hline $80-84$ & $100.0 \%$ & $117.6 \%$ & $140.3 \%$ & $151.7 \%$ & $156.0 \%$ & $175.5 \%$ & $221.0 \%$ \\
\hline $85+$ & $100.0 \%$ & $115.8 \%$ & $135.6 \%$ & $158.4 \%$ & $174.9 \%$ & $181.0 \%$ & $200.1 \%$ \\
\hline Total & $100.0 \%$ & $107.0 \%$ & $115.9 \%$ & $126.9 \%$ & $144.2 \%$ & $167.9 \%$ & $200.3 \%$ \\
\hline \multicolumn{8}{|c|}{ Northeast } \\
\hline & 1995 & 2000 & 2005 & 2010 & 2015 & 2020 & 2025 \\
\hline $65-69$ & $100.0 \%$ & $110.5 \%$ & $114.0 \%$ & $137.4 \%$ & $173.8 \%$ & $197.6 \%$ & $227.3 \%$ \\
\hline $70-74$ & $100.0 \%$ & $94.2 \%$ & $85.4 \%$ & $88.0 \%$ & $105.2 \%$ & $130.9 \%$ & $147.1 \%$ \\
\hline $75-79$ & $100.0 \%$ & $132.9 \%$ & $135.0 \%$ & $125.8 \%$ & $131.8 \%$ & $161.5 \%$ & $207.3 \%$ \\
\hline $80-84$ & $100.0 \%$ & $153.8 \%$ & $183.0 \%$ & $194.4 \%$ & $189.1 \%$ & $209.7 \%$ & $269.2 \%$ \\
\hline $85+$ & $100.0 \%$ & $188.0 \%$ & $225.2 \%$ & $269.5 \%$ & $300.9 \%$ & $306.1 \%$ & $335.7 \%$ \\
\hline Total & $100.0 \%$ & $127.4 \%$ & $135.5 \%$ & $145.7 \%$ & $161.6 \%$ & $184.6 \%$ & $219.6 \%$ \\
\hline \multicolumn{8}{|c|}{ South } \\
\hline & 1995 & 2000 & 2005 & 2010 & 2015 & 2020 & 2025 \\
\hline $65-69$ & $100.0 \%$ & $118.6 \%$ & $135.1 \%$ & $172.0 \%$ & $229.0 \%$ & $269.7 \%$ & $314.1 \%$ \\
\hline $70-74$ & $100.0 \%$ & $134.2 \%$ & $134.8 \%$ & $151.0 \%$ & $188.5 \%$ & $244.4 \%$ & $282.6 \%$ \\
\hline $75-79$ & $100.0 \%$ & $164.1 \%$ & $173.6 \%$ & $176.9 \%$ & $199.7 \%$ & $254.6 \%$ & $339.4 \%$ \\
\hline $80-84$ & $100.0 \%$ & $147.0 \%$ & $182.5 \%$ & $201.2 \%$ & $214.2 \%$ & $255.2 \%$ & $340.7 \%$ \\
\hline $85+$ & $100.0 \%$ & $113.3 \%$ & $142.4 \%$ & $179.1 \%$ & $209.3 \%$ & $228.3 \%$ & $267.7 \%$ \\
\hline Total & $100.0 \%$ & $136.2 \%$ & $153.0 \%$ & $174.8 \%$ & $208.6 \%$ & $252.7 \%$ & $311.3 \%$ \\
\hline \multicolumn{8}{|c|}{ West } \\
\hline & 1995 & 2000 & 2005 & 2010 & 2015 & 2020 & 2025 \\
\hline $65-69$ & $100.0 \%$ & $95.4 \%$ & $111.7 \%$ & $145.0 \%$ & $195.6 \%$ & $234.7 \%$ & $273.4 \%$ \\
\hline $70-74$ & $100.0 \%$ & $109.7 \%$ & $109.0 \%$ & $125.3 \%$ & $158.8 \%$ & $208.2 \%$ & $245.0 \%$ \\
\hline $75-79$ & $100.0 \%$ & $123.1 \%$ & $127.1 \%$ & $129.3 \%$ & $150.4 \%$ & $194.8 \%$ & $263.3 \%$ \\
\hline $80-84$ & $100.0 \%$ & $147.2 \%$ & $180.6 \%$ & $193.2 \%$ & $202.4 \%$ & $244.3 \%$ & $326.0 \%$ \\
\hline $85+$ & $100.0 \%$ & $147.5 \%$ & $158.4 \%$ & $167.6 \%$ & $163.7 \%$ & $150.6 \%$ & $151.4 \%$ \\
\hline Total & $100.0 \%$ & $120.2 \%$ & $131.8 \%$ & $147.4 \%$ & $173.6 \%$ & $210.9 \%$ & $258.9 \%$ \\
\hline
\end{tabular}


Table A.4.3. Projected Elderly Driver Fatalities, Females, Total Number of Fatalities

\begin{tabular}{|c|c|c|c|c|c|c|c|}
\hline \multicolumn{8}{|c|}{ National } \\
\hline & 1995 & 2000 & 2005 & 2010 & 2015 & 2020 & 2025 \\
\hline $65-69$ & 267 & 328 & 388 & 513 & 709 & 872 & 1051 \\
\hline $70-74$ & 358 & 363 & 371 & 422 & 540 & 722 & 869 \\
\hline $75-79$ & 323 & 357 & 397 & 418 & 488 & 645 & 895 \\
\hline $80-84$ & 229 & 400 & 514 & 568 & 596 & 701 & 927 \\
\hline $85+$ & 146 & 247 & 334 & 438 & 532 & 596 & 702 \\
\hline Total & 1323 & 1696 & 2004 & 2359 & 2864 & 3535 & 4444 \\
\hline \multicolumn{8}{|c|}{ Midwest } \\
\hline & 1995 & 2000 & 2005 & 2010 & 2015 & 2020 & 2025 \\
\hline $65-69$ & 68 & 61 & 71 & 90 & 122 & 149 & 177 \\
\hline $70-74$ & 81 & 78 & 77 & 85 & 103 & 134 & 158 \\
\hline $75-79$ & 92 & 74 & 81 & 83 & 94 & 118 & 159 \\
\hline $80-84$ & 50 & 82 & 98 & 104 & 104 & 116 & 146 \\
\hline $85+$ & 35 & 57 & 77 & 97 & 115 & 125 & 143 \\
\hline Total & 326 & 352 & 403 & 459 & 537 & 643 & 784 \\
\hline \multicolumn{8}{|c|}{ Northeast } \\
\hline & 1995 & 2000 & 2005 & 2010 & 2015 & 2020 & 2025 \\
\hline $65-69$ & 37 & 39 & 42 & 53 & 69 & 81 & 96 \\
\hline $70-74$ & 60 & 58 & 53 & 56 & 69 & 88 & 102 \\
\hline $75-79$ & 45 & 58 & 58 & 54 & 57 & 71 & 93 \\
\hline $80-84$ & 33 & 58 & 69 & 72 & 68 & 75 & 96 \\
\hline $85+$ & 24 & 42 & 52 & 64 & 74 & 78 & 87 \\
\hline Total & 199 & 255 & 275 & 299 & 337 & 393 & 474 \\
\hline \multicolumn{8}{|c|}{ South } \\
\hline & 1995 & 2000 & 2005 & 2010 & 2015 & 2020 & 2025 \\
\hline $65-69$ & 117 & 164 & 197 & 264 & 367 & 453 & 550 \\
\hline $70-74$ & 153 & 172 & 182 & 210 & 272 & 364 & 439 \\
\hline $75-79$ & 137 & 149 & 171 & 186 & 221 & 296 & 414 \\
\hline $80-84$ & 99 & 189 & 251 & 284 & 308 & 370 & 496 \\
\hline $85+$ & 61 & 114 & 159 & 215 & 268 & 308 & 371 \\
\hline Total & 567 & 787 & 960 & 1160 & 1436 & 1791 & 2270 \\
\hline \multicolumn{8}{|c|}{ West } \\
\hline & 1995 & 2000 & 2005 & 2010 & 2015 & 2020 & 2025 \\
\hline $65-69$ & 45 & 64 & 78 & 106 & 151 & 189 & 228 \\
\hline $70-74$ & 64 & 56 & 59 & 72 & 97 & 136 & 170 \\
\hline $75-79$ & 49 & 77 & 87 & 95 & 116 & 159 & 229 \\
\hline $80-84$ & 47 & 71 & 95 & 108 & 115 & 140 & 189 \\
\hline $85+$ & 26 & 34 & 46 & 61 & 75 & 84 & 101 \\
\hline Total & 231 & 301 & 366 & 442 & 554 & 708 & 917 \\
\hline
\end{tabular}


Table A.4.4. Projected Elderly Driver Fatalities, Females, Total Number of Fatalities as Percent of 1995 Fatalities

\begin{tabular}{|c|c|c|c|c|c|c|c|}
\hline \multicolumn{8}{|c|}{ National } \\
\hline & 1995 & 2000 & 2005 & 2010 & 2015 & 2020 & 2025 \\
\hline $65-69$ & $100.0 \%$ & $122.9 \%$ & $145.3 \%$ & $192.1 \%$ & $265.4 \%$ & $326.7 \%$ & $393.6 \%$ \\
\hline 70-74 & $100.0 \%$ & $101.5 \%$ & $103.6 \%$ & $117.9 \%$ & $150.9 \%$ & $201.6 \%$ & $242.8 \%$ \\
\hline $75-79$ & $100.0 \%$ & $110.6 \%$ & $122.9 \%$ & $129.3 \%$ & $150.9 \%$ & $199.5 \%$ & $277.0 \%$ \\
\hline $80-84$ & $100.0 \%$ & $174.6 \%$ & $224.5 \%$ & $248.1 \%$ & $260.3 \%$ & $306.0 \%$ & $404.9 \%$ \\
\hline $85+$ & $100.0 \%$ & $169.0 \%$ & $228.6 \%$ & $300.0 \%$ & $364.2 \%$ & $407.9 \%$ & $481.0 \%$ \\
\hline Total & $100.0 \%$ & $128.2 \%$ & $151.5 \%$ & $178.3 \%$ & $216.5 \%$ & $267.2 \%$ & $335.9 \%$ \\
\hline \multicolumn{8}{|c|}{ Midwest } \\
\hline & 1995 & 2000 & 2005 & 2010 & 2015 & 2020 & 2025 \\
\hline $65-69$ & $100.0 \%$ & $89.6 \%$ & $103.8 \%$ & $132.1 \%$ & $179.4 \%$ & $219.7 \%$ & $260.4 \%$ \\
\hline $70-74$ & $100.0 \%$ & $95.7 \%$ & $95.2 \%$ & $104.4 \%$ & $127.0 \%$ & $164.9 \%$ & $195.3 \%$ \\
\hline $75-79$ & $100.0 \%$ & $80.1 \%$ & $87.9 \%$ & $90.1 \%$ & $101.7 \%$ & $128.2 \%$ & $173.3 \%$ \\
\hline $80-84$ & $100.0 \%$ & $164.4 \%$ & $196.4 \%$ & $207.8 \%$ & $207.7 \%$ & $232.6 \%$ & $291.1 \%$ \\
\hline $85+$ & $100.0 \%$ & $164.2 \%$ & $219.4 \%$ & $278.4 \%$ & $328.8 \%$ & $358.0 \%$ & $409.6 \%$ \\
\hline Total & $100.0 \%$ & $107.9 \%$ & $123.8 \%$ & $140.7 \%$ & $164.8 \%$ & $197.1 \%$ & $240.4 \%$ \\
\hline \multicolumn{8}{|c|}{ Northeast } \\
\hline & 1995 & 2000 & 2005 & 2010 & 2015 & 2020 & 2025 \\
\hline $65-69$ & $100.0 \%$ & $106.2 \%$ & $113.6 \%$ & $142.7 \%$ & $187.2 \%$ & $219.9 \%$ & $259.3 \%$ \\
\hline 70-74 & $100.0 \%$ & $97.1 \%$ & $88.3 \%$ & $92.8 \%$ & $114.4 \%$ & $146.7 \%$ & $169.8 \%$ \\
\hline $75-79$ & $100.0 \%$ & $128.2 \%$ & $129.3 \%$ & $118.9 \%$ & $125.9 \%$ & $157.5 \%$ & $206.6 \%$ \\
\hline $80-84$ & $100.0 \%$ & $175.9 \%$ & $209.6 \%$ & $219.0 \%$ & $207.4 \%$ & $227.5 \%$ & $291.5 \%$ \\
\hline $85+$ & $100.0 \%$ & $173.6 \%$ & $217.4 \%$ & $267.7 \%$ & $308.7 \%$ & $323.8 \%$ & $360.8 \%$ \\
\hline Total & $100.0 \%$ & $128.1 \%$ & $138.0 \%$ & $150.0 \%$ & $169.4 \%$ & $197.5 \%$ & $238.0 \%$ \\
\hline \multicolumn{8}{|c|}{ South } \\
\hline & 1995 & 2000 & 2005 & 2010 & 2015 & 2020 & 2025 \\
\hline $65-69$ & $100.0 \%$ & $140.0 \%$ & $168.5 \%$ & $225.8 \%$ & $313.5 \%$ & $387.2 \%$ & $470.1 \%$ \\
\hline 70-74 & $100.0 \%$ & $112.2 \%$ & $118.6 \%$ & $137.2 \%$ & $177.7 \%$ & $238.1 \%$ & $286.7 \%$ \\
\hline $75-79$ & $100.0 \%$ & $109.1 \%$ & $124.9 \%$ & $136.1 \%$ & $161.5 \%$ & $216.3 \%$ & $302.0 \%$ \\
\hline $80-84$ & $100.0 \%$ & $190.9 \%$ & $253.8 \%$ & $287.2 \%$ & $311.5 \%$ & $373.3 \%$ & $501.4 \%$ \\
\hline $85+$ & $100.0 \%$ & $186.3 \%$ & $260.4 \%$ & $352.9 \%$ & $439.3 \%$ & $505.1 \%$ & $608.4 \%$ \\
\hline Total & $100.0 \%$ & $138.9 \%$ & $169.3 \%$ & $204.6 \%$ & $253.3 \%$ & $315.9 \%$ & $400.3 \%$ \\
\hline \multicolumn{8}{|c|}{ West } \\
\hline & 1995 & 2000 & 2005 & 2010 & 2015 & 2020 & 2025 \\
\hline $65-69$ & $100.0 \%$ & $142.6 \%$ & $173.5 \%$ & $235.9 \%$ & $334.5 \%$ & $419.0 \%$ & $506.6 \%$ \\
\hline 70-74 & $100.0 \%$ & $87.2 \%$ & $92.7 \%$ & $112.1 \%$ & $151.6 \%$ & $212.5 \%$ & $266.3 \%$ \\
\hline $75-79$ & $100.0 \%$ & $156.3 \%$ & $177.4 \%$ & $193.8 \%$ & $236.9 \%$ & $325.3 \%$ & $466.5 \%$ \\
\hline $80-84$ & $100.0 \%$ & $150.4 \%$ & $203.1 \%$ & $229.1 \%$ & $245.7 \%$ & $297.5 \%$ & $402.6 \%$ \\
\hline $85+$ & $100.0 \%$ & $130.6 \%$ & $176.9 \%$ & $235.1 \%$ & $286.9 \%$ & $324.6 \%$ & $389.4 \%$ \\
\hline Total & $100.0 \%$ & $130.4 \%$ & $158.4 \%$ & $191.2 \%$ & $239.7 \%$ & $306.6 \%$ & $397.1 \%$ \\
\hline
\end{tabular}


Table A.5.1. Projected Total Fatality Rate Attributed to Male Drivers, Deaths per 100 Million Miles

\begin{tabular}{|c|c|c|c|c|c|c|c|}
\hline \multicolumn{8}{|c|}{ National } \\
\hline & 1995 & 2000 & 2005 & 2010 & 2015 & 2020 & 2025 \\
\hline $65-69$ & 1.61 & 1.68 & 1.65 & 1.62 & 1.58 & 1.55 & 1.52 \\
\hline $70-74$ & 2.09 & 2.25 & 2.17 & 2.10 & 2.02 & 1.95 & 1.89 \\
\hline $75-79$ & 3.43 & 3.72 & 3.65 & 3.58 & 3.52 & 3.46 & 3.40 \\
\hline $80-84$ & 9.51 & 8.05 & 7.89 & 7.72 & 7.58 & 7.43 & 7.31 \\
\hline $85+$ & 13.88 & 14.02 & 13.03 & 12.13 & 11.33 & 10.60 & 10.01 \\
\hline \multicolumn{8}{|c|}{ Midwest } \\
\hline & 1995 & 2000 & 2005 & 2010 & 2015 & 2020 & 2025 \\
\hline $65-69$ & 1.61 & 1.41 & 1.38 & 1.35 & 1.32 & 1.29 & 1.26 \\
\hline $70-74$ & 1.86 & 1.90 & 1.83 & 1.75 & 1.69 & 1.62 & 1.57 \\
\hline $75-79$ & 3.20 & 3.14 & 3.08 & 3.01 & 2.95 & 2.88 & 2.83 \\
\hline $80-84$ & 7.91 & 7.13 & 6.95 & 6.78 & 6.61 & 6.44 & 6.31 \\
\hline $85+$ & 14.24 & 13.08 & 12.42 & 11.79 & 11.19 & 10.62 & 10.19 \\
\hline \multicolumn{8}{|c|}{ Northeast } \\
\hline & 1995 & 2000 & 2005 & 2010 & 2015 & 2020 & 2025 \\
\hline $65-69$ & 1.15 & 1.41 & 1.38 & 1.35 & 1.32 & 1.28 & 1.26 \\
\hline 70-74 & 2.29 & 1.89 & 1.82 & 1.75 & 1.68 & 1.62 & 1.57 \\
\hline $75-79$ & 3.11 & 3.13 & 3.07 & 3.00 & 2.94 & 2.87 & 2.83 \\
\hline $80-84$ & 5.33 & 5.36 & 5.23 & 5.10 & 4.97 & 4.85 & 4.75 \\
\hline $85+$ & 13.50 & 13.05 & 12.38 & 11.76 & 11.16 & 10.59 & 10.16 \\
\hline \multicolumn{8}{|c|}{ South } \\
\hline & 1995 & 2000 & 2005 & 2010 & 2015 & 2020 & 2025 \\
\hline $65-69$ & 1.76 & 2.04 & 2.00 & 1.95 & 1.91 & 1.86 & 1.83 \\
\hline $70-74$ & 2.32 & 2.75 & 2.64 & 2.54 & 2.44 & 2.35 & 2.27 \\
\hline $75-79$ & 3.95 & 4.55 & 4.45 & 4.35 & 4.26 & 4.17 & 4.10 \\
\hline $80-84$ & 19.88 & 10.31 & 10.05 & 9.80 & 9.56 & 9.32 & 9.13 \\
\hline $85+$ & 19.79 & 18.92 & 17.96 & 17.05 & 16.18 & 15.36 & 14.73 \\
\hline \multicolumn{8}{|c|}{ West } \\
\hline & 1995 & 2000 & 2005 & 2010 & 2015 & 2020 & 2025 \\
\hline $65-69$ & 1.69 & 1.59 & 1.56 & 1.52 & 1.48 & 1.45 & 1.42 \\
\hline 70-74 & 1.86 & 2.14 & 2.06 & 1.98 & 1.90 & 1.83 & 1.77 \\
\hline $75-79$ & 3.08 & 3.54 & 3.46 & 3.39 & 3.32 & 3.25 & 3.19 \\
\hline $80-84$ & 7.08 & 8.02 & 7.82 & 7.63 & 7.44 & 7.26 & 7.11 \\
\hline $85+$ & 7.57 & 8.15 & 6.56 & 5.28 & 4.25 & 3.43 & 2.79 \\
\hline
\end{tabular}


Table A.5.2. Projected Total Fatality Rate Attributed to Male Drivers, Deaths per 100 Million Miles, as Percentage of 1995 Rates

\begin{tabular}{|c|c|c|c|c|c|c|c|}
\hline \multicolumn{8}{|c|}{ National } \\
\hline & 1995 & 2000 & 2005 & 2010 & 2015 & 2020 & 2025 \\
\hline $65-69$ & $100.0 \%$ & $104.5 \%$ & $102.6 \%$ & $100.6 \%$ & $98.5 \%$ & $96.3 \%$ & $94.7 \%$ \\
\hline $70-74$ & $100.0 \%$ & $107.6 \%$ & $103.9 \%$ & $100.3 \%$ & $96.7 \%$ & $93.2 \%$ & $90.3 \%$ \\
\hline $75-79$ & $100.0 \%$ & $108.4 \%$ & $106.4 \%$ & $104.5 \%$ & $102.7 \%$ & $100.8 \%$ & $99.3 \%$ \\
\hline $80-84$ & $100.0 \%$ & $84.7 \%$ & $83.0 \%$ & $81.2 \%$ & $79.7 \%$ & $78.2 \%$ & $76.9 \%$ \\
\hline $85+$ & $100.0 \%$ & $101.1 \%$ & $93.9 \%$ & $87.4 \%$ & $81.7 \%$ & $76.4 \%$ & $72.1 \%$ \\
\hline \multicolumn{8}{|c|}{ Midwest } \\
\hline & 1995 & 2000 & 2005 & 2010 & 2015 & 2020 & 2025 \\
\hline $65-69$ & $100.0 \%$ & $88.1 \%$ & $86.1 \%$ & $84.1 \%$ & $82.2 \%$ & $80.3 \%$ & $78.8 \%$ \\
\hline $70-74$ & $100.0 \%$ & $101.9 \%$ & $97.9 \%$ & $94.1 \%$ & $90.5 \%$ & $87.0 \%$ & $84.3 \%$ \\
\hline $75-79$ & $100.0 \%$ & $98.1 \%$ & $96.0 \%$ & $93.9 \%$ & $91.9 \%$ & $90.0 \%$ & $88.4 \%$ \\
\hline $80-84$ & $100.0 \%$ & $90.1 \%$ & $87.9 \%$ & $85.7 \%$ & $83.5 \%$ & $81.5 \%$ & $79.8 \%$ \\
\hline $85+$ & $100.0 \%$ & $91.9 \%$ & $87.2 \%$ & $82.8 \%$ & $78.6 \%$ & $74.6 \%$ & $71.5 \%$ \\
\hline \multicolumn{8}{|c|}{ Northeast } \\
\hline & 1995 & 2000 & 2005 & 2010 & 2015 & 2020 & 2025 \\
\hline $65-69$ & $100.0 \%$ & $122.7 \%$ & $119.9 \%$ & $117.1 \%$ & $114.5 \%$ & $111.8 \%$ & $109.8 \%$ \\
\hline 70-74 & $100.0 \%$ & $82.6 \%$ & $79.4 \%$ & $76.3 \%$ & $73.4 \%$ & $70.5 \%$ & $68.3 \%$ \\
\hline $75-79$ & $100.0 \%$ & $100.9 \%$ & $98.8 \%$ & $96.7 \%$ & $94.6 \%$ & $92.6 \%$ & $91.0 \%$ \\
\hline $80-84$ & $100.0 \%$ & $100.5 \%$ & $98.0 \%$ & $95.6 \%$ & $93.2 \%$ & $90.9 \%$ & $89.1 \%$ \\
\hline $85+$ & $100.0 \%$ & $96.6 \%$ & $91.7 \%$ & $87.1 \%$ & $82.6 \%$ & $78.4 \%$ & $75.2 \%$ \\
\hline \multicolumn{8}{|c|}{ South } \\
\hline & 1995 & 2000 & 2005 & 2010 & 2015 & 2020 & 2025 \\
\hline $65-69$ & $100.0 \%$ & $116.0 \%$ & $113.3 \%$ & $110.7 \%$ & $108.2 \%$ & $105.7 \%$ & $103.7 \%$ \\
\hline 70-74 & $100.0 \%$ & $118.6 \%$ & $114.0 \%$ & $109.6 \%$ & $105.3 \%$ & $101.3 \%$ & $98.1 \%$ \\
\hline $75-79$ & $100.0 \%$ & $115.0 \%$ & $112.5 \%$ & $110.1 \%$ & $107.8 \%$ & $105.5 \%$ & $103.6 \%$ \\
\hline $80-84$ & $100.0 \%$ & $51.8 \%$ & $50.6 \%$ & $49.3 \%$ & $48.1 \%$ & $46.9 \%$ & $45.9 \%$ \\
\hline $85+$ & $100.0 \%$ & $95.6 \%$ & $90.7 \%$ & $86.1 \%$ & $81.8 \%$ & $77.6 \%$ & $74.4 \%$ \\
\hline \multicolumn{8}{|c|}{ West } \\
\hline & 1995 & 2000 & 2005 & 2010 & 2015 & 2020 & 2025 \\
\hline $65-69$ & $100.0 \%$ & $94.2 \%$ & $92.1 \%$ & $90.0 \%$ & $87.9 \%$ & $85.9 \%$ & $84.3 \%$ \\
\hline 70-74 & $100.0 \%$ & $114.8 \%$ & $110.4 \%$ & $106.1 \%$ & $102.0 \%$ & $98.0 \%$ & $95.0 \%$ \\
\hline $75-79$ & $100.0 \%$ & $115.0 \%$ & $112.6 \%$ & $110.2 \%$ & $107.8 \%$ & $105.5 \%$ & $103.7 \%$ \\
\hline $80-84$ & $100.0 \%$ & $113.3 \%$ & $110.5 \%$ & $107.8 \%$ & $105.1 \%$ & $102.5 \%$ & $100.4 \%$ \\
\hline $85+$ & $100.0 \%$ & $107.7 \%$ & $86.7 \%$ & $69.8 \%$ & $56.2 \%$ & $45.3 \%$ & $36.8 \%$ \\
\hline
\end{tabular}


Table A.5.3. Projected Total Fatality Rates Attributed to Female Drivers, Deaths per 100 Million Miles

\begin{tabular}{|c|c|c|c|c|c|c|c|}
\hline \multicolumn{8}{|c|}{ National } \\
\hline & 1995 & 2000 & 2005 & 2010 & 2015 & 2020 & 2025 \\
\hline $65-69$ & 1.47 & 1.65 & 1.62 & 1.59 & 1.56 & 1.52 & 1.50 \\
\hline $70-74$ & 2.52 & 2.25 & 2.18 & 2.10 & 2.03 & 1.95 & 1.89 \\
\hline $75-79$ & 4.34 & 3.58 & 3.51 & 3.46 & 3.39 & 3.32 & 3.27 \\
\hline $80-84$ & 6.18 & 6.59 & 6.41 & 6.24 & 6.07 & 5.90 & 5.78 \\
\hline $85+$ & 11.82 & 11.30 & 10.68 & 10.08 & 9.53 & 9.00 & 8.58 \\
\hline \multicolumn{8}{|c|}{ Midwest } \\
\hline & 1995 & 2000 & 2005 & 2010 & 2015 & 2020 & 2025 \\
\hline $65-69$ & 1.29 & 1.41 & 1.38 & 1.35 & 1.32 & 1.29 & 1.26 \\
\hline 70-74 & 2.23 & 1.90 & 1.83 & 1.75 & 1.69 & 1.62 & 1.57 \\
\hline $75-79$ & 5.14 & 3.14 & 3.08 & 3.01 & 2.95 & 2.88 & 2.83 \\
\hline $80-84$ & 6.17 & 7.13 & 6.95 & 6.78 & 6.61 & 6.44 & 6.31 \\
\hline $85+$ & 16.08 & 13.08 & 12.42 & 11.79 & 11.19 & 10.62 & 10.19 \\
\hline \multicolumn{8}{|c|}{ Northeast } \\
\hline & 1995 & 2000 & 2005 & 2010 & 2015 & 2020 & 2025 \\
\hline $65-69$ & 1.30 & 1.41 & 1.38 & 1.35 & 1.32 & 1.28 & 1.26 \\
\hline 70-74 & 2.56 & 1.89 & 1.82 & 1.75 & 1.68 & 1.62 & 1.57 \\
\hline $75-79$ & 3.49 & 3.13 & 3.07 & 3.00 & 2.94 & 2.87 & 2.83 \\
\hline $80-84$ & 6.06 & 7.11 & 6.93 & 6.76 & 6.59 & 6.43 & 6.30 \\
\hline $85+$ & 24.01 & 13.05 & 12.38 & 11.76 & 11.16 & 10.59 & 10.16 \\
\hline \multicolumn{8}{|c|}{ South } \\
\hline & 1995 & 2000 & 2005 & 2010 & 2015 & 2020 & 2025 \\
\hline $65-69$ & 1.80 & 2.04 & 2.00 & 1.95 & 1.91 & 1.86 & 1.83 \\
\hline 70-74 & 2.57 & 2.75 & 2.64 & 2.54 & 2.44 & 2.35 & 2.27 \\
\hline $75-79$ & 5.61 & 4.55 & 4.45 & 4.35 & 4.26 & 4.17 & 4.10 \\
\hline $80-84$ & 6.80 & 6.00 & 5.85 & 5.70 & 5.56 & 5.42 & 5.31 \\
\hline $85+$ & 10.56 & 11.01 & 10.45 & 9.92 & 9.42 & 8.94 & 8.57 \\
\hline \multicolumn{8}{|c|}{ West } \\
\hline & 1995 & 2000 & 2005 & 2010 & 2015 & 2020 & 2025 \\
\hline $65-69$ & 1.26 & 1.44 & 1.40 & 1.37 & 1.34 & 1.31 & 1.29 \\
\hline 70-74 & 2.75 & 2.14 & 2.06 & 1.98 & 1.90 & 1.83 & 1.77 \\
\hline $75-79$ & 2.66 & 2.81 & 2.75 & 2.70 & 2.64 & 2.58 & 2.54 \\
\hline $80-84$ & 5.33 & 6.38 & 6.22 & 6.07 & 5.92 & 5.77 & 5.66 \\
\hline $85+$ & 7.10 & 7.21 & 6.84 & 6.49 & 6.16 & 5.85 & 5.61 \\
\hline
\end{tabular}


Table A.5.4. Projected Total Fatality Rates Attributed to Female Drivers, Deaths per 100 Million Miles, as Percent of 1995 Rates

\begin{tabular}{|c|c|c|c|c|c|c|c|}
\hline \multicolumn{8}{|c|}{ National } \\
\hline & 1995 & 2000 & 2005 & 2010 & 2015 & 2020 & 2025 \\
\hline $65-69$ & $100.0 \%$ & $112.7 \%$ & $110.5 \%$ & $108.3 \%$ & $105.9 \%$ & $103.6 \%$ & $101.9 \%$ \\
\hline 70-74 & $100.0 \%$ & $89.5 \%$ & $86.6 \%$ & $83.6 \%$ & $80.6 \%$ & $77.6 \%$ & $75.3 \%$ \\
\hline $75-79$ & $100.0 \%$ & $82.5 \%$ & $81.0 \%$ & $79.7 \%$ & $78.2 \%$ & $76.6 \%$ & $75.3 \%$ \\
\hline $80-84$ & $100.0 \%$ & $106.7 \%$ & $103.8 \%$ & $101.0 \%$ & $98.2 \%$ & $95.6 \%$ & $93.5 \%$ \\
\hline $85+$ & $100.0 \%$ & $95.6 \%$ & $90.4 \%$ & $85.3 \%$ & $80.6 \%$ & $76.1 \%$ & $72.6 \%$ \\
\hline \multicolumn{8}{|c|}{ Midwest } \\
\hline & 1995 & 2000 & 2005 & 2010 & 2015 & 2020 & 2025 \\
\hline $65-69$ & $100.0 \%$ & $109.6 \%$ & $107.1 \%$ & $104.6 \%$ & $102.2 \%$ & $99.9 \%$ & $98.0 \%$ \\
\hline $70-74$ & $100.0 \%$ & $85.2 \%$ & $81.9 \%$ & $78.7 \%$ & $75.6 \%$ & $72.7 \%$ & $70.4 \%$ \\
\hline $75-79$ & $100.0 \%$ & $61.2 \%$ & $59.8 \%$ & $58.6 \%$ & $57.3 \%$ & $56.1 \%$ & $55.1 \%$ \\
\hline $80-84$ & $100.0 \%$ & $115.4 \%$ & $112.6 \%$ & $109.8 \%$ & $107.0 \%$ & $104.4 \%$ & $102.3 \%$ \\
\hline $85+$ & $100.0 \%$ & $81.4 \%$ & $77.2 \%$ & $73.3 \%$ & $69.6 \%$ & $66.1 \%$ & $63.3 \%$ \\
\hline \multicolumn{8}{|c|}{ Northeast } \\
\hline & 1995 & 2000 & 2005 & 2010 & 2015 & 2020 & 2025 \\
\hline $65-69$ & $100.0 \%$ & $108.3 \%$ & $105.8 \%$ & $103.4 \%$ & $101.0 \%$ & $98.7 \%$ & $96.9 \%$ \\
\hline 70-74 & $100.0 \%$ & $74.0 \%$ & $71.2 \%$ & $68.4 \%$ & $65.8 \%$ & $63.2 \%$ & $61.2 \%$ \\
\hline $75-79$ & $100.0 \%$ & $89.8 \%$ & $87.8 \%$ & $86.0 \%$ & $84.1 \%$ & $82.3 \%$ & $80.9 \%$ \\
\hline $80-84$ & $100.0 \%$ & $117.3 \%$ & $114.4 \%$ & $111.5 \%$ & $108.7 \%$ & $106.0 \%$ & $103.9 \%$ \\
\hline $85+$ & $100.0 \%$ & $54.3 \%$ & $51.6 \%$ & $49.0 \%$ & $46.5 \%$ & $44.1 \%$ & $42.3 \%$ \\
\hline \multicolumn{8}{|c|}{ South } \\
\hline & 1995 & 2000 & 2005 & 2010 & 2015 & 2020 & 2025 \\
\hline $65-69$ & $100.0 \%$ & $113.4 \%$ & $110.8 \%$ & $108.2 \%$ & $105.7 \%$ & $103.3 \%$ & $101.4 \%$ \\
\hline 70-74 & $100.0 \%$ & $106.8 \%$ & $102.7 \%$ & $98.7 \%$ & $94.9 \%$ & $91.2 \%$ & $88.4 \%$ \\
\hline $75-79$ & $100.0 \%$ & $81.1 \%$ & $79.3 \%$ & $77.6 \%$ & $76.0 \%$ & $74.3 \%$ & $73.1 \%$ \\
\hline $80-84$ & $100.0 \%$ & $88.2 \%$ & $86.0 \%$ & $83.9 \%$ & $81.8 \%$ & $79.7 \%$ & $78.1 \%$ \\
\hline $85+$ & $100.0 \%$ & $104.2 \%$ & $98.9 \%$ & $93.9 \%$ & $89.1 \%$ & $84.6 \%$ & $81.1 \%$ \\
\hline \multicolumn{8}{|c|}{ West } \\
\hline & 1995 & 2000 & 2005 & 2010 & 2015 & 2020 & 2025 \\
\hline $65-69$ & $100.0 \%$ & $113.7 \%$ & $111.1 \%$ & $108.6 \%$ & $106.1 \%$ & $103.6 \%$ & $101.7 \%$ \\
\hline 70-74 & $100.0 \%$ & $77.6 \%$ & $74.6 \%$ & $71.7 \%$ & $69.0 \%$ & $66.3 \%$ & $64.2 \%$ \\
\hline $75-79$ & $100.0 \%$ & $105.7 \%$ & $103.5 \%$ & $101.3 \%$ & $99.1 \%$ & $97.0 \%$ & $95.3 \%$ \\
\hline $80-84$ & $100.0 \%$ & $119.7 \%$ & $116.7 \%$ & $113.8 \%$ & $110.9 \%$ & $108.2 \%$ & $106.0 \%$ \\
\hline $85+$ & $100.0 \%$ & $101.5 \%$ & $96.3 \%$ & $91.5 \%$ & $86.8 \%$ & $82.4 \%$ & $79.0 \%$ \\
\hline
\end{tabular}


Table A.6.1. Projected Total Fatalities Attributed to Male Drivers, Number of Fatalities

\begin{tabular}{|c|c|c|c|c|c|c|c|}
\hline \multicolumn{8}{|c|}{ National } \\
\hline & 1995 & 2000 & 2005 & 2010 & 2015 & 2020 & 2025 \\
\hline $65-69$ & 805 & 871 & 989 & 1272 & 1711 & 2055 & 2424 \\
\hline $70-74$ & 733 & 814 & 800 & 885 & 1112 & 1467 & 1735 \\
\hline $75-79$ & 613 & 890 & 950 & 980 & 1127 & 1463 & 1996 \\
\hline $80-84$ & 469 & 670 & 831 & 924 & 981 & 1161 & 1545 \\
\hline $85+$ & 270 & 351 & 421 & 512 & 583 & 617 & 706 \\
\hline Total & 2890 & 3596 & 3991 & 4573 & 5513 & 6763 & 8406 \\
\hline \multicolumn{8}{|c|}{ Midwest } \\
\hline & 1995 & 2000 & 2005 & 2010 & 2015 & 2020 & 2025 \\
\hline $65-69$ & 206 & 189 & 205 & 253 & 333 & 397 & 459 \\
\hline $70-74$ & 175 & 168 & 163 & 173 & 207 & 266 & 311 \\
\hline $75-79$ & 141 & 161 & 171 & 172 & 189 & 234 & 312 \\
\hline $80-84$ & 126 & 185 & 223 & 248 & 259 & 293 & 371 \\
\hline $85+$ & 71 & 81 & 96 & 115 & 130 & 136 & 153 \\
\hline Total & 718 & 785 & 859 & 962 & 1117 & 1326 & 1607 \\
\hline \multicolumn{8}{|c|}{ Northeast } \\
\hline & 1995 & 2000 & 2005 & 2010 & 2015 & 2020 & 2025 \\
\hline $65-69$ & 94 & 111 & 118 & 146 & 188 & 217 & 254 \\
\hline $70-74$ & 129 & 118 & 107 & 111 & 134 & 169 & 192 \\
\hline $75-79$ & 93 & 130 & 134 & 127 & 136 & 169 & 221 \\
\hline $80-84$ & 61 & 95 & 114 & 124 & 122 & 136 & 176 \\
\hline $85+$ & 38 & 66 & 80 & 97 & 111 & 114 & 127 \\
\hline Total & 415 & 520 & 553 & 604 & 690 & 805 & 970 \\
\hline \multicolumn{8}{|c|}{ South } \\
\hline & 1995 & 2000 & 2005 & 2010 & 2015 & 2020 & 2025 \\
\hline $65-69$ & 345 & 413 & 477 & 623 & 844 & 1016 & 1205 \\
\hline $70-74$ & 286 & 367 & 371 & 419 & 536 & 716 & 851 \\
\hline $75-79$ & 255 & 430 & 469 & 497 & 581 & 763 & 1049 \\
\hline $80-84$ & 197 & 238 & 304 & 346 & 380 & 464 & 636 \\
\hline $85+$ & 118 & 137 & 175 & 226 & 271 & 301 & 360 \\
\hline Total & 1200 & 1585 & 1797 & 2110 & 2612 & 3260 & 4102 \\
\hline \multicolumn{8}{|c|}{ West } \\
\hline & 1995 & 2000 & 2005 & 2010 & 2015 & 2020 & 2025 \\
\hline $65-69$ & 159 & 158 & 189 & 250 & 346 & 425 & 506 \\
\hline $70-74$ & 143 & 161 & 158 & 183 & 236 & 316 & 380 \\
\hline $75-79$ & 125 & 169 & 176 & 184 & 222 & 297 & 414 \\
\hline $80-84$ & 86 & 152 & 189 & 206 & 220 & 268 & 362 \\
\hline $85+$ & 43 & 66 & 70 & 73 & 71 & 66 & 66 \\
\hline Total & 557 & 706 & 782 & 897 & 1094 & 1371 & 1727 \\
\hline
\end{tabular}


Table A.6.2. Projected Total Fatalities Attributed to Male Drivers, as Percentage of 1995 Fatalities

\begin{tabular}{|c|c|c|c|c|c|c|c|}
\hline \multicolumn{8}{|c|}{ National } \\
\hline & 1995 & 2000 & 2005 & 2010 & 2015 & 2020 & 2025 \\
\hline $65-69$ & $100.0 \%$ & $108.3 \%$ & $122.9 \%$ & $158.1 \%$ & $212.7 \%$ & $255.4 \%$ & $301.3 \%$ \\
\hline $70-74$ & $100.0 \%$ & $111.1 \%$ & $109.1 \%$ & $120.8 \%$ & $151.8 \%$ & $200.1 \%$ & $236.7 \%$ \\
\hline $75-79$ & $100.0 \%$ & $145.1 \%$ & $154.9 \%$ & $159.9 \%$ & $183.7 \%$ & $238.6 \%$ & $325.5 \%$ \\
\hline $80-84$ & $100.0 \%$ & $142.9 \%$ & $177.1 \%$ & $196.9 \%$ & $209.0 \%$ & $247.5 \%$ & $329.3 \%$ \\
\hline $85+$ & $100.0 \%$ & $129.7 \%$ & $155.9 \%$ & $189.3 \%$ & $215.4 \%$ & $228.1 \%$ & $261.1 \%$ \\
\hline Total & $100.0 \%$ & $124.4 \%$ & $138.1 \%$ & $158.2 \%$ & $190.8 \%$ & $234.0 \%$ & $290.8 \%$ \\
\hline \multicolumn{8}{|c|}{ Midwest } \\
\hline & 1995 & 2000 & 2005 & 2010 & 2015 & 2020 & 2025 \\
\hline $65-69$ & $100.0 \%$ & $91.9 \%$ & $99.7 \%$ & $123.1 \%$ & $161.7 \%$ & $193.0 \%$ & $223.2 \%$ \\
\hline $70-74$ & $100.0 \%$ & $96.0 \%$ & $93.0 \%$ & $98.6 \%$ & $117.9 \%$ & $151.6 \%$ & $177.6 \%$ \\
\hline $75-79$ & $100.0 \%$ & $114.5 \%$ & $121.0 \%$ & $122.3 \%$ & $134.1 \%$ & $166.1 \%$ & $221.5 \%$ \\
\hline $80-84$ & $100.0 \%$ & $147.4 \%$ & $177.9 \%$ & $197.7 \%$ & $206.2 \%$ & $233.2 \%$ & $295.3 \%$ \\
\hline $85+$ & $100.0 \%$ & $115.0 \%$ & $136.6 \%$ & $163.2 \%$ & $183.9 \%$ & $193.1 \%$ & $216.8 \%$ \\
\hline Total & $100.0 \%$ & $109.3 \%$ & $119.6 \%$ & $134.0 \%$ & $155.6 \%$ & $184.6 \%$ & $223.7 \%$ \\
\hline \multicolumn{8}{|c|}{ Northeast } \\
\hline & 1995 & 2000 & 2005 & 2010 & 2015 & 2020 & 2025 \\
\hline $65-69$ & $100.0 \%$ & $118.2 \%$ & $125.3 \%$ & $154.8 \%$ & $199.4 \%$ & $230.5 \%$ & $269.6 \%$ \\
\hline $70-74$ & $100.0 \%$ & $91.5 \%$ & $83.1 \%$ & $85.8 \%$ & $103.7 \%$ & $130.9 \%$ & $149.2 \%$ \\
\hline $75-79$ & $100.0 \%$ & $139.8 \%$ & $144.5 \%$ & $136.5 \%$ & $146.1 \%$ & $182.4 \%$ & $238.4 \%$ \\
\hline $80-84$ & $100.0 \%$ & $156.2 \%$ & $187.1 \%$ & $203.2 \%$ & $200.2 \%$ & $223.7 \%$ & $289.5 \%$ \\
\hline $85+$ & $100.0 \%$ & $173.0 \%$ & $209.6 \%$ & $255.2 \%$ & $289.7 \%$ & $298.3 \%$ & $331.7 \%$ \\
\hline Total & $100.0 \%$ & $125.4 \%$ & $133.3 \%$ & $145.6 \%$ & $166.2 \%$ & $194.0 \%$ & $233.8 \%$ \\
\hline \multicolumn{8}{|c|}{ South } \\
\hline & 1995 & 2000 & 2005 & 2010 & 2015 & 2020 & 2025 \\
\hline $65-69$ & $100.0 \%$ & $119.5 \%$ & $138.2 \%$ & $180.3 \%$ & $244.5 \%$ & $294.1 \%$ & $349.0 \%$ \\
\hline $70-74$ & $100.0 \%$ & $128.6 \%$ & $130.0 \%$ & $146.7 \%$ & $187.8 \%$ & $250.7 \%$ & $298.1 \%$ \\
\hline $75-79$ & $100.0 \%$ & $168.9 \%$ & $184.2 \%$ & $195.2 \%$ & $228.1 \%$ & $299.8 \%$ & $412.0 \%$ \\
\hline $80-84$ & $100.0 \%$ & $121.1 \%$ & $154.8 \%$ & $175.8 \%$ & $193.4 \%$ & $236.2 \%$ & $323.7 \%$ \\
\hline $85+$ & $100.0 \%$ & $115.8 \%$ & $148.0 \%$ & $191.1 \%$ & $228.9 \%$ & $254.5 \%$ & $304.5 \%$ \\
\hline Total & $100.0 \%$ & $132.0 \%$ & $149.7 \%$ & $175.8 \%$ & $217.6 \%$ & $271.6 \%$ & $341.7 \%$ \\
\hline \multicolumn{8}{|c|}{ West } \\
\hline & 1995 & 2000 & 2005 & 2010 & 2015 & 2020 & 2025 \\
\hline $65-69$ & $100.0 \%$ & $99.2 \%$ & $118.4 \%$ & $157.2 \%$ & $217.3 \%$ & $266.8 \%$ & $317.5 \%$ \\
\hline $70-74$ & $100.0 \%$ & $112.3 \%$ & $110.7 \%$ & $127.8 \%$ & $164.7 \%$ & $221.0 \%$ & $265.6 \%$ \\
\hline $75-79$ & $100.0 \%$ & $135.0 \%$ & $141.3 \%$ & $147.6 \%$ & $177.3 \%$ & $237.4 \%$ & $331.1 \%$ \\
\hline $80-84$ & $100.0 \%$ & $176.6 \%$ & $219.4 \%$ & $239.6 \%$ & $255.2 \%$ & $311.2 \%$ & $420.0 \%$ \\
\hline $85+$ & $100.0 \%$ & $153.3 \%$ & $161.3 \%$ & $168.7 \%$ & $164.5 \%$ & $151.5 \%$ & $152.5 \%$ \\
\hline Total & $100.0 \%$ & $126.8 \%$ & $140.5 \%$ & $161.1 \%$ & $196.6 \%$ & $246.3 \%$ & $310.2 \%$ \\
\hline
\end{tabular}


Table A.6.3. Projected Total Fatalities Attributed to Female Drivers, Number of Fatalities

\begin{tabular}{|c|c|c|c|c|c|c|c|}
\hline \multicolumn{8}{|c|}{ National } \\
\hline & 1995 & 2000 & 2005 & 2010 & 2015 & 2020 & 2025 \\
\hline $65-69$ & 316 & 396 & 475 & 645 & 917 & 1167 & 1446 \\
\hline $70-74$ & 362 & 407 & 420 & 484 & 632 & 866 & 1067 \\
\hline $75-79$ & 322 & 350 & 392 & 419 & 500 & 676 & 957 \\
\hline $80-84$ & 196 & 351 & 451 & 505 & 537 & 642 & 865 \\
\hline $85+$ & 106 & 179 & 245 & 328 & 408 & 465 & 559 \\
\hline Total & 1302 & 1683 & 1982 & 2382 & 2995 & 3816 & 4894 \\
\hline \multicolumn{8}{|c|}{ Midwest } \\
\hline & 1995 & 2000 & 2005 & 2010 & 2015 & 2020 & 2025 \\
\hline $65-69$ & 70 & 75 & 87 & 114 & 159 & 202 & 246 \\
\hline $70-74$ & 80 & 85 & 84 & 93 & 115 & 153 & 184 \\
\hline $75-79$ & 95 & 73 & 80 & 83 & 95 & 122 & 167 \\
\hline $80-84$ & 45 & 90 & 108 & 117 & 119 & 137 & 175 \\
\hline $85+$ & 26 & 43 & 58 & 75 & 91 & 101 & 118 \\
\hline Total & 315 & 366 & 418 & 482 & 580 & 715 & 891 \\
\hline \multicolumn{8}{|c|}{ Northeast } \\
\hline & 1995 & 2000 & 2005 & 2010 & 2015 & 2020 & 2025 \\
\hline $65-69$ & 47 & 49 & 54 & 69 & 93 & 111 & 134 \\
\hline $70-74$ & 69 & 66 & 60 & 64 & 80 & 105 & 124 \\
\hline $75-79$ & 47 & 60 & 61 & 58 & 62 & 79 & 106 \\
\hline $80-84$ & 36 & 76 & 91 & 96 & 92 & 103 & 134 \\
\hline $85+$ & 20 & 32 & 40 & 51 & 60 & 64 & 72 \\
\hline Total & 218 & 283 & 307 & 338 & 387 & 462 & 570 \\
\hline \multicolumn{8}{|c|}{ South } \\
\hline & 1995 & 2000 & 2005 & 2010 & 2015 & 2020 & 2025 \\
\hline $65-69$ & 137 & 193 & 235 & 322 & 461 & 588 & 734 \\
\hline $70-74$ & 144 & 188 & 202 & 238 & 315 & 435 & 538 \\
\hline $75-79$ & 128 & 148 & 171 & 192 & 234 & 322 & 461 \\
\hline $80-84$ & 75 & 117 & 159 & 187 & 209 & 256 & 353 \\
\hline $85+$ & 42 & 78 & 112 & 157 & 201 & 237 & 292 \\
\hline Total & 527 & 724 & 879 & 1095 & 1420 & 1838 & 2378 \\
\hline \multicolumn{8}{|c|}{ West } \\
\hline & 1995 & 2000 & 2005 & 2010 & 2015 & 2020 & 2025 \\
\hline $65-69$ & 62 & 79 & 99 & 140 & 205 & 266 & 331 \\
\hline $70-74$ & 69 & 68 & 73 & 89 & 122 & 173 & 220 \\
\hline $75-79$ & 52 & 69 & 79 & 87 & 109 & 152 & 223 \\
\hline $80-84$ & 40 & 68 & 93 & 106 & 117 & 146 & 204 \\
\hline $85+$ & 18 & 26 & 34 & 46 & 56 & 64 & 77 \\
\hline Total & 241 & 311 & 378 & 467 & 607 & 801 & 1056 \\
\hline
\end{tabular}


Table A.6.4. Projected Total Fatalities Attributed to Female Drivers, as Percentage of 1995 Fatalities

\begin{tabular}{|c|c|c|c|c|c|c|c|}
\hline \multicolumn{8}{|c|}{ National } \\
\hline & 1995 & 2000 & 2005 & 2010 & 2015 & 2020 & 2025 \\
\hline $65-69$ & $100.0 \%$ & $125.4 \%$ & $150.3 \%$ & $204.1 \%$ & $290.4 \%$ & $369.3 \%$ & $457.8 \%$ \\
\hline $70-74$ & $100.0 \%$ & $112.6 \%$ & $116.0 \%$ & $134.0 \%$ & $174.8 \%$ & $239.5 \%$ & $295.0 \%$ \\
\hline $75-79$ & $100.0 \%$ & $108.6 \%$ & $121.6 \%$ & $130.2 \%$ & $155.3 \%$ & $209.8 \%$ & $297.0 \%$ \\
\hline $80-84$ & $100.0 \%$ & $179.3 \%$ & $230.5 \%$ & $257.8 \%$ & $274.2 \%$ & $327.8 \%$ & $441.5 \%$ \\
\hline $85+$ & $100.0 \%$ & $168.3 \%$ & $230.0 \%$ & $308.5 \%$ & $383.3 \%$ & $437.6 \%$ & $526.1 \%$ \\
\hline Total & $100.0 \%$ & $129.3 \%$ & $152.2 \%$ & $183.0 \%$ & $230.0 \%$ & $293.1 \%$ & $375.9 \%$ \\
\hline \multicolumn{8}{|c|}{ Midwest } \\
\hline & 1995 & 2000 & 2005 & 2010 & 2015 & 2020 & 2025 \\
\hline $65-69$ & $100.0 \%$ & $106.9 \%$ & $124.8 \%$ & $163.2 \%$ & $228.6 \%$ & $289.5 \%$ & $353.3 \%$ \\
\hline 70-74 & $100.0 \%$ & $106.8 \%$ & $106.1 \%$ & $117.5 \%$ & $145.0 \%$ & $192.1 \%$ & $231.7 \%$ \\
\hline $75-79$ & $100.0 \%$ & $76.8 \%$ & $84.1 \%$ & $87.4 \%$ & $100.1 \%$ & $128.3 \%$ & $175.7 \%$ \\
\hline $80-84$ & $100.0 \%$ & $198.6 \%$ & $240.1 \%$ & $258.7 \%$ & $264.7 \%$ & $303.1 \%$ & $387.1 \%$ \\
\hline $85+$ & $100.0 \%$ & $170.4 \%$ & $228.6 \%$ & $293.7 \%$ & $355.1 \%$ & $396.3 \%$ & $464.4 \%$ \\
\hline Total & $100.0 \%$ & $116.0 \%$ & $132.7 \%$ & $153.0 \%$ & $184.1 \%$ & $226.8 \%$ & $282.8 \%$ \\
\hline \multicolumn{8}{|c|}{ Northeast } \\
\hline & 1995 & 2000 & 2005 & 2010 & 2015 & 2020 & 2025 \\
\hline $65-69$ & $100.0 \%$ & $106.4 \%$ & $115.6 \%$ & $148.2 \%$ & $199.0 \%$ & $239.4 \%$ & $288.6 \%$ \\
\hline 70-74 & $100.0 \%$ & $95.3 \%$ & $87.3 \%$ & $93.2 \%$ & $116.7 \%$ & $153.0 \%$ & $180.5 \%$ \\
\hline $75-79$ & $100.0 \%$ & $127.8 \%$ & $131.0 \%$ & $122.9 \%$ & $132.5 \%$ & $169.0 \%$ & $225.7 \%$ \\
\hline $80-84$ & $100.0 \%$ & $213.0 \%$ & $255.5 \%$ & $269.0 \%$ & $258.4 \%$ & $287.7 \%$ & $373.9 \%$ \\
\hline $85+$ & $100.0 \%$ & $155.9 \%$ & $197.7 \%$ & $250.4 \%$ & $294.9 \%$ & $313.3 \%$ & $353.6 \%$ \\
\hline Total & $100.0 \%$ & $129.6 \%$ & $140.6 \%$ & $154.7 \%$ & $177.4 \%$ & $211.8 \%$ & $261.0 \%$ \\
\hline \multicolumn{8}{|c|}{ South } \\
\hline & 1995 & 2000 & 2005 & 2010 & 2015 & 2020 & 2025 \\
\hline $65-69$ & $100.0 \%$ & $140.5 \%$ & $170.8 \%$ & $234.5 \%$ & $335.6 \%$ & $428.1 \%$ & $534.9 \%$ \\
\hline 70-74 & $100.0 \%$ & $131.0 \%$ & $140.6 \%$ & $165.4 \%$ & $219.1 \%$ & $302.3 \%$ & $374.0 \%$ \\
\hline $75-79$ & $100.0 \%$ & $115.1 \%$ & $133.4 \%$ & $149.4 \%$ & $182.6 \%$ & $251.1 \%$ & $359.1 \%$ \\
\hline $80-84$ & $100.0 \%$ & $155.3 \%$ & $211.0 \%$ & $247.3 \%$ & $276.9 \%$ & $340.0 \%$ & $467.7 \%$ \\
\hline $85+$ & $100.0 \%$ & $184.3 \%$ & $264.1 \%$ & $370.1 \%$ & $475.3 \%$ & $559.2 \%$ & $689.4 \%$ \\
\hline Total & $100.0 \%$ & $137.4 \%$ & $166.7 \%$ & $207.7 \%$ & $269.4 \%$ & $348.6 \%$ & $451.0 \%$ \\
\hline \multicolumn{8}{|c|}{ West } \\
\hline & 1995 & 2000 & 2005 & 2010 & 2015 & 2020 & 2025 \\
\hline $65-69$ & $100.0 \%$ & $126.9 \%$ & $159.4 \%$ & $224.8 \%$ & $328.3 \%$ & $425.9 \%$ & $531.4 \%$ \\
\hline 70-74 & $100.0 \%$ & $98.2 \%$ & $104.8 \%$ & $128.1 \%$ & $175.1 \%$ & $249.5 \%$ & $317.4 \%$ \\
\hline $75-79$ & $100.0 \%$ & $133.6 \%$ & $152.5 \%$ & $168.0 \%$ & $209.6 \%$ & $294.2 \%$ & $430.6 \%$ \\
\hline $80-84$ & $100.0 \%$ & $172.7 \%$ & $234.1 \%$ & $266.8 \%$ & $294.4 \%$ & $368.7 \%$ & $514.7 \%$ \\
\hline $85+$ & $100.0 \%$ & $141.7 \%$ & $188.7 \%$ & $250.8 \%$ & $307.6 \%$ & $351.4 \%$ & $425.1 \%$ \\
\hline Total & $100.0 \%$ & $128.7 \%$ & $156.7 \%$ & $193.7 \%$ & $251.6 \%$ & $331.9 \%$ & $437.5 \%$ \\
\hline
\end{tabular}




\section{APPENDIX B. EXOGENOUS VARIABLE PROJECTIONS}

\section{B.1. NON-INSTITUTIONALIZED POPULATION PROJECTIONS ${ }^{1}$}

Adjustments to Census Bureau Population Estimates to Account for Non-institutionalized Population

The population estimates provided by the Census Bureau project total population, not taking into account institutionalized status. Using estimates of institutionalized population by age from AARP and the Census Bureau, these total population numbers were adjusted downward to remove the institutionalized portion of the elderly population from our estimates.

\footnotetext{
${ }^{1}$ Data for population projections were derived from the Census Bureau web site (http://www.census.gov/population/www/projections/stproj.htmlas of January 8, 1999 and the percentage of institutionalized elderly as noted in the 1996 Statistical Abstract of the United States, also published by the Census Bureau.
} 
Table B.1. Projections of Non-Institutionalized Population, Males

\begin{tabular}{|c|c|c|c|c|c|c|c|}
\hline \multicolumn{8}{|c|}{ National } \\
\hline & 1995 & 2000 & 2005 & 2010 & 2015 & 2020 & 2025 \\
\hline $65-69$ & $4,441,007$ & $4,254,151$ & $4,577,821$ & $5,572,529$ & $7,142,692$ & $8,190,136$ & $9,215,012$ \\
\hline 70-74 & $3,781,060$ & $3,799,423$ & $3,693,202$ & $4,031,432$ & $4,966,407$ & $6,411,892$ & $7,397,098$ \\
\hline $75-79$ & $2,561,733$ & $2,916,192$ & $2,993,089$ & $2,955,493$ & $3,250,372$ & $4,056,984$ & $5,311,543$ \\
\hline $80-84$ & $1,515,468$ & $1,740,620$ & $2,024,681$ & $2,111,585$ & $2,112,372$ & $2,387,147$ & $3,027,950$ \\
\hline $85+$ & 736,606 & 882,223 & $1,052,097$ & $1,271,548$ & $1,447,238$ & $1,544,189$ & $1,768,914$ \\
\hline \multicolumn{8}{|c|}{ Midwest } \\
\hline & 1995 & 2000 & 2005 & 2010 & 2015 & 2020 & 2025 \\
\hline $65-69$ & $1,056,828$ & $1,012,231$ & $1,051,850$ & $1,227,212$ & $1,543,805$ & $1,763,067$ & $1,946,517$ \\
\hline 70-74 & 889,148 & 896,313 & 868,929 & 915,905 & $1,083,785$ & $1,376,248$ & $1,582,670$ \\
\hline $75-79$ & 613,341 & 685,117 & 703,774 & 692,251 & 736,198 & 884,765 & $1,141,612$ \\
\hline $80-84$ & 368,805 & 412,904 & 470,131 & 489,107 & 486,817 & 532,842 & 652,059 \\
\hline $85+$ & 185,216 & 214,114 & 247,734 & 291,198 & 326,092 & 343,423 & 383,703 \\
\hline \multicolumn{8}{|c|}{ Northeast } \\
\hline & 1995 & 2000 & 2005 & 2010 & 2015 & 2020 & 2025 \\
\hline $65-69$ & 937,376 & 832,856 & 840,097 & 991,096 & $1,225,290$ & $1,361,905$ & $1,526,124$ \\
\hline 70-74 & 799,287 & 778,855 & 703,317 & 721,845 & 863,533 & $1,077,341$ & $1,206,911$ \\
\hline $75-79$ & 543,802 & 602,168 & 600,584 & 552,718 & 573,173 & 695,822 & 882,059 \\
\hline $80-84$ & 323,911 & 359,263 & 407,073 & 414,066 & 387,048 & 414,062 & 512,005 \\
\hline $85+$ & 157,019 & 181,730 & 210,483 & 248,934 & 278,156 & 285,323 & 314,218 \\
\hline \multicolumn{8}{|c|}{ South } \\
\hline & 1995 & 2000 & 2005 & 2010 & 2015 & 2020 & 2025 \\
\hline $65-69$ & $1,570,741$ & $1,559,096$ & $1,723,376$ & $2,140,123$ & $2,777,528$ & $3,196,122$ & $3,624,162$ \\
\hline 70-74 & $1,323,734$ & $1,362,966$ & $1,366,806$ & $1,526,902$ & $1,914,550$ & $2,497,906$ & $2,887,473$ \\
\hline $75-79$ & 882,080 & $1,026,286$ & $1,075,154$ & $1,090,510$ & $1,224,072$ & $1,552,232$ & $2,049,929$ \\
\hline $80-84$ & 515,898 & 603,928 & 716,442 & 759,509 & 778,238 & 894,740 & $1,150,475$ \\
\hline $85+$ & 246,889 & 300,405 & 361,840 & 442,168 & 508,151 & 549,796 & 638,026 \\
\hline \multicolumn{8}{|c|}{ West } \\
\hline & 1995 & 2000 & 2005 & 2010 & 2015 & 2020 & 2025 \\
\hline $65-69$ & 876,061 & 849,968 & 962,499 & $1,214,098$ & $1,596,069$ & $1,869,043$ & $2,118,209$ \\
\hline $70-74$ & 768,891 & 761,289 & 754,150 & 866,780 & $1,104,540$ & $1,460,396$ & $1,720,044$ \\
\hline $75-79$ & 522,510 & 602,621 & 613,576 & 620,013 & 716,929 & 924,165 & $1,237,943$ \\
\hline $80-84$ & 306,853 & 364,525 & 431,035 & 448,904 & 460,269 & 545,504 & 713,410 \\
\hline $85+$ & 147,483 & 185,975 & 232,040 & 289,249 & 334,839 & 365,646 & 432,967 \\
\hline
\end{tabular}


Table B.2. Projections of Non-Institutionalized Population, Males, as Percent of 1995 Population

\begin{tabular}{|c|c|c|c|c|c|c|c|}
\hline \multicolumn{8}{|c|}{ National } \\
\hline & 1995 & 2000 & 2005 & 2010 & 2015 & 2020 & 2025 \\
\hline $65-69$ & $100.0 \%$ & $95.8 \%$ & $103.1 \%$ & $125.5 \%$ & $160.8 \%$ & $184.4 \%$ & $207.5 \%$ \\
\hline $70-74$ & $100.0 \%$ & $100.5 \%$ & $97.7 \%$ & $106.6 \%$ & $131.3 \%$ & $169.6 \%$ & $195.6 \%$ \\
\hline $75-79$ & $100.0 \%$ & $113.8 \%$ & $116.8 \%$ & $115.4 \%$ & $126.9 \%$ & $158.4 \%$ & $207.3 \%$ \\
\hline $80-84$ & $100.0 \%$ & $114.9 \%$ & $133.6 \%$ & $139.3 \%$ & $139.4 \%$ & $157.5 \%$ & $199.8 \%$ \\
\hline $85+$ & $100.0 \%$ & $119.8 \%$ & $142.8 \%$ & $172.6 \%$ & $196.5 \%$ & $209.6 \%$ & $240.1 \%$ \\
\hline \multicolumn{8}{|c|}{ Midwest } \\
\hline & 1995 & 2000 & 2005 & 2010 & 2015 & 2020 & 2025 \\
\hline $65-69$ & $100.0 \%$ & $95.8 \%$ & $99.5 \%$ & $116.1 \%$ & $146.1 \%$ & $166.8 \%$ & $184.2 \%$ \\
\hline $70-74$ & $100.0 \%$ & $100.8 \%$ & $97.7 \%$ & $103.0 \%$ & $121.9 \%$ & $154.8 \%$ & $178.0 \%$ \\
\hline $75-79$ & $100.0 \%$ & $111.7 \%$ & $114.7 \%$ & $112.9 \%$ & $120.0 \%$ & $144.3 \%$ & $186.1 \%$ \\
\hline $80-84$ & $100.0 \%$ & $112.0 \%$ & $127.5 \%$ & $132.6 \%$ & $132.0 \%$ & $144.5 \%$ & $176.8 \%$ \\
\hline $85+$ & $100.0 \%$ & $115.6 \%$ & $133.8 \%$ & $157.2 \%$ & $176.1 \%$ & $185.4 \%$ & $207.2 \%$ \\
\hline \multicolumn{8}{|c|}{ Northeast } \\
\hline & 1995 & 2000 & 2005 & 2010 & 2015 & 2020 & 2025 \\
\hline $65-69$ & $100.0 \%$ & $88.8 \%$ & $89.6 \%$ & $105.7 \%$ & $130.7 \%$ & $145.3 \%$ & $162.8 \%$ \\
\hline 70-74 & $100.0 \%$ & $97.4 \%$ & $88.0 \%$ & $90.3 \%$ & $108.0 \%$ & $134.8 \%$ & $151.0 \%$ \\
\hline $75-79$ & $100.0 \%$ & $110.7 \%$ & $110.4 \%$ & $101.6 \%$ & $105.4 \%$ & $128.0 \%$ & $162.2 \%$ \\
\hline $80-84$ & $100.0 \%$ & $110.9 \%$ & $125.7 \%$ & $127.8 \%$ & $119.5 \%$ & $127.8 \%$ & $158.1 \%$ \\
\hline $85+$ & $100.0 \%$ & $115.7 \%$ & $134.0 \%$ & $158.5 \%$ & $177.1 \%$ & $181.7 \%$ & $200.1 \%$ \\
\hline \multicolumn{8}{|c|}{ South } \\
\hline & 1995 & 2000 & 2005 & 2010 & 2015 & 2020 & 2025 \\
\hline $65-69$ & $100.0 \%$ & $99.3 \%$ & $109.7 \%$ & $136.2 \%$ & $176.8 \%$ & $203.5 \%$ & $230.7 \%$ \\
\hline $70-74$ & $100.0 \%$ & $103.0 \%$ & $103.3 \%$ & $115.3 \%$ & $144.6 \%$ & $188.7 \%$ & $218.1 \%$ \\
\hline $75-79$ & $100.0 \%$ & $116.3 \%$ & $121.9 \%$ & $123.6 \%$ & $138.8 \%$ & $176.0 \%$ & $232.4 \%$ \\
\hline $80-84$ & $100.0 \%$ & $117.1 \%$ & $138.9 \%$ & $147.2 \%$ & $150.9 \%$ & $173.4 \%$ & $223.0 \%$ \\
\hline $85+$ & $100.0 \%$ & $121.7 \%$ & $146.6 \%$ & $179.1 \%$ & $205.8 \%$ & $222.7 \%$ & $258.4 \%$ \\
\hline \multicolumn{8}{|c|}{ West } \\
\hline & 1995 & 2000 & 2005 & 2010 & 2015 & 2020 & 2025 \\
\hline $65-69$ & $100.0 \%$ & $97.0 \%$ & $109.9 \%$ & $138.6 \%$ & $182.2 \%$ & $213.3 \%$ & $241.8 \%$ \\
\hline 70-74 & $100.0 \%$ & $99.0 \%$ & $98.1 \%$ & $112.7 \%$ & $143.7 \%$ & $189.9 \%$ & $223.7 \%$ \\
\hline $75-79$ & $100.0 \%$ & $115.3 \%$ & $117.4 \%$ & $118.7 \%$ & $137.2 \%$ & $176.9 \%$ & $236.9 \%$ \\
\hline $80-84$ & $100.0 \%$ & $118.8 \%$ & $140.5 \%$ & $146.3 \%$ & $150.0 \%$ & $177.8 \%$ & $232.5 \%$ \\
\hline $85+$ & $100.0 \%$ & $126.1 \%$ & $157.3 \%$ & $196.1 \%$ & $227.0 \%$ & $247.9 \%$ & $293.6 \%$ \\
\hline
\end{tabular}


Table B.3. Projections of Non-Institutionalized Population, Females

\begin{tabular}{|c|c|c|c|c|c|c|c|}
\hline \multicolumn{8}{|c|}{ National } \\
\hline & 1995 & 2000 & 2005 & 2010 & 2015 & 2020 & 2025 \\
\hline $65-69$ & $5,344,097$ & $5,010,527$ & $5,294,830$ & $6,355,453$ & $8,033,834$ & $9,116,045$ & $10,118,177$ \\
\hline $70-74$ & $4,923,057$ & $4,791,438$ & $4,503,108$ & $4,778,034$ & $5,750,525$ & $7,266,802$ & $8,244,250$ \\
\hline $75-79$ & $3,729,854$ & $4,076,868$ & $3,999,011$ & $3,774,837$ & $3,992,599$ & $4,825,222$ & $6,133,231$ \\
\hline $80-84$ & $2,687,951$ & $2,881,112$ & $3,181,331$ & $3,138,449$ & $2,974,548$ & $3,205,144$ & $3,908,321$ \\
\hline $85+$ & $1,891,563$ & $2,177,180$ & $2,447,383$ & $2,799,038$ & $3,046,026$ & $3,115,712$ & $3,377,327$ \\
\hline \multicolumn{8}{|c|}{ Midwest } \\
\hline & 1995 & 2000 & 2005 & 2010 & 2015 & 2020 & 2025 \\
\hline $65-69$ & $1,252,514$ & $1,162,441$ & $1,200,971$ & $1,382,440$ & $1,711,458$ & $1,924,397$ & $2,093,097$ \\
\hline $70-74$ & $1,155,573$ & $1,114,784$ & $1,034,305$ & $1,071,645$ & $1,238,990$ & $1,535,905$ & $1,727,367$ \\
\hline $75-79$ & 916,789 & 962,469 & 933,584 & 868,345 & 897,110 & $1,043,791$ & $1,303,033$ \\
\hline $80-84$ & 674,177 & 711,001 & 753,217 & 733,183 & 684,077 & 720,737 & 848,060 \\
\hline $85+$ & 498,451 & 563,620 & 622,489 & 689,861 & 734,829 & 737,855 & 783,229 \\
\hline \multicolumn{8}{|c|}{ Northeast } \\
\hline & 1995 & 2000 & 2005 & 2010 & 2015 & 2020 & 2025 \\
\hline $65-69$ & $1,156,581$ & 992,345 & 985,908 & $1,153,851$ & $1,412,038$ & $1,548,197$ & $1,697,843$ \\
\hline $70-74$ & $1,078,263$ & $1,006,914$ & 868,044 & 868,628 & $1,020,925$ & $1,250,850$ & $1,373,495$ \\
\hline $75-79$ & 836,561 & 871,303 & 821,674 & 714,104 & 714,236 & 844,256 & $1,042,459$ \\
\hline $80-84$ & 602,810 & 627,999 & 662,512 & 630,496 & 551,495 & 563,629 & 673,489 \\
\hline $85+$ & 432,180 & 473,561 & 514,691 & 568,095 & 598,692 & 582,087 & 601,852 \\
\hline \multicolumn{8}{|c|}{ South } \\
\hline & 1995 & 2000 & 2005 & 2010 & 2015 & 2020 & 2025 \\
\hline $65-69$ & $1,911,242$ & $1,878,407$ & $2,034,389$ & $2,484,278$ & $3,170,489$ & $3,622,381$ & $4,063,329$ \\
\hline $70-74$ & $1,740,774$ & $1,744,729$ & $1,710,211$ & $1,853,628$ & $2,265,411$ & $2,885,942$ & $3,291,998$ \\
\hline $75-79$ & $1,285,533$ & $1,458,063$ & $1,466,785$ & $1,437,565$ & $1,549,785$ & $1,898,966$ & $2,429,883$ \\
\hline $80-84$ & 924,682 & $1,006,997$ & $1,149,336$ & $1,157,652$ & $1,135,747$ & $1,244,460$ & $1,535,827$ \\
\hline $85+$ & 629,182 & 746,923 & 852,200 & 992,681 & $1,094,896$ & $1,140,960$ & $1,255,198$ \\
\hline \multicolumn{8}{|c|}{ West } \\
\hline & 1995 & 2000 & 2005 & 2010 & 2015 & 2020 & 2025 \\
\hline $65-69$ & $1,023,759$ & 977,334 & $1,073,562$ & $1,334,884$ & $1,739,850$ & $2,021,071$ & $2,263,908$ \\
\hline $70-74$ & 948,447 & 925,011 & 890,547 & 984,133 & $1,225,199$ & $1,594,105$ & $1,851,390$ \\
\hline $75-79$ & 690,971 & 785,033 & 776,968 & 754,824 & 831,468 & $1,038,209$ & $1,357,856$ \\
\hline $80-84$ & 486,282 & 535,115 & 616,266 & 617,118 & 603,228 & 676,319 & 850,947 \\
\hline $85+$ & 331,750 & 393,076 & 458,002 & 548,401 & 617,610 & 654,811 & 737,049 \\
\hline
\end{tabular}


Table B.4. Projections of Non-Institutionalized Population, Females, as Percent of 1995 Population

\begin{tabular}{|c|c|c|c|c|c|c|c|}
\hline \multicolumn{8}{|c|}{ National } \\
\hline & 1995 & 2000 & 2005 & 2010 & 2015 & 2020 & 2025 \\
\hline $65-69$ & $100.0 \%$ & $93.8 \%$ & $99.1 \%$ & $118.9 \%$ & $150.3 \%$ & $170.6 \%$ & $189.3 \%$ \\
\hline $70-74$ & $100.0 \%$ & $97.3 \%$ & $91.5 \%$ & $97.1 \%$ & $116.8 \%$ & $147.6 \%$ & $167.5 \%$ \\
\hline $75-79$ & $100.0 \%$ & $109.3 \%$ & $107.2 \%$ & $101.2 \%$ & $107.0 \%$ & $129.4 \%$ & $164.4 \%$ \\
\hline $80-84$ & $100.0 \%$ & $107.2 \%$ & $118.4 \%$ & $116.8 \%$ & $110.7 \%$ & $119.2 \%$ & $145.4 \%$ \\
\hline $85+$ & $100.0 \%$ & $115.1 \%$ & $129.4 \%$ & $148.0 \%$ & $161.0 \%$ & $164.7 \%$ & $178.5 \%$ \\
\hline \multicolumn{8}{|c|}{ Midwest } \\
\hline & 1995 & 2000 & 2005 & 2010 & 2015 & 2020 & 2025 \\
\hline $65-69$ & $100.0 \%$ & $92.8 \%$ & $95.9 \%$ & $110.4 \%$ & $136.6 \%$ & $153.6 \%$ & $167.1 \%$ \\
\hline $70-74$ & $100.0 \%$ & $96.5 \%$ & $89.5 \%$ & $92.7 \%$ & $107.2 \%$ & $132.9 \%$ & $149.5 \%$ \\
\hline $75-79$ & $100.0 \%$ & $105.0 \%$ & $101.8 \%$ & $94.7 \%$ & $97.9 \%$ & $113.9 \%$ & $142.1 \%$ \\
\hline $80-84$ & $100.0 \%$ & $105.5 \%$ & $111.7 \%$ & $108.8 \%$ & $101.5 \%$ & $106.9 \%$ & $125.8 \%$ \\
\hline $85+$ & $100.0 \%$ & $113.1 \%$ & $124.9 \%$ & $138.4 \%$ & $147.4 \%$ & $148.0 \%$ & $157.1 \%$ \\
\hline \multicolumn{8}{|c|}{ Northeast } \\
\hline & 1995 & 2000 & 2005 & 2010 & 2015 & 2020 & 2025 \\
\hline $65-69$ & $100.0 \%$ & $85.8 \%$ & $85.2 \%$ & $99.8 \%$ & $122.1 \%$ & $133.9 \%$ & $146.8 \%$ \\
\hline $70-74$ & $100.0 \%$ & $93.4 \%$ & $80.5 \%$ & $80.6 \%$ & $94.7 \%$ & $116.0 \%$ & $127.4 \%$ \\
\hline $75-79$ & $100.0 \%$ & $104.2 \%$ & $98.2 \%$ & $85.4 \%$ & $85.4 \%$ & $100.9 \%$ & $124.6 \%$ \\
\hline $80-84$ & $100.0 \%$ & $104.2 \%$ & $109.9 \%$ & $104.6 \%$ & $91.5 \%$ & $93.5 \%$ & $111.7 \%$ \\
\hline $85+$ & $100.0 \%$ & $109.6 \%$ & $119.1 \%$ & $131.4 \%$ & $138.5 \%$ & $134.7 \%$ & $139.3 \%$ \\
\hline \multicolumn{8}{|c|}{ South } \\
\hline & 1995 & 2000 & 2005 & 2010 & 2015 & 2020 & 2025 \\
\hline $65-69$ & $100.0 \%$ & $98.3 \%$ & $106.4 \%$ & $130.0 \%$ & $165.9 \%$ & $189.5 \%$ & $212.6 \%$ \\
\hline $70-74$ & $100.0 \%$ & $100.2 \%$ & $98.2 \%$ & $106.5 \%$ & $130.1 \%$ & $165.8 \%$ & $189.1 \%$ \\
\hline $75-79$ & $100.0 \%$ & $113.4 \%$ & $114.1 \%$ & $111.8 \%$ & $120.6 \%$ & $147.7 \%$ & $189.0 \%$ \\
\hline $80-84$ & $100.0 \%$ & $108.9 \%$ & $124.3 \%$ & $125.2 \%$ & $122.8 \%$ & $134.6 \%$ & $166.1 \%$ \\
\hline $85+$ & $100.0 \%$ & $118.7 \%$ & $135.4 \%$ & $157.8 \%$ & $174.0 \%$ & $181.3 \%$ & $199.5 \%$ \\
\hline \multicolumn{8}{|c|}{ West } \\
\hline & 1995 & 2000 & 2005 & 2010 & 2015 & 2020 & 2025 \\
\hline $65-69$ & $100.0 \%$ & $95.5 \%$ & $104.9 \%$ & $130.4 \%$ & $169.9 \%$ & $197.4 \%$ & $221.1 \%$ \\
\hline $70-74$ & $100.0 \%$ & $97.5 \%$ & $93.9 \%$ & $103.8 \%$ & $129.2 \%$ & $168.1 \%$ & $195.2 \%$ \\
\hline $75-79$ & $100.0 \%$ & $113.6 \%$ & $112.4 \%$ & $109.2 \%$ & $120.3 \%$ & $150.3 \%$ & $196.5 \%$ \\
\hline $80-84$ & $100.0 \%$ & $110.0 \%$ & $126.7 \%$ & $126.9 \%$ & $124.0 \%$ & $139.1 \%$ & $175.0 \%$ \\
\hline $85+$ & $100.0 \%$ & $118.5 \%$ & $138.1 \%$ & $165.3 \%$ & $186.2 \%$ & $197.4 \%$ & $222.2 \%$ \\
\hline
\end{tabular}




\section{B.2. INDEPENDENT VARIABLES PROJECTIONS}

\section{B.2.1 Income}

The following explains the process by which income for the elderly was forecasted by Standard \& Poor's DRI for use in the Oak Ridge National Laboratory (ORNL) projection model. These projections can be seen in Tables B.5 and B.6.

\section{B.2.1.1 Standard \& Poor's DRI}

Tables B.5 and B.6 contain historical estimates and forecasts of the median money income of persons of age 65 and over in 1998 dollars for demographic groups defined: by gender, within age groups 65-69, 70-74, 75-79, 80-84, and 85+, for the U.S. and each of four Census regions, at five-year intervals for the period 1975-2025.

Historical annual time series for 1975-1998 were tabulated from the Annual Demographic File of the Current Population Survey. All series were converted to constant dollars using the Census Bureau's CPIU-X1 deflator. These annual time series show substantial year-to-year variation. To eliminate outliers in the historical data, model-predicted values are shown for historical years in the accompanying spreadsheet.

The money income of persons aged 65 and over comes from the following sources (1995 data):

$\begin{array}{lr}\text { Earnings } & 18 \% \\ \text { Social Security } & 42 \% \\ \text { Retirement/pensions } & 20 \% \\ \text { Interest, dividends, rental income } & 16 \% \\ \text { Other } & 5 \%\end{array}$

DRI's Quarterly Model of the U.S. Economy contains some variables that are related to these components of the money income of the elderly. The forecasting models for regions do not include such direct measures of income but do provide projections of total per capita income, which were used to capture regional differences that affect all demographic groups. 
Models of median real money income for the U.S. in each of the ten demographic groups defined above were estimated employing the following variables:

- Real Social Security payments per person aged 65 and over

- Real pension payments per person 65 and over

- Real interest income per capita

- Real wages (ECI for private wages and salaries deflated with CPIU-X1)

All models were estimated in log-log form. Only variables with positive coefficients were retained in the models.

Models for each of the ten demographic groups in each region were estimated employing these national variables plus real per capita income of the region. In instances where this combination of variables did not produce a satisfactory model, a simple model relating the income of the demographic group in a region to the income of the corresponding group in the U.S. as a whole was employed.

Forecasts through 2010 are based on DRI's TRENDLONG forecast of November 1999. Projections were extended to 2025 based on the TREND25YEAR forecast of August 1999. 
Table B.5. Male DRI Income Projections

\begin{tabular}{|c|c|c|c|c|c|c|c|}
\hline \multicolumn{8}{|c|}{ National } \\
\hline & 1995 & 2000 & 2005 & 2010 & 2015 & 2020 & 2025 \\
\hline $65-69$ & 20,020 & 21,490 & 22,771 & 24,245 & 25,485 & 26,818 & 28,127 \\
\hline $70-74$ & 17,531 & 18,210 & 18,436 & 18,904 & 19,929 & 21,216 & 22,467 \\
\hline $75-79$ & 16,381 & 17,029 & 17,770 & 18,911 & 20,124 & 21,229 & 22,389 \\
\hline $80-84$ & 14,716 & 15,390 & 16,204 & 17,382 & 18,457 & 19,301 & 20,181 \\
\hline $85+$ & 12,880 & 13,335 & 13,876 & 14,670 & 15,436 & 16,074 & 16,737 \\
\hline \multicolumn{8}{|c|}{ Midwest } \\
\hline & 1995 & 2000 & 2005 & 2010 & 2015 & 2020 & 2025 \\
\hline $65-69$ & 20,095 & 21,945 & 23,781 & 25,662 & 26,812 & 28,172 & 29,547 \\
\hline $70-74$ & 17,826 & 18,128 & 18,209 & 18,665 & 19,513 & 20,575 & 21,603 \\
\hline $75-79$ & 16,512 & 16,761 & 17,015 & 17,473 & 18,155 & 18,914 & 19,711 \\
\hline $80-84$ & 15,451 & 15,687 & 16,285 & 17,531 & 18,317 & 18,773 & 19,216 \\
\hline $85+$ & 13,677 & 14,241 & 14,913 & 15,908 & 16,877 & 17,689 & 18,539 \\
\hline \multicolumn{8}{|c|}{ Northeast } \\
\hline & 1995 & 2000 & 2005 & 2010 & 2015 & 2020 & 2025 \\
\hline $65-69$ & 21,461 & 23,272 & 24,821 & 26,293 & 27,517 & 28,702 & 29,895 \\
\hline $70-74$ & 17,808 & 18,465 & 18,747 & 19,102 & 19,871 & 20,770 & 21,652 \\
\hline $75-79$ & 16,410 & 17,515 & 18,202 & 18,802 & 19,707 & 20,570 & 21,432 \\
\hline $80-84$ & 15,267 & 15,400 & 15,852 & 16,845 & 17,568 & 18,080 & 18,609 \\
\hline $85+$ & 13,628 & 14,201 & 14,791 & 15,589 & 16,418 & 17,128 & 17,864 \\
\hline \multicolumn{8}{|c|}{ South } \\
\hline & 1995 & 2000 & 2005 & 2010 & 2015 & 2020 & 2025 \\
\hline $65-69$ & 18,165 & 19,091 & 19,853 & 21,032 & 22,033 & 23,186 & 24,257 \\
\hline $70-74$ & 16,194 & 17,251 & 17,711 & 18,258 & 19,534 & 21,112 & 22,671 \\
\hline $75-79$ & 15,024 & 16,032 & 17,161 & 18,701 & 20,212 & 21,623 & 23,133 \\
\hline $80-84$ & 13,878 & 15,218 & 16,460 & 17,788 & 19,345 & 20,709 & 22,149 \\
\hline $85+$ & 11,783 & 12,332 & 12,988 & 13,980 & 14,984 & 15,856 & 16,778 \\
\hline \multicolumn{8}{|c|}{ West } \\
\hline & 1995 & 2000 & 2005 & 2010 & 2015 & 2020 & 2025 \\
\hline $65-69$ & 22,545 & 24,122 & 25,321 & 26,735 & 28,352 & 29,945 & 31,524 \\
\hline $70-74$ & 19,337 & 19,702 & 19,629 & 20,084 & 21,118 & 22,523 & 23,840 \\
\hline $75-79$ & 18,303 & 19,000 & 19,604 & 20,796 & 22,372 & 24,071 & 25,817 \\
\hline $80-84$ & 15,041 & 15,542 & 16,173 & 17,168 & 18,029 & 18,680 & 19,358 \\
\hline $85+$ & 12,781 & 12,986 & 12,978 & 13,237 & 13,762 & 14,448 & 15,081 \\
\hline
\end{tabular}


Table B.6. Female DRI Income Projections

\begin{tabular}{|c|c|c|c|c|c|c|c|}
\hline \multicolumn{8}{|c|}{ National } \\
\hline & 1995 & 2000 & 2005 & 2010 & 2015 & 2020 & 2025 \\
\hline $65-69$ & 9,656 & 10,313 & 10,742 & 11,458 & 12,273 & 13,228 & 14,134 \\
\hline $70-74$ & 9,382 & 9,964 & 10,285 & 10,762 & 11,335 & 12,110 & 12,835 \\
\hline $75-79$ & 9,738 & 10,037 & 10,239 & 10,674 & 11,208 & 11,767 & 12,295 \\
\hline $80-84$ & 9,780 & 10,452 & 11,041 & 11,862 & 12,665 & 13,493 & 14,313 \\
\hline $85+$ & 9,555 & 10,001 & 10,419 & 11,155 & 11,983 & 12,791 & 13,603 \\
\hline \multicolumn{8}{|c|}{ Midwest } \\
\hline & 1995 & 2000 & 2005 & 2010 & 2015 & 2020 & 2025 \\
\hline $65-69$ & 10,306 & 10,814 & 11,083 & 11,806 & 12,700 & 13,736 & 14,697 \\
\hline $70-74$ & 9,884 & 10,260 & 10,382 & 10,738 & 11,230 & 11,909 & 12,518 \\
\hline $75-79$ & 10,028 & 10,021 & 10,001 & 10,314 & 10,682 & 11,081 & 11,430 \\
\hline $80-84$ & 10,202 & 10,823 & 11,263 & 11,875 & 12,669 & 13,464 & 14,229 \\
\hline $85+$ & 10,250 & 10,688 & 10,953 & 11,435 & 12,223 & 13,099 & 13,966 \\
\hline \multicolumn{8}{|c|}{ Northeast } \\
\hline & 1995 & 2000 & 2005 & 2010 & 2015 & 2020 & 2025 \\
\hline $65-69$ & 10,164 & 10,873 & 11,313 & 11,868 & 12,554 & 13,306 & 14,023 \\
\hline 70-74 & 9,699 & 10,255 & 10,559 & 11,071 & 11,614 & 12,355 & 13,032 \\
\hline $75-79$ & 9,915 & 10,428 & 10,820 & 11,321 & 11,798 & 12,327 & 12,833 \\
\hline $80-84$ & 9,997 & 10,536 & 10,832 & 11,164 & 11,684 & 12,224 & 12,744 \\
\hline $85+$ & 9,830 & 10,222 & 10,671 & 11,532 & 12,250 & 12,799 & 13,327 \\
\hline \multicolumn{8}{|c|}{ South } \\
\hline & 1995 & 2000 & 2005 & 2010 & 2015 & 2020 & 2025 \\
\hline $65-69$ & 8,763 & 9,188 & 9,428 & 9,997 & 10,732 & 11,576 & 12,371 \\
\hline 70-74 & 8,709 & 9,469 & 9,921 & 10,438 & 11,113 & 12,004 & 12,865 \\
\hline $75-79$ & 8,856 & 9,165 & 9,436 & 10,037 & 10,713 & 11,367 & 11,991 \\
\hline $80-84$ & 8,937 & 9,502 & 10,091 & 11,045 & 11,988 & 12,811 & 13,640 \\
\hline $85+$ & 8,618 & 9,294 & 9,967 & 10,886 & 11,833 & 12,630 & 13,451 \\
\hline \multicolumn{8}{|c|}{ West } \\
\hline & 1995 & 2000 & 2005 & 2010 & 2015 & 2020 & 2025 \\
\hline $65-69$ & 10,195 & 11,339 & 12,225 & 13,312 & 14,263 & 15,478 & 16,647 \\
\hline $70-74$ & 10,243 & 10,706 & 10,952 & 11,371 & 11,788 & 12,396 & 12,943 \\
\hline $75-79$ & 10,700 & 11,121 & 11,275 & 11,508 & 12,044 & 12,658 & 13,252 \\
\hline $80-84$ & 10,706 & 11,395 & 11,628 & 12,062 & 12,998 & 14,179 & 15,337 \\
\hline $85+$ & 12,781 & 12,557 & 12,291 & 12,495 & 12,831 & 13,312 & 13,729 \\
\hline
\end{tabular}




\section{B.2.1.2. Projection Adjustments to Account for Differences Between DRI and NPTS Income Data}

Our income projections into the year 2025 are taken from DRI estimates. These DRI estimates include 1995 values as well. The 1995 NPTS averages are anywhere from one and a half to two and a half times those of the DRI estimates. Thus, in our "driver" and crash rate projections, we adjusted the DRI income estimates by a factor associated with the differences in the two sources' 1995 estimates by gender and age. These adjustment factors (ratio of average 1995 NPTS income to 1995 DRI estimates) are found in Table B.7 below.

Table B.7. Ratio of Average 1995 NPTS Income to 1995 DRI Estimates, by Gender and Age

\begin{tabular}{|lcl|}
\hline & Men & Women \\
$65-69$ & 1.566251 & 2.748448 \\
$70-74$ & 1.633565 & 2.592415 \\
$75-79$ & 1.684624 & 2.269106 \\
$80-84$ & 1.815173 & 2.124292 \\
$85+$ & 1.783454 & 1.916215 \\
\hline
\end{tabular}

\section{B.2.2 Health Index (The Modified Health Factor Score)}

Our projections reflect no change in the health index scores in the future. For explanation of how these scores were calculated, see Section 5.1.

\section{B.2.3 Employment Status}

Our employment status projections are based on projections to 2008 by the Bureau of Labor Statistics. These gender and age specific projection trends were then extrapolated into the year 2025, and can be seen in Table B.8. 
Table B.8. Employment Status Projections as a Percent of Population

\begin{tabular}{|c|c|c|c|c|c|c|c|}
\hline \multicolumn{8}{|c|}{ Male } \\
\hline & 1995 & 2000 & 2005 & 2010 & 2015 & 2020 & 2025 \\
\hline $65-69$ & $27.0 \%$ & $28.6 \%$ & $30.4 \%$ & $32.1 \%$ & $33.9 \%$ & $35.7 \%$ & $37.4 \%$ \\
\hline 70-74 & $16.6 \%$ & $16.6 \%$ & $17.2 \%$ & $17.9 \%$ & $18.6 \%$ & $19.2 \%$ & $19.9 \%$ \\
\hline $75-79$ & $7.4 \%$ & $7.4 \%$ & $7.5 \%$ & $7.6 \%$ & $7.6 \%$ & $7.7 \%$ & $7.7 \%$ \\
\hline $80-84$ & $7.4 \%$ & $7.4 \%$ & $7.5 \%$ & $7.6 \%$ & $7.6 \%$ & $7.7 \%$ & $7.7 \%$ \\
\hline $85+$ & $7.4 \%$ & $7.4 \%$ & $7.5 \%$ & $7.6 \%$ & $7.6 \%$ & $7.7 \%$ & $7.7 \%$ \\
\hline \multicolumn{8}{|c|}{ Female } \\
\hline & 1995 & 2000 & 2005 & 2010 & 2015 & 2020 & 2025 \\
\hline $65-69$ & $17.5 \%$ & $17.8 \%$ & $18.4 \%$ & $19.0 \%$ & $19.6 \%$ & $20.2 \%$ & $20.8 \%$ \\
\hline 70-74 & $5.3 \%$ & $6.5 \%$ & $6.6 \%$ & $6.7 \%$ & $6.9 \%$ & $7.0 \%$ & $7.2 \%$ \\
\hline $75-79$ & $2.9 \%$ & $2.9 \%$ & $3.0 \%$ & $3.0 \%$ & $3.1 \%$ & $3.1 \%$ & $3.2 \%$ \\
\hline $80-84$ & $2.9 \%$ & $2.9 \%$ & $3.0 \%$ & $3.0 \%$ & $3.1 \%$ & $3.1 \%$ & $3.2 \%$ \\
\hline $85+$ & $2.9 \%$ & $2.9 \%$ & $3.0 \%$ & $3.0 \%$ & $3.1 \%$ & $3.1 \%$ & $3.2 \%$ \\
\hline
\end{tabular}

\section{B.2.4 Other Driver}

We maintained 1995 levels of the other driver variable taken from NPTS data in our projections. For these 1995 levels, see Table B.9.

Table B.9. Other Driver Projections as a Percent of Population

\begin{tabular}{|crr|}
\hline \multicolumn{3}{|c|}{ 1995 Values } \\
\hline & Male & Female \\
$65-69$ & $74.0 \%$ & $57.0 \%$ \\
$70-74$ & $71.0 \%$ & $51.0 \%$ \\
$75-79$ & $56.0 \%$ & $38.0 \%$ \\
$80-84$ & $59.0 \%$ & $28.0 \%$ \\
$85+$ & $37.0 \%$ & $23.0 \%$ \\
\hline
\end{tabular}




\section{B.2.5 Seatbelt Use}

Our projections on seatbelt use assumed that the goal of $85 \%$ usage will be met in the year 2025. Values in between 1995 and 2025 were computed using a simple linear regression involving time for NHTSA seatbelt use data between 1991 and 1995 and the 2025 expected rate (see Table B.10). This simple linear regression is described in the equation below:

Projected Seatbelt Usage $=0.5731+0.0066^{*}$ year $($ where year $=2000,2005$, etc. $)$ This regression equation had an $\mathrm{R}^{2}$ value of 0.9174 .

Table B.10. National Seat Belt Use Projections

\begin{tabular}{|rrrrrrr|}
\hline 1995 & 2000 & 2005 & 2010 & 2015 & 2020 & 2025 \\
\hline $68.0 \%$ & $69.2 \%$ & $72.5 \%$ & $75.8 \%$ & $79.1 \%$ & $82.4 \%$ & $85.0 \%$ \\
\hline
\end{tabular}

\section{B.2.6 Urban}

We maintained 1990 percentages of urban population provided by the Census Bureau in our projections. For these 1990 levels, see Table B.11.

Table B.11. Percent of Population in Urban Areas, 1990 Census

\begin{tabular}{|lr|}
\hline \multicolumn{2}{|c|}{ Nation } \\
\hline & 1990 \\
Nation & $76.1 \%$ \\
Midwest & $71.7 \%$ \\
Northeast & $78.9 \%$ \\
South & $68.6 \%$ \\
West & $86.3 \%$ \\
\hline
\end{tabular}




\section{APPENDIX C. NOTES}

\section{C.1. REGIONAL VMT AND HEALTH INDEX COMPUTATIONS FOR 1983 DATA}

The 1983 NPTS did not contain a variable identifying the respondent's region of residence. Therefore, in order to obtain the average health score and vehicle miles of travel numbers needed for the aggregate crash rate model, we took the percent difference between the regional and national figures for the two variables in 1990 and adjusted the national average for each respective gender/age average in 1983 by these regional variation measures.

\section{C.2. STARTING VALUES FOR VMT VALUES OF SOUTHERN MEN}

The 1995 starting values used in the projections were slightly modified due to the inconsistencies in historical VMT for Southern men. These inconsistencies involved two cases where an older grouphad a higher average VMT in 1995 than a younger group. The two cases involved 70-74 Southern men having less VMT than their 75-79 year old counterparts, and the 80-85 group having a lower averagethan the $85+$ group. In order to account for this, a simple iterative proportional fitting procedure was used. Given the simple nature of the problem, this iterative proportional fitting amounted to taking the average of the two groups affected in each case and using that average as the starting point for both groups. In Table C. 1 below are the original values observed from the 1995 NPTS for each group, along with their modified numbers used in projections.

Table C.1. Average VMT per Person of Southern Men, 1995 NPTS and Adjusted Numbers

\begin{tabular}{|crr|}
\hline Age & 1995 NPTS & \multicolumn{2}{c|}{ Base Used } \\
& & in Projections \\
\hline $70-74$ & 10431 & 10909 \\
$75-79$ & 11388 & 10909 \\
$80-84$ & 4681 & 5336 \\
$85+$ & 5991 & 5336 \\
\hline
\end{tabular}




\section{C.3. DECREASING GROWTH RATES OF DRIVER PROJECTIONS}

We constructed these decreasing growth rates by comparing the growth rates (the coefficient of the year trend variable) estimated on 1977-95 and 1977-90 samples; these results are reported in Table C.2. With declining growth rates, we expected the estimated coefficients on the time trend to be larger in absolute magnitude in the shorter sample period (1977-90) than in the longer one (1977-95), and in all but avery few cases this expectation proved correct. We used the ratio of the coefficient values from the 1977-95 sample to those from the 1977-90 sample to represent the pattern of declining growth rate to use in the future. This procedure yielded ratios of later growth rates to earlier growth rates, which were smaller than one. In the few cases in which the longer sample period yielded larger time trend coefficients, we interpolated the ratio of growth rates from adjoining age/gender groups. In projecting the driver rates, we multiplied each subsequent year's time trend coefficient by this ratio. For example, in projecting the 2000 driver percentages, we multiplied the estimated age-and-gender-specific time trend coefficients by the corresponding growth rate factors to obtain a lower time effect; then in projecting the 2000 driver percentages, we multiplied the growth factor used for the 1995-2000 projection by the same growth-rate factor, further depressing the pure time effect.

This method of creating a decreasing autonomous effect of time improved the projections - using the estimated time coefficients generally yielded values of one for every age and gender group by 2010 to 2015-but still yielded age and gender patterns of driver rates that were not "smooth" in the sense of having older groups systematically having lower driver ratios at each projection time. The set of modified time-trend coefficients performed satisfactorily in projections for 65-69 males, which we considered the base group against which the behavior of the other groups reasonably could be compared. We had clear anticipations (Bayesian priors) on how the other older age groups should behave over time (and by 2025) relative to this group: lower driver ratios for each older age group, and generally lower rates for women, which would otherwise parallel the trend for men of corresponding age unless influenced otherwise byother variables. While the ratio-adjusted 
time coefficients did not yield such a pattern outright, across all age groups and between genders, it did give some key points, however-the 75-79 men, the 85+ age group for males in the Northeast and South, and the 85+ women in the Midwest and Northeast. Consequently, using the 65-69 men, the 75-79 men, and the two groups of 85+ men and women, we further adjusted the already-adjusted time coefficients on the remaining age/gender/regiongroups to make them fit the pattern of fall-offs with age that our priors gave us. To get acceptable time coefficients for the 65-69 women with which to begin the female pattern of age-specific driver ratios, we compared their 1995 actual driver ratios with the 65-69 men's 1995 actual ratios and found a set of time coefficient values that aligned the 2000 projections between the 1995 actual values and the 2025 ratios projected using the empirically adjusted time coefficient ratios for the $85+$ women in the Midwest and Northeast. 
Table C.2. Year Coefficients (Adjusted and Non-Adjusted, and 1977-90/1977-95 Coefficient Ratios)

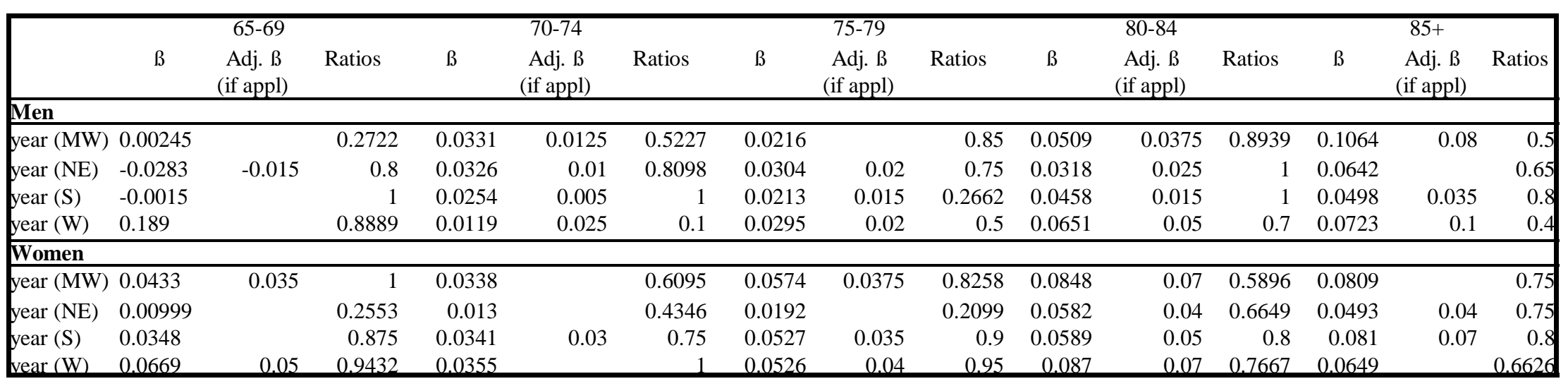

